\title{
Diretrizes da Sociedade Brasileira de Cardiologia sobre Angina Instável e Infarto Agudo do Miocárdio sem Supradesnível do Segmento ST - 2021
}

\author{
Brazilian Society of Cardiology Guidelines on Unstable Angina and Acute Myocardial \\ Infarction without ST-Segment Elevation - 2021
}

Realização: Departamento de Cardiologia Clínica (DCC) da Sociedade Brasileira de Cardiologia (SBC)

Conselho de Normatizações e Diretrizes (2020-2021): Brivaldo Markman Filho, Antonio Carlos Sobral Sousa, Aurora Felice Castro Issa, Bruno Ramos Nascimento, Harry Correa Filho, Marcelo Luiz Campos Vieira

Coordenador de Normatizações e Diretrizes (2020-2021): Brivaldo Markman Filho

Editor: José Carlos Nicolau

Editores Associados: Gilson Feitosa Filho, João Luiz Petriz, Dalton Bertolim Précoma, Walmor Lemke, Ari Timerman, José A. Marin-Netto, Luiz Bezerra Neto, Bruno Ferraz, Eduardo Lapa, Leopoldo S. Piegas

Comitê de Redação: José Carlos Nicolau, Gilson Feitosa Filho, João Luiz Petriz, Remo Holanda de Mendonça Furtado, Dalton Bertolim Précoma, Walmor Lemke, Renato D. Lopes, Ari Timerman, José A. Marin-Netto, Luiz Bezerra Neto, Bruno Ferraz, Eduardo Lapa, Leopoldo S. Piegas.

Autores da Diretriz: José Carlos Nicolau, ${ }^{1 \oplus}$ Gilson Soares Feitosa Filho, ${ }^{2,3}{ }^{\oplus}$ João Luiz Petriz, ${ }^{4}{ }^{\circledR}$ Remo Holanda de Mendonça Furtado, ${ }^{5}$ Dalton Bertolim Précoma, ${ }^{6}$ Walmor Lemke, ${ }^{7,8}$ Renato Delascio Lopes, ${ }^{9}{ }^{\circledR}$ Ari Timerman, ${ }^{10}{ }^{\oplus}$ José A. Marin-Neto, ${ }^{11}$ Luiz Bezerra Neto, ${ }^{12}$ Bruno Ferraz de Oliveira Gomes, ${ }^{4,13}$ Eduardo Cavalcanti Lapa Santos, ${ }^{14}$ Leopoldo Soares Piegas, ${ }^{15}$ Alexandre de Matos Soeiro, ${ }^{16}$ Alexandre Jorge de Andrade Negri, ${ }^{17}$ Andre Franci, ${ }^{18}{ }^{\circledR}$ Brivaldo Markman Filho, ${ }^{14}$ Bruno Mendonça Baccaro, ${ }^{10}$ Carlos Eduardo Lucena Montenegro, ${ }^{19}$ Carlos Eduardo Rochitte, ${ }^{15,16}$ Carlos José Dornas Gonçalves Barbosa, ${ }^{20}$ Cláudio Marcelo Bittencourt das Virgens, ${ }^{21}$ Edson Stefanini, ${ }^{22}$ Euler Roberto Fernandes Manenti, ${ }^{23}{ }^{\circledR}$ Felipe Gallego Lima, ${ }^{1}$ Francisco das Chagas Monteiro Júnior, ${ }^{24}$ Harry Correa Filho, ${ }^{25}$ Henrique Patrus Mundim Pena, ${ }^{26}$ Ibraim Masciarelli Francisco Pinto, ${ }^{27}$ João Luiz de Alencar Araripe Falcão, ${ }^{28}$ Joberto Pinheiro Sena, ${ }^{29}$ José Maria Peixoto, ${ }^{30} \oplus$ Juliana Ascenção de Souza, ${ }^{1}$ Leonardo Sara da Silva, ${ }^{31}{ }^{\oplus}$ Lilia Nigro Maia, ${ }^{32}$ Louis Nakayama Ohe, ${ }^{10}{ }^{\oplus}$ Luciano Moreira Baracioli, ${ }^{1}$ Luís Alberto de Oliveira Dallan, ${ }^{1}$ Luis Augusto Palma Dallan, ${ }^{1 \bullet}$ Luiz Alberto Piva e Mattos, ${ }^{33}$ Luiz Carlos Bodanese, ${ }^{34}{ }^{\circledR}$ Luiz Eduardo Fonteles Ritt, ${ }^{35}{ }^{\circledR}$ Manoel Fernandes Canesin, ${ }^{36}$ Marcelo Bueno da Silva Rivas, ${ }^{37,38}$ Marcelo Franken, ${ }^{5 \odot}$ Marcos José Gomes Magalhães, ${ }^{39}$ Múcio Tavares de Oliveira Júnior, ${ }^{1}$ Nivaldo Menezes Filgueiras Filho, ${ }^{40,41,42 @}$ Oscar Pereira Dutra, ${ }^{43}$ Otávio Rizzi Coelho, ${ }^{44}$ Paulo Ernesto Leães, ${ }^{45}$ Paulo Roberto Ferreira Rossi, ${ }^{46}$ Paulo Rogério Soares, ${ }^{1}$ Pedro Alves Lemos Neto, ${ }^{5}$ Pedro Silvio Farsky, ${ }^{10}{ }^{\circledR}$ Rafael Rebêlo C. Cavalcanti, ${ }^{47}$ Renato Jorge Alves, ${ }^{48}$ Renato Abdala Karam Kalil, ${ }^{49}$ Roberto Esporcatte, ${ }^{38}{ }^{8}$ Roberto Luiz Marino, ${ }^{50}$ Roberto Rocha Corrêa Veiga Giraldez, ${ }^{1}$ Romeu Sérgio Meneghelo, ${ }^{10}$ Ronaldo de Souza Leão Lima, ${ }^{51}$ Rui Fernando Ramos, ${ }^{10}$ Sandra Nivea dos Reis Saraiva Falcão, ${ }^{52}$ Talia Falcão Dalçóquio, ${ }^{1 \oplus}$ Viviana de Mello Guzzo Lemke, ${ }^{53}$ @ William Azem Chalela, ${ }^{\circledR}$ Wilson Mathias Júnior ${ }^{1}$

Instituto do Coração (InCor), Hospital das Clínicas da Faculdade de Medicina da Universidade de São Paulo (HCFMUSP), ${ }^{1}$ São Paulo, SP - Brasil Escola Bahiana de Medicina e Saúde Pública, ${ }^{2}$ Salvador, BA - Brasil

Centro Universitário de Tecnologia e Ciência (UniFTC), ${ }^{3}$ Salvador, BA - Brasil

Hospital Barra D'Or, Rede D'Or São Luiz, ${ }^{4}$ Rio de Janeiro, RJ - Brasil

Hospital Israelita Albert Einstein, ${ }^{5}$ São Paulo, SP - Brasil

Sociedade Hospitalar Angelina Caron, ${ }^{6}$ Campina Grande do Sul, PR - Brasil

Clínica Cardiocare, ${ }^{7}$ Curitiba, $P R-$ Brasil

Hospital das Nações, ${ }^{8}$ Curitiba, $P R-$ Brasil

Duke University, ${ }^{9}$ Durham - EUA

Instituto Dante Pazzanese de Cardiologia, ${ }^{10}$ São Paulo, SP - Brasil

DOI: https://doi.org/10.36660/abc.20210180 
Hospital das Clínicas da Faculdade de Medicina da Universidade de São Paulo, ${ }^{11}$ Ribeirão Preto, SP - Brasil

Centro Universitário UNINOVAFAPI, ${ }^{12}$ Teresina, PI - Brasil

Universidade Federal do Rio de Janeiro (UFRJ), ${ }^{13}$ Rio de Janeiro, RJ - Brasil

Hospital das Clínicas da Universidade Federal de Pernambuco (UFPE), ${ }^{14}$ Recife, PE - Brasil

Hospital do Coração (HCor), ${ }^{15}$ São Paulo, SP - Brasil

Faculdade de Medicina da Universidade de São Paulo (HCFMUSP), ${ }^{16}$ São Paulo, SP - Brasil

Hospital Universitário Lauro Wanderley, ${ }^{17}$ João Pessoa, PB - Brasil

Hospital Sírio-Libanês, ${ }^{18}$ São Paulo, SP - Brasil

Pronto Socorro Cardiológico de Pernambuco (PROCAPE), ${ }^{19}$ Recife, PE - Brasil

Hospital do Coração do Brasil, Rede D'Or São Luiz, ${ }^{20}$ Brasília, DF - Brasil

Universidade Federal da Bahia (UFBA), ${ }^{21}$ Salvador, BA - Brasil

Escola Paulista de Medicina da Universidade Federal de São Paulo (UNIFESP), ${ }^{22}$ São Paulo, SP - Brasil

Instituto de Medicina Vascular Mãe de Deus, ${ }^{23}$ Porto Alegre, RS - Brasil

Universidade Federal do Maranhão (UFMA), ${ }^{24}$ São Luís, MA - Brasil

Clínica Unicardio, ${ }^{25}$ Florianópolis, SC - Brasil

Faculdade de Ciências Médicas de Minas Gerais (FELUMA), ${ }^{26}$ Belo Horizonte, MG - Brasil

Grupo Fleury, ${ }^{27}$ São Paulo, SP - Brasil

Universidade Federal do Ceará (UFC), ${ }^{28}$ Fortaleza, CE - Brasil

Hospital Santa Izabel da Santa Casa da Bahia, ${ }^{29}$ Salvador, BA - Brasil

Universidade José do Rosário Vellano (UNIFENAS), ${ }^{30}$ Belo Horizonte, MG - Brasil

Centro de Diagnóstico por Imagem (CDI), ${ }^{31}$ Goiânia, GO - Brasil

Faculdade de Medicina de São José do Rio Preto (FAMERP), ${ }^{32}$ São José do Rio Preto, SP - Brasil

Rede D'Or São Luiz, ${ }^{33}$ Recife, PE - Brasil

Pontifícia Universidade Católica do Rio Grande do Sul (PUC-RS), ,4 Porto Alegre, RS - Brasil

Hospital Cárdio Pulmonar, ${ }^{35}$ Salvador, BA - Brasil

Universidade Estadual de Londrina, ${ }^{36}$ Londrina, $P R$ - Brasil

Rede D'Or São Luiz, ${ }^{37}$ Rio de Janeiro, RJ - Brasil

Universidade do Estado do Rio de Janeiro (UERJ), ${ }^{38}$ Rio de Janeiro, RJ - Brasil

Real Hospital Português, ${ }^{39}$ São Paulo, SP - Brasil

Universidade do Estado da Bahia (UNEB), ${ }^{40}$ Salvador, BA - Brasil

Universidade Salvador (UNIFACS), ${ }^{41}$ Salvador, BA - Brasil

Hospital EMEC, ${ }^{42}$ Salvador, BA - Brasil

Instituto de Cardiologia - Fundação Universitária de Cardiologia do Rio Grande do Sul, ${ }^{43}$ Porto Alegre, RS - Brasil

Faculdade de Ciências Médicas da Universidade Estadual de Campinas (UNICAMP), ${ }^{44}$ Campinas, SP - Brasil

Santa Casa de Misericórdia de Porto Alegre, ${ }^{45}$ Porto Alegre, $R S$ - Brasil

Faculdade de Medicina Evangélica Mackenzie, ${ }^{46}$ Curitiba, PR - Brasil

Hospital do Coração de Alagoas, ${ }^{47}$ Maceió, AL - Brasil

Santa Casa de Misericórdia da São Paulo, ${ }^{48}$ São Paulo, SP - Brasil

Universidade Federal de Ciências da Saúde de Porto Alegre, ${ }^{49}$ Porto Alegre, RS - Brasil

Hospital Madre Teresa, ${ }^{50}$ Belo Horizonte, MG - Brasil

Universidade Federal do Rio de Janeiro (UFRJ), ${ }^{51}$ Rio de Janeiro, RJ - Brasil

Universidade de Fortaleza (UNIFOR), ${ }^{52}$ Fortaleza, CE - Brasil

Cardiocare Clínica Cardiológica, ${ }^{53}$ Curitiba, PR - Brasil

Esta diretriz deverá ser citada como: Nicolau JC, Feitosa-Filho G, Petriz JL, Furtado RHM, Précoma DB, Lemke W, et al. Diretrizes da Sociedade Brasileira de Cardiologia sobre Angina Instável e Infarto Agudo do Miocárdio sem Supradesnível do Segmento ST - 2021. Arq Bras Cardiol. 2021; 117(1):181-264

Nota: Estas diretrizes se prestam a informar e não a substituir o julgamento clínico do médico que, em última análise, deve determinar o tratamento apropriado para seus pacientes.

Correspondência: Sociedade Brasileira de Cardiologia - Av. Marechal Câmara, 360/330 - Centro - Rio de Janeiro CEP: 20020-907. E-mail: diretrizes@cardiol.br 


\begin{tabular}{ll}
\hline Especialista & Tipo de relacionamento com a indústria \\
\hline Alexandre de Matos Soeiro & Nada a ser declarado \\
\hline
\end{tabular}

Declaração financeira

A - Pagamento de qualquer espécie e desde que economicamente apreciáveis, feitos a (i) você, (ii) ao seu cônjuge/ companheiro ou a qualquer outro membro que resida com você, (iii) a qualquer pessoa jurídica em que qualquer destes seja controlador, sócio, acionista ou participante, de

Alexandre Jorge de Andrade Negri forma direta ou indireta, recebimento por palestras, aulas, atuação como proctor de treinamentos, remunerações, honorários pagos por participações em conselhos consultivos, de investigadores, ou outros comitês, etc. Provenientes da indústria farmacêutica, de órteses, próteses, equipamentos e implantes, brasileiras ou estrangeiras:

- AMIB: Instrutor de cursos de pós-graduação. pessoa jurídica em que qualquer destes seja controlador, sócio, acionista ou participante, de forma direta ou indireta, recebimento por palestras, aulas, atuação como proctor de treinamentos, remunerações, honorários pagos por participações em conselhos consultivos, de investigadores, ou

Ari Timerman outros comitês, etc. Provenientes da indústria farmacêutica, de órteses, próteses, equipamentos e implantes, brasileiras ou estrangeiras:

- Sanofi e Daiichi Sankyo: Aulas sobre Síndromes Coronárias Agudas.

Outros relacionamentos

Financiamento de atividades de educação médica continuada, incluindo viagens, hospedagens e inscrições para congressos e cursos, provenientes da indústria farmacêutica, de órteses, próteses, equipamentos e implantes, brasileiras ou estrangeiras: - Sanofi: Viagem para Congresso.

\begin{tabular}{ll}
\hline Brivaldo Markman Filho & Nada a ser declarado \\
\hline Bruno Ferraz de Oliveira Gomes & Nada a ser declarado \\
\hline Bruno Mendonça Baccaro & Nada a ser declarado \\
\hline & Declaração financeira
\end{tabular}

A - Pagamento de qualquer espécie e desde que economicamente apreciáveis, feitos a (i) você, (ii) ao seu cônjuge/companheiro ou a qualquer outro membro que resida com você, (iii) a qualquer pessoa jurídica em que qualquer destes seja controlador, sócio, acionista ou participante, de forma direta ou indireta, recebimento por palestras, aulas, atuação como proctor de treinamentos, remunerações, honorários pagos por participações em conselhos consultivos, de investigadores, ou

Carlos Eduardo Lucena Montenegro outros comitês, etc. Provenientes da indústria farmacêutica, de órteses, próteses, equipamentos e implantes, brasileiras ou estrangeiras:

- Servier: Vastarel/Procoralan; Novartis: Entresto; Merk: Concor; Astrazeneca.

Outros relacionamentos

Financiamento de atividades de educação médica continuada, incluindo viagens, hospedagens e inscrições para congressos e cursos, provenientes da indústria farmacêutica, de órteses, próteses, equipamentos e implantes, brasileiras ou estrangeiras:

- Pfizer: Amiloidose; Servier: DAC/IC; Novartis: IC.

\section{Carlos Eduardo Rochitte}

Carlos José Dornas Gonçalves Barbosa

\section{Nada a ser declarado}

\section{Declaração financeira}

A - Pagamento de qualquer espécie e desde que economicamente apreciáveis, feitos a (i) você, (ii) ao seu cônjuge/companheiro ou a qualquer outro membro que resida com você, (iii) a qualquer pessoa jurídica em que qualquer destes seja controlador, sócio, acionista ou participante, de forma direta ou indireta, recebimento por palestras, aulas, atuação como proctor de treinamentos, remunerações, honorários pagos por participações em conselhos consultivos, de investigadores, ou outros comitês, etc. Provenientes da indústria farmacêutica, de órteses, próteses, equipamentos e implantes, brasileiras ou estrangeiras:

- Daiichi Sankyo: Effient; Servier: Brilinta.

Outros relacionamentos

Financiamento de atividades de educação médica continuada, incluindo viagens, hospedagens e inscrições para congressos e cursos, provenientes da indústria farmacêutica, de órteses, próteses, equipamentos e implantes, brasileiras ou estrangeiras:

- Bayer: Xarelto; Daiichi Sankyo: Lixiana. 
A - Pagamento de qualquer espécie e desde que economicamente apreciáveis, feitos a (i) você, (ii) ao seu cônjuge/companheiro ou a qualquer outro membro que resida com você, (iii) a qualquer pessoa jurídica em que qualquer destes seja controlador, sócio, acionista ou participante, de forma direta ou indireta, recebimento por palestras, aulas, atuação como proctor de treinamentos, remunerações, honorários pagos por participações em conselhos consultivos, de investigadores, ou outros comitês, etc. Provenientes da indústria farmacêutica, de órteses, próteses, equipamentos e implantes, brasileiras ou estrangeiras:

- Novo Nordisk: Semaglutida; Daiichi Sankyo: Edoxabana.

\section{Declaração financeira}

A - Pagamento de qualquer espécie e desde que economicamente apreciáveis, feitos a (i) você, (ii) ao seu cônjuge/ companheiro ou a qualquer outro membro que resida com você, (iii) a qualquer pessoa jurídica em que qualquer destes seja controlador, sócio, acionista ou participante, de forma direta ou indireta, recebimento por palestras, aulas, atuação como proctor de treinamentos, remunerações, honorários pagos por participações em conselhos consultivos, de investigadores, ou outros comitês, etc. Provenientes da indústria farmacêutica, de órteses, próteses, equipamentos e implantes, brasileiras ou estrangeiras:

- Servier: Doença Coronariana; Bayer: Anticoagulates; Daiichi Sankyo: Anticoagulantes; Novo Nordisk.

Dalton Bertolim Précoma

B - financiamento de pesquisas sob sua responsabilidade direta/pessoal (direcionado ao departamento ou instituição) provenientes da indústria farmacêutica, de órteses, próteses, equipamentos e implantes, brasileiras ou estrangeiras:

- Novartis: Insuficiência Cardíaca; Apellis: Antiinflamatório para Covid; Astrazeneca: Antidiabético/ Insuficiência Cardíaca; Boehringer.

Outros relacionamentos

Financiamento de atividades de educação médica continuada, incluindo viagens, hospedagens e inscrições para congressos e cursos, provenientes da indústria farmacêutica, de órteses, próteses, equipamentos e implantes, brasileiras ou estrangeiras:

- Bayer: Anticoagulates; Novo Nordisk: Antidiabético; Servier: DAC; Daiichi Sankyo.

\begin{tabular}{ll}
\hline Edson Stefanini & Nada a ser declarado \\
\hline Eduardo Cavalcanti Lapa Santos & Nada a ser declarado \\
\hline & Declaração financeira \\
A - Pagamento de qua
\end{tabular}

A - Pagamento de qualquer espécie e desde que economicamente apreciáveis, feitos a (i) você, (ii) ao seu cônjuge/ companheiro ou a qualquer outro membro que resida com você, (iii) a qualquer pessoa jurídica em que qualquer destes seja controlador, sócio, acionista ou participante, de forma direta ou indireta, recebimento por palestras, aulas, atuação como proctor de treinamentos, remunerações, honorários pagos por participações em conselhos consultivos, de investigadores, ou outros comitês, etc. Provenientes da indústria farmacêutica, de órteses, próteses, equipamentos e implantes, brasileiras ou estrangeiras:

- Bayer e Pfizer: Anticoagulantes; Daiichi Sankyo: Antiplaquetários; Boeheringer.

B - financiamento de pesquisas sob sua responsabilidade direta/pessoal (direcionado ao

Euler Roberto Fernandes Manent departamento ou instituição) provenientes da indústria farmacêutica, de órteses, próteses, equipamentos e implantes, brasileiras ou estrangeiras:

- Astrazeneca: Antiplaquetários, ISGLT2; Daiichi Sankyo: Antiplaquetários; Astra Zeneca: Insuficiência Cardíaca, Antiplaquetários.

C - Financiamento de pesquisa (pessoal), cujas receitas tenham sido provenientes da indústria farmacêutica, de órteses, próteses, equipamentos e implantes, brasileiras ou estrangeiras:

- Boerinhger: Insuficiência Cardíaca; AstraZeneca: Dapaglifozina.

Outros relacionamentos

Financiamento de atividades de educação médica continuada, incluindo viagens, hospedagens e inscrições para congressos e cursos, provenientes da indústria farmacêutica, de órteses, próteses, equipamentos e implantes, brasileiras ou estrangeiras:

- Bayer: Anticoagulates.

Declaração financeira

A - Pagamento de qualquer espécie e desde que economicamente apreciáveis, feitos a (i) você, (ii) ao seu cônjuge/companheiro ou a qualquer outro membro que resida com você, (iii) a qualquer pessoa jurídica em que qualquer destes seja controlador, sócio, acionista ou participante, de forma direta ou indireta, recebimento por palestras, aulas, atuação como proctor de treinamentos, remunerações, honorários pagos por participações em conselhos consultivos, de investigadores, ou

Felipe Gallego Lima outros comitês, etc. Provenientes da indústria farmacêutica, de órteses, próteses, equipamentos e implantes, brasileiras ou estrangeiras:

- Sanofi: Clexane; Servier: Ticagrelor.

Outros relacionamentos

Financiamento de atividades de educação médica continuada, incluindo viagens, hospedagens e inscrições para congressos e cursos, provenientes da indústria farmacêutica, de órteses, próteses, equipamentos e implantes, brasileiras ou estrangeiras:

- Sanofi: Enoxaparina; Servier: Ticagrelor. 


\begin{tabular}{ll}
\hline Francisco das Chagas Monteiro Júnior & Nada a ser declarado \\
\hline & Declaração financeira \\
A - Pagamento de qualquer espécie e desde que economicamente apreciáveis, feitos a (i) você, & (ii) ao seu cônjuge/companheiro ou a qualquer outro membro que resida com você, (iii) a qualquer \\
pessoa jurídica em que qualquer destes seja controlador, sócio, acionista ou participante, de & forma direta ou indireta, recebimento por palestras, aulas, atuação como proctor de treinamentos, \\
Gilson Soares Feitosa Filho & remunerações, honorários pagos por participações em conselhos consultivos, de investigadores, ou \\
& outros comitês, etc. Provenientes da indústria farmacêutica, de órteses, próteses, equipamentos e \\
& implantes, brasileiras ou estrangeiras: \\
& - Bayer: Estudo COMPASS.
\end{tabular}

\section{Declaração financeira}

A - Pagamento de qualquer espécie e desde que economicamente apreciáveis, feitos a (i) você, (ii) ao seu cônjuge/companheiro ou a qualquer outro membro que resida com você, (iii) a qualquer pessoa jurídica em que qualquer destes seja controlador, sócio, acionista ou participante, de forma direta ou indireta, recebimento por palestras, aulas, atuação como proctor de treinamentos, remunerações, honorários pagos por participações em conselhos consultivos, de investigadores, ou outros comitês, etc. Provenientes da indústria farmacêutica, de órteses, próteses, equipamentos e implantes, brasileiras ou estrangeiras:

- Bayer: Anticoagulação.

\section{Declaração financeira}

A - Pagamento de qualquer espécie e desde que economicamente apreciáveis, feitos a (i) você, (ii) ao seu cônjuge/companheiro ou a qualquer outro membro que resida com você, (iii) a qualquer pessoa jurídica em que qualquer destes seja controlador, sócio, acionista ou participante, de forma direta ou indireta, recebimento por palestras, aulas, atuação como proctor de treinamentos, remunerações, honorários pagos por participações em conselhos consultivos, de investigadores, ou outros comitês, etc. Provenientes da indústria farmacêutica, de órteses, próteses, equipamentos e Henrique Patrus Mundim Pena implantes, brasileiras ou estrangeiras: - Lilly: Diabetes e Risco Cardiovascular; Daiichi Sankyo: Antiagregante Plaquetário; Pfizer e Bayer: Anticoagulante Oral. Outros relacionamentos

Financiamento de atividades de educação médica continuada, incluindo viagens, hospedagens e inscrições para congressos e cursos, provenientes da indústria farmacêutica, de órteses, próteses, equipamentos e implantes, brasileiras ou estrangeiras: - Pfizer e Bayer: Anticoagulante Oral; Daiichi Sankyo: Antiagregante Plaquetário.

\section{Declaração financeira}

A - Pagamento de qualquer espécie e desde que economicamente apreciáveis, feitos a (i) você, (ii) ao seu cônjuge/companheiro ou a qualquer outro membro que resida com você, (iii) a qualquer pessoa jurídica em que qualquer destes seja controlador, sócio, acionista ou participante, de Ibraim Masciarelli Francisco Pinto forma direta ou indireta, recebimento por palestras, aulas, atuação como proctor de treinamentos, remunerações, honorários pagos por participações em conselhos consultivos, de investigadores, ou outros comitês, etc. Provenientes da indústria farmacêutica, de órteses, próteses, equipamentos e implantes, brasileiras ou estrangeiras: - Novo Nordisk: Diabetes.

\begin{tabular}{|c|c|}
\hline João Luiz de Alencar Araripe Falcão & Nada a ser declarado \\
\hline João Luiz Petriz & $\begin{array}{l}\text { Declaração financeira } \\
\text { A - Pagamento de qualquer espécie e desde que economicamente apreciáveis, feitos a (i) você, } \\
\text { (ii) ao seu cônjuge/companheiro ou a qualquer outro membro que resida com você, (iii) a qualquer } \\
\text { pessoa jurídica em que qualquer destes seja controlador, sócio, acionista ou participante, de } \\
\text { forma direta ou indireta, recebimento por palestras, aulas, atuação como proctor de treinamentos, } \\
\text { remunerações, honorários pagos por participações em conselhos consultivos, de investigadores, ou } \\
\text { outros comitês, etc. Provenientes da indústria farmacêutica, de órteses, próteses, equipamentos e } \\
\text { implantes, brasileiras ou estrangeiras: } \\
\text { - Daiichi Sankyo e Servier: Cardiologia. }\end{array}$ \\
\hline Joberto Pinheiro Sena & $\begin{array}{l}\text { Declaração financeira } \\
\text { A - Pagamento de qualquer espécie e desde que economicamente apreciáveis, feitos a (i) você, } \\
\text { (ii) ao seu cônjuge/companheiro ou a qualquer outro membro que resida com você, (iii) a qualquer } \\
\text { pessoa jurídica em que qualquer destes seja controlador, sócio, acionista ou participante, de } \\
\text { forma direta ou indireta, recebimento por palestras, aulas, atuação como proctor de treinamentos, } \\
\text { remunerações, honorários pagos por participações em conselhos consultivos, de investigadores, ou } \\
\text { outros comitês, etc. Provenientes da indústria farmacêutica, de órteses, próteses, equipamentos e } \\
\text { implantes, brasileiras ou estrangeiras: } \\
\text { - Servier: Palestras sobre SCA; Bayer: Aulas em manejo de anticoagulantes e antitrombóticos; Daiichi } \\
\text { Sankyo: Manejo de antiplaquetários em SCA. }\end{array}$ \\
\hline
\end{tabular}




José A. Marin-Neto Nada a ser declarado

Declaração financeira

A - Pagamento de qualquer espécie e desde que economicamente apreciáveis, feitos a (i) você, (ii) ao seu cônjuge/ companheiro ou a qualquer outro membro que resida com você, (iii) a qualquer pessoa jurídica em que qualquer destes seja controlador, sócio, acionista ou participante, de forma direta ou indireta, recebimento por palestras, aulas, atuação como proctor de treinamentos, remunerações, honorários pagos por participações em conselhos consultivos, de investigadores, ou outros comitês, etc. Provenientes da indústria farmacêutica, de órteses, próteses, equipamentos e implantes, brasileiras ou estrangeiras:

- Amgen: Hipolipemiante; Bayer: Anticoagulante; Daiichi Sankyo: Antiplaquetário, anticoagulante; Novartis: Inibidor SRA, hipolipemiante; Sanofi: Anticoagulante, hipolipemiante, antiplaquetário; Servier: antiplaquetário.

José Carlos Nicolau B - financiamento de pesquisas sob sua responsabilidade direta/pessoal (direcionado ao departamento ou instituição) provenientes da indústria farmacêutica, de órteses, próteses, equipamentos e implantes, brasileiras ou estrangeiras:

- Astrazeneca: Antiplaquetário, hipoglicemiante; Bayer: Anticoagulante; Esperion: Hipolipemante; CSL Behring: hipolipemiante; Dalcor: Aumento HDL; Jansen: Anticoagulante; Novartis: Inibidor SRA; Novo Nordisk: Hipoglicemiante; Sanofi: Anticoagulate, hipolipemiante; Vifor: Deficiência de Ferro.

C - Financiamento de pesquisa (pessoal), cujas receitas tenham sido provenientes da indústria farmacêutica, de órteses, próteses, equipamentos e implantes, brasileiras ou estrangeiras:

- Roche: Kits de laboratório para avaliação de agregabilidade plaquetária.

Outros relacionamentos

Financiamento de atividades de educação médica continuada, incluindo viagens, hospedagens e inscrições para congressos e cursos, provenientes da indústria farmacêutica, de órteses, próteses, equipamentos e implantes, brasileiras ou estrangeiras:

- Sanofi: Anticoagulante, antiplaquetário, hipolipemiante; Bayer: Anticoagulante; Servier: antiplaquetário.

\begin{tabular}{l}
\hline José Maria Peixoto \\
\hline Juliana Ascenção de Souza \\
\hline Leonardo Sara da Silva \\
\hline Leopoldo Soares Piegas \\
\hline Lilia Nigro Maia
\end{tabular}

Nada a ser declarado

Nada a ser declarado

Nada a ser declarado

Nada a ser declarado

Nada a ser declarado

Declaração financeira

A - Pagamento de qualquer espécie e desde que economicamente apreciáveis, feitos a (i) você, (ii) ao seu cônjuge/ companheiro ou a qualquer outro membro que resida com você, (iii) a qualquer pessoa jurídica em que qualquer destes seja controlador, sócio, acionista ou participante, de forma direta ou indireta, recebimento por palestras, aulas, atuação como proctor de treinamentos, remunerações, honorários pagos por participações em conselhos consultivos, de investigadores, ou outros comitês, etc. Provenientes da indústria farmacêutica, de órteses, próteses, equipamentos e implantes, brasileiras ou estrangeiras:

- Daiichi Sankyo: Edoxabana.

Louis Nakayama Ohe

Outros relacionamentos

Financiamento de atividades de educação médica continuada, incluindo viagens, hospedagens e inscrições para congressos e cursos, provenientes da indústria farmacêutica, de órteses, próteses, equipamentos e implantes, brasileiras ou estrangeiras:

Outros relacionamentos

- Abbott e Meryl: Hemodinâmica.

Outros relacionamentos

Participação em comitês de compras de materiais ou fármacos em instituições de saúde ou funções assemelhadas:

- Comitê para compra de aparelhos para unidades de Covid-19.

Declaração financeira

A - Pagamento de qualquer espécie e desde que economicamente apreciáveis, feitos a (i) você, (ii) ao seu cônjuge/ companheiro ou a qualquer outro membro que resida com você, (iii) a qualquer pessoa jurídica em que qualquer destes seja controlador, sócio, acionista ou participante, de forma direta ou indireta, recebimento por palestras, aulas, atuação como proctor de treinamentos, remunerações, honorários pagos por participações em conselhos consultivos, de investigadores, ou

Luciano Moreira Baracioli outros comitês, etc. Provenientes da indústria farmacêutica, de órteses, próteses, equipamentos e implantes, brasileiras ou estrangeiras:

- Sandoz: Clopidogrel; Bayer: Rivaroxabana.

Outros relacionamentos

Financiamento de atividades de educação médica continuada, incluindo viagens, hospedagens e inscrições para congressos e cursos, provenientes da indústria farmacêutica, de órteses, próteses, equipamentos e implantes, brasileiras ou estrangeiras:

- Bayer: Anticoagulação. 
Luís Alberto de Oliveira Dallan

Luis Augusto Palma Dallan

Luiz Alberto Piva e Mattos
Outros relacionamentos

Participação em comitês de compras de materiais ou fármacos em instituições de saúde ou funções assemelhadas: - Pregão.

\author{
Nada a ser declarado
}

Nada a ser declarado

Declaração financeira

A - Pagamento de qualquer espécie e desde que economicamente apreciáveis, feitos a (i) você, (ii) ao seu cônjuge/ companheiro ou a qualquer outro membro que resida com você, (iii) a qualquer pessoa jurídica em que qualquer destes seja controlador, sócio, acionista ou participante, de forma direta ou indireta, recebimento por palestras, aulas, atuação como proctor de treinamentos, remunerações, honorários pagos por participações em conselhos consultivos, de investigadores, ou outros comitês, etc. Provenientes da indústria farmacêutica, de órteses, próteses, equipamentos e implantes, brasileiras ou estrangeiras:

- Pfizer e Bayer: Aula anticoagulante; Libbs: Aula anti-hipertensivos.

Outros relacionamentos

Participação societária de qualquer natureza e qualquer valor economicamente apreciável de empresas na área de saúde, de ensino ou em empresas concorrentes ou fornecedoras da SBC: - Sócio da L\&P Cardio, empresa de serviços médicos.

Luiz Carlos Bodanese

Nada a ser declarado

Declaração financeira

A - Pagamento de qualquer espécie e desde que economicamente apreciáveis, feitos a (i) você, (ii) ao seu cônjuge/ companheiro ou a qualquer outro membro que resida com você, (iii) a qualquer pessoa jurídica em que qualquer destes seja controlador, sócio, acionista ou participante, de forma direta ou indireta, recebimento por palestras, aulas, atuação como proctor de treinamentos, remunerações, honorários pagos por participações em conselhos consultivos, de investigadores, ou outros comitês, etc. Provenientes da indústria farmacêutica, de órteses, próteses, equipamentos e implantes, brasileiras ou estrangeiras: - Pfizer: Amiloidose.

\begin{tabular}{ll}
\hline Manoel Fernandes Canesin & Nada a ser declarado \\
\hline Marcelo Bueno da Silva Rivas & Nada a ser declarado \\
\hline Marcelo Franken & Nada a ser declarado \\
\hline Marcos José Gomes Magalhães & Nada a ser declarado \\
\hline Múcio Tavares de Oliveira Júnior & Nada a ser declarado \\
\hline & Declaração financeira
\end{tabular}

A - Pagamento de qualquer espécie e desde que economicamente apreciáveis, feitos a (i) você, (ii) ao seu cônjuge/ companheiro ou a qualquer outro membro que resida com você, (iii) a qualquer pessoa jurídica em que qualquer destes seja controlador, sócio, acionista ou participante, de forma direta ou indireta, recebimento por palestras, aulas, atuação como proctor de treinamentos, remunerações, honorários pagos por participações em conselhos consultivos, de investigadores, ou outros comitês, etc. Provenientes da indústria farmacêutica, de órteses, próteses, equipamentos e implantes, brasileiras ou estrangeiras: - Pfizer: Eliquis, Apixabana; Boehringer: Pradaxa, Praxbind, Jardiance; Astrazenca: Forxiga; Novo Nordisk; Daiichi Sankyo; Novartis; Bayer.

B - financiamento de pesquisas sob sua responsabilidade direta/pessoal (direcionado ao departamento ou instituição) provenientes da indústria farmacêutica, de órteses, próteses, equipamentos e implantes, brasileiras ou estrangeiras:

- Astrazeneca: Dapaglifozina.

Outros relacionamentos

Financiamento de atividades de educação médica continuada, incluindo viagens, hospedagens e inscrições para congressos e cursos, provenientes da indústria farmacêutica, de órteses, próteses, equipamentos e implantes, brasileiras ou estrangeiras:

- Pfizer: Eliquis; Daiichi Sankyo: Effient; Bayer: Xarelto. 
Oscar Pereira Dutra

Otávio Rizzi Coelho

\section{Declaração financeira}

A - Pagamento de qualquer espécie e desde que economicamente apreciáveis, feitos a (i) você, (ii) ao seu cônjuge/ companheiro ou a qualquer outro membro que resida com você, (iii) a qualquer pessoa jurídica em que qualquer destes seja controlador, sócio, acionista ou participante, de forma direta ou indireta, recebimento por palestras, aulas, atuação como proctor de treinamentos, remunerações, honorários pagos por participações em conselhos consultivos, de investigadores, ou outros comitês, etc. Provenientes da indústria farmacêutica, de órteses, próteses, equipamentos e implantes, brasileiras ou estrangeiras:

- Astrazeneca: Antiglicêmicos; Daiichi Sankyo: Anticoagulantes; Sandoz: Anti-hipertensivos.

B - financiamento de pesquisas sob sua responsabilidade direta/pessoal (direcionado ao departamento ou instituição) provenientes da indústria farmacêutica, de órteses, próteses, equipamentos e implantes, brasileiras ou estrangeiras:

- Boheringer: Antiglicêmicos; Novartis: Insuficiência Cardíaca; Sanofi: Antilipêmicos.

C - Financiamento de pesquisa (pessoal), cujas receitas tenham sido provenientes da indústria farmacêutica, de órteses, próteses, equipamentos e implantes, brasileiras ou estrangeiras:

- Sanofi e EMS: Anticoagulantes; Amgen: Antilipêmicos.

Outros relacionamentos

Financiamento de atividades de educação médica continuada, incluindo viagens, hospedagens e inscrições para congressos e cursos, provenientes da indústria farmacêutica, de órteses, próteses, equipamentos e implantes, brasileiras ou estrangeiras:

- Bayer: Anticoagulantes.

Declaração financeira

B - financiamento de pesquisas sob sua responsabilidade direta/pessoal (direcionado ao departamento ou instituição) provenientes da indústria farmacêutica, de órteses, próteses, equipamentos e implantes, brasileiras ou estrangeiras:

- Boheringer: Empaglifozina.

Outros relacionamentos

Financiamento de atividades de educação médica continuada, incluindo viagens, hospedagens e inscrições para congressos e cursos, provenientes da indústria farmacêutica, de órteses, próteses, equipamentos e implantes, brasileiras ou estrangeiras:

- Daiichi Sankyo: Prasugrel; Bayer: Rivaroxabana; Astrazeneca: Dapaglifozina.

Outros relacionamentos

Financiamento de atividades de educação médica continuada, incluindo viagens, hospedagens e inscrições para congressos e cursos, provenientes da indústria farmacêutica, de órteses, próteses, equipamentos e implantes, brasileiras ou estrangeiras:

- Boehringer: Anticoagulantes

Participação em comitês de compras de materiais ou fármacos em instituições de saúde ou funções assemelhadas:

Comitê de Padronização da Santa Casa de Porto Alegre

Declaração financeira

A - Pagamento de qualquer espécie e desde que economicamente apreciáveis, feitos a (i) você, (ii) ao seu cônjuge/ companheiro ou a qualquer outro membro que resida com você, (iii) a qualquer pessoa jurídica em que qualquer destes seja controlador, sócio, acionista ou participante, de forma direta ou indireta, recebimento por palestras, aulas, atuação como proctor de treinamentos, remunerações, honorários pagos por participações em conselhos consultivos, de investigadores, ou outros comitês, etc. Provenientes da indústria farmacêutica, de órteses, próteses, equipamentos e implantes, brasileiras ou estrangeiras:

- Novartis: Sacubitril, Valsartan.

\section{Declaração financeira}

A - Pagamento de qualquer espécie e desde que economicamente apreciáveis, feitos a (i) você, (ii) ao seu cônjuge/ companheiro ou a qualquer outro membro que resida com você, (iii) a qualquer pessoa jurídica em que qualquer destes seja controlador, sócio, acionista ou participante, de forma direta ou indireta, recebimento por palestras, aulas, atuação como proctor de treinamentos, remunerações, honorários pagos por participações em conselhos consultivos, de investigadores, ou outros comitês, etc. Provenientes da indústria farmacêutica, de órteses, próteses, equipamentos e implantes, brasileiras ou estrangeiras:

- Astrazeneca: Dapagliflozina; Servier: Ticagrelor; Bayer: Rivaroxabana.

Pedro Alves Lemos Neto

Nada a ser declarado

Declaração financeira

A - Pagamento de qualquer espécie e desde que economicamente apreciáveis, feitos a (i) você, (ii) ao seu cônjuge/ companheiro ou a qualquer outro membro que resida com você, (iii) a qualquer pessoa jurídica em que qualquer destes seja controlador, sócio, acionista ou participante, de forma direta ou indireta, recebimento por palestras, aulas, atuação como proctor de treinamentos, remunerações, honorários pagos por participações em conselhos consultivos, de investigadores, ou outros comitês, etc. Provenientes da indústria farmacêutica, de órteses, próteses, equipamentos e implantes, brasileiras ou estrangeiras:

- Aliança Boehringer Ingelheim/Lilly: I -SGLT2. 
A - Pagamento de qualquer espécie e desde que economicamente apreciáveis, feitos a (i) você, (ii) ao seu cônjuge/ companheiro ou a qualquer outro membro que resida com você, (iii) a qualquer pessoa jurídica em que qualquer destes seja controlador, sócio, acionista ou participante, de forma direta ou indireta, recebimento por palestras, aulas, atuação como proctor de treinamentos, remunerações, honorários pagos por participações em conselhos consultivos, de investigadores, ou outros comitês, etc. Provenientes da indústria farmacêutica, de órteses, próteses, equipamentos e implantes, brasileiras ou estrangeiras:

- Astra Zeneca: Dapagliflozina (Diabetes, Insuficiência Cardíaca); Servier: Ticagrelor; Bayer: Rivaroxabana. B - financiamento de pesquisas sob sua responsabilidade direta/pessoal (direcionado ao departamento ou instituição) provenientes da indústria farmacêutica, de órteses, próteses, equipamentos e implantes, brasileiras ou estrangeiras:

- Bayer: Rivaroxabana (Covid); Astra Zeneca: Dapagliflozina (Covid), Dapagliflozina (IC); Pfizer: Tofacitinib (Covid), Apixabana (FA); EMS, Aché, Servier, Health Canada, GSK, Servier.

\begin{tabular}{ll}
\hline Renato Abdala Karam Kalil & Nada a ser declarado \\
\hline Declaração financeira \\
A - Pagamento de qualquer espécie e desde que economicamente apreciáveis, feitos a (i) você, (ii) \\
ao seu cônjuge/ companheiro ou a qualquer outro membro que resida com você, (iii) a qualquer \\
pessoa jurídica em que qualquer destes seja controlador, sócio, acionista ou participante, de \\
forma direta ou indireta, recebimento por palestras, aulas, atuação como proctor de treinamentos, \\
remunerações, honorários pagos por participações em conselhos consultivos, de investigadores, ou \\
outros comitês, etc. Provenientes da indústria farmacêutica, de órteses, próteses, equipamentos e
\end{tabular}
implantes, brasileiras ou estrangeiras:

Renato Delascio Lopes

- Bayer: Anticoagulante; Boehringer Ingleheim: Anticoagulação e Diabetes; Pfizer: Anticoagulação; Bristol-Myers Squibb; Daiichi Sankyo; Glaxo Smith Kline; Medtronic; Merck; Portola; Sanofi. $B$ - financiamento de pesquisas sob sua responsabilidade direta/pessoal (direcionado ao departamento ou instituição) provenientes da indústria farmacêutica, de órteses, próteses, equipamentos e implantes, brasileiras ou estrangeiras:

- Pfizer: Apixaban; Bayer: Rivaroxaban; Novartis: Sacubitril, Valsartan.

Outros relacionamentos

Financiamento de atividades de educação médica continuada, incluindo viagens, hospedagens e inscrições para congressos e cursos, provenientes da indústria farmacêutica, de órteses, próteses, equipamentos e implantes, brasileiras ou estrangeiras:

- Bayer: Rivaroxabana; Pfizer: Apixabana.

\section{Declaração financeira}

A - Pagamento de qualquer espécie e desde que economicamente apreciáveis, feitos a (i) você, (ii) ao seu cônjuge/ companheiro ou a qualquer outro membro que resida com você, (iii) a qualquer pessoa jurídica em que qualquer destes seja controlador, sócio, acionista ou participante, de

Renato Jorge Alves forma direta ou indireta, recebimento por palestras, aulas, atuação como proctor de treinamentos, remunerações, honorários pagos por participações em conselhos consultivos, de investigadores, ou outros comitês, etc. Provenientes da indústria farmacêutica, de órteses, próteses, equipamentos e implantes, brasileiras ou estrangeiras:

- Amgen: Evolocumabe; PTC: Volanesorsen; Pfizer: Apixaban.

\section{Declaração financeira}

A - Pagamento de qualquer espécie e desde que economicamente apreciáveis, feitos a (i) você, (ii) ao seu cônjuge/ companheiro ou a qualquer outro membro que resida com você, (iii) a qualquer pessoa jurídica em que qualquer destes seja controlador, sócio, acionista ou participante, de

Roberto Esporcatte forma direta ou indireta, recebimento por palestras, aulas, atuação como proctor de treinamentos, remunerações, honorários pagos por participações em conselhos consultivos, de investigadores, ou outros comitês, etc. Provenientes da indústria farmacêutica, de órteses, próteses, equipamentos e implantes, brasileiras ou estrangeiras:

- Bayer: Anticoagulação.

\section{Declaração financeira}

B - financiamento de pesquisas sob sua responsabilidade direta/pessoal (direcionado ao

Roberto Luiz Marino departamento ou instituição) provenientes da indústria farmacêutica, de órteses, próteses, equipamentos e implantes, brasileiras ou estrangeiras: - CSL Behring: Infarto do Miocárdio.

\begin{tabular}{ll}
\hline Roberto Rocha Corrêa Veiga Giraldez & Nada a ser declarado \\
\hline Romeu Sérgio Meneghelo & Nada a ser declarado
\end{tabular}


Nicolau et al.

Diretrizes da Sociedade Brasileira de Cardiologia sobre Angina Instável e Infarto Agudo do Miocárdio sem Supradesnível do Segmento ST - 2021

\section{Diretrizes}

Ronaldo de Souza Leão Lima

Rui Fernando Ramos

\section{Outros relacionamentos}

Participação societária de qualquer natureza e qualquer valor economicamente apreciável de empresas na área de saúde, de ensino ou em empresas concorrentes ou fornecedoras da SBC: - Fonte Imagem: sócio minoritário.

Declaração financeira

A - Pagamento de qualquer espécie e desde que economicamente apreciáveis, feitos a (i) você, (ii) ao seu cônjuge/ companheiro ou a qualquer outro membro que resida com você, (iii) a qualquer pessoa jurídica em que qualquer destes seja controlador, sócio, acionista ou participante, de forma direta ou indireta, recebimento por palestras, aulas, atuação como proctor de treinamentos, remunerações, honorários pagos por participações em conselhos consultivos, de investigadores, ou outros comitês, etc. Provenientes da indústria farmacêutica, de órteses, próteses, equipamentos e implantes, brasileiras ou estrangeiras:

- Aspen: Fondaparinux.

Financiamento de atividades de educação médica continuada, incluindo viagens, hospedagens e inscrições para congressos e cursos, provenientes da indústria farmacêutica, de órteses, próteses, equipamentos e implantes, brasileiras ou estrangeiras:

- Aspen: Fondaparinux.

Sandra Nivea dos Reis Saraiva Falcão Nada a ser declarado

Declaração financeira

B - financiamento de pesquisas sob sua responsabilidade direta/pessoal (direcionado ao

Talia Falcão Dalçóquio departamento ou instituição) provenientes da indústria farmacêutica, de órteses, próteses, equipamentos e implantes, brasileiras ou estrangeiras:

- Amgen, DalCor Pharma UK Ltd, CSL Behring LLC: Farmacêutica.

Viviana de Mello Guzzo Lemke

Nada a ser declarado

Walmor Lemke

Nada a ser declarado

William Azem Chalela Nada a ser declarado

Wilson Mathias Júnior Nada a ser declarado 
Diretrizes da SBC sobre Angina Instável e IAM sem supradesnível de ST - Atualização 2021

Coordenador Geral: José C. Nicolau; Assistente da Coordenação: Remo H.M. Furtado; Supervisão da versão em Inglês: Renato D. Lopes; Secretaria: Daniele Gullo

\begin{tabular}{|c|c|c|}
\hline Parte 1 - Avaliação e Condutas na Emergência & Parte 2 - Condutas Durante a Hospitalização & $\begin{array}{l}\text { Parte 3: Recomendações na Alta e Cuidados } \\
\text { Pós-alta Hospitalar }\end{array}$ \\
\hline Coordenadores: & Coordenadores: & Coordenadores: \\
\hline Ari Timerman & Leopoldo S. Piegas & Gilson Feitosa Filho \\
\hline João Luiz Petriz & José A. Marin-Netto & Luiz Bezerra Neto \\
\hline \multirow[t]{2}{*}{ Bruno Ferraz } & Dalton Précoma & Eduardo Lapa \\
\hline & Walmor Lemke & \\
\hline Revisores Parte 1 & Revisores Parte 2 & Revisores Parte 3 \\
\hline Brivaldo Markman Filho & Andre Franci & Alexandre de Matos Soeiro \\
\hline Bruno Mendonça Baccaro & Edson Stefanini & Alexandre Jorge de Andrade Negri \\
\hline Carlos Eduardo Rochitte & Euler Roberto Fernandes Manenti & Carlos Eduardo Lucena Montenegro \\
\hline Leonardo Sara & Felipe Galego Lima & Cláudio Marcelo Bittencourt das Virgens \\
\hline Carlos Jose Dornas Gonçalves Barbosa & Harry Correa Filho & Francisco das Chagas Monteiro Júnior \\
\hline Louis Nakayama Ohe & Ibraim Masciarelli Francisco Pinto & Henrique Patrus Mundim Pena \\
\hline Luiz Carlos Bodanese & Lilia Nigro Maia & João Luiz de Alencar Araripe Falcão \\
\hline Marcelo Bueno da Silva Rivas & Luciano Moreira Baracioli & Joberto Pinheiro Sena \\
\hline Paulo Roberto Ferreira Rossi & Luís Alberto de Oliveira Dallan & José Maria Peixoto \\
\hline Paulo Rogério Soares & Luis Augusto P. Dallan & Juliana Ascenção de Souza \\
\hline Pedro Alves Lemos Neto & Luiz Alberto Piva e Mattos & Luiz Eduardo Fonteles Ritt \\
\hline Renato Delascio Lopes & Marcelo Franken & Manoel Fernandes Canesin \\
\hline Roberto Esporcatte & Oscar Pereira Dutra & Marcos José Gomes Magalhães \\
\hline Roberto Luiz Marino & Otávio Rizzi Coelho & Múcio Tavares de Oliveira Júnior \\
\hline Roberto Rocha Corrêa Veiga Giraldez & Paulo Ernesto Leães & Nivaldo Menezes Filgueiras Filho \\
\hline Rui Fernando Ramos & Renato Kalil & Pedro Silvio Farsky \\
\hline Talia Falcão Dalçóquio & Romeu Sérgio Meneghelo & Rafael Rebêlo C. Cavalcanti \\
\hline \multirow[t]{2}{*}{ William Azem Chalela } & Ronaldo de Souza Leão Lima & Renato Jorge Alves \\
\hline & Vivivana Lemke & Sandra Nives dos Reis Saraiva Falcão \\
\hline
\end{tabular}




\section{Definições das Recomendações e Evidências}

\section{Recomendações}

Classe I: Condições para as quais há evidências conclusivas, ou, na sua falta, consenso geral de que o procedimento é seguro e útil/eficaz.

Classe II: Condições para as quais há evidências conflitantes e/ou divergência de opinião sobre segurança e utilidade/eficácia do procedimento.

Classe Ila: Peso ou evidência/opinião a favor do procedimento. A maioria aprova.

Classe IIb: Segurança e utilidade/eficácia menos bem estabelecida, não havendo predomínio de opiniões a favor.

Classe III: Condições para as quais há evidências e/ou consenso de que o procedimento não é útil/eficaz e, em alguns casos, pode ser prejudicial.

\section{Evidências}

Nível A: Dados obtidos a partir de múltiplos estudos randomizados de bom porte, concordantes e/ou de metanálise robusta de estudos clínicos randomizados.

Nível B: Dados obtidos a partir de metanálise menos robusta, a partir de um único estudo randomizado ou de estudos não randomizados (observacionais).

Nível C: Dados obtidos de opiniões consensuais de especialistas.

\section{Mudança de recomendações}

Mudança de recomendações - Marcadores Bioquímicos

Diretriz 2014

Marcadores bioquímicos de necrose miocárdica devem ser mensurados em todos os pacientes com suspeita de síndromes coronarianas agudas sem supradesnível do segmento ST (SCASSST). Os marcadores devem ser medidos na admissão e repetidos pelo menos uma vez, 6 a 9h após (preferencialmente 9 a 12h após o início dos sintomas), caso a primeira dosagem seja normal ou discretamente elevada.

Creatinoquinase MB (CK-MB) massa e troponinas são os marcadores bioquímicos de escolha.

Para pacientes que chegam precocemente à emergência (antes de 6h do início dos sintomas), mioglobina e troponina ultrassensivel podem ser consideradas em adição a um marcador mais tardio (CK-MB ou troponina).

\section{Diretriz 2020}

Biomarcadores bioquímicos de necrose miocárdica devem ser mensurados em todos os pacientes com suspeita de SCASSST. Quando troponina ultrassensivel estiver disponível, a dosagem sérica deve ser realizada na admissão e idealmente reavaliada em $1 \mathrm{~h}$ ou até $2 \mathrm{~h}$. Caso indisponível, a troponina convencional deve ser coletada na admissão e repetida pelo menos uma vez, 3 a $6 \mathrm{~h}$ após, caso a primeira dosagem seja normal ou discretamente elevada.

Dosagens CK-MB massa podem ser utilizadas se dosagens de troponina não estiverem disponíveis.

As troponinas são os biomarcadores de escolha em pacientes com suspeita de IAM.

Utilização da mioglobina para detecção de necrose miocárdica em pacientes com suspeita de SCASSST.
Mudança de recomendações - Teste ergométrico

\section{Diretriz 2014}

Pacientes de risco baixo (clínica e eletrocardiograma [ECG]) e com marcadores bioquímicos normais devem ser encaminhados para teste ergométrico após $9 \mathrm{~h}$, idealmente até $12 \mathrm{~h}$, em regime ambulatorial.

\section{Diretriz 2020}

Pacientes de risco baixo (clínica e ECG) e com biomarcadores normais devem ser encaminhados para teste ergométrico após 9 a $12 \mathrm{~h}$ em observação. Dentro das rotas da unidade de dor torácica (UDT), estes exames podem ser feitos como critério de alta.
Mudança de recomendações - Cardiologia nuclear

\section{Diretriz 2014}

Cintilografia miocárdica de perfusão em estresse e repouso é uma alternativa ao teste ergométrico nos pacientes com impossibilidade para o mesmo.

Pacientes em vigência de dor torácica podem ser avaliados pela cintilografia miocárdica de perfusão em repouso para determinar a origem isquêmica ou não da dor

\section{Diretriz 2020}

Cintilografia miocárdica de estresse (físico ou farmacológico) pode ser utilizada como método de estratificação em pacientes sem dor torácica recorrente, sem evidências eletrocardiográficas de isquemia e/ou elevação de troponina.

Pacientes em vigência de dor torácica e eletrocardiograma

Ila A sem alterações isquêmicas podem ser avaliados pela cintilografia miocárdica de perfusão em repouso para determinar a origem isquêmica ou não da dor. 


\section{Mudança de Recomendações - Analgesia e sedação}

Diretriz 2014

Administrar sulfato de morfina a pacientes de risco intermediário e alto.

Administrar benzodiazepínicos a pacientes de alto risco.

Administrar benzodiazepínicos a pacientes de risco intermediário.

\section{Diretriz 2020}

Administrar sulfato de morfina em pacientes que mantêm dor contínua, apesar de terapia anti-isquêmica otimizada

Administrar benzodiazepínicos em pacientes com sinais e sintomas de ansiedade persistente.

Mudança de recomendações - Nitratos

Diretriz 2014 Diretriz 2020

Uso de nitrato em pacientes com risco intermediário e alto.

Uso de nitrato sublingual para alivio da angina.

Uso de nitrato endovenoso para controle de angina persistente, hipertensão arterial ou sinais de congestão.

Mudança de recomendações - Betabloqueadores

\section{Diretriz 2014}

Administrar betabloqueadores por via oral (VO) a pacientes de risco intermediário e alto.

\section{Diretriz 2020}

Administrar betabloqueadores $\mathrm{VO}$ nas primeiras $24 \mathrm{~h} \mathrm{em}$ pacientes sem contraindicações (sinais de insuficiência cardíaca, sinais de baixo débito, risco aumentado de choque cardiogênico ou outras contraindicações ao betabloqueador).

Mudança de recomendações - Uso de antiplaquetários na sala de emergência

Diretriz 2014

Tienopiridínicos em pacientes com contraindicação ao ácido acetilsalicilico (AAS)

\section{Diretriz 2020}

Em pacientes alérgicos a AAS, está indicada monoterapia inicial com inibidor $\mathrm{P} 2 \mathrm{Y}_{12}$ (uso preferencial de ticagrelor ou prasugrel).

Mudança de recomendações - Antagonistas dos receptores da glicoproteína IIlb/llla

Diretriz 2014

Adição de inibidores da GP IIb/llla em pacientes que apresentam recorrência de sintomas isquêmicos na vigência de dupla antiagregação plaquetária oral e anticoagulação.

\section{Diretriz 2020}

Na estratégia conservadora, adição de tirofiban em pacientes que presentam recorrência de sintomas isquêmicos na vigência de dupla antiagregação plaquetária oral e anticoagulação.

\section{Mudança de recomendações - Anticoagulantes}

Diretriz 2014

Uso de heparina não fracionada (HNF) em todos os pacientes.

Uso de heparinas de baixo peso molecular (HBPM) em todos os pacientes.

\section{Diretriz 2020}

Uso preferencial de HNF em pacientes com disfunção renal grave (clearance $<15 \mathrm{~mL} / \mathrm{min}$ ) e obesos com peso $>150 \mathrm{~kg}$

Uso de enoxaparina em pacientes sem disfunção renal grave (clearance $<15 \mathrm{~mL} / \mathrm{min} / 1,73 \mathrm{~m}^{2}$ ), até a revascularização, por 8 dias ou até a alta hospitalar, $1 \mathrm{mg} / \mathrm{kg} 12 / 12 \mathrm{~h}(0,75 \mathrm{mg} / \mathrm{kg}, 12 / 12 \mathrm{~h}$, se $\geq 75$ anos; $1 \mathrm{mg} / \mathrm{kg}, 24 / 24 \mathrm{~h}$, se clearence de creatinina entre 15 e $30 \mathrm{~mL} / \mathrm{min} / 1,73 \mathrm{~m}^{2}$; máximo de $150 \mathrm{mg}$ por dose.

\section{Novas recomendações}

\section{História e exame físico}

Pacientes com suspeita de SCASSST e dor persistente, dispneia, palpitações ou síncope devem ser encaminhados para serviços de emergência idealmente monitorados em ambulância.

Pacientes com suspeita de SCASSST com achados de menor gravidade, (i. e., sem dor persistente, dispneia, palpitações ou síncope) podem procurar por meios próprios o serviço de emergência mais próximo com capacidade de realizar ECG e dosagem de troponina.

\section{Eletrocardiograma}

O ECG deve ser repetido em caso de recorrência dos sintomas.

As derivações V3R-V4R, V7-V9 devem ser realizadas em pacientes que permanecem sintomáticos e apresentam ECG de 12 derivações não diagnóstico. 


\section{Diretrizes}

\section{Marcadores bioquímicos}

Na disponibilidade de troponina, nenhum outro marcador necessita ser solicitado para fins diagnósticos.

\section{Angiografia por tomografia computadorizada das artérias coronárias}

Investigação da dor torácica aguda pela técnica do descarte triplo (triple rule-out).

\section{Rotina diagnóstica e critérios de internação}

A triagem inicial deve ser realizada com base em história clínica, exame físico, ECG de 12 derivações em até 10min e troponina.

0 escore HEART deve ser utilizado para estratificação de risco e auxilio na decisão de alta hospitalar.

Pacientes com escore HEART $\leq 3$ associado à troponina negativa, ECG sem alteração isquêmica e ausência de antecedentes de doença arterial coronariana (DAC) podem ser liberados do serviço de emergência para reavaliação ambulatorial.

Triagem hospitalar realizada por enfermeiros habilitados visando ao reconhecimento precoce de pacientes sob maior risco.

Uso de escore EDACS e ADAPT para estratificação de risco clínico como opção ao escore HEART.

Utilização do escore HEART visando à liberação precoce em pacientes atendidos por ambulância.

\section{Estratégia invasiva de urgência}

A estratégia invasiva urgente/imediata está indicada em pacientes com SCASSST com angina refratária e/ou instabilidade hemodinâmica e/ou elétrica (sem comorbidades graves ou contraindicações para esses procedimentos).

\section{Controle glicêmico}

É recomendável mensurar, na admissão, os níveis glicêmicos de todos os pacientes com suspeita de infarto agudo do miocárdio (IAM), assim como monitorar evolutivamente a glicemia dos pacientes diabéticos ou que apresentem hiperglicemia durante a internação.

Controle glicêmico com protocolos de utilização de insulina intermitente deve ser considerado em pacientes com níveis glicêmicos > 180mg/ dL, com cautela, para evitar episódios de hipoglicemia.

Em pacientes com maior risco de hipoglicemia, tais como idosos, nefropatas e pacientes com efeito residual de hipoglicemiantes orais e/ou em jejum, o controle glicêmico deve ser ajustado para tolerar niveis glicêmicos um pouco mais altos e, assim, prevenir hipoglicemia.

\section{Betabloqueadores}

Administrar betabloqueador por via intravenosa (IV) em pacientes com fatores de risco para choque cardiogênico.

\section{Terapia antiplaquetária inicial}

Não realizar pré-tratamento com segundo antiplaquetário inibidor do receptor $\mathrm{P} 2 \mathrm{Y}_{12}$ nos pacientes instáveis e/ou com risco elevado, indicados para estratégia invasiva de forma imediata, sendo sua utilização recomendada para sala de cateterismo quando anatomia coronariana conhecida e intervenção coronária percutânea (ICP) programada.

Não há indicação rotineira de se iniciar $\mathrm{P}_{2} \mathrm{Y}_{12}$ como pré-tratamento em pacientes indicados para estratégia invasiva precoce (<24h).

Clopidogrel (dose de ataque) independente da estratégia inicial (conservadora ou invasiva) em pacientes de muito alto risco para sangramento ou necessidade de anticoagulação oral a longo prazo.

Estratégia de pré-tratamento com prasugrel não é recomendada.

\section{Anticoagulantes}

Uso de fondaparinux 2,5mg por via subcutânea (SC) 1 vez/dia por 8 dias ou até a alta hospitalar como alternativa à enoxaparina, especialmente no paciente de elevado risco hemorrágico.

Monitoramento do fator anti-Xa em pacientes com clearance entre 15 e $30 \mathrm{~mL} / \mathrm{min}$ e obesos com peso entre 100 e $150 \mathrm{~kg}$ em uso de enoxaparina.

Uso preferencial de enoxaparina versus $\mathrm{HNF}$ em pacientes com clearance $\geq 15 \mathrm{~mL} / \mathrm{min} / 1,73 \mathrm{~m}^{2}$ ), a não ser que cirurgia de revascularização miocárdica esteja planejada para as próximas $24 \mathrm{~h}$.

Uso preferencial de HNF na emergência ou sala de hemodinâmica em pacientes de muito alto risco, com proposta de cateterismo imediato $(<2 \mathrm{~h})$.

Uso de enoxaparina em pacientes com clearance de creatinina $<15 \mathrm{~mL} / \mathrm{min}$ e peso $>150 \mathrm{~kg}$.

Uso de fondaparinux em pacientes com clearance de creatinina $<20 \mathrm{~mL} / \mathrm{min}$. 


\section{Sumário}

Parte 1 - Avaliação e Condutas na Emergência ................ 196

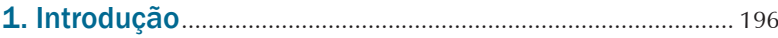

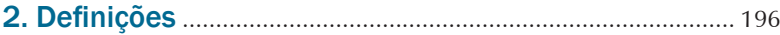

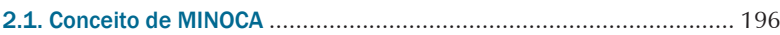

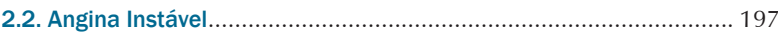

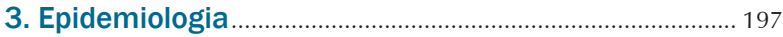

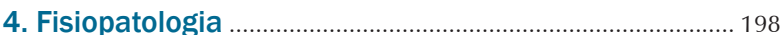

5. Avaliação inicial ...................................................................... 200

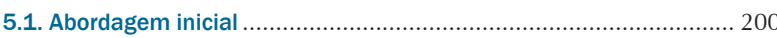

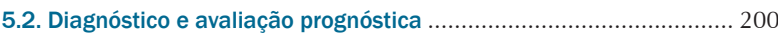

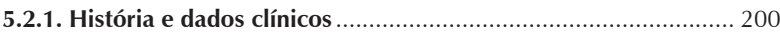

5.2.1.1. Caracterização da dor torácica e angina .................................. 200

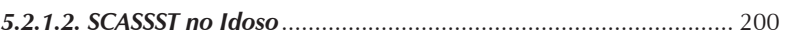

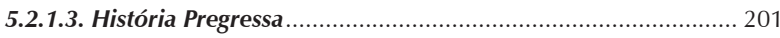

5.2.1.3.1. Pacientes Submetidos a Procedimentos de Revascularização

Miocárdica-Intervenção Coronária Percutânea e/ou Cirurgia de

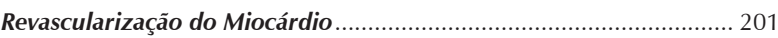

5.2.1.3.2. Fatores de Risco para Doença Arterial Coronariana ............. 201

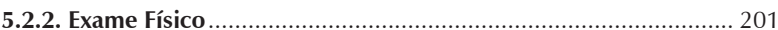

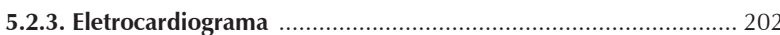

5.2.3.1. Achados do Eletrocardiograma e Prognóstico .......................... 202

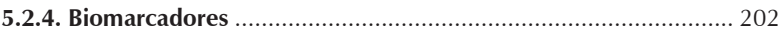

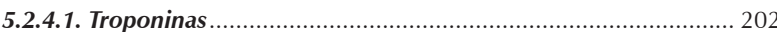

5.2.4.2. Creatinoquinase, suas Isoenzimas e Isoformas ...................... 203

5.2.5. Exames de Imagem Não Invasivos na Emergência .................... 203

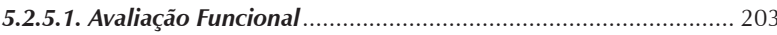

5.2.5.2. Teste Ergométrico na Sala de Emergência ............................. 203

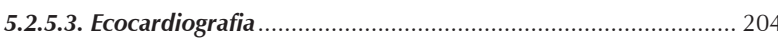

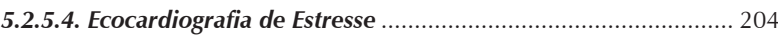

5.2.5.5. Cardiologia Nuclear ....................................................... 204

5.2.5.6. Avaliação Anatômica: Angiotomografia das Artérias Coronárias.... 205

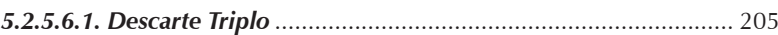

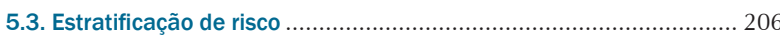

5.3.1. Estratificação de risco de eventos isquêmicos cardiovasculares

5.3.2. Estratificação de Risco de Sangramento..................................... 206

5.4. Fluxograma de Rotina Diagnóstica na Emergência e Critérios para

Hospitalização................................................................................... 209

5.5. Atuação da Enfermagem no Protocolo de Dor Torácica ................... 210

6. Condutas na Emergência após Estratificação de Risco.....211

6.1. Indicações de Estratégia Invasiva Emergencial .............................. 211

6.2. Tratamento Inicial (Sala de Emergência/Ambulância)..................... 211

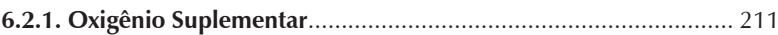

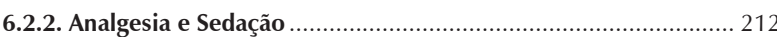

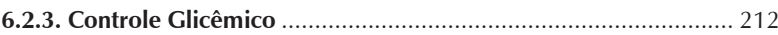

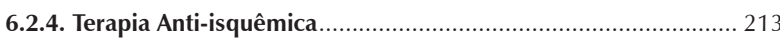

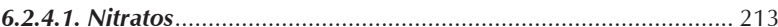

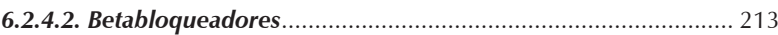

6.2.5. Terapia Antitrombótica Inicial (Sala de Emergência/

Ambulância)

6.2.5.1. Antiplaquetários Orais

6.2.5.1.1. Fundamentos do Pré-tratamento com Bloqueadores de P2Y $Y_{12} \ldots . .214$

6.2.5.1.2. Estudos Comparativos de Pré-tratamento versus Utilização do

Segundo Antiplaquetário na Sala de Cateterismo ................................ 214

6.2.5.1.3. Dados de Pré-tratamento em Metanálises............................ 215

6.2.5.2. Antagonistas dos Receptores Glicoproteicos IIb/IIIa ............... 216

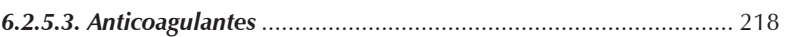

Parte 2 - Condutas Durante a Hospitalização.................... 219

1. Internação e Alta da Unidade Coronária de Terapia

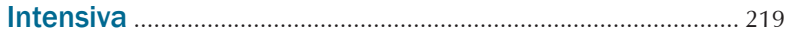

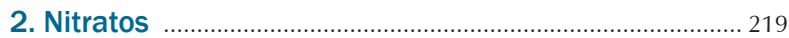

3. Betabloqueadores Adrenérgicos ....................................... 219

4. Antagonistas dos Canais de Cálcio Antiplaquetários.....219

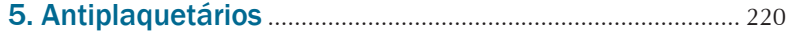

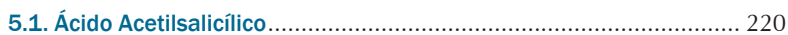

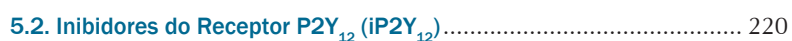

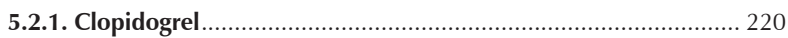

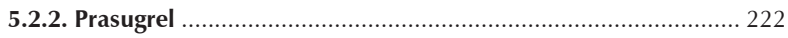

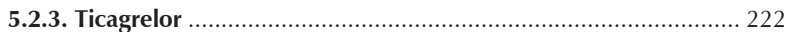

5.3. Terapia Antiplaquetária Ajustada por Testes de Agregação Plaquetária ou por Testes Genéticos .................................................................. 223

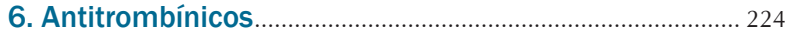

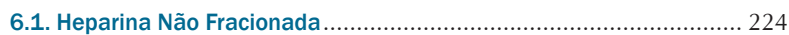

6.2. Heparinas de Baixo Peso Molecular.............................................. 225

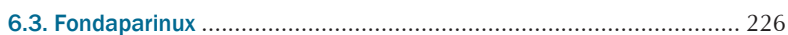

7. Associação de Antiplaquetários e Anticoagulantes Orais

Diretos em Situações Especiais............................................. 226

8. Hipolipemiantes ................................................................... 227

9. Inibidores do Sistema Renina-Angiotensina-Aldosterona. 227

10. Estratificação de Risco com os Métodos

Complementares ..................................................................... 228

11. Exames Não Invasivos para Diagnóstico de Isquemia e Avaliação Prognóstica ................................................................. 228

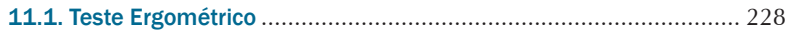

11.2. Métodos Ecocardiográficos (Isquemia, Viabilidade - Estresse,

Contraste/ Microbolhas, Strain etc.) (.................................................... 228

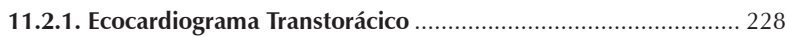

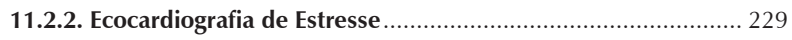

11.2.3. Avaliação da Perfusão Miocárdica pela Ecocardiografia .......... 229

11.2.3.1. Avaliação da Perfusão Miocárdica pelo Ecocardiograma |

Sumário de Recomendações e Evidências ............................................ 230

11.3. Métodos de Cardiologia Nuclear.................................................. 230

11.4. Ressonância Magnética Cardiovascular ..................................... 231

12. Cinecoronariografia e Avaliações Coronárias

Intravasculares (FFR, IVUS, OCT) ............................................ 231

13. Revascularização Miocárdica (Cirurgia de

Revascularização Miocárdica e Intervenção Coronária

Percutânea)

Parte 3 - Recomendações na Alta e Cuidados Pós-Alta

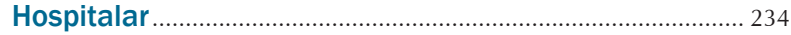

1. Mudança de Estilo de Vida ................................................... 234

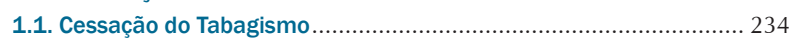

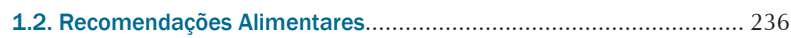

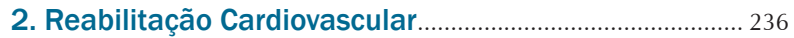

2.1. Orientação sobre Atividade Física na Ocasião da Alta .................... 236

3. Medicamentos a Serem Prescritos por Ocasião da Alta

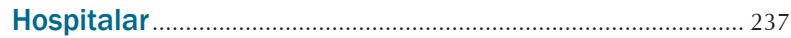

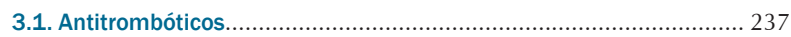

3.2. Inibidores do Sistema Renina-Angiotensina-Aldosterona................ 243

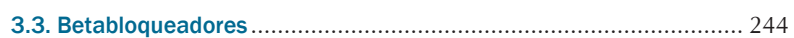

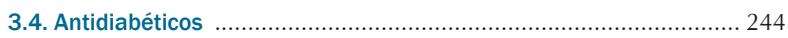

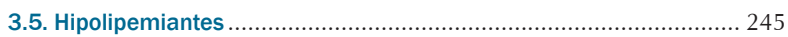

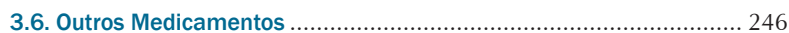

4. Rastreamento Clínico Pós-alta ............................................. 247

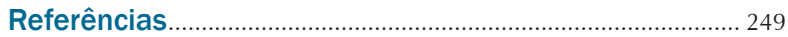




\section{Parte 1 - Avaliação e Condutas na Emergência}

\section{Introdução}

A dor torácica aguda é uma das causas mais frequentes de atendimento nas unidades de emergência (UE), correspondendo a mais de $5 \%$ das visitas em UE e até $10 \%$ das visitas não relacionadas a traumatismos. A incidência de dor torácica varia entre 9 e 19 por 1.000 pessoas/ano atendidas em UE e pode representar até $40 \%$ das causas de internação hospitalar. A maioria desses pacientes recebe alta com diagnóstico de dor torácica não especificada ou causa não cardíaca; no entanto, cerca de 25\% dos pacientes internados apresentam diagnóstico final de síndrome coronariana aguda (SCA). ${ }^{1,2}$

O subgrupo de pacientes que não apresentam supradesnível do segmento ST no eletrocardiograma (ECG) e contêm sintomas ou achados em exames complementares compatíveis com etiologia coronariana compõem as síndromes coronarianas agudas sem supradesnível do segmento ST (SCASSST), objeto dessa diretriz. A SCASSST pode causar morbidade significativa e mortalidade se não for tratada de forma imediata e adequada. Atraso no tratamento apropriado pode resultar em resultados adversos graves, salientando a necessidade de verificar a presença de SCA pela avaliação de dados clínicos e exames complementares. ${ }^{3}$

\section{Definições}

A dor torácica é o principal sintoma em um paciente com SCA. O ECG deve ser realizado e interpretado nos primeiros 10min do contato médico em pacientes suspeitos para SCA, e seus achados podem diferenciar o paciente em dois grupos:

- SCACSST: paciente com dor torácica aguda e supradesnivelamento persistente do segmento ST ou bloqueio de ramo esquerdo (BRE) novo ou presumivelmente novo, condição geralmente relacionada com oclusão coronariana e necessidade de reperfusão imediata.

- SCASSST: paciente com dor torácica aguda sem supradesnivelamento persistente do segmento ST, associado ou não a outras alterações de ECG que sugerem isquemia miocárdica de alguma natureza com amplo espectro de gravidade: elevação transitória do segmento ST, infradesnivelamento transitório ou persistente do seguimento ST, inversão de onda $T$, outras alterações inespecíficas da onda T (plana ou pseudonormalização) e até mesmo ECG normal. Neste grupo, estão os pacientes com angina instável (Al), ou seja, sem alterações de marcadores de necrose miocárdica, e aqueles com infarto agudo do miocárdio sem supradesnivelamento do segmento ST (IAMSSST), quando há elevação de marcadores de necrose miocárdica.

O diagnóstico de IAMSSST é confirmado quando da presença de isquemia na lesão miocárdica aguda, confirmada por elevação nos níveis de troponina. Com base em sua fisiopatologia e contexto clínico, o IAM é classificado em vários subtipos (Tabela 1.1 e 1.2). A elevação dos níveis de troponina pode ser secundária à isquemia miocárdica, mas também pode ocorrer em outras situações clínicas (Tabela 1.3).

Situações em que ocorre elevação de marcadores de necrose miocárdica, na ausência de isquemia detectada por quadro clínico, ECG ou exames de imagem, devem ser definidas como lesão miocárdica aguda, e não IAM. Podem ser secundárias a causas cardíacas (como procedimentos cardiovasculares, miocardite, arritmias, insuficiência cardíaca descompensada) ou extracardíacas (como choque, anemia grave, sepse e hipóxia). ${ }^{4}$

A lesão miocárdica é frequentemente relacionada a condições clínicas de pior prognóstico. É preciso realizar a diferenciação entre causas isquêmicas ou não isquêmicas, a fim de evitar intervenções invasivas desnecessárias e direcionar condutas a outras etiologias possíveis (Tabela 1.3).

A Figura 1.1 sumariza a interpretação da elevação de troponina frente aos cenários de lesão e isquemia coronariana.

\subsection{Conceito de MINOCA}

Os casos de IAM sem a presença de doença arterial coronariana (DAC) obstrutiva são classificados como MINOCA (do inglês, myocardial infarction with nonobstructive coronary arteries). Aproximadamente dois terços dos pacientes com MINOCA têm apresentação clínica de IAMSSST. ${ }^{5}$

Conforme documento elaborado por grupo de trabalho organizado pela Sociedade Europeia de Cardiologia ${ }^{6}$ e a $4^{\text {o }}$ Definição Universal de Infarto do Miocárdio, ${ }^{4}$ os critérios diagnósticos para MINOCA são: IAM, documentação angiográfica com ausência de DAC obstrutiva (ateromatose com estenose $<50 \%$ ou coronária normais) e nenhuma causa clinicamente evidente não coronariana que justifique a apresentação aguda.

Diferentes mecanismos fisiopatológicos podem causar MINOCA:

- Disfunções coronárias epicárdicas (p. ex., ruptura de placa aterosclerótica, ulceração, fissuração, erosão ou dissecção coronária).

- Desequilíbrio entre oferta e consumo de oxigênio (p. ex., espasmo coronariano e embolia coronariana).

- Disfunção endotelial coronariana (p. ex., doença microvascular).

O prognóstico da MINOCA é extremamente variável e depende do mecanismo subjacente e de fatores de risco associados, tais como idade e sexo feminino. Alguns estudos apontam para mortalidade hospitalar inferior ao IAM com coronariopatia obstrutiva e mortalidade em 1 ano semelhante ao IAM com obstrução univascular. No entanto, na análise dos pacientes com IAMSSST do estudo ACUITY, o subgrupo com MINOCA apresentou maior mortalidade em 1 ano (4,7\% vs. 3,6\%), ligada a um aumento de mortes não cardíacas. ${ }^{7-9}$

O grande grupo de pacientes que se apresentam com elevação de troponina na ausência de obstrução coronariana e manifestações clínicas de infarto é classificado como portador de TINOCA (do inglês, troponin-positive nonobstructive coronary arteries), contemplando aqueles com lesão de etiologia isquêmica (MINOCA) e as demais etiologias descritas de lesão miocárdica não isquêmica (p. ex., miocardite ou síndrome de Takotsubo; vide Figura 1.2). 


\section{Tabela 1.1 - Lesão e infarto do miocárdio ${ }^{1}$}

\section{Definição de lesão miocárdica}

0 termo lesão miocárdica deve ser empregado em pacientes com valores de troponina cardíaca, em pelo menos uma dosagem, acima do percentil 99 do limite da normalidade. A lesão é considerada aguda se houver comportamento dinâmico com ascensão e/ou queda dos valores basais. Valores de troponina persistentemente elevados são considerados lesão miocárdica crônica.

Definição de infarto agudo do miocárdio (IAM tipos 1, 2 e 3)

A definição de IAM implica a presença de lesão miocárdica aguda em um contexto clínico de isquemia miocárdica:

- Sintomas sugestivos de isquemia miocárdica aguda

- Nova alteração isquêmica no ECG

- Nova onda $Q$ patológica no ECG

- Exame de imagem evidenciando nova alteração de contratilidade ou perda de miocárdio viável consistente com etiologia isquêmica

- Identificação de trombo intracoronário por angiografia ou necrópsia (apenas para o tipo 1)

Tabela 1.2 - Classificação do infarto agudo do miocárdio (IAM) de acordo com fatores desencadeantes

\begin{tabular}{|c|c|}
\hline $\begin{array}{l}\text { Classificação } \\
\text { (tipos) }\end{array}$ & Descrição \\
\hline 1 & $\begin{array}{c}\text { IAM espontâneo relacionado com isquemia miocárdica secundária a evento coronariano como ruptura ou erosão de placa } \\
\text { aterosclerótica coronariana }\end{array}$ \\
\hline 2 & $\begin{array}{c}\text { IAM secundário à isquemia por desequilíbrio de oferta/ demanda de oxigênio pelo miocárdio, não relacionado diretamente à } \\
\text { aterotrombose coronariana }\end{array}$ \\
\hline 3 & $\begin{array}{l}\text { Morte súbita na presença de sintomas sugestivos de isquemia acompanhada por novas alterações isquêmicas no ECG ou fibrilação } \\
\text { ventricular e que ocorre antes de os biomarcadores serem coletados ou de sua elevação. Ou IAM confirmado por necrópsia }\end{array}$ \\
\hline $4 a$ & $\begin{array}{r}\text { IAM associado à intervenção coronariana percutânea } \leq 48 \mathrm{~h} \text { - definido pelo aumento de troponina maior que } 5 \text { vezes do percentil } 99 \text { do } \\
\text { limite da normalidade ou } 20 \% \text { de níveis basais já aumentados, associado a um dos achados a seguir: } \\
\text { • Nova alteração isquêmica no ECG } \\
\text { • Nova onda Q patológica no ECG }\end{array}$ \\
\hline $4 \mathrm{~b}$ & IAM associado à trombose de stent documentada por angiografia ou necrópsia \\
\hline $4 c$ & IAM relacionado à reestenose intrastent ou pós-angioplastia na ausência de outras lesões ou trombo intracoronário que o justifiquem \\
\hline 5 & $\begin{array}{r}\text { IAM associado à cirurgia de revascularização miocárdica } \leq 48 \mathrm{~h} \text { - definido pelo aumento maior que } 10 \text { vezes do percentil } 99 \text { do limite da } \\
\text { normalidade ou } 20 \% \text { de níveis basais já aumentados, associado a um dos achados a seguir: } \\
\text { • Nova onda } Q \text { patológica no ECG } \\
\text { - Exame de imagem evidenciando nova alteração de contratilidade ou perda de miocárdio viável com padrão de etiologia isquêmica } \\
\text { • Achado angiográfico que evidencie oclusão de novo enxerto ou artéria coronária nativa }\end{array}$ \\
\hline
\end{tabular}

Fonte: adaptada de Thygesen $\mathrm{K}$ et al.4 ECG: eletrocardiograma.

\subsection{Angina Instável}

A Al é definida como isquemia miocárdica na ausência de necrose miocárdica, ou seja, com biomarcadores negativos. Durante o manejo inicial da SCA, frequentemente, é difícil diferenciar AI do IAMSSST com base apenas em critérios clínicos (i. e., antes que a dosagem de marcadores de necrose miocárdica esteja disponível), devendo ambas as entidades serem conduzidas de forma semelhante nessa fase. $\mathrm{O}$ aumento da sensibilidade da troponina diminuiu o percentual de pacientes diagnosticados como Al e aumentou o de pacientes com IAMSSST. Pacientes com AI têm prognósticos diferentes, podendo ter desde um risco relativamente baixo até um risco alto. As classificações de Al baseadas na apresentação clínica e em informações prognósticas facilitam a condução terapêutica, como será discutido no decorrer deste documento. ${ }^{11-16}$

\section{Epidemiologia}

O IAM é a principal causa de morte no Brasil e no mundo. ${ }^{17}$ Em 2017, segundo o DATASUS, 7,06\% (92.657 pacientes) do total de óbitos foram causados por IAM. O IAM representou 10,2\% das internações no Sistema Único de Saúde (SUS), sendo mais prevalente em pacientes com idade superior a 50 anos, em que representou $25 \%$ das internações). ${ }^{18}$

No registro BRACE, que avaliou as internações por SCA em 72 hospitais no Brasil, as SCASSST representaram 45,7\% das internações, das quais cerca de 2/3 ocorreram por IAM e 1/3 por Al. O estudo revelou, no geral, uma taxa reduzida de uso de terapias que impactam o prognóstico de pacientes com SCA, com importantes diferenças regionais. Além disso, desenvolveu um escore de desempenho demonstrando que quanto maior a aderência a tratamentos comprovados, menor a mortalidade. ${ }^{19}$ 


\section{Diretrizes}

Tabela 1.3 - Causas de lesão miocárdica

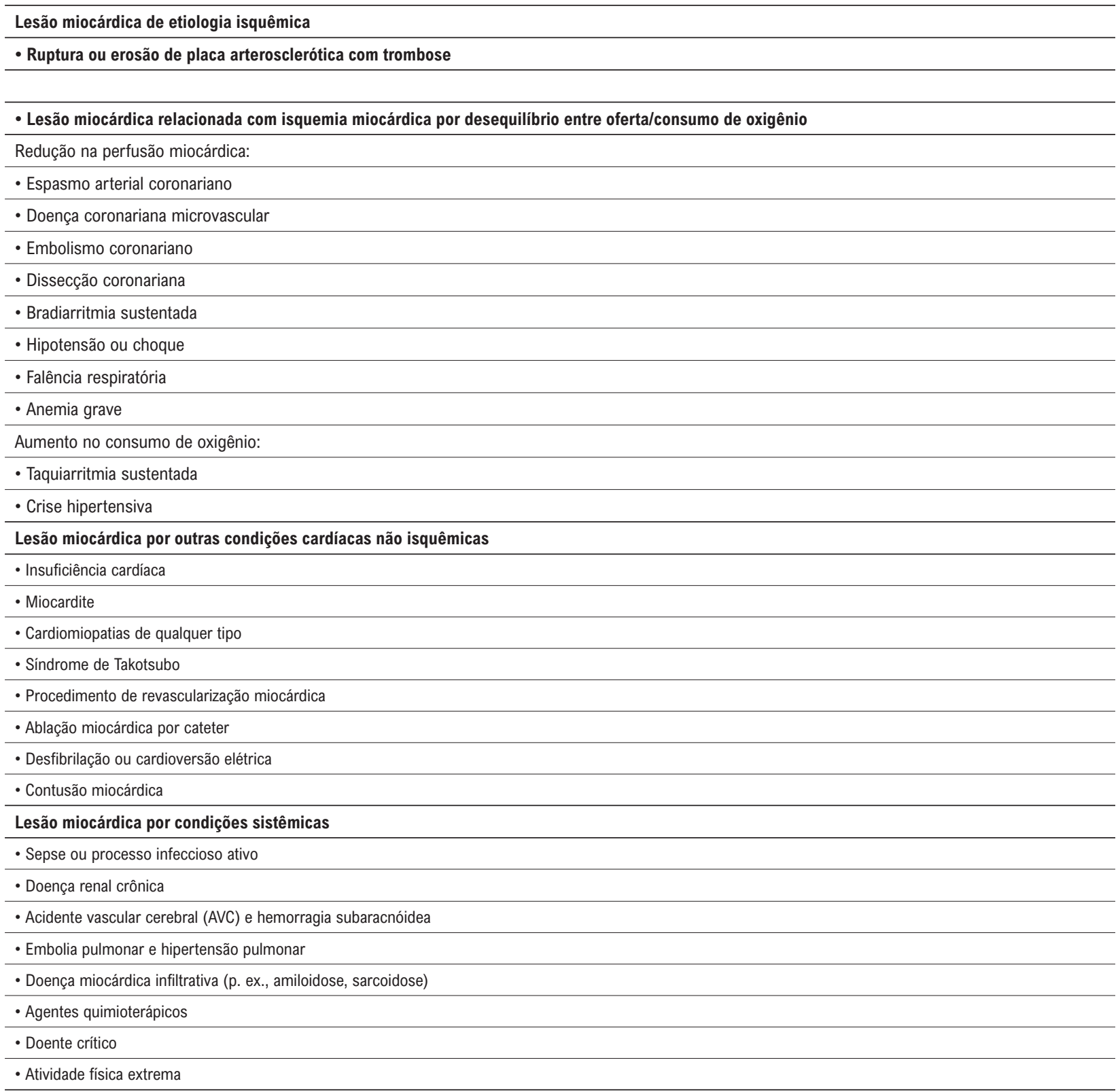

\section{Fisiopatologia}

A principal característica fisiopatológica da SCA é a instabilização da placa aterosclerótica, envolvendo erosão ou ruptura e subsequente formação de trombo oclusivo ou suboclusivo. Tal limitação de fluxo, no entanto, pode ocorrer por outros mecanismos como vasospasmo, embolia ou dissecção coronariana. Outros fatores podem estar envolvidos na fisiopatologia da SCA por alterar a oferta e/ ou o consumo de oxigênio miocárdico, tais como anemia, hipertensão, taquicardia, cardiomiopatia hipertrófica, estenose aórtica, entre outras. ${ }^{20}$

Em animais, observou-se que a isquemia progride do subendocárdio ao subepicárdio. O tempo de progressão pode prolongar-se quando há a presença de irrigação colateral eficiente, redução no consumo de oxigênio pelo miocárdio e intermitência no fluxo (gerando précondicionamento isquêmico). A função ventricular sofre alterações decorrentes da progressão da isquemia miocárdica, ocorrendo disfunção diastólica inicialmente, seguida ou não por disfunção sistólica. A redução na duração do insulto isquêmico está relacionada com a menor área de necrose miocárdica. Diversos estudos também sugerem que o restabelecimento da perfusão é responsável por algum grau de lesão miocárdica (lesão de reperfusão), principalmente em situações de oclusão total da coronária. ${ }^{21}$ 


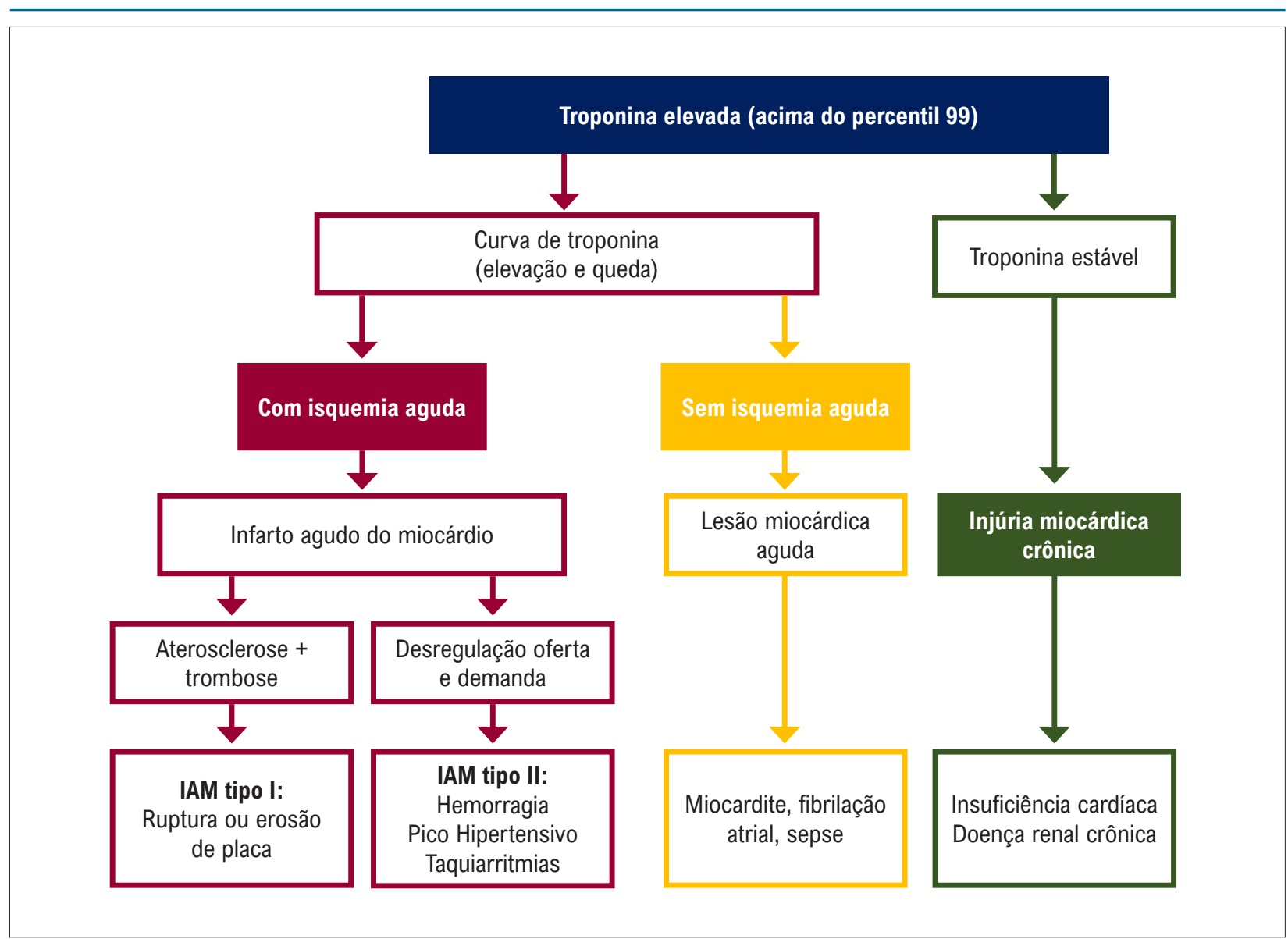

Figura 1.1 - Algoritmo de interpretação da elevação de troponina. Curva de troponina significa elevação superior a 20\%

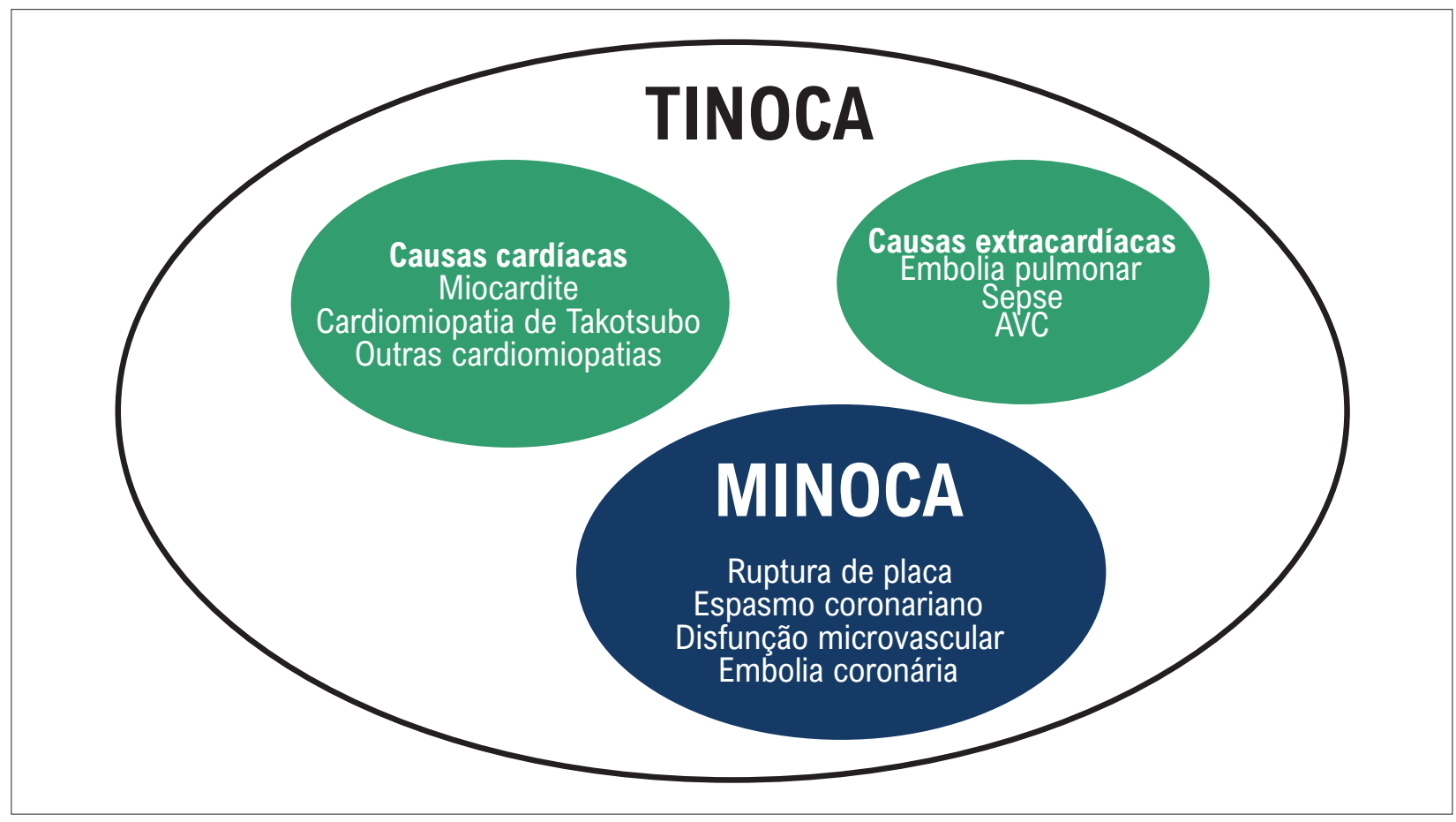

Figura 1.2 - MINOCA e TINOCA: paradigma conceitual. Adaptada de Pasupathy et al., 2017.10 


\section{Avaliação inicial}

\subsection{Abordagem inicial}

Pacientes com suspeita de SCA e sinais de gravidade (dor persistente, dispneia, palpitações decorrentes de arritmias potencialmente graves e síncope) devem ser encaminhados para serviços de emergência, idealmente monitorados em ambulância. Pacientes sem sinais de gravidade (ver sinais citados anteriormente) podem ser orientados a procurar por meios próprios o serviço de emergência mais próximo com capacidade de realizar ECG e dosagem de biomarcadores cardíacos, de preferência a troponina.

Pacientes com SCA devem ser prontamente avaliados quanto ao seu risco de complicações isquêmicas e hemorrágicas.

Diversas ferramentas (escores) foram idealizadas com esse intuito e, em conjunto com o julgamento clínico, podem auxiliar a definir quais pacientes se beneficiam de internação, exames complementares e tratamento específico.

\subsection{Diagnóstico e avaliação prognóstica}

\subsubsection{História e dados clínicos}

\subsubsection{Caracterização da dor torácica e angina}

O quadro clínico de angina pode ser definido por quatro características principais da dor: localização, característica, duração e fatores de intensificação ou alívio.

- Localização: usualmente localizado no tórax, próximo ao esterno. Contudo, pode acometer ou irradiar do epigástrio à mandíbula, região interescapular e braços (mais comumente para o esquerdo, menos comumente para ambos ou para o braço direito).

- Tipo: o desconforto geralmente é descrito como pressão, aperto ou peso. Por vezes, como uma sensação de estrangulamento, compressão ou queimação. Pode ser acompanhado por dispneia, sudorese, náuseas ou síncope.

- Duração: o tempo de duração do desconforto anginoso estável geralmente é curta $(<10 \mathrm{~min})$; episódios $\geq 10 \mathrm{~min}$ sugerem SCA. Contudo, duração contínua prolongada (horas ou dias) ou efêmera (poucos segundos) tem menor probabilidade de SCA.

- Fatores de intensificação ou alívio: uma importante característica da angina é a sua relação com o esforço físico. Os sintomas classicamente aparecem ou se intensificam ao esforço. Em pacientes com antecedente de angina, uma redução no limiar de esforço necessário para desencadear angina sugere SCA. O desconforto por SCA não costuma se modificar com relação à respiração ou posição.

A história clínica do paciente com SCASSST desempenha importante papel na estratificação de risco. Na presença de angina, pacientes com SCASSST podem se apresentar em quatro situações:

- Angina de repouso prolongada (> 20min).

- Angina de início recente (classe II ou III pela classificação da Canadian Cardiovascular Society): em geral, são pacientes que manifestam sintomas típicos de angina em um período inferior a 2 meses e progressão para esforços menores, habituais.

- Agravamento recente de angina estável prévia (angina em crescendo). Esforços menores desencadeando angina, aumento da intensidade e/ou duração da dor, alterações na irradiação, alterações no padrão de resposta ao uso de nitratos.

- Angina pós-infarto.

Algumas características, antecedentes e comorbidades se relacionam com uma maior probabilidade de SCA:

- Idade avançada e sexo masculino.

- Fatores de risco para aterosclerose: tabagismo, diabetes, dislipidemia, hipertensão arterial e insuficiência renal crônica.

- Antecedente familiar de DAC.

- Aterosclerose prévia sintomática, tais como doença arterial obstrutiva periférica, doença carotídea, doença coronariana prévia.

- Doenças inflamatórias crônicas, como lúpus ou atrite reumatoide.

Pacientes com SCA podem se apresentar com sintomas atípicos, tais como dor epigástrica isolada, sensação de plenitude gástrica, dor perfurante, dor pleurítica ou dispneia. Embora a principal forma de apresentação de SCA em mulheres e idosos (>75 anos) seja angina típica, a ocorrência de apresentações atípicas é maior nesses indivíduos, assim como em pacientes com diabetes, insuficiência renal e demência.

Sumariamente, a dor torácica pode ser classificada conforme proposto pelos investigadores do estudo CASS ${ }^{22}$ (Tabela 1.4).

\subsubsection{SCASSST no Idoso}

Os idosos com SCA geralmente apresentam perfil de risco diferente dos não idosos: têm maior prevalência de hipertensão arterial, diabetes melito, IAM prévio, angina, doença vascular periférica, acidente vascular cerebral (AVC), doença multiarterial e insuficiência cardíaca. Em geral, o idoso se apresenta para o atendimento médico mais tardiamente após o início dos sintomas. Na SCASSST, em vez de dor, frequentemente apresentam os chamados "equivalentes isquêmicos", como dispneia, mal-estar, confusão mental, síncope ou edema pulmonar. Os idosos têm maior incidência de complicações na SCASSST, o que implica a necessidade de tratamento mais intensivo. Entretanto, especialmente naqueles acima de 75 anos de idade, frequentemente, a terapêutica mais adequada - com betabloqueador, ácido acetilsalicílico (AAS), anticoagulante e hipolipemiante - não é utilizada. No registro do estudo TIMI III, ${ }^{23} \mathrm{Com} 3.318$ pacientes portadores de SCASSST, 828 pacientes tinham mais de 75 anos. Esses indivíduos receberam terapêutica anti-isquêmica e foram submetidos à cinecoronariografia em menor percentual, em relação aos mais jovens. Embora apresentassem DAC mais grave e extensa, foram menos frequentemente submetidos a procedimentos de revascularização miocárdica e tiveram 
Tabela 1.4 - Classificação de angina proposta pelos investigadores do estudo CASS

\begin{tabular}{lc} 
Dor definitivamente anginosa & $\begin{array}{c}\text { Dor retroesternal precipitada por esforço com irradiação para ombro, pescoço ou braço esquerdo e atenuada por } \\
\text { repouso ou nitrato em menos de } 10 \mathrm{~min}\end{array}$ \\
\hline Dor provavelmente anginosa & Apresenta a maioria das características da dor definitivamente anginosa \\
\hline Dor provavelmente não anginosa & Dor de característica atípica que não preenche critérios para dor anginosa \\
\hline Dor definitivamente não anginosa & Dor sem correlação com atividade física, sugere ser de origem extracardíaca e não é atenuada por nitratos \\
\hline
\end{tabular}

Fonte: Adaptada de National Heart Lung and Blood Institute Coronary Artery Study.22

mais eventos adversos em até 6 semanas de evolução. Em estudo de banco de dados nacional, a utilização de terapias comprovadamente eficazes após SCA aumentou nos últimos 15 anos tanto nos muito idosos (idade $>80$ anos) quanto nos mais jovens ( $<50$ anos), sendo tal aumento associado à melhora da sobrevida pós-alta nos dois grupos. ${ }^{24}$

\subsubsection{História Pregressa}

5.2.1.3.1. Pacientes Submetidos a Procedimentos de Revascularização Miocárdica-Intervenção Coronária Percutânea e/ou Cirurgia de Revascularização do Miocárdio

A recorrência de angina após cirurgia de revascularização do miocárdio (CRVM) ou intervenção coronária percutânea (ICP) pode significar o desenvolvimento de complicações agudas, novas lesões, trombose do stent ou reestenose. Dor torácica até $48 \mathrm{~h}$ após intervenção percutânea sugere a ocorrência de obstrução aguda, espasmo coronário transitório, trombo não oclusivo, oclusão de ramo ou embolização distal. A dor torácica recorrente cerca de 6 meses após implante de stent convencional ou, mais tardiamente, após implante de stent farmacológico está mais provavelmente relacionada à reestenose. Por outro lado, o aparecimento de angina após 1 ano do implante de stent geralmente se relaciona à nova lesão coronária ou a reestenose de stent por neoaterosclerose. No caso da CRVM, o aparecimento de dor precocemente geralmente se associa à obstrução trombótica do enxerto. Do primeiro mês até o primeiro ano pós-CRVM, o mecanismo geralmente é o de hiperplasia fibrosa da íntima; após esse período, é indicativo de nova lesão aterosclerótica e/ou degeneração não trombótica do enxerto. O registro TIMI III comparou a incidência de óbito ou infarto não fatal entre pacientes que apresentaram SCASSST com ou sem CRVM prévia. Os pacientes com CRVM prévia tiveram taxas mais elevadas de complicações tanto na análise de até 10 dias pós-admissão (4,5\% no grupo com CRVM prévia vs. 2,8\% no grupo sem CRVM) quanto na análise após 42 dias (7,7\% vs. 5,1\%, respectivamente), sugerindo que este seja um grupo de maior risco, sobretudo por apresentarem aterosclerose mais extensa. ${ }^{25}$

\subsection{Fatores de Risco para Doença Arterial Coronariana}

Alguns estudos sugerem melhor evolução entre os tabagistas, provavelmente pelo fato de tais indivíduos sofrerem SCA em idade mais precoce e com menor carga aterosclerótica do que os não tabagistas. ${ }^{26,27}$ Por outro lado, Antman et al. demonstraram que a presença de três ou mais fatores de risco para DAC (hipertensão arterial sistêmica, diabetes, dislipidemia, história familiar e tabagismo) constitui marcador independente de pior prognóstico. ${ }^{28}$

\subsubsection{Exame Físico}

Durante a avaliação de indivíduos com SCASSST, o exame físico auxilia na identificação de indivíduos de maior risco (aqueles com sinais de disfunção ventricular grave ou complicações mecânicas) e no diagnóstico diferencial da dor torácica não relacionada com SCA.

Como regra, o exame físico normal ou com discretas alterações é insuficiente para estratificação de risco do paciente, pois até pacientes com lesões multiarteriais ou de tronco de coronária esquerda podem apresentar exame físico normal. ${ }^{29-31}$ No entanto, quando presentes, as alterações no exame físico podem ter implicações importantes na categorização do paciente como de alto risco.

Entre os achados de mau prognóstico, destacam-se a presença de sopro sistólico em foco mitral, taquicardia, taquipneia, hipotensão, sudorese, pulsos finos, terceira bulha e estertores pulmonares.

Alterações do exame físico permitem o diagnóstico diferencial de SCA com outras causas de dor torácica:

- Cardíacas: pericardite (atrito pericárdico), tamponamento cardíaco (pulso paradoxal), estenose aórtica (sopro sistólico aórtico), miocardiopatia hipertrófica (sopro sistólico ejetivo paraesternal que aumenta com manobra de Valsalva).

- Não cardíacas: dissecção de aorta (divergência de pulso e pressão entre os braços e sopro diastólico de insuficiência aórtica), embolia pulmonar/infarto pulmonar (atrito pleural), pneumotórax (murmúrio vesicular diminuído e timpanismo à percussão), musculoesquelética (dor à palpação).

\section{História e exame físico - Sumário de recomendações e evidências}

Pacientes com suspeita de SCASSST e dor persistente, dispneia, palpitações ou síncope devem ser encaminhados para serviços de emergência, idealmente monitorados em ambulância.

Pacientes com suspeita de SCASSST com achados de menor gravidade, (i. e., sem dor persistente, dispneia, palpitações ou síncope) podem procurar por meios próprios o serviço de emergência mais próximo com capacidade de realizar ECG e dosagem de troponina. 


\subsubsection{Eletrocardiograma}

O ECG de 12 derivações é a primeira ferramenta diagnóstica no manejo de pacientes com SCA suspeita. Idealmente, deve ser realizado e interpretado no atendimento pré-hospitalar ou em até 10min após a admissão hospitalar.

Cerca de $1 \%$ a $6 \%$ dos pacientes com SCASSST têm ECG normal, ou não diagnóstico, à admissão. Nessa situação, o ECG deve ser repetido entre 15 e 30min, principalmente em indivíduos que seguem sintomáticos. Um ECG normal ou não diagnóstico pode ocorrer mesmo na vigência da oclusão da artéria circunflexa ou da coronária direita. Dessa forma, recomenda-se a realização adicional das derivações $V_{3 R^{\prime}}$ $V_{4 R^{\prime}} V_{7}, V_{8}$ e $V_{9}$ para aumentar a sensibilidade do método.

Mais de $1 / 3$ dos pacientes apresentam alterações características de SCA como depressão do segmento ST, elevação transitória de segmento ST e inversão de onda T. Alterações dinâmicas no segmento ST (depressão ou elevação do ST) ou inversões da onda T durante episódio doloroso, que se resolvem pelo menos parcialmente quando os sintomas são aliviados, são importantes marcadores de prognóstico adverso, ou seja, subsequente IAM ou morte. ${ }^{32}$ Pacientes com alterações de ST em derivações anteriores frequentemente apresentam estenose significativa da artéria coronária descendente anterior e constituem um grupo de alto risco.

Alterações do segmento ST e da onda T não são específicos da SCASSST e podem ocorrer em uma série de condições, que incluem: hipertrofia ventricular, pericardite, miocardite, repolarização precoce, alteração eletrolítica, choque, disfunção metabólica e efeito digitálico.

A acurácia diagnóstica de um ECG anormal aumenta quando se dispõe de um traçado de ECG prévio para comparação.

A presença de elevação transitória de segmento ST caracteriza a clássica descrição da angina variante de prinzmetal ou angina vasoespástica. A presença concomitante de elevação do ST nas derivações anteriores e inferiores (refletindo isquemia extensa) se associa a maior risco de morte súbita. ${ }^{33}$

\subsubsection{Achados do Eletrocardiograma e Prognóstico}

Pacientes com SCASSST têm elevado risco de apresentarem, durante sua evolução, alterações isquêmicas de ECG (infra ou supra ST), fibrilação atrial e arritmias ventriculares. Essas alterações implicam pior prognóstico. ${ }^{31}$ No estudo GUSTO II, o ECG de apresentação dos pacientes com SCA teve importância prognóstica em relação à mortalidade precoce. ${ }^{34}$

Bloqueio de ramo esquerdo, hipertrofia ventricular esquerda ou ritmo de marca-passo (MP) cursaram com mortalidade de 11,6\%; depressão do segmento ST com 8\%; elevação do segmento ST com 7,4\%; e inversão da onda T ou ECG normal com 1,2\%. No estudo complementar com ECG do Registro TIMI III, ${ }^{35}$ em 1.416 pacientes com SCA, as seguintes formas de apresentação do ECG foram observadas: desvio do segmento ST $\geq 1 \mathrm{~mm}$ em 14,3\%; bloqueio de ramo esquerdo (BRE) em 19\%; inversão isolada da onda T em 21,9\%; e ausência dessas alterações em 54,9\%.
Eletrocardiograma - Sumário de recomendações e evidências

Todos os pacientes com suspeita de SCASSST devem realizar ECG. Idealmente, o ECG deve ser realizado em até $10 \mathrm{~min}$ após a chegada do paciente ao hospital.

O ECG deve ser repetido nos casos não diagnósticos, pelo menos uma vez, em até $6 \mathrm{~h}$.

O ECG deve ser repetido em caso de recorrência dos sintomas.

As derivações V3R-V4R, V7-V9 devem ser realizadas em pacientes que permanecem sintomáticos e apresentam ECG de 12 derivações não diagnóstico.

\subsubsection{Biomarcadores}

Marcadores bioquímicos são úteis para auxiliar tanto no diagnóstico quanto no prognóstico de pacientes com SCA. Quando as células miocárdicas sofrem lesão, suas membranas celulares perdem a integridade, as proteínas intracelulares se difundem no interstício e vão para os linfáticos e capilares. Após a lesão miocárdica, a cinética dos marcadores depende de diversos fatores: o compartimento intracelular das proteínas; o tamanho das moléculas; o fluxo regional linfático e sanguíneo; e a taxa de depuração do marcador. Tais fatores, em conjunto com as características de cada marcador, diferenciam o desempenho diagnóstico de cada um para IAM. ${ }^{36}$

Em pacientes que se apresentam com quadro sugestivo de SCA, nos quais o diagnóstico de IAM não está estabelecido, os biomarcadores cardíacos são úteis para confirmar o diagnóstico de infarto. Além disso, os mesmos fornecem importantes informações prognósticas, na medida em que existe uma direta associação entre a elevação dos marcadores séricos e o risco de eventos cardíacos a curto e médio prazo. ${ }^{37}$ Os resultados dos marcadores de necrose devem estar disponíveis em até 60min a partir da coleta. Caso a estrutura disponível de laboratório de análises clínicas não viabilize esta meta, as tecnologias point of care devem ser consideradas. ${ }^{38}$

\subsubsection{Troponinas}

As troponinas são proteínas do complexo de regulação miofibrilar presentes no músculo estriado cardíaco. Existem três subunidades: troponina $T$, troponina I e troponina C. A troponina $\mathrm{C}$ é coexpressa nas fibras musculares esqueléticas de contração lenta e não é considerada como um marcador específico cardíaco. Nas últimas décadas, foram desenvolvidas técnicas de imunoensaios com anticorpos monoclonais específicos para troponinas $\mathrm{T}$ cardíaca (TnTc) e troponina I cardíaca (Tnlc). Metanálises demonstraram que Tnlc tem sensibilidade e especificidade clínica para o diagnóstico de IAM na ordem de $90 \%$ e $97 \%$, respectivamente. As troponinas cardíacas permanecem elevadas por tempo mais prolongado, podendo permanecer elevadas por até 7 dias depois do IAM. As troponinas são os biomarcadores de primeira escolha para avaliação diagnóstica de pacientes com suspeita de IAM, pois apresentam acurácia diagnóstica superior à da CK-MB massa e dos demais biomarcadores de lesão miocárdica. Pacientes com troponinas elevadas apresentam risco aumentado de eventos cardíacos nos primeiros dias de internação e identificam um 
subgrupo de SCASSST com potencial maior de benefício para manuseio invasivo. ${ }^{39}$ Apesar da identificação acurada de lesão miocárdica pelas troponinas, elas não identificam o(s) mecanismo(s) de lesão; estes podem ser múltiplos, incluindo etiologias não coronarianas como taquiarritmias e miocardite, ou ainda condições não cardíacas, como sepse, embolia pulmonar e insuficiência renal. ${ }^{40}$ Assim, principalmente naqueles casos em que a apresentação clínica não é típica de SCA, devem ser consideradas outras causas de lesão cardíaca relacionadas com aumento de troponinas.

As troponinas têm reconhecido valor na avaliação de pacientes com alterações isquêmicas no ECG ou com clínica sugestiva de dor anginosa. A maior limitação das troponinas convencionais é sua baixa sensibilidade quando o paciente tem um tempo de início do quadro inferior a 6h. Com a introdução das troponinas de alta sensibilidade (Trop-US), passou a ser possível a detecção de níveis mais baixos de troponina, em menor tempo após início do quadro de lesão miocárdica de causa isquêmica. ${ }^{41,42} \mathrm{~A}$ unidade usada para expressar os valores da troponina convencional é $\mathrm{ng} / \mathrm{mL}$, e nas Trop-US, os valores podem ser expressos em ng/L, com poder de detecção 10 a 100 vezes maior que o das troponinas convencionais.

Nos pacientes que chegam ao serviço de emergência com menos de $3 \mathrm{~h}$ do início do quadro, as Trop-US são significativamente mais sensíveis que a troponina convencional para diagnóstico de SCA, melhorando em $61 \%$ o poder diagnóstico de IAM naquele momento e em $100 \%$ se a coleta for $6 \mathrm{~h}$ após o início do quadro. ${ }^{43}$ Com o aumento da sensibilidade e da acurácia diagnóstica para detecção do IAM utilizando a troponina ultrassensível, foram propostos algoritmos de diagnóstico acelerado. Assim, podemos reduzir o tempo até o diagnóstico, traduzindo menor tempo de permanência na emergência e menor custo. ${ }^{44-46}$ É recomendada a utilização do algoritmo de investigação em 3 h (ver fluxograma de rotina diagnóstica e critérios de internação)

\subsubsection{Creatinoquinase, suas Isoenzimas e Isoformas}

Antes da consolidação das troponinas como biomarcadores com maior acurácia para diagnóstico do IAM, a creatinoquinase $\mathrm{MB}$ (CK-MB) era o biomarcador mais utilizado nos protocolos de dor torácica. Idealmente, a CK-MB deve ser mensurada por imunoensaio para dosagem da sua concentração no plasma (CK-MB massa) em vez da sua atividade. Essa mudança no padrão de aferição se deve, em parte, a estudos que demonstraram uma maior sensibilidade e especificidade para IAM com o uso de CK-MB massa. ${ }^{47}$ As subformas da CK-MB têm surgido como marcadores precoces (menos de $6 \mathrm{~h}$ ) de lesão miocárdica e inferência precoce da magnitude do IAM, conforme dado de estudo de necrópsia que demonstrou melhor correlação entre CK-MB massa e tamanho de IAM. ${ }^{48}$ No entanto, a CK-MB massa apresenta como principal limitação elevar-se após dano em outros tecidos não cardíacos (falso-positivos), especialmente após lesão em músculo liso e esquelético. Podem acontecer resultados falso-positivos, em que a CK-MB é positiva e a troponina é negativa em cerca de $4 \%$ dos pacientes. ${ }^{49}$ Nos casos em que a CK-MB está elevada e a troponina está normal, ambas dentro de sua janela cinética, deve-se basear a decisão clínica no resultado da troponina.
Marcadores bioquímicos - Sumário de recomendações e evidências

As troponinas são os biomarcadores de escolha no diagnóstico de pacientes com suspeita de IAM.

$\mathrm{Na}$ disponibilidade de troponina ultrassensível, nenhum outro marcador deve ser solicitado rotineiramente para diagnóstico de IAM.

Biomarcadores bioquímicos de necrose miocárdica devem ser mensurados em todos os pacientes com suspeita de SCASSST. Quando troponina ultrassensível estiver disponível, a dosagem sérica deve ser realizada na admissão e, idealmente, reavaliada em $1 \mathrm{~h}$ ou até $2 \mathrm{~h}$. Caso indisponível, a troponina convencional deve ser coletada na admissão e repetida pelo menos uma vez, 3 a $6 \mathrm{~h}$ após, caso a primeira dosagem seja normal ou discretamente elevada.

Dosagens CK-MB massa podem ser utilizadas se dosagens de troponina não estiverem disponíveis.

Utilização da mioglobina para detecção de necrose miocárdica em pacientes com suspeita de SCASSST.

\subsubsection{Exames de Imagem Não Invasivos na Emergência}

\subsubsection{Avaliação Funcional}

Os exames não invasivos têm importante papel no diagnóstico (sobretudo em pacientes com ECG e biomarcador normal) e na estratificação de risco do paciente com suspeita de SCA. A escolha de cada um - quer teste ergométrico, cintilografia de perfusão miocárdica, ressonância cardíaca ou angiografia por tomografia computadorizada das artérias coronárias - dependerá do objetivo e da questão clínica a ser respondida. ${ }^{50}$

\subsubsection{Teste Ergométrico na Sala de Emergência}

Pacientes com dor torácica no setor de emergência, identificados como de risco baixo ou intermediário, podem ser submetidos ao teste ergométrico (TE), cujo resultado normal confere risco anual baixo de eventos cardiovasculares, permitindo a alta hospitalar mais precoce e segura. ${ }^{50}$ Diretrizes nacionais e internacionais recomendam o TE como exame de primeira escolha para a estratificação de risco em pacientes que possam realizar exercício, por ser procedimento de baixo custo, ter larga disponibilidade e com baixa frequência de intercorrências. ${ }^{51}$ No entanto, devem ser afastadas as situações de SCA de moderado a alto risco e alto risco, doenças agudas da aorta, tromboembolismo pulmonar, miocardite e pericardite, pois são contraindicações absolutas para realizar esse exame. Os protocolos devem ser definidos de acordo com as condições clínicas do paciente, sendo os mais recomendados em rampa, Naughton ou Bruce modificado.

Resumo das indicações do TE na SCA (caracterizar baixo risco após estratificação clínica inicial):

- ECG basal e biomarcadores (necrose) sem alterações.

- Ausência de sintomas (dor precordial ou dispneia).

- Estabilidade hemodinâmica e condições adequadas para o esforço físico. 
Se o resultado do TE for normal e o paciente tiver evidenciado boa capacidade funcional, outros procedimentos podem não ser necessários em virtude do alto valor preditivo negativo da prova. ${ }^{51}$

\begin{tabular}{l} 
Teste ergométrico - Sumário de recomendações e evidências \\
Pacientes de risco baixo (clínica e ECG) e com \\
biomarcadores normais devem ser encaminhados para \\
teste ergométrico após 9 a $12 \mathrm{~h}$ em observação. Dentro \\
das rotas da unidade de dor torácica (UDT), estes exames \\
podem ser feitos como critério de alta. \\
\hline Na impossibilidade de realização do TE ou ECG não \\
interpretável (bloqueio de ramo esquerdo, marca-passo \\
artificial, fibrilação atrial, sobrecarga ventricular esquerda \\
etc.), o paciente pode ser submetido a exames provocativos \\
de isquemia associados à imagem não invasiva
\end{tabular}

\subsubsection{Ecocardiografia}

O ecocardiograma é um método complementar de grande utilidade na avaliação da dor torácica na emergência. ${ }^{52-54}$ É um exame não invasivo, e a informação diagnóstica é disponibilizada em curto espaço de tempo. ${ }^{55-59}$ Quando realizado durante um episódio de dor precordial, a ausência de anormalidade de contração segmentar ventricular é uma evidência contrária à isquemia como causa do sintoma. Embora o ecocardiograma não seja capaz de garantir se a alteração segmentar é recente ou preexistente, a presença de anormalidades de contração segmentar reforça a probabilidade de DAC, sendo indicativa de infarto, isquemia ou ambos, embora possa também ser evidenciada em casos de miocardites. ${ }^{60-62}$

Além disso, outras etiologias não menos importantes de dor torácica - tais como dissecção aórtica, estenose aórtica, miocardiopatia hipertrófica e doença pericárdica - podem ser avaliadas pelo método. Doença coronária importante é habitualmente encontrada em pacientes com Al. Esses pacientes são geralmente identificados por história clínica, e alterações eletrocardiográficas reversíveis podem ser detectadas, concomitantes aos episódios de dor. Quando a história e o ECG não são típicos, a documentação de anormalidade da contração segmentar ao ecocardiograma, durante ou imediatamente após um episódio doloroso, sugere fortemente o diagnóstico. ${ }^{63}$ O ecocardiograma avalia ainda a presença e a extensão da disfunção ventricular, assim como a presença e a gravidade de anormalidades valvares.

Além da fração de ejeção do ventrículo esquerdo (FEVE) e da motilidade segmentar, outros parâmetros também são importantes para se avaliar prognóstico. Ersbøll et al. estudaram pacientes com infarto e FEVE $>40 \%$ dentro de $48 \mathrm{~h}$ da admissão de forma prospectiva. Todos os pacientes foram submetidos à ecocardiografia com avaliação semiautomatizada de strain global longitudinal (SGL). De um total de 849 pacientes, 57 $(6,7 \%)$ tiveram eventos cardíacos graves, e SGL $>-14 \%$ se associou a um aumento de 3 vezes no risco daqueles eventos. ${ }^{63}$

\subsubsection{Ecocardiografia de Estresse}

A ecocardiografia de estresse vem adquirindo aceitação crescente na avaliação de pacientes no departamento de emergência, e precocemente após hospitalização. ${ }^{64} \mathrm{Um}$ estudo analisou 108 pacientes observados por $4 \mathrm{~h}$ com enzimas seriadas e ECG e submetidos a teste ergométrico ou à ecocardiografia de estresse com dobutamina. Dez pacientes evidenciaram positividade ao teste ergométrico. O mesmo aconteceu com 8 pacientes à ecocardiografia de estresse. Os exames foram concordantes em 4 pacientes. Todos os pacientes com ecocardiografia de estresse sem evidência de isquemia estiveram livres de eventos cardíacos ao final de 12 meses de seguimento, bem como $97 \%$ dos pacientes com testes ergométricos negativos. ${ }^{65}$

Estudo nacional avaliou 95 pacientes com Al de baixo e moderado risco com o ecocardiograma sob estresse com dobutamina, a maioria estudada nas primeiras $72 \mathrm{~h}$ de internação hospitalar. Em relação aos desfechos clínicos analisados (morte, IAM, nova internação por Al e procedimentos de revascularização miocárdica), o exame demonstrou ser seguro e com um excelente valor preditivo negativo (96\%), permitindo alta hospitalar precoce sem a necessidade de outros exames. ${ }^{66} \mathrm{~A}$ utilização de técnicas de perfusão para realização do ecocardiograma de estresse pode aumentar sensibilidade diagnóstica, e suas aplicações são discutidas.na Parte 2 desta diretriz.

Por ser um exame acessível, rápido, não invasivo e de baixo custo, a ecocardiografia tem a capacidade de oferecer informação prognóstica adicional aos parâmetros anteriormente citados, por meio da avaliação da função ventricular global, regional e a identificação de valvopatia associada, podendo ser utilizado rotineiramente na investigação desses pacientes. Suas desvantagens são janela limitada em alguns pacientes e sensibilidade reduzida do estresse com dobutamina em pacientes utilizando betabloqueador.

\section{Ecocardiografia - Sumário de recomendações e evidências}

0 ecocardiograma transtorácico deve ser realizado no diagnóstico diferencial com outras doenças, quando houver suspeita clínica de doenças de aorta, doenças do pericárdio, embolia pulmonar e valvopatias.

Ecocardiograma de urgência nos casos de complicações decorrentes de SCASSST, como comunicação interventricular e insuficiência mitral.

Ecocardiografia de estresse pode ser utilizada como método de estratificação funcional em pacientes sem dor torácica recorrente e sem evidências eletrocardiográficas de isquemia e/ou elevação de troponina.

Pacientes em vigência de dor torácica podem ser avaliados por ecocardiograma em repouso, para verificar a presença de alterações compatíveis com etiologia isquêmica.

\subsubsection{Cardiologia Nuclear}

Vários estudos sugerem que indivíduos com uma cintilografia miocárdica em repouso de baixo risco, realizada na unidade de emergência, apresentam risco de eventos cardíacos subsequentes bastante reduzido. Por outro lado, em pacientes com uma CMP de alto risco, há probabilidade muito aumentada de eles desenvolverem IAM, serem revascularizados (cirurgia ou angioplastia) ou de apresentarem lesões coronárias obstrutivas à 
coronariografia. ${ }^{67-69}$ No estudo ERASE (Emergency Room Assessment of Sestamibi for Evalution of Chest Pain), em que foram avaliadas estratégias de atendimento de pacientes com SCA com ECG normal ou não diagnóstico, ainda na sala de emergência, observou-se taxa de admissão de 54\% para os pacientes que realizaram CMP e de $63 \%$ para os outros, sugerindo que a estratégia inicial com estudo cintigráfico ao repouso é um bom estratificador de risco. ${ }^{70}$

Diretrizes internacionais recomendam o emprego da imagem de perfusão miocárdica em repouso na dor torácica aguda para estratificação de risco em pacientes com suspeita de SCA e ECG não diagnóstico. ${ }^{71-73}$

\section{Momento de injeção do radiofármaco:}

As principais aplicações da CPM dentro das primeiras horas da chegada do paciente ao hospital são:

- Injeção do radiofármaco (sestamibi/MIBI ou tetrofosmin marcados com tecnécio-99m, ou sestamibi-99mTc e tetrofosmin-99mTc) em repouso, durante o episódio de dor torácica, com ECG normal ou inespecífico, objetivando rápida definição diagnóstica.

- Injeção do radiofármaco em repouso, na ausência de dor torácica, com ECG normal ou inespecífico, com cessação do sintoma há menos que $6 \mathrm{~h}$, mas preferencialmente dentro das $2 \mathrm{~h}$ precedentes. Wackers et al. demonstraram, nos casos de injeção realizada até $6 \mathrm{~h}$ da dor na SCA, que a incidência de anormalidades de perfusão foi de $84 \%$, diminuindo para $19 \%$ quando a administração intravenosa do radiofármaco ocorreu entre 12 e $18 \mathrm{~h}$ do último episódio doloroso. ${ }^{74}$

De modo global, as imagens de perfusão em repouso com radiofármacos na avaliação da dor torácica aguda não apresentam contraindicações formais e são bem toleradas pela maioria dos pacientes. A CMP com estresse físico ou estímulo farmacológico nos pacientes com SCA de risco baixo ou intermediário é recomendada após estabilização do quadro agudo, sendo realizada habitualmente durante hospitalização. Condições clínicas e hemodinâmicas estáveis são primordiais em ambas as situações. Limitações do método são disponibilidade no nosso meio e custo.

\section{Cardiologia nuclear - Sumário de recomendações e evidências \\ CPM em repouso na dor torácica aguda para estratificação de risco em pacientes com suspeita clínica de SCA e ECG não diagnóstico. \\ Cintilografia miocárdica de estresse (físico ou farmacológico) pode ser utilizada como método de estratificação funcional em pacientes sem dor torácica recorrente, sem evidências eletrocardiográficas de isquemia e/ou elevação de troponina}

Pacientes em vigência de dor torácica e eletrocardiograma sem alterações isquêmicas podem ser avaliados pela cintilografia miocárdica de perfusão em repouso para determinar a origem isquêmica ou não da dor na avaliação de pacientes com suspeita de doença coronariana obstrutiva. A acurácia do método para o diagnóstico de estenose luminal, quando comparada à angiografia coronariana invasiva, já está bem demonstrada, com destaque para o seu alto valor preditivo negativo. ${ }^{75-77}$ Além disso, vários trabalhos comprovam o valor prognóstico do método relacionado à presença e extensão de DAC obstrutiva e não obstrutiva, testado em diversas situações clínicas, auxiliando na tomada de decisões. ${ }^{78,79}$

Três grandes estudos multicêntricos, controlados e randomizados avaliaram o uso da angioTC na dor torácica atendida em unidades de emergência, incluindo, no total, mais de 3 mil pacientes. O estudo multicêntrico CT-STAT randomizou 699 pacientes com dor torácica de baixo risco para estratégias de estratificação utilizando a angioTC de coronárias ou a cintilografia miocárdica de repouso e estresse. ${ }^{80} \mathrm{~A}$ estratégia com a angioTC reduziu em $54 \%$ o tempo para o diagnóstico e em $38 \%$ os custos da internação, sem que houvesse diferença na taxa de eventos adversos com relação à estratégia com a cintilografia. O estudo ACRIN-PA teve como objetivo primário avaliar a segurança da utilização da angioTC na avaliação de pacientes com dor torácica de risco baixo e intermediário em comparação com a abordagem tradicional. ${ }^{81}$ Nenhum dos pacientes com angioTC negativa apresentou o desfecho primário analisado, composto de morte cardíaca ou infarto nos primeiros 30 dias após a admissão. Além disso, os pacientes do grupo angioTC tiveram maior taxa de alta das unidades de emergência (49,6\% vs. $22,7 \%$ ) e menos dias de internação (18h vs. 24,8h, p < 0,001), sem diferenças significativas nas incidências de coronariografias ou revascularizações em 30 dias. Finalmente, o estudo ROMICAT II avaliou, em grupos semelhante de pacientes, o tempo de permanência na unidade de emergência e custos hospitalares. ${ }^{82} \mathrm{O}$ estudo incluiu 1.000 pacientes com idade média de 54 anos (46\% do sexo feminino). O tempo de permanência no hospital foi significativamente menor nos pacientes estratificados para angioTC quando comparados ao grupo submetido à avaliação tradicional $(23,2 \pm 37 \mathrm{~h}$ vs. 30,8 $\pm 28 \mathrm{~h} ; \mathrm{p}=0,0002)$. O tempo até a exclusão do diagnóstico de SCA também foi menor no grupo submetido à angioTC $(17,2 \pm$ $24,6 h$ vs. $27,2 \pm 19,5 h ; p<0,0001)$. Em relação às metas de segurança, não houve diferença significativa entre os grupos. No grupo estratificado pela angioTC, houve aumento significativo dos pacientes que receberam alta hospitalar diretamente da emergência (46,7\% vs. 12,4\%; p =0,001), mas o uso de testes diagnósticos foi significativamente maior neste grupo (97\% vs. $82 \%, p<0,001)$. Apesar do custo mais elevado associado à realização da angioTC e de uma tendência a maior número de cateterismos e revascularizações, os custos globais foram similares entre os dois grupos $(p=0,65)$.

Metanálise posteriormente publicada confirmou que a estratégia de avaliação de pacientes com dor torácica aguda utilizando a angioTC das artérias coronárias, em comparação com abordagens tradicionais, está relacionada à redução de custo e tempo de internação, com aparente aumento do número de angiografias invasivas e revascularização miocárdica. ${ }^{83}$

\subsection{Descarte Triplo}

A angioTC pode ser utilizada na sala de emergência tanto para a visualização das artérias coronárias quanto para obter informações relativas à aorta e às artérias pulmonares, permitindo a avaliação
Nos últimos anos, a angiotomografia (angioTC) das artérias coronárias se tornou uma ferramenta cada vez mais utilizada 
de síndromes aórticas agudas, tromboembolismo pulmonar ou outras alterações torácicas que possam ser diagnósticos diferenciais das SCA (como pneumonias e traumatismos). ${ }^{84,85}$ Por meio de protocolos de aquisição específicos, todas essas informações podem ser obtidas em um único exame. Essa abordagem recebe o nome de descarte triplo (triple rule-out), porém só deve ser utilizada em situações específicas, nas quais a avaliação clínica é incapaz de direcionar o diagnóstico. ${ }^{86}$

Em resumo, a utilização da angioTC das artérias coronárias nas unidades de emergência é uma estratégia segura e eficiente para a avaliação de pacientes com dor torácica aguda de risco baixo e intermediário, reduzindo o tempo para o diagnóstico correto e o tempo de internação. ${ }^{87}$ Desvantagens do método são a utilização de radiação ionizante, custo elevado, necessidade de contraste iodado, limitação em pacientes com frequência cardíaca acima de 80 batimentos por minuto ou que não possam utilizar betabloqueador e disponibilidade reduzida em nosso meio.

Angiografia por tomografia computadorizada das artérias coronárias Sumário de recomendações e evidências

Em pacientes com dor torácica aguda de probabilidade baixa a intermediária de DAC, com ECG não diagnóstico e marcadores de necrose miocárdica negativos.

Investigação da dor torácica aguda pela técnica do descarte triplo (triple rule-out).

\subsection{Estratificação de risco}

\subsubsection{Estratificação de risco de eventos isquêmicos cardiovasculares}

Antman et al., a partir de uma análise do banco de dados do estudo TIMI (Thrombolysis In Myocardial Infarction) 11B, encontraram os seguintes marcadores independentes de pior prognóstico em pacientes com SCASSST ("escore de risco do grupo TIMI"): idade $\geq 65$ anos; elevação de marcadores bioquímicos; depressão do segmento $\mathrm{ST} \geq 0,5 \mathrm{~mm}$; uso de AAS nos 7 dias prévios aos sintomas; presença de três ou mais fatores de risco tradicionais para DAC (hipertensão, hipercolesterolemia, diabetes melito, tabagismo, história familiar); DAC conhecida; angina grave recente $(<24 \mathrm{~h}) .{ }^{28}$ Conferindo um ponto para cada um desses itens, o paciente é classificado em baixo risco (escore de 0 a 2), risco intermediário (escore de 3 a 4) ou alto risco (escore de 5 a 7). Tal escore de risco foi validado em outros estudos de SCASSST, observando-se em todos eles uma associação entre elevação na incidência de eventos (óbito, reinfarto e isquemia recorrente necessitando de revascularização) e maior escore de risco (Figura 1.3).

O escore de risco GRACE (Global Registry of Acute Coronary Events) permite uma estratificação mais acurada tanto na admissão quanto na alta hospitalar, graças ao seu bom poder discriminatório (Figura 1.4). Entretanto, apresenta maior complexidade, com a necessidade da utilização de computador ou aparelho digital de uso pessoal para o cálculo do risco. ${ }^{88} \mathrm{O}$ escore GRACE original fornece uma estimativa de óbito intra-hospitalar ou óbito e IAM em 6 meses após a alta e, posteriormente, o escore também foi validado para estimativa de risco de 1 e 3 anos. Neste escore, 8 variáveis prognósticas de mortalidade hospitalar foram identificadas, sendo o escore total de um determinado paciente obtido pela soma dos pontos de cada uma delas:

1 - Idade em anos - variando de 0 ponto (< 30) a 100 pontos (>90).

2 - Frequência cardíaca (bpm) - variando de 0 ponto $(<50)$ a 46 pontos ( $>200)$.

3 - Pressão arterial sistólica ( $\mathrm{mmHg}$ - variando de 0 ponto (> 200) a 58 pontos $(<80)$.

4 - Níveis de creatinina $(\mathrm{mg} / \mathrm{dL})$ - variando de 1 ponto $(<$ $0,40)$ a 28 pontos $(>4,0)$.

5 - Insuficiência cardíaca (Classe Killip) - variando de 0 ponto (classe I) a 59 pontos (classe IV).

6 - Parada cardíaca na admissão - variando de 0 ponto (não) a 39 pontos (sim).

7 - Desvio do segmento ST - variando de 0 ponto (não) a 28 pontos (sim).

8 - Elevação dos níveis de biomarcadores de lesão cardíaca - variando de 0 ponto (não) a 14 pontos (sim).

Quando a soma dos pontos for $\leq 108$, o paciente é considerado de baixo risco para óbito hospitalar, cuja incidência é $\leq 1 \%$. Quando se situa entre 109 e 140 (risco intermediário) a mortalidade está entre 1\% e 3\%; quando a soma for maior que 140 (alto risco), a mortalidade é superior a 3\%. ${ }^{89}$ Uma nova versão do ESCORE GRACE (GRACE 2.0), com as mesmas variáveis preditoras de desfecho, foi desenvolvida. ampliando a estimativa de risco para os desfechos de morte intra-hospitalar aos 6 meses, 1 ano e 3 anos e de risco de morte ou IAM em 1 ano. ${ }^{90} \mathrm{~A}$ Tabela 1.5 mostra a estratificação de risco baseada em variáveis clínicas, eletrocardiográficas e laboratoriais.

O escore HEART avalia o risco de um evento cardíaco maior (infarto, necessidade ou revascularização ou morte) em 6 semanas após sua apresentação inicial em pacientes atendidos com dor torácica, e será discutido no item 5.4.

\subsubsection{Estratificação de Risco de Sangramento}

O sangramento é associado com prognóstico adverso nas SCASSST, e todos os esforços devem ser implementados para reduzi-lo, sempre que possível. Algumas variáveis podem auxiliar a classificar os pacientes em diferentes níveis de risco para sangramento maior durante a hospitalização. Escores de risco de sangramento foram desenvolvidos baseados em coortes de registros e de estudos clínicos no cenário de SCA. O escore CRUSADE (Can rapid risk stratification of unstable angina patients supress adverse) (www.crusadebleedingscocre.org/) foi desenvolvido a partir de uma coorte de 71.277 pacientes do registro de mesmo nome, posteriormente validado em coorte de 17.857 pacientes do mesmo registro ${ }^{92}$ (Tabela $1.6 \mathrm{e}$, em população brasileira foi preditor não apenas de sangramento mas também de mortalidade intra-hospitalar (área sob a curva ROC $=0,753, \mathrm{p}<0.001) .{ }^{93} \mathrm{~A}$ taxa de sangramento maior aumentou gradualmente com a elevação do escore de risco de sangramento. Esse escore tem uma acurácia relativamente alta para estimar o risco de sangramento por incorporar variáveis de admissão e de tratamento. Nesse escore, a idade não está listada entre os fatores prognósticos, mas está contida no cálculo do clearance de creatinina. 


\section{Escore HEART}

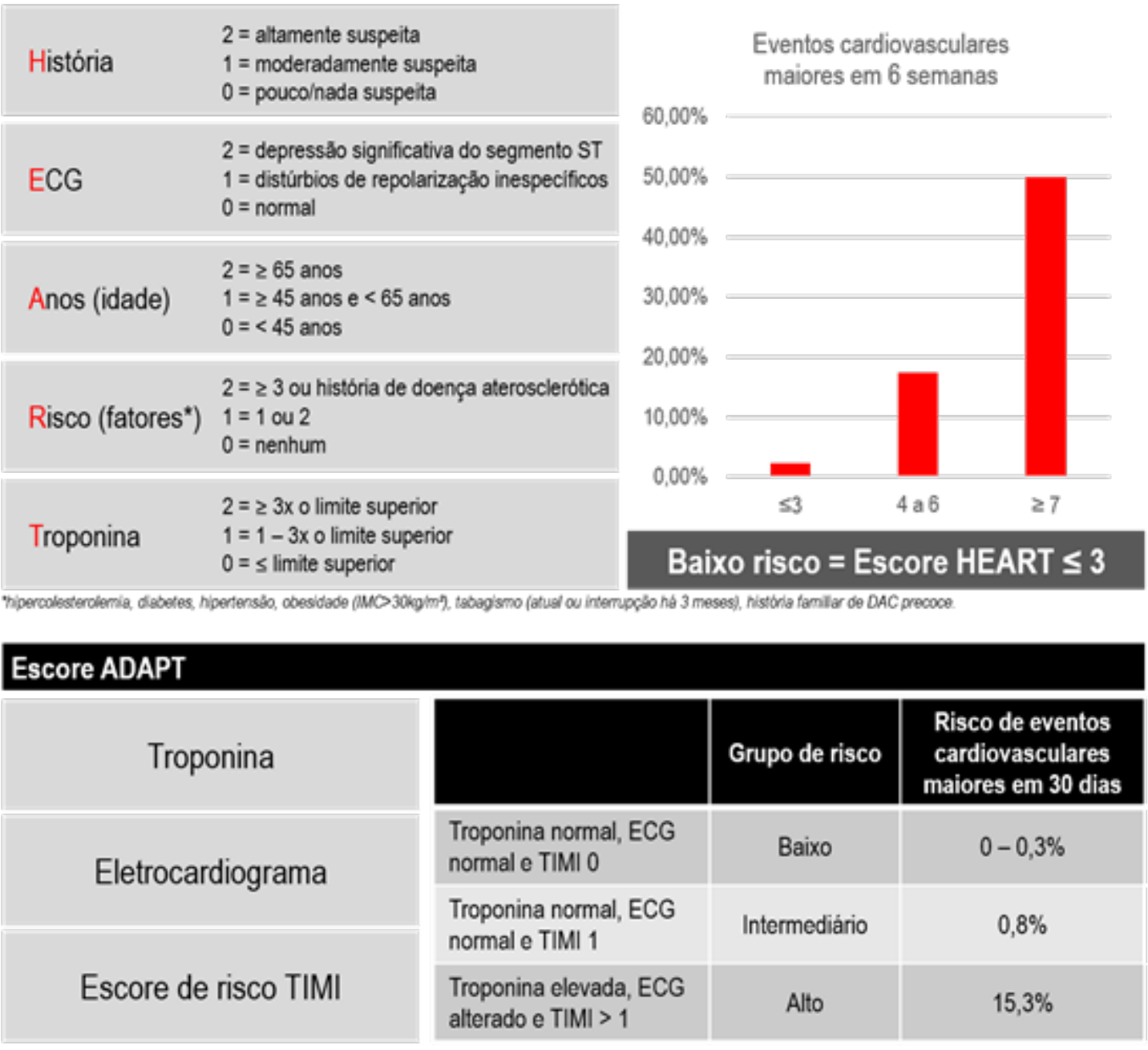

\section{Escore EDACS}

dade

\begin{tabular}{cc}
$18-45$ & 2 \\
\hline $46-50$ & 4 \\
\hline $51-55$ & 6 \\
\hline $56-60$ & 8 \\
\hline $61-65$ & 10 \\
\hline $66-70$ & 12 \\
\hline $71-75$ & 14 \\
\hline $76-80$ & 16 \\
\hline $81-85$ & 18 \\
\hline 286 & 20 \\
\hline
\end{tabular}

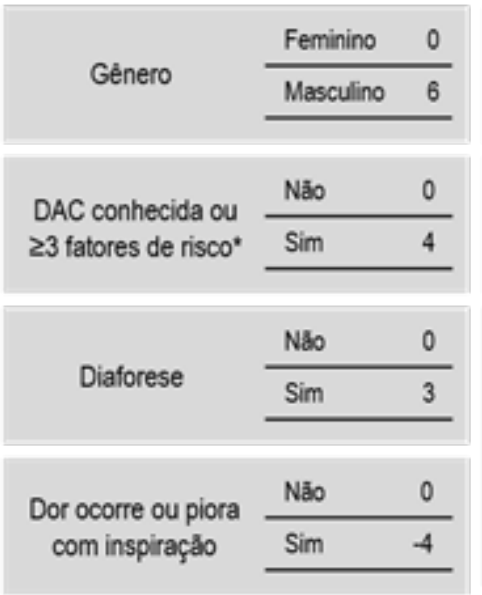

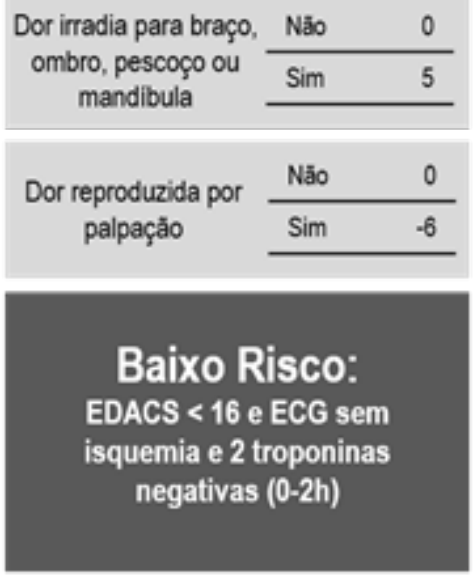

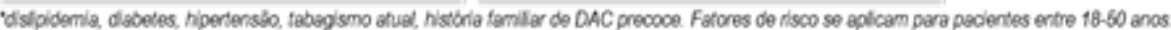




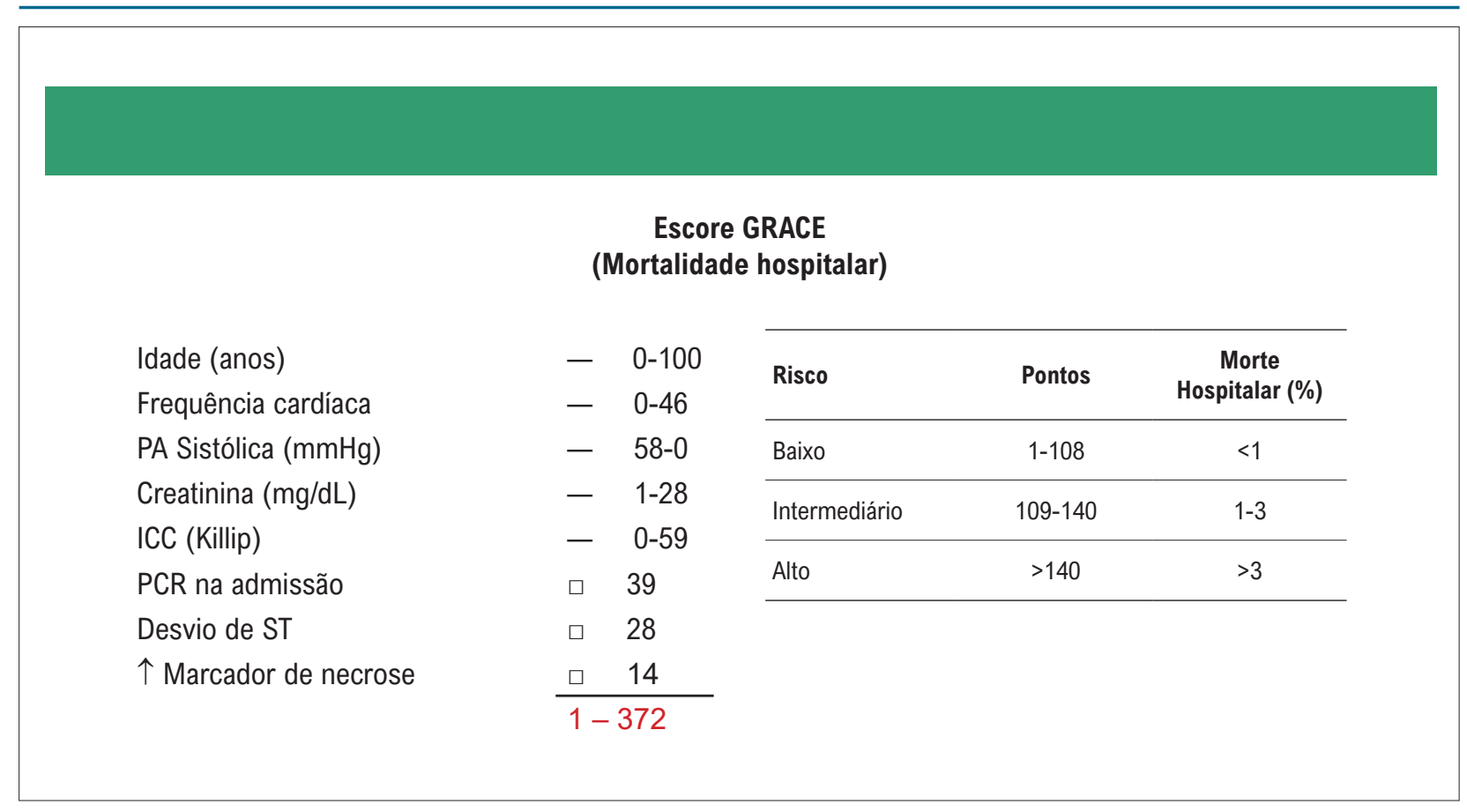

Figura 1.4 - Escore de risco GRACE. Fonte: adaptada de Granger et al..$^{89}$

Tabela 1.5 - Estratificação de risco de morte ou infarto em pacientes com síndrome isquêmica aguda sem supradesnível do segmento $\mathrm{ST}^{91}$

\begin{tabular}{|c|c|c|c|}
\hline & Alto & Moderado & Baixo \\
\hline Varável Prognóstica & $\begin{array}{l}\text { Pelo menos uma das } \\
\text { características a seguir deve } \\
\text { estar presente }\end{array}$ & $\begin{array}{l}\text { Nenhuma característica de } \\
\text { alto risco, mas com alguma } \\
\text { das que seguem adiante }\end{array}$ & $\begin{array}{l}\text { Nenhuma característica de } \\
\text { risco intermediário ou alto, } \\
\text { mas com alguma das que } \\
\text { seguem adiante }\end{array}$ \\
\hline História & $\begin{array}{c}\text { Agravamento dos sintomas } \\
\text { nas últimas } 48 \mathrm{~h} \text {. Idade }>75 \\
\text { anos }\end{array}$ & $\begin{array}{c}\text { Idade = } 70 \text { a } 75 \text { anos } \\
\text { Infarto prévio, doença } \\
\text { cerebrovascular ou periférica, } \\
\text { diabetes melito, cirurgia de } \\
\text { revascularização, uso prévio } \\
\text { de AAS }\end{array}$ & \\
\hline Dor precordial & $\begin{array}{c}\text { Dor prolongada }(>20 \mathrm{~min}), \text { em } \\
\text { repouso. }\end{array}$ & $\begin{array}{l}\text { Angina de repouso }>20 \mathrm{~min} \text {, } \\
\text { resolvida, com probabilidade } \\
\text { de DAC moderada a alta } \\
\text { Angina em repouso } \leq 20 \mathrm{~min} \text {, } \\
\text { com alívio espontâneo ou } \\
\text { com nitrato }\end{array}$ & $\begin{array}{l}\text { Novo episódio de angina } \\
\text { classe III ou IV da CCS nas } \\
\text { últimas } 2 \text { semanas sem dor } \\
\text { prolongada em repouso, } \\
\text { mas com moderada ou alta } \\
\text { probabilidade de DAC }\end{array}$ \\
\hline
\end{tabular}

Exame físico

Edema pulmonar, piora ou

surgimento de sopro de

regurgitação mitral, $B_{3}$, novos

estertores, hipotensão,

bradicardia ou taquicardia

Infradesnível do segmento

ST $\geq 0,5 \mathrm{~mm}$ (associado ou

não com angina), alteração

Eletrocardiograma

dinâmica do ST, bloqueio

completo de ramo, novo

Inversão onda T > 2mm; $\quad$ Normal ou inalterado durante

ou presumidamente novo.

Taquicardia ventricular sustentada

\begin{tabular}{lll}
\hline Marcadores séricos de isquemia* Acentuadamente elevados & Discretamente elevados
\end{tabular}

*Troponina I cardiaca (Tn/c); Troponina T cardiaca (TnTC) ou CK-MB (preferencialmente massa) elevados = acima do percentil 99; elevação discreta = acima do nível de detecção e inferior ao percentil 99. CCS: Canadian Cardiovascular Society; DAC: doença arterial coronariana. 
Tabela 1.6 - Escore de risco de sangramento CRUSADE (referência b) | Algoritmo usado para determinar o escore de risco CRUSADE para sangramento maior intra-hospitalar

\begin{tabular}{ll}
\hline Fator prognóstico & Escores \\
\hline Hematócrito basal (\%) & \\
\hline$<31$ & 9 \\
\hline $31-33,9$ & 7 \\
\hline $34-36,9$ & 3 \\
\hline $37-39,9$ & 2 \\
\hline$>40$ & 0 \\
\hline Clearance de creatinina (mL/min) & \\
\hline$<15$ & 39 \\
\hline $16-30$ & 35 \\
\hline $31-60$ & 28 \\
\hline $61-90$ & 17 \\
\hline $91-120$ & 7 \\
\hline$>120$ & 0 \\
\hline
\end{tabular}

\section{Frequência cardíaca (bpm)}

\begin{tabular}{ll}
\hline$<70$ & 0 \\
\hline $71-80$ & 1 \\
\hline $81-90$ & 3 \\
\hline $91-100$ & 6 \\
\hline $101-110$ & 8 \\
\hline $111-120$ & 10 \\
\hline$>120$ & 11 \\
\hline Sexo & \\
\hline Masculino & 0 \\
\hline Feminino & 8
\end{tabular}

\section{Sinais de IC na apresentação}

\begin{tabular}{ll}
\hline Não & 0 \\
\hline Sim & 7 \\
\hline
\end{tabular}

\begin{tabular}{ll}
\hline Doença vascular prévia & \\
\hline Não & 0 \\
\hline Sim & 6 \\
\hline Diabetes melito & \\
\hline Não & 0 \\
\hline Sim & 6 \\
\hline
\end{tabular}

\begin{tabular}{ll}
\hline Pressão arterial sistólica $(\mathbf{m m H g})$ & \\
\hline$<90$ & 10 \\
\hline $91-100$ & 8 \\
\hline $101-120$ & 5 \\
\hline $121-180$ & 1 \\
\hline $181-200$ & 3 \\
\hline$>200$ & 5
\end{tabular}

IC: insuficiência cardíaca.
Outro escore foi derivado dos estudos ACUITY e HORIZONS. Seis variáveis independentes (sexo feminino, idade avançada, creatinina séria elevada, contagem de leucócitos elevada, anemia, SCA com ou sem elevação de ST) e uma variável relacionada ao tratamento (uso de heparina e inibidor de GP IIbllla no lugar de bivalirudina isolada), foram identificadas (Tabela 1.7). Esse escore identificou pacientes em risco aumentado de sangramento não relacionado à CRVM e mortalidade após 1 ano. ${ }^{94}$

Ambos os escores foram derivados de coortes em que o acesso femoral foi predominantemente ou exclusivamente utilizado. Seu valor prognóstico pode ser menor no cenário de acesso radial..$^{95}$

Finalmente, os autores salientam que nenhum escore (seja de eventos isquêmicos, seja de eventos hemorrágicos) deve substituir a avaliação clínica. São apenas ferramentas que auxiliam o médico na sua decisão.

\section{Estratificação de risco - Sumário de recomendações e evidências}

Todos pacientes devem ser estratificados e classificados em risco alto, intermediário ou baixo de desenvolverem eventos cardíacos maiores. É recomendável a classificação por mais de um método, e o pior cenário deve ser considerado nas decisões quanto às condutas a serem adotadas.

Todos os pacientes devem ser estratificados e classificados em risco alto, intermediário ou baixo de sangramento.

\subsection{Fluxograma de Rotina Diagnóstica na Emergência e Critérios para Hospitalização}

É fundamental um fluxograma de rotina diagnóstica do paciente com dor torácica, definindo os critérios para alta precoce e internação hospitalar. Isso permite identificar pacientes de baixo risco, que podem ser investigados em ambiente ambulatorial, assim como a detecção de condições cardiológicas de maior gravidade que demandam investigação e internação hospitalar.

A triagem da dor torácica no serviço de emergência é baseada em uma breve história clínica, exame físico, ECG de 12 derivações em até 10min após chegada e mensuração de biomarcadores. Esta rotina de investigação visa principalmente identificar precocemente o paciente de maior risco que necessita de internação hospitalar ou urgente transferência para serviço de hemodinâmica.

Com o objetivo de evitar uma alta inadvertida, esses pacientes devem permanecer monitorados onde um protocolo de diagnóstico acelerado possa ser utilizado. Este protocolo envolve ECG seriado e mensuração de troponina ultrassensível na chegada à emergência e 3h após. Além desse protocolo, a incorporação de escores de risco aplicáveis na sala de emergência, que integram dados demográficos, sintomas, achados eletrocardiográficos e biomarcadores, representa uma importante ferramenta de auxílio para o emergencista na avaliação dos pacientes com dor torácica. Os escores mais utilizados são: HEART, ADAPT e EDACS. ${ }^{96-98}$ Tais escores estão sumarizados na Figura 1.3.

Greenslade et al. realizaram estudo comparando a eficácia desses escores na liberação precoce no serviço de emergência, verificando que todos os escores foram eficazes com sensibilidade muito elevada. ${ }^{99}$

O escore HEART foi construído utilizando troponina convencional como biomarcador. No entanto, estudos 


\begin{tabular}{|c|c|c|}
\hline & & Soma \\
\hline Sexo & $\begin{array}{l}\text { Homens Mulheres } \\
\qquad 0+8\end{array}$ & \\
\hline Idade (anos) & $\begin{array}{c}<5050-6960-6970-79 \geq 80 \\
0+3+6+9+12\end{array}$ & \\
\hline Creatinina sérica (mg/dL) & $\begin{array}{c}<1,01,0-1,2-1,4-1,6-1,8-\geq 2,0 \\
0+2+3+5+6+8+10\end{array}$ & \\
\hline Leucócitos totais (giga/mL) & $\begin{array}{c}<1010-12-14-16-18-\geq 20 \\
0+2+3+5+6+8+10\end{array}$ & \\
\hline Anemia & $\begin{array}{l}\text { Não Sim } \\
0+6\end{array}$ & \\
\hline Apresentação da SCA & $\begin{array}{l}\text { IAM com supra - IAM sem supra - angina instável } \\
\qquad+6+20\end{array}$ & \\
\hline \multirow[t]{2}{*}{ Medicações antitrombóticas } & $\begin{array}{l}\text { Heparina+|GP IIb/IIla - bivalirudina } \\
0-5\end{array}$ & \\
\hline & Valor total & \\
\hline
\end{tabular}

retrospectivos que utilizaram troponina ultrassensível apresentaram resultados similares aos observados nos estudos de validação. ${ }^{100,101}$ Não existem estudos validando o uso desta ferramenta no atendimento extra-hospitalar. Contudo, há um estudo (ARTICA) em curso que visa validar o uso deste escore no atendimento pré-hospitalar. ${ }^{102}$

O escore HEART de 0 a 3 permite identificar 35\% a 46\% de pacientes com baixo risco, exibindo alta sensibilidade e valor preditivo negativo, enquanto pacientes com escore de 7 a 10 apresentam alto risco com uma taxa de eventos superior a 50\% em 6 semanas. ${ }^{103-106}$

Quando comparado ao escores GRACE e TIMI, o escore HEART demonstrou maior habilidade em distinguir pacientes de baixo risco para eventos cardíacos maiores, com menor taxa de perda e maior acurácia para a estratificação de risco inicial na sala de emergência. ${ }^{107,108}$

A crescente utilização conjunta dos dados clínicos, eletrocardiográficos e mensuração de troponina ultrassensível e a sistematização da utilização dos escores amplificaram a eficácia dos protocolos de avaliação diagnóstica e a estratificação de risco da dor torácica na sala de emergência, promovendo alta precoce com segurança e redução de exames adicionais em 30 dias. $^{109}$

Estudo que comparou de forma randomizada a aplicação do escore HEART no fluxo de atendimento emergencial de pacientes com dor torácica verificou um elevado valor preditivo negativo para ocorrência de eventos cardiovasculares maiores no primeiro ano, sem diferenças observadas quanto à internação hospitalar ou readmissão em serviço de emergência. ${ }^{110}$

Neste sentido, o atual impacto da avaliação adicional rotineira por exames de imagem em paciente classificados como baixo risco tem sido reconsiderado, pois, apesar do reconhecido valor quanto à redução do tempo para o diagnóstico, evidências atuais identificaram que essa estratégia pode proporcionar um aumento de exames adicionais sem benefício verificado quanto à ocorrência de IAM ou eventos clínicos relevantes. ${ }^{111}$

\subsection{Atuação da Enfermagem no Protocolo de Dor Torácica}

A triagem hospitalar, quando realizada por enfermeiros habilitados, melhora a identificação de pacientes de maior risco, assim como reduz o tempo de realização do ECG. ${ }^{112}$ Já foi demonstrado que, em hospitais de zona rural, enfermeiros emergencistas apresentaram alto nível de acurácia, reduzindo tempo de espera e tempo de permanência sem comprometer a segurança dos pacientes. ${ }^{113}$ Dessa forma, a participação ativa da enfermagem na triagem de pacientes com dor torácica deve ser estimulada, assim como o treinamento constante da equipe multidisciplinar na abordagem do paciente com dor torácica.

O fluxograma proposto para abordagem do paciente com dor torácica na emergência está exposto na Figura 1.5.

Rotina diagnóstica e critérios de internação - Sumário de recomendações e evidências

A triagem inicial deve ser realizada com base em história clínica, exame físico, ECG de 12 derivações em até $10 \mathrm{~min}$ e troponina.

0 escore HEART deve ser utilizado para estratificação de risco e auxílio na decisão de alta hospitalar precoce.

Pacientes com escore HEART $\leq 3$ associado à troponina em tempo hábil negativa, ECG sem alteração isquêmica e ausência de antecedentes de DAC podem ser liberados do serviço de emergência com segurança para reavaliação ambulatorial.

Triagem hospitalar realizada por enfermeiros habilitados, visando ao reconhecimento precoce de pacientes sob maior risco.

Uso de escore EDACS e ADAPT para estratificação de risco clínico como opção ao escore HEART.

Utilização do escore HEART visando à liberação precoce em pacientes atendidos por ambulância. 


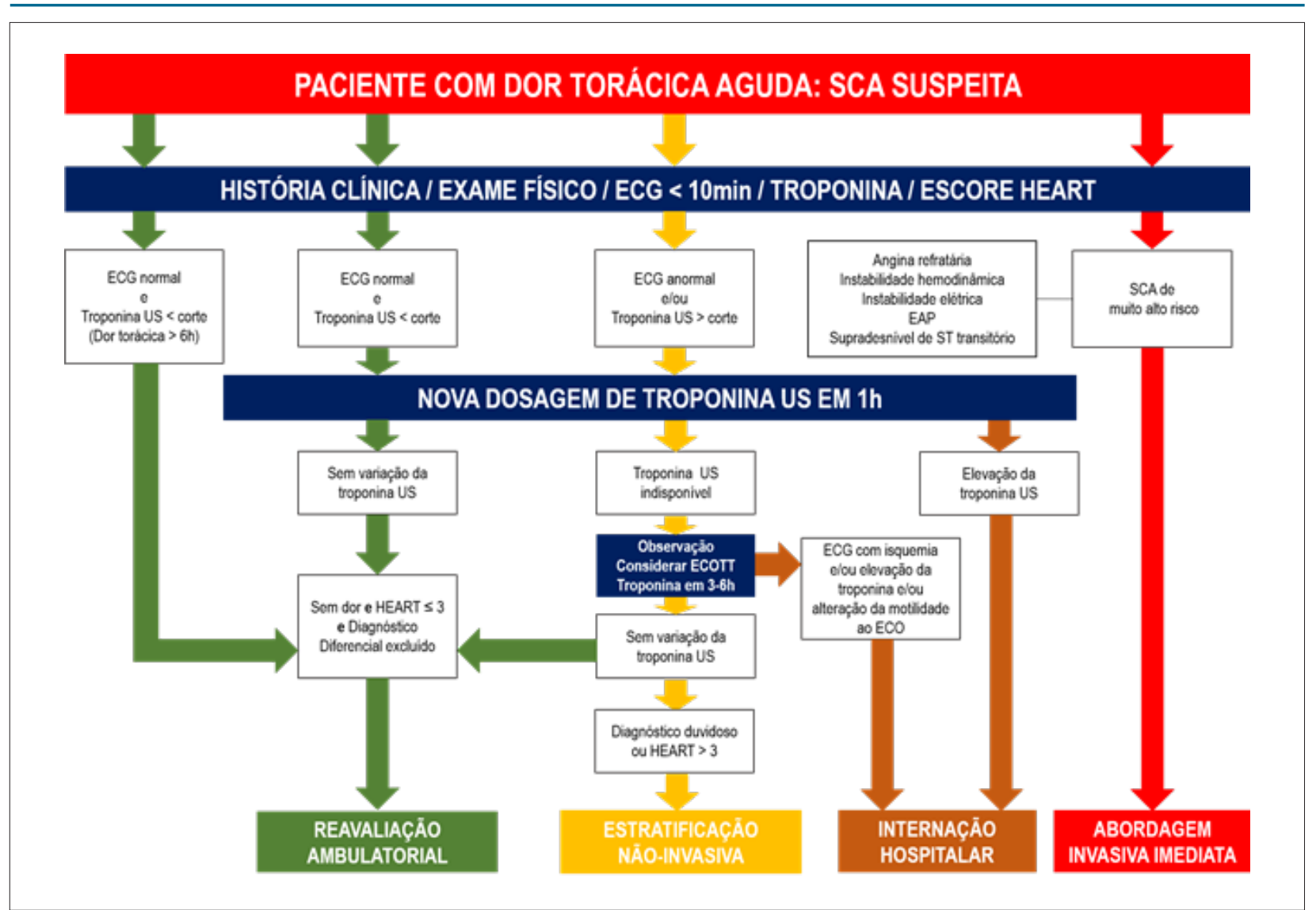

Figura 1.5 - Fluxograma de rotina diagnóstica do paciente com dor torácica aguda na emergência. US: ultrassensível; ECOTT: ecocardiograma transtorácico.

\section{Condutas na Emergência após Estratificação de Risco}

\subsection{Indicações de Estratégia Invasiva Emergencial}

A estratégia invasiva emergencial está indicada em situações de muito alto risco de morte (Tabela 1.8). Esse perfil de pacientes geralmente não está amplamente representado na maioria dos estudos randomizados. Nesses pacientes, está indicada a intervenção coronariana em até $2 \mathrm{~h}$. Em centros onde não há serviço de cardiologia intervencionista disponível, esses pacientes devem idealmente ser transferidos.

Estratégia invasiva de urgência - Sumário de recomendações e evidências

A estratégia invasiva urgente/imediata está indicada em pacientes com SCASSST com angina refratária ou instabilidade hemodinâmica ou elétrica (sem comorbidades graves ou contraindicações para estes procedimentos).

\subsection{Tratamento inicial (sala de emergência/ambulância)}

\subsubsection{Oxigênio Suplementar}

Hipoxemia associada à isquemia miocárdica pode ocorrer devido a alterações da relação ventilação-perfusão, secundárias a shunt arteriovenoso pulmonar (consequente ao aumento da pressão diastólica final do ventrículo esquerdo) e, além disso, formação de edema intersticial e/ou alveolar pulmonar. A hipoxemia, por sua vez, agrava a isquemia miocárdica, aumentando a lesão miocárdica. A mensuração da saturação de $\mathrm{O} 2$ ( $\mathrm{SaO} 2)$ através de oximetria digital deve ser realizada desde o atendimento pré-hospitalar e/ou na ambulância, visando ao diagnóstico precoce da hipoxemia.

A administração de oxigenioterapia suplementar em pacientes com IAM está indicada quando o paciente apresentar hipóxia com $\mathrm{SaO} 2<90 \%$ ou sinais clínicos de desconforto respiratório. ${ }^{114}$ No entanto, a administração de oxigenioterapia a pacientes com suspeita de SCA e SaO2 $\geq$ $90 \%$ não se associou à redução de mortalidade ou a outros desfechos cardiovasculares em 1 ano de seguimento, em um estudo randomizado que incluiu mais de 6 mil pacientes. ${ }^{115}$

A oxigenoterapia deve ser cuidadosa para não eliminar o estímulo respiratório hipóxico na presença de doença pulmonar obstrutiva crônica ou de outras causas de hipercapnia. Pacientes com congestão pulmonar, cianose, hipoxemia arterial comprovada ou insuficiência respiratória associadas devem receber suplementação de oxigênio e ser cuidadosamente acompanhados com gasometrias seriadas. Em casos selecionados que evoluem com sinais de insuficiência respiratória, com persistência de congestão pulmonar e hipoxemia, o suporte ventilatório não invasivo (VNI) deve ser instituído, além de progressão para ventilação invasiva 


\begin{tabular}{l}
\hline Tabela 1.8 - Indicação de estratégia invasiva de urgência \\
\hline Instabilidade hemodinâmica ou choque cardiogênico \\
\hline Dor torácica refratária ao tratamento medicamentoso \\
\hline Arritmias malignas ou parada cardiorrespiratória \\
\hline Complicações mecânicas do infarto \\
\hline Insuficiência cardíaca aguda \\
\hline Alterações recorrentes do segmento ST-T com elevação intermitente do segmento ST \\
\hline
\end{tabular}

na ocorrência de choque circulatório, falência da VNI e nos pacientes instáveis em transição para revascularização miocárdica urgente (ICP ou CRVM). A administração desnecessária de oxigênio por tempo prolongado pode causar vasoconstrição sistêmica e até mesmo ser prejudicial.

\section{Oxigenioterapia - Sumário de recomendações e evidências}

Oxigenioterapia ( 2 a $4 \mathrm{~L} / \mathrm{min}$ ) em pacientes com risco intermediário e alto, na presença de $\mathrm{SaO} 2<90 \%$ e/ou sinais clínicos de desconforto respiratório.

\subsubsection{Analgesia e Sedação}

A dor precordial e a ansiedade costumeiramente associada, presentes nas SCA, geralmente levam à hiperatividade do sistema nervoso simpático. Esse estado hiperadrenérgico, além de aumentar o consumo miocárdico de oxigênio, predispõe ao aparecimento de taquiarritmias atriais e ventriculares. A terapêutica antianginosa inicial deve ser realizada com betabloqueadores e nitratos, desde que não haja contraindicações, como choque cardiogênico e/ou hipotensão. O sulfato de morfina poderá ser utilizado em casos refratários ou com contraindicação aos nitratos ou betabloqueadores. Deve ser administrado por via intravenosa, na dose de 2 a $4 \mathrm{mg}$ diluídos a cada 5 min até, no máximo, 25mg. A administração em pequenos incrementos tem por objetivo evitar efeitos adversos como hipotensão e depressão respiratória. Deve-se evitar derivados da morfina, a não ser em casos de hipersensibilidade a esta, que, nessa situação (de hipersensibilidade), pode ser substituída pelo sulfato de meperidina em doses fracionadas de 20 a $50 \mathrm{mg}$ IV.

Apesar de seu potente e eficaz efeito no controle da angina, há evidência de que o uso da morfina reduza o efeito antiplaquetário dos inibidores do receptor $\mathrm{P}_{2} \mathrm{Y}_{12}$ tanto o clopidogrel ${ }^{116}$ quanto antiplaquetários mais potentes como prasugrel e ticagrelor. ${ }^{117,118}$

Do ponto de vista de eventos clínicos, uma subanálise do registro CRUSADE ${ }^{119} \mathrm{e}$, mais recentemente, uma metanálise que incluiu quase 70 mil pacientes demonstraram que o uso rotineiro precoce de morfina pode estar associado a aumento de mortalidade intra-hospitalar e eventos cardiovasculares maiores. ${ }^{120}$ Em uma análise post-hoc do estudo EARLY-ACS, verificou-se que a morfina se associou a maior risco de eventos isquêmicos precoces quando utilizada concomitantemente ao pré-tratamento com clopidogrel. Porém, no grupo de pacientes sem uso de clopidogrel antes do cateterismo, não se verificou piora de desfecho clínico com uso de morfina. ${ }^{121}$

O emprego rotineiro de ansiolíticos tem sido prática comum em nosso meio. Parece muitas vezes ser dispensável, devendo ser reservado para situações especiais. Estudo clínico randomizado, duplo-cego, envolvendo 131 pacientes do gênero masculino com IAM observou que o grau de ansiedade, pressão arterial, frequência cardíaca e desconforto precordial não diferiu, quer os pacientes tenham sido tratados com diazepam ou com placebo ${ }^{122}$. Os derivados diazepínicos têm sido os mais utilizados nessa indicação.

Anti-inflamatórios não esteroides (AINE) não devem ser utilizados (com exceção do AAS) para controle da dor em pacientes com IAM, pois aumentam o risco de eventos cardiovasculares maiores. Se o paciente estiver em uso prévio de AINE, estes devem ser suspensos durante a internação devido aos efeitos deletérios associados a elevação da pressão arterial, risco de lesão renal aguda e hiperviscosidade sanguínea com piora do prognóstico cardiovascular. ${ }^{123}$

\section{Analgesia e sedação - Sumário de recomendações e evidências}

Administrar sulfato de morfina em pacientes que mantêm dor contínua, apesar de terapia anti-isquêmica otimizada.

Administrar benzodiazepínicos em pacientes com sinais e sintomas de ansiedade.

Anti-inflamatórios não esteroides (AINE) não devem ser administrados (com exceção do AAS) em pacientes com suspeita de IAM.

\subsubsection{Controle Glicêmico}

Mais de $30 \%$ dos pacientes admitidos com IAM apresentam diabetes melito ou desconhecem o diagnóstico de diabetes. Tais indivíduos apresentam maiores taxas de sangramento e pior prognóstico em 30 dias, quando comparados com pacientes com níveis glicêmicos normais. ${ }^{124-127}$ Nesse sentido, protocolos de controle glicêmico devem ser instituídos para pacientes com IAM que apresentem hiperglicemia significativa ( $>180 \mathrm{mg} / \mathrm{dL})$. O alvo dessa terapia é reduzir os níveis glicêmicos e evitar episódios de hipoglicemia $(<70 \mathrm{mg} / \mathrm{dL})$, que podem causar diversos efeitos deletérios incluindo a expansão da área de IAM. Em pacientes com maior risco de hipoglicemia, tais como idosos, nefropatas e pacientes com efeito residual de hipoglicemiantes orais e/ou em jejum, o controle glicêmico 
deve ser ajustado para tolerar níveis glicêmicos um pouco mais altos e, assim, prevenir hipoglicemia.

\section{Controle glicêmico - Sumário de recomendações e evidências}

É recomendável mensurar, na admissão, os níveis glicêmicos de todos os pacientes com suspeita de SCA, assim como monitorar evolutivamente a glicemia dos pacientes diabéticos ou que apresentem hiperglicemia durante a internação.

Controle glicêmico com protocolos de utilização de insulina intermitente, devem ser considerados em pacientes com níveis glicêmicos $>180 \mathrm{mg} / \mathrm{dL}$, com cautela, para evitar episódios de hipoglicemia.

Em pacientes com maior risco de hipoglicemia, tais como idosos, nefropatas e pacientes com efeito residual de hipoglicemiantes orais e/ou em jejum, o controle glicêmico deve ser ajustado para tolerar níveis glicêmicos um pouco IIa mais altos e, assim, prevenir hipoglicemia.

\subsubsection{Terapia anti-isquêmica}

O objetivo da terapêutica anti-isquêmica é reduzir o consumo de oxigênio (diminuindo a frequência cardíaca, a pressão arterial e a contratilidade miocárdica) ou aumentar a oferta de oxigênio (administrando oxigênio ou promovendo vasodilatação)

\subsubsection{Nitratos}

Os benefícios terapêuticos dos nitratos estão relacionados aos seus efeitos na circulação periférica e coronária. O seu efeito venodilatador, diminuindo o retorno venoso ao coração e o volume diastólico final do ventrículo esquerdo, reduz o consumo de oxigênio pelo miocárdio. Adicionalmente, observam-se efeitos de vasodilatação de artérias coronárias, normais ou ateroscleróticas, redirecionamento de fluxo intercoronário, com aumento da circulação colateral e inibição da agregação plaquetária. Além do efeito sintomático, os nitratos agem reduzindo a congestão pulmonar, principalmente pela redução do retorno venoso sistêmico.

Não existem estudos clínicos controlados que tenham testado os efeitos dos nitratos em desfechos clínicos e mortalidade na SCASSST, embora seu uso seja universalmente aceito. Os estudos em Al que os avaliaram foram pequenos e do tipo observacional. ${ }^{128-132}$ A melhora dos sintomas tanto anginosos como congestivos está relacionada ao uso dos nitratos, porém sem impacto quanto a mortalidade, infarto ou necessidade de revascularização.

O tratamento é iniciado na sala de emergência, administrando-se o nitrato por via sublingual (nitroglicerina, mononitrato ou dinitrato de isossorbida). Caso não haja alívio rápido da dor, esses pacientes podem se beneficiar com a administração intravenosa (nitroglicerina e mononitrato de isossorbida são os disponíveis em nosso meio).

Os nitratos estão contraindicados na presença de hipotensão arterial importante (pressão arterial sistólica [PAS] $<100 \mathrm{mmHg}$ ) ou uso prévio de sildenafil nas últimas 24h, ou uso de tadalafila nas últimas $48 \mathrm{~h}$. Um efeito colateral comum é a cefaleia. O uso sublingual de nitroglicerina $(0,4 \mathrm{mg} /$ comp. $)$, dinitrato de isossorbida $(5 \mathrm{mg} / \mathrm{comp}$.$) ou$ mononitrato de isossorbida ( $5 \mathrm{mg} / \mathrm{comp}$.) não deve ultrapassar 3 comprimidos, separadas as administrações por intervalos de 5 min. A nitroglicerina IV é empregada na dose de $10 \mu \mathrm{g}$ min com incrementos de $10 \mu \mathrm{g}$ a cada $5 \mathrm{~min}$ até obter-se melhora sintomática ou redução da pressão arterial (queda da PAS não deve ser superior a 30\% ou PAS não atingindo $<110 \mathrm{mmHg}$ ), ou então aumento da frequência cardíaca (> $10 \%$ da basal). É de se esperar o aparecimento de tolerância aos efeitos hemodinâmicos do medicamento após $24 \mathrm{~h}$ de uso. O tratamento intravenoso deverá ser mantido por 24 a 48h da última dor anginosa e sua suspensão deverá ser feita de forma gradual.

Nitratos - Sumário de recomendações e evidências

Uso de nitrato sublingual para alívio da angina.

Uso de nitrato endovenoso para controle de angina persistente, hipertensão arterial ou sinais de congestão.

\subsubsection{Betabloqueadores}

Assim como com os nitratos, a experiência clínica controlada do emprego de betabloqueadores na Al é limitada. A evidência de efeitos benéficos baseia-se em seu mecanismo de ação, em estudos clínicos controlados de pequeno porte, e na extrapolação de resultados de estudos em angina estável e IAM com supra de ST. Os betabloqueadores inibem competitivamente os efeitos das catecolaminas circulantes. $\mathrm{Na} \mathrm{Al}$, seus benefícios estão relacionados com sua ação nos receptores beta-1. Diminuem a frequência cardíaca, a pressão arterial e a contratilidade miocárdica, provocando redução do consumo de oxigênio pelo miocárdio. Apesar de a inexistência de estudos randomizados em larga escala avaliando a ação sobre desfechos clínicos graves como mortalidade em pacientes com SCASSST, esses fármacos, juntamente com os nitratos, são considerados agentes de primeira escolha no tratamento das SCA na sala de emergência para pacientes sem contraindicação. $\mathrm{Na} \mathrm{Al}$, foram poucos e de pequeno porte os estudos que compararam betabloqueadores com placebo. ${ }^{133-135}$ Apesar da ausência de efeito redutor de mortalidade, metanálise de cinco pequenos estudos ${ }^{136}$ avaliando a utilização da terapêutica betabloqueadora em 4.700 pacientes com Al mostrou redução de $13 \%$ no risco relativo de progressão para IAM. Estudo nacional em pacientes com SCASSST encontrou associação significativa entre o uso de betabloqueador oral com início nas primeiras $24 \mathrm{~h}$ de hospitalização e menor mortalidade intra-hospitalar, independentemente da presença ou não de disfunção ventricular esquerda. ${ }^{137}$

Apesar de realizado em pacientes com IAM com supradesnível do segmento ST, o estudo COMMIT ${ }^{138}$ sugere que a utilização rotineira de dose elevada de betabloqueador IV seguido de administração oral pode aumentar a incidência de choque cardiogênico, principalmente quando utilizado nas primeiras 24 a 48h de evolução, e em pacientes com quadro clínico de disfunção ventricular esquerda ou com fatores de risco para choque cardiogênico (idade superior a 70 anos, frequência cardíaca $>110 \mathrm{bpm} / \mathrm{min}$ ou pressão sistólica $<120 \mathrm{mmHg}$ ). 
Apesar de não haver estudo clínico randomizado específico para população com SCASSST, estudo de banco de dados com mais de 20 mil pacientes mostra comportamento semelhante ao observado no estudo COMMIT. ${ }^{139}$

Assim, recomenda-se o uso rotineiro de betabloqueador oral nos pacientes sem contraindicação (mais detalhes na Parte 2 desta Diretriz). Caso o paciente apresente dor isquêmica persistente e/ ou taquicardia (não compensatória de um quadro de insuficiência cardíaca), pode-se utilizar a formulação venosa. São usados vários regimes terapêuticos na dependência do betabloqueador selecionado. Não existem evidências de superioridade de um betabloqueador sobre outro. Em pacientes que evoluem com disfunção ventricular (FEVE $<40 \%$ ) o emprego de betabloqueadores é muito recomendado (carvedilol, bisoprolol e succinato de metoprolol) em pacientes sem congestão pulmonar.

A seguir, há uma relação das doses de metoprolol e atenolol, os mais usados em nosso país com essa indicação.

Metoprolol: IV - $5 \mathrm{mg}(1$ a $2 \mathrm{~min})$ a cada $5 \mathrm{~min}$ até completar a dose máxima de $15 \mathrm{mg}$.

VO - 50 a 100mg a cada 12h, iniciado 15min após a última administração IV.

Atenolol: $\quad$ IV $-5 \mathrm{mg}(1$ a $2 \mathrm{~min})$ a cada $5 \mathrm{~min}$ até completar a dose máxima de $10 \mathrm{mg}$.

VO - 25 a 50mg a cada 12h, iniciado $15 \mathrm{~min}$ após a última administração IV.

Durante a administração intravenosa, deverão ser monitorados, cuidadosamente, a frequência cardíaca, a pressão arterial, o ECG e a ausculta pulmonar.

Betabloqueadores não devem ser utilizados em pacientes com sintomas relacionados a vasospasmo por uso de cocaína durante intoxicação aguda. Em pacientes com asma ou doença pulmonar obstrutiva crônica, são contraindicados apenas na vigência de broncospasmo - nessa situação, betabloqueadores beta-1 seletivo são preconizados.

\section{Betabloqueadores - Sumário de recomendações e evidências}

Administrar betabloqueadores VO nas primeiras $24 \mathrm{~h}$ em pacientes sem contraindicações (sinais de insuficiência cardíaca, sinais de baixo débito, risco aumentado de choque cardiogênico ou outras contraindicações ao betabloqueador).

Administrar betabloqueador IV em pacientes de risco intermediário e alto com isquemia persistente, taquicardia e hipertensão, desde que não apresente sinais clínicos/ radiológicos de insuficiência cardíaca.

Administrar betabloqueador IV em pacientes com fatores de risco para choque cardiogênico.

\subsubsection{Terapia Antitrombótica Inicial (Sala de Emergência/} Ambulância)

\subsubsection{Antiplaquetários Orais}

O fenômeno de instabilidade da placa aterosclerótica coronariana consequente à ruptura ou erosão, com subsequente ativação plaquetária e trombose, é um reconhecido mecanismo de deflagração das SCA. ${ }^{140}$
Esse conceito direcionou os estudos e avanços na terapia antiplaquetária e o conceito atual da dupla terapia com AAS e um fármaco inibidor de receptor plaquetário $\mathrm{P}_{2} \mathrm{Y}_{12}$ em pacientes com SCA, contemplando os alocados para estratégia invasiva e/ou proposta inicial de tratamento clínico. ${ }^{141}$

As características e evidências científicas para escolhas individualizadas dos fármacos antiplaquetários encontramse detalhadamente descritas na Parte 2. No entanto, uma das importantes decisões na sala de emergência consiste no momento ideal para o início de um inibidor de $\mathrm{P} 2 \mathrm{Y}_{12^{\prime}}$ particularmente em pacientes submetidos à estratégia invasiva precoce com cinecoronariografia e perspectiva de ICP. O termo "pré-tratamento" geralmente se refere ao início de um inibidor de $\mathrm{P} 2 \mathrm{Y}_{12}$ antes da definição da anatomia coronariana, seja na ambulância ou na sala de emergência.

\subsection{Fundamentos do Pré-tratamento com} Bloqueadores de $\mathrm{P} \mathrm{Y}_{12}$

O objetivo do pré-tratamento com segundo antiplaquetário potente na SCASSST seria a possibilidade de alcançar inibição plaquetária eficaz e prevenção de maior agregação, sobretudo preparando e protegendo o paciente para estratégia invasiva, potencialmente reduzindo a extensão da trombose, risco de IAM recorrente e minimizando o risco de complicações relacionadas à ICP como trombose de stent e infarto periprocedimento. ${ }^{142}$

Em contrapartida, a proposta de pré-tratamento tem reconhecido impacto em aumentar o risco de sangramento associado ou não à cirurgia de revascularização miocárdica, fator que está associado a um relevante aumento da morbimortalidade na SCA. ${ }^{143-145}$

Uma questão importante se refere ao tempo mínimo ideal para ação clinicamente eficaz do fármaco, sabendo que até mesmo os mais potentes agentes antiplaquetários orais eficazes requerem pelo menos 30 a 60 min para inibição plaquetária efetiva e, assim, obter "pré-tratamento apropriado" antes de cateterismo e perspectiva de ICP. ${ }^{146-149}$

A utilização do segundo agente plaquetário seguindo a proposta de pré-tratamento com bloqueadores de $\mathrm{P}_{2} \mathrm{Y}_{12}$ foi adotada nos estudos CURE (clopidogrel) ${ }^{150,151}$ e PLATO (ticagrelor); ${ }^{152,153}$ no estudo TRITON, o prasugrel poderia ser administrado somente após a identificação da anatomia coronariana. ${ }^{154}$

6.2.5.1.2. Estudos Comparativos de Pré-tratamento versus Utilização do Segundo Antiplaquetário na Sala de Cateterismo

O estudo PRELOAD ARMIDA-5 avaliou o pré-tratamento com clopidogrel em pacientes com SCASSST $(n=409)$ ou angina estável e não verificou associação com redução de eventos cardiovasculares adversos. ${ }^{155}$

O estudo CREDO foi planejado para avaliar o benefício de início do pré-tratamento com clopidogrel, além de AAS, em pacientes submetidos à ICP. Ensaio este controlado, no qual 2.116 pacientes, sendo 39\% com SCA e 61\% com DAC estável, receberam $300 \mathrm{mg}$ de clopidogrel $(\mathrm{n}=1.053)$ ou 
placebo $(n=1.063), 3$ a $24 \mathrm{~h}$ antes da ICP. O tempo médio entre a dose de ataque do medicamento de estudo e a ICP foi de $9,8 \mathrm{~h}$, dos quais $51 \%$ recebem a dose de ataque entre 3 e $6 \mathrm{~h}$ e os $49 \%$ restantes, entre 6 e $24 \mathrm{~h}$ antes da ICP. O estudo não encontrou redução estatisticamente significativa no desfecho combinado de morte, infarto ou revascularização urgente do vaso-alvo em 28 dias. No entanto, quando a população foi analisada com base no tempo de intervalos de tratamento de 3 a $6 \mathrm{~h}, 6$ a $12 \mathrm{~h}$ e 12 a $24 \mathrm{~h}$ antes da ICP, observou-se interação significativa em que não houve benefício de pré-tratamento se a dose de clopidogrel tiver sido administrada $<6 \mathrm{~h}$ antes da ICP, mas houve redução relativa de $35,5 \%$ e $40,1 \%$ no desfecho final combinado, respectivamente, em grupos que receberam clopidogrel entre 6 e $12 \mathrm{~h}$ e 12 e $24 \mathrm{~h}$ antes da ICP, respectivamente. Esses achados corroboram a hipótese da necessidade de maior tempo de ação quando utilizado clopidogrel em proposta de pré-tratamento. ${ }^{156}$

O ensaio clínico ACCOAST $(n=4.033)$ foi um estudo controlado multicêntrico e randomizado que comparou o tratamento com $60 \mathrm{mg}$ de prasugrel administrado na sala de cateterismo no momento da intervenção coronária percutânea com a estratégia de utilização de pré-tratamento com 30mg de prasugrel e uma segunda dose de $30 \mathrm{mg}$ durante a angiografia coronariana dentro de 2 a 48h após a randomização. ${ }^{157}$

O desfecho final composto primário foi morte por causas cardiovasculares, IAM, AVC, revascularização urgente ou necessidade de terapia de resgate com inibidores de glicoproteína IIb/IIla até o sétimo dia. ICP foi realizada em $69 \%$ dos pacientes em um tempo médio de 4,3h após a dose inicial de ataque, e apenas $9 \%$ dos pacientes incluídos no ensaio ACCOAST tiveram um escore GRACE $>140$. A incidência do desfecho final primário até o sétimo dia e aos 30 dias não diferiu significativamente entre o grupo que recebe pré-tratamento com prasugrel versus o grupo placebo (10,0\% vs. 9,8\%, HR 1,02, IC 95\% 0,84-1,25, p $=0,81)$. Foi documentada maior taxa de sangramento maior relacionado ou não à CRVM com a estratégia de pré-tratamento (HR, 1,90; IC 95\%, 1,19-3,02; $\mathrm{p}=0$ 0,006). As taxas de sangramento maior (TIMI) e sangramento ameaçador de vida não relacionado à CRVM foram $3 \mathrm{e}$ 6 vezes maiores, respectivamente. Metade de todos os episódios foi relacionada com cirurgia de revascularização urgente, e metade dos eventos de sangramento maior não relacionados à CRVM foi causada por sangramento vascular no local de acesso.

O ensaio clínico randomizado DUBIUS (Downstream versus Upstream administration of $\mathrm{P}_{2} \mathrm{Y}_{12}$ receptor Blockers In non-ST elevated acUte coronary Syndromes) avaliou 1.449 pacientes com SCASSST e coronariografia programada em até $72 \mathrm{~h}$, comparando a estratégia de pré-tratamento com ticagrelor versus a utilização do segundo antiplaquetário prasugrel ou ticagrelor (randomização 1:1) administrados na sala de hemodinâmica nos pacientes com indicação de intervenção coronária percutânea. ${ }^{158} \mathrm{~A}$ população estudada exibia perfil de risco isquêmico moderado (escore GRACE médio $=122$ ) e risco hemorrágico não elevado (escore CRUSADE médio $=22$ ). Análise provisória pré-especificada para futilidade orientou a interrupção precoce do estudo. A taxa do desfecho primário em 30 dias, composto de morte devido a causas vasculares, infarto não fatal ou AVC não fatal e fenômenos hemorrágicos relevantes (BARC tipo 3,4 e 5), não diferiu significativamente entre a estratégias ( $2,9 \%$ e $3,3 \%$, respectivamente, para não pré-tratar vs. pré-tratamento). Esse achado foi consistente no subgrupo que realizou ICP ( $72 \%$ da população), e o tempo médio de realização de ICP foi de $23,3 \mathrm{~h}$, notadamente superior ao estudo ACCOAST (4h); os achados, no entanto, foram semelhantes naqueles que realizaram coronariografia após 24h. Esse estudo teve a originalidade de metade da população alocada para não pré-tratamento ter utilizado ticagrelor, porém sem poder para comparação de fármacos. Apesar das limitações de análise por interrupção prematura, representa uma observação de não benefício da estratégia de pré-tratamento na SCASSST com manuseio invasivo, porém salienta a possibilidade de escolha individualizada de fármacos na sala de hemodinâmica.

\subsection{Dados de Pré-tratamento em Metanálises}

Metanálise que contemplou 16 estudos, incluindo 61.517 pacientes com SCA com ou sem supradesnível do segmento ST, verificou incidência significativamente menor de MACE no subgrupo com SCASSST alocado para pré-tratamento com clopidogrel $(\mathrm{OR}=0,83$; IC 95\% 0,71-0,96, $\mathrm{p}=0,01)$, sem aumento de sangramento maior em pacientes submetidos à ICP em até 48 h. ${ }^{159}$

Outra metanálise que incluiu 23 estudos e 60.907 pacientes teve o objetivo de comparar a eficácia e a segurança dos inibidores plaquetários $\mathrm{P}_{2} \mathrm{Y}_{12}$ : clopidogrel, ticagrelor e prasugrel administrados em dois cortes de tempo diferentes em relação à ICP: precoce $(<2 \mathrm{~h}$ pré-ICP) versus tardio ( $>2 \mathrm{~h}$ pré-ICP ou pós-ICP). A análise de estudos que incluíram pacientes com SCASSST não demostrou benefício no pré-tratamento com ticagrelor ou prasugrel, mas prasugrel aumentou o risco de sangramento nessa população com SCASSST. ${ }^{160}$

Conforme exposto, não existe um claro benefício estabelecido para uso rotineiro do segundo agente antiplaquetário via oral na abordagem inicial da SCASSST, sobretudo no cenário de estratégia invasiva em caráter emergencial, quando o uso e a escolha do fármaco podem ser definidos na sala de cateterismo. Porém, o pré-tratamento pode ser considerado nos pacientes sem risco hemorrágico crítico, com risco isquêmico moderado ou elevado, com programação para realizar cinecoronariografia ou manuseio inicial conservador em terapia anti-isquêmica plena.

O desafio de equilibrar risco isquêmico com risco de sangramento nos conduz à necessidade de abordagem personalizada para decisão do momento de utilização e escolha do segundo antiplaquetário. Devemos considerar características clínicas, disponibilidade para realizar cinecoronariografia, dados de eficácia, segurança e propriedades farmacodinâmicas dos inibidores plaquetários P2Y ${ }_{12}$ disponíveis para uso no Brasil; contudo, importante salientar que, na decisão de pré-tratamento sem anatomia conhecida, está contraindicado o uso de prasugrel. Na 
decisão de administração na sala de cateterismo, todos os inibidores $\mathrm{P}_{2} \mathrm{Y}_{12}$ podem ser utilizados conforme escolha individualizada. Neste contexto, se aplica, na ausência de contraindicações, o uso preferencial de prasugrel ou ticagrelor, fármacos com rápido início de ação e maior eficácia antitrombótica, e a opção do clopidogrel na presença de risco hemorrágico muito elevado (Figura 1.6).

Terapia antiplaquetária inicial - Sumário de recomendações e evidências

0 uso de AAS é recomendado na sala de emergência o mais precoce possível em todos pacientes sem contraindicação, em dose inicial de 150 a $300 \mathrm{mg}$ (pacientes sem uso prévio de AAS) e dose de manutenção de 75 a $100 \mathrm{mg}$.

E recomendado o uso de um inibidor receptor $P 2 Y_{12}$ em adição a AAS, exceto contraindicações ou elevado risco de sangramento.

Não realizar pré-tratamento com segundo antiplaquetário inibidor do receptor $\mathrm{P}_{2 \mathrm{Y}_{12}}$ nos pacientes instáveis e/ou com risco elevado, indicados para estratégia invasiva de forma imediata, sendo sua utilização recomendada para sala de cateterismo, quando anatomia coronariana conhecida e ICP programada.

Não há indicação rotineira de se iniciar $\mathrm{P}_{2} \mathrm{Y}_{12}$ como prétratamento em pacientes indicados para estratégia invasiva precoce $(<24 h)$.

Prasugrel (dose de ataque) na sala de hemodinâmica somente após a realização da angiografia se a intervenção coronariana for programada em pacientes sem história de AVC ou AIT prévios.

Ticagrelor (dose de ataque), independentemente da estratégia inicial conservadora ou invasiva.

Clopidogrel (dose de ataque), independentemente da estratégia inicial (conservadora ou invasiva) na indisponibilidade ou contraindicação ao ticagrelor ou prasugrel.

Em pacientes alérgicos a AAS, está indicada monoterapia inicial com inibidor P2Y $_{12}$ (uso preferencial de ticagrelor ou prasugrel).

Clopidogrel (dose de ataque), independentemente da estratégia inicial (conservadora ou invasiva) em pacientes de muito alto risco para sangramento ou necessidade de anticoagulação oral a longo prazo.

Estratégia de pré-tratamento com prasugrel

\subsubsection{Antagonistas dos Receptores Glicoproteicos IIb/IIIa}

A ativação dos receptores existentes na superfície das plaquetas, denominados glicoproteína (GP) Ilb/IIla, constitui-se no mecanismo final de agregação plaquetária, em consequência de alteração morfológica sofrida pelo receptor, que aumenta a sua afinidade para ligar-se à molécula de fibrinogênio, elemento que funciona como ponte de ligação entre duas plaquetas. Esses fármacos têm sido utilizados em situações clínicas com grande potencial de ativação plaquetária, como, por exemplo, ICPs complexas e complicações trombóticas como no-reflow após angioplastia.

O abciximab é um anticorpo monoclonal que atua como bloqueador não competitivo e irreversível dos receptores de GP IIb/IIla. Tem meia-vida plasmática curta de 5 a 10min, e sua meia-vida biológica é de 6 a $12 \mathrm{~h}$ após a injeção de um bolus isolado. Com essas doses terapêuticas, consegue-se o bloqueio de $80 \%$ a $90 \%$ dos receptores de superfície. Cinquenta por cento desses receptores ainda permanecem bloqueados 1 semana após sua utilização. A dose recomendada é de $0,25 \mathrm{mg} / \mathrm{kg}$ em bolus, seguida de uma administração de $0,125 \mu \mathrm{g} / \mathrm{kg}$ durante $12 \mathrm{~h}$.

O tirofiban é um derivado sintético, não peptídio, de molécula pequena, que possui em sua estrutura molecular a sequência RGD (arginina-glicina-aspartato), sítio de reconhecimento das integrinas e presente nas proteínas adesivas do tipo fibrinogênio, fator von Willebrand e vetronectina, entre outras. O tirofiban também age competitivamente no receptor celular IIb/IIla, impedindo sua ligação ao fibrinogênio. A dose recomendada é a de $0,4 \mu \mathrm{g} / \mathrm{kg} /$ min por 30min, seguida da dose de manutenção de $0,1 \mu \mathrm{g} / \mathrm{kg} /$ min por 12 a 24 horas após o procedimento (máximo de 96 horas). No caso de se iniciar a utilização do medicamento na sala de cateterismo, deve-se iniciar com a dose de $10 \mu \mathrm{g} / \mathrm{kg}$ administrada em bolus em 3min, seguida de 0,15 $\mu \mathrm{g} / \mathrm{kg} / \mathrm{min}$.

Com relação à eficácia, o abciximab e o tirofiban apresentam resultados comparáveis quando o tirofiban é empregado com bolus elevado, de $25 \mu \mathrm{g} / \mathrm{kg}$, porém o abciximab mostrou-se superior ao tirofiban quando este foi empregado com a dose de bolus habitual de $10 \mu \mathrm{g} / \mathrm{kg} .{ }^{161,162}$

Genericamente, os bloqueadores GP IIb/IIla tendem a aumentar o risco de hemorragia, e trombocitopenia é complicação rara, mas não negligível.

No contexto de pacientes com SCASSST submetidos à estratégia essencialmente "conservadora" (não realização rotineira de procedimentos intervencionistas precoces), os bloqueadores GP IIb/Ila tiveram seu uso fundamentado em estudos nos quais, além de heparinização, a ativação plaquetária era antagonizada, sistematicamente, apenas por AAS. ${ }^{163-170}$ Metanálise que incluiu $>30.000$ pacientes demonstrou redução de $9 \%$ no risco relativo de óbito ou infarto aos 30 dias de seguimento $(p=0,015),{ }^{169}$ sendo o benefício restrito aos pacientes de maior risco, fundamentalmente com troponina elevada e/ou com depressão do segmento ST e/ou submetidos à ICP (24\% aos 30 dias de seguimento).

Diversos estudos testaram o papel dos bloqueadores GP IIb/IIla no contexto de pacientes submetidos à ICP. ${ }^{171-}$ 177 Os resultados desses estudos são mais homogêneos, demonstrando invariavelmente benefício com o uso destes medicamentos, porém à custa de importante aumento na incidência de sangramento. Salienta-se que esses estudos foram desenvolvidos sem o uso rotineiro de tienopiridínico quando da chegada do paciente ao hospital. Metanálise que incluiu estudos que analisaram o papel dos bloqueadores Ilb/IIla em pacientes com SCA sem ou com supradesnível de ST demonstrou, além de diminuições significativas nas incidências de óbito ou (re)infarto ( $p<0,0001)$, diminuição de $21 \%$ (IC de 95\%: 0,64-0,67) no risco relativo de óbito aos 6 meses de seguimento. ${ }^{178}$

Em pacientes em uso de dupla antiagregação plaquetária com AAS + clopidogrel, a adição de abciximab foi comparada 


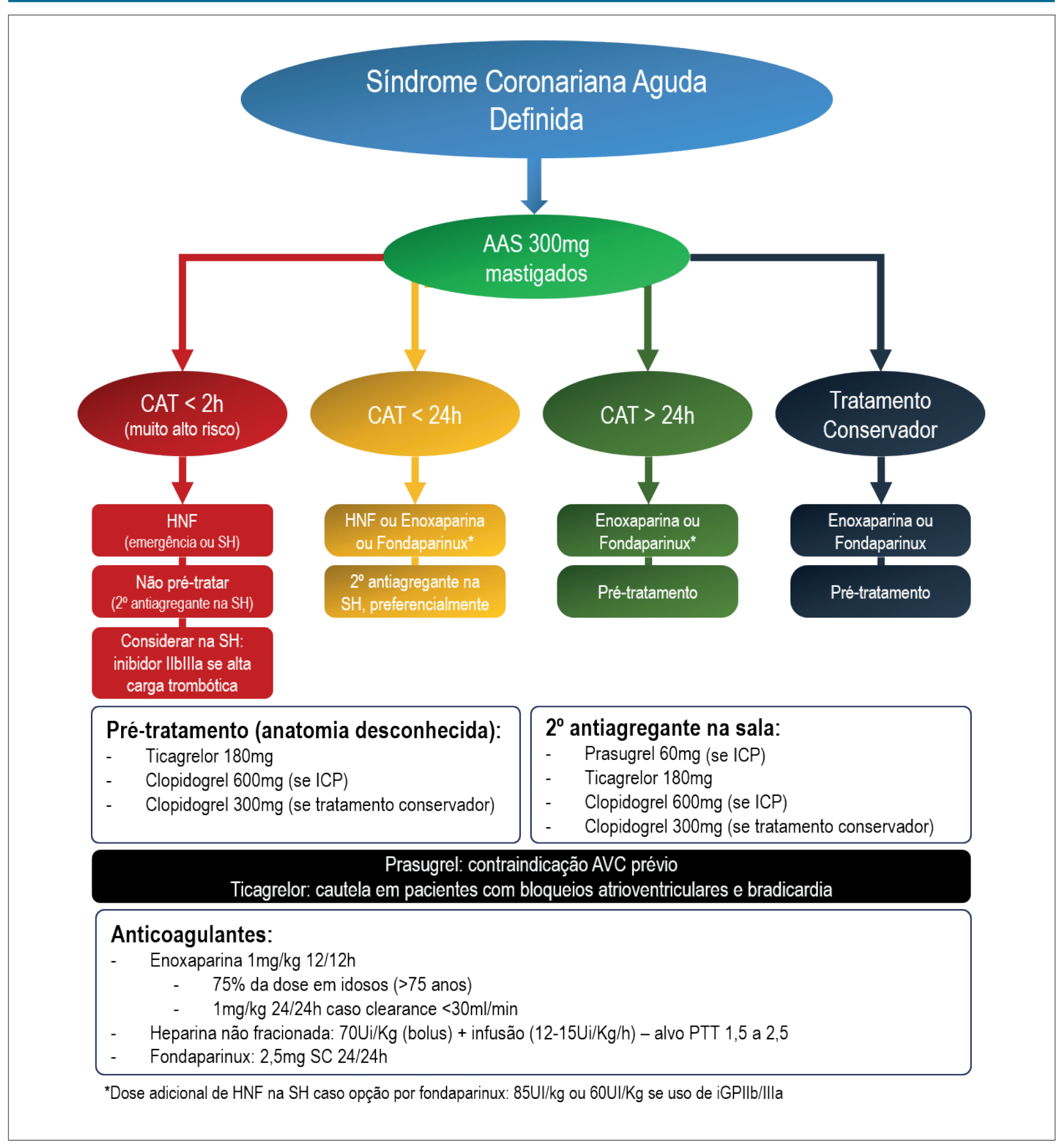

Figura 1.6 - Terapia antitrombótica inicial nas síndromes coronarianas agudas sem supradesnivel do segmento ST. CAT: cateterismo; HNF: heparina não fracionada; SH: sala de hemodinâmica

a placebo no estudo ISAR-REACT-2, que envolveu 2.022 pacientes com SCASSST. Nesse estudo, o emprego do abiciximab associou-se a menor incidência do desfecho composto de óbito, IAM e revascularização urgente (RR 0,75; IC 0,58-0,97; $p=0,03$ ), sem aumento significativo na incidência de desfechos hemorrágicos graves ou não graves. Vale ressaltar que o benefício do emprego do abciximab só foi encontrado nos indivíduos que apresentavam elevação de troponina. ${ }^{179}$
O estudo ACUITY-TIMING incluiu 9.207 pacientes com SCASSST (98\% com AAS e 65\% com bloqueador P2Y ${ }_{12}$ préangiografia) e avaliou qual o melhor momento para o emprego do bloqueador GP IIb/IIla, randomizando os pacientes para o emprego rotineiro de tirofiban ou eptifibatide quando da randomização do paciente ou de forma eletiva quando da realização de ICP, já na sala de hemodinâmica. Nesse estudo, o emprego rotineiro dos bloqueadores GP Ilb/IIla não fol capaz de reduzir desfechos isquêmicos, e aumentou de forma 
significativa a incidência de sangramento importante $(R R=$ $0,80, p<0,001) .{ }^{180}$

Resultados semelhantes foram encontrados no estudo EARLY-ACS, em que 9.492 pacientes com SCASSST foram randomizados para emprego de antiagregação plaquetária com epitifibatide iniciado antes do cateterismo versus uso somente em casos selecionados antes da angioplastia (a partir de aspectos angiográficos). Novamente, a estratégia de uso rotineiro do bloqueador da GP IIb/IIla não foi capaz de reduzir complicações isquêmicas; contudo, resultou em aumento na incidência de sangramentos e necessidade de transfusões. ${ }^{181}$

Com base no conjunto dessas evidências, o emprego dos bloqueadores da GP IIb/IIla, como um terceiro antiagregante plaquetário, deve ser reservado para pacientes que não apresentem alto risco hemorrágico e que tenham alto risco isquêmico/trombótico por critérios clínicos e angiográficos.

\subsubsection{Anticoagulantes}

A terapia anticoagulante deve ser administrada o mais rápido possível em todos os pacientes com SCASSST, visto que a utilização desses compostos reduz as incidências de IAM e óbito, sendo empregada poucas horas após o diagnóstico. ${ }^{182}$

A escolha e o momento do anticoagulante são determinados por estratégia de tratamento (abordagem invasiva ou conservadora), gravidade da apresentação clínica e particularidades de cada serviço. Nos pacientes com proposta de tratamento conservador inicial, recomenda-se o uso preferencial de enoxaparina ou fondaparinux. As doses preconizadas estão disponíveis na Tabela 1.9. A enoxaparina não deve ser administrada em pacientes com clearance de creatinina $<15 \mathrm{~mL} / \mathrm{min}$ e o fondaparinux com clearance de creatinina $<20 \mathrm{~mL} / \mathrm{min}$. Nos pacientes com clearance entre 15 e $30 \mathrm{~mL} / \mathrm{min}$ e nos obesos (IMC > 30kg/m² ou peso $>$ $100 \mathrm{~kg}$, o monitoramento do fator anti-Xa é recomendado nas diretrizes para o uso de enoxaparina, com a justificativa de minimizar o risco de doses excessivas e consequências hemorrágicas graves. ${ }^{183-185}$
Nos obesos mórbidos, estudos de farmacodinâmica e dados observacionais identificaram a frequente necessidade de ajuste de doses para alcance de meta terapêutica (IMC > $40 \mathrm{~kg} / \mathrm{m}^{2}$ ) guiada pela dosagem do fator anti-Xa, sugerindo utilidade do monitoramento quando disponível. ${ }^{186,187}$

No entanto, na avaliação de obesos com SCA no registro norte-americano CRUSADE, o uso de enoxaparina em dose padrão (1 mg/kg/peso) naqueles com peso $>150 \mathrm{~kg}$ esteve associado a um maior risco de sangramento em comparação com subgrupo entre 120 e $150 \mathrm{~kg}$. $(11,4 \%$ vs. 5,6\%, p < $0,001)$. Nesses pacientes, o uso alternativo de heparina não fracionada (HNF) é uma opção. ${ }^{188,189}$

Nos pacientes alocados para estratégia invasiva, existe a opção de uso da enoxaparina, fondaparinux e HNF. No subgrupo de pacientes de muito alto risco, com proposta de cateterismo imediato, apesar da semelhante eficácia da enoxaparina e HNF demostrada no estudo SINERGY, escolha da HNF iniciada na emergência ou, preferencialmente, na sala de cateterismo, pode reduzir a chance da ocorrência de transição de enoxaparina para HNF (cross over) e o conhecido maior risco hemorrágico dessa prática. ${ }^{190}$

Nos demais pacientes, a escolha deve ser orientada por características de risco isquêmico e hemorrágico do paciente e na experiência do serviço.

O uso preferencial da enoxaparina versus HNF é sugerido por dados de revisão sistemática dos ensaios randomizados em todo o espectro das SCA, sendo demonstrado que a enoxaparina é mais eficaz que a HNF em prevenir o desfecho combinado de morte por qualquer causa ou sangramento grave em pacientes com SCASSST submetidos à ICP. ${ }^{191-193}$

Fondaparinux é uma opção segura conforme proposta inicial de tratamento não invasivo, e, se posteriormente indicado cateterismo, está recomendado o uso de HNF durante o procedimento pelo risco de trombose de cateter. ${ }^{194,195}$

Paciente em uso prévio de anticoagulantes orais de ação direta, em vigência de SCA, deve ser manejado com cautela visando não incrementar o risco hemorrágico. Não existem evidências se a anticoagulação parenteral ou ICP podem ser

Tabela 1.9 - Dose dos anticoagulantes conforme função renal

\begin{tabular}{|c|c|c|c|}
\hline \multirow[t]{2}{*}{ Medicamento } & \multicolumn{3}{|c|}{ Recomendação } \\
\hline & $\begin{array}{l}\text { Função renal normal ou IRC estágio } \\
1-3(\text { clearance de creatinina } \geq \\
\left.30 \mathrm{~mL} / \mathrm{min} / 1,73 \mathrm{~m}^{2}\right)\end{array}$ & $\begin{array}{l}\text { IRC estágio } 4 \text { (clearance de } \\
\text { creatinina entre } 15 \text { e } 29 \mathrm{~mL} / \\
\left.\min / 1,73 \mathrm{~m}^{2}\right)\end{array}$ & $\begin{array}{l}\text { IRC estágio } 5 \text { (clearance de } \\
\left.\text { creatinina }<15 \mathrm{~mL} / \mathrm{min} / 1,73 \mathrm{~m}^{2}\right)\end{array}$ \\
\hline Heparina não fracionada (HNF) & $\begin{array}{c}\text { Antes da coronariografia: } 60 \text { a } \\
\text { 70Ul/kg bolus IV (máx. } 5.000 U I) \text { e } \\
\text { infusão (12 a 15UI/kg/h) com alvo } \\
\text { de PTT 1,5-2,5x controle } \\
\text { Durante coronariografia: } 70 \text { a } \\
\text { 100UI/kg IV em pacientes não } \\
\text { anticoagulados ou } 50 \text { a } 70 U l / k g ~ s e \\
\text { uso concomitante com inibidores } \\
\text { GPIllbllla }\end{array}$ & Sem ajuste de dose & Sem ajuste de dose \\
\hline Enoxaparina & $\begin{aligned} & 1 \mathrm{mg} / \mathrm{kg} \mathrm{SC} 12 / 12 \mathrm{~h} \\
> & 75 \text { anos: } 75 \% \text { da dose }\end{aligned}$ & $1 \mathrm{mg} / \mathrm{kg} 24 / 24 \mathrm{~h}$ & Não recomendado \\
\hline Fondaparinux & $2,5 \mathrm{mg} \mathrm{SC} 24 / 24 \mathrm{~h}$ & $\begin{array}{l}\text { Não recomendado se clearance } \\
\quad<20 \mathrm{~mL} / \mathrm{min} / 1,73 \mathrm{~m}^{2}\end{array}$ & Não recomendado \\
\hline
\end{tabular}


realizadas precocemente ou não. Em situações de urgência, a ICP deve ser realizada independentemente do momento de última dose do anticoagulante oral direto (DOAC). Nos pacientes com risco isquêmico mais baixo, o procedimento deve ser postergado. Em pacientes com função renal normal (clearance de creatinina $>50 \mathrm{~mL} / \mathrm{min}$ ), o efeito do DOAC é reduzido após $24 \mathrm{~h}$ da administração da última dose. Nos pacientes com disfunção renal, o prazo é de 48h. Assim, o paciente pode ser submetido à ICP com menor risco de sangramento. A anticoagulação parenteral está indicada em pacientes submetidos à ICP de urgência independentemente do horário da última dose de DOAC. ${ }^{196}$

Dentre as diversas estratégias no sentido de diminuir sangramento, a utilização da via radial quando da realização do estudo hemodinâmico/ICP é a que se mostrou mais efetiva, com evidências de redução de mortalidade nos pacientes com SCA. ${ }^{197}$

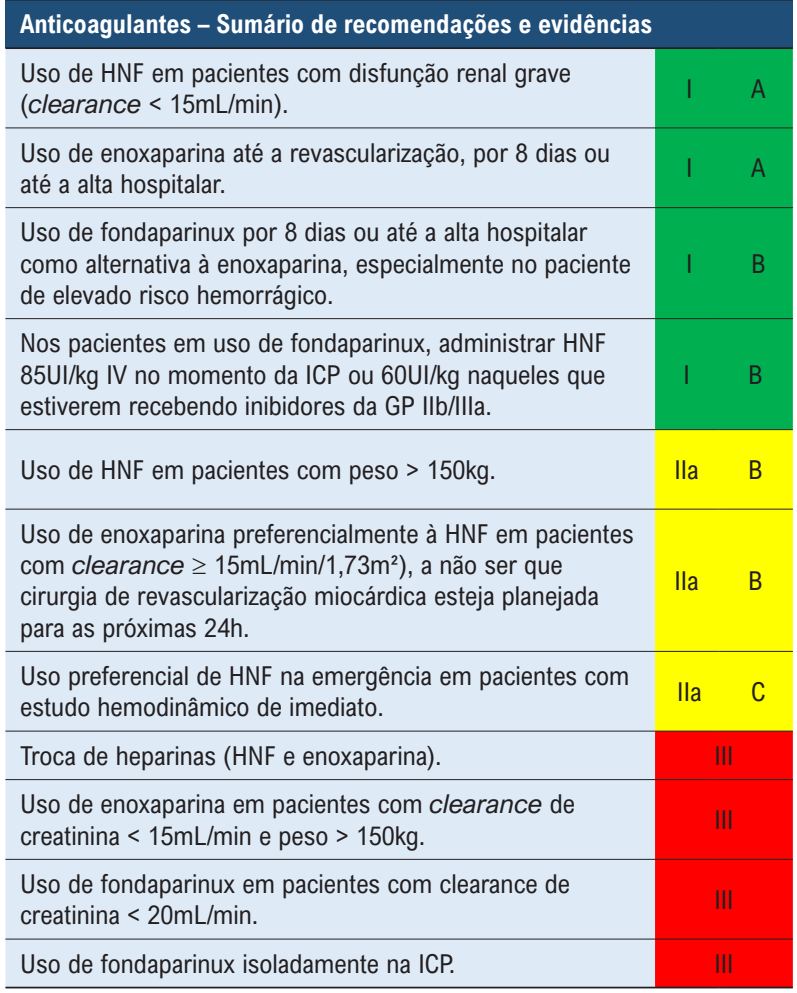

A escolha individualizada dos fármacos antiplaquetários e anticoagulantes e de evidências que fundamentam o melhor perfil de utilização na SCASSST será discutida de de forma detalhada na Parte 2 desta Diretriz.

\section{Parte 2 - Condutas Durante a Hospitalização}

\section{Internação e Alta da Unidade Coronária de Terapia Intensiva}

Pacientes com SCASSST de risco intermediário e alto devem permanecer hospitalizados em unidade coronariana (UCO), sempre que possível, até que a conduta definitiva seja implementada. Após a efetivação de uma ICP, o paciente deverá retornar à UCO e permanecer de 12 a $24 \mathrm{~h}$, se não houver complicações. As complicações após a ICP são a ocorrência de desfechos graves como oclusão do vaso-alvo, necessidade de cirurgia de revascularização de emergência ou nova ICP não programada, angina recorrente e óbito. Nos casos em que a decisão for de revascularização miocárdica cirúrgica, o paciente deverá permanecer em ambiente hospitalar (unidade semi-intensiva ou no quarto) até que a cirurgia seja realizada. Na indicação de tratamento medicamentoso intravenoso, também deverá permanecer na UCO até que o paciente esteja estável e em condições de ser liberado com medicações por via oral.

\section{Nitratos}

Não existem estudos clínicos controlados que tenham testado os efeitos dos nitratos em desfechos clínicos e mortalidade na angina instável (Al), embora seu uso seja universalmente aceito. Os estudos em Al que os avaliaram foram pequenos e do tipo observacional. ${ }^{128-130,198}$ Estudo de Borzak et al. avaliou, em 410 pacientes, os efeitos da medicação antianginosa pré e intra-hospitalar (antagonista do cálcio, betabloqueador e nitrato) nos desfechos clínicos, mortalidade e infarto do miocárdio não fatal. Não houve benefício na evolução. Análise multivariada também não mostrou haver correlação com a incidência de morte, infarto não fatal ou angina recorrente. ${ }^{199}$

\section{Nitratos na fase hospitalar - Sumário de recomendações e} evidências

Uso de nitrato em pacientes com risco intermediário e alto que persistem sintomáticos ou para controle da pressão arterial.

Uso associado a hipotensão arterial, infarto do ventrículo direito e uso dos inibidores da fosfodiesterase sildenafil e vardenafila dentro de $24 \mathrm{~h}$ e tadalafila dentro de $48 \mathrm{~h} \mathrm{com}$ a dose de $20 \mathrm{mg}$.

\section{Betabloqueadores Adrenérgicos}

A experiência clínica com os betabloqueadores é limitada a estudos clínicos controlados de pequeno porte e na extrapolação de resultados em pacientes com Al e síndrome coronariana com supradesnível de ST (SCACSST). Apesar da inexistência de estudos randomizados em larga escala, são amplamente utilizados, como os nitratos. Mais detalhes sobre esta classe são mencionados na Parte 1 desta Diretriz.

\section{Antagonistas dos canais de cálcio}

Os antagonistas dos canais de cálcio constituem um grupo heterogêneo de fármacos que têm em comum uma ação vasodilatadora coronária e cronotrópica negativa (para alguns agentes da classe). A ação anti-isquêmica se deve à redução do influxo de cálcio pela membrana celular, reduzindo a contratilidade miocárdica e o tônus vascular, a velocidade de condução atrioventricular (AV) e a atividade do nó sinusal. 
Esses agentes se diferenciam em relação à sua capacidade de produzir vasodilatação arterial, reduzir a contratilidade miocárdica e retardar a condução AV. Os efeitos benéficos nas SCASSST se devem a uma combinação das suas ações, diminuindo o consumo miocárdico de oxigênio, a pós-carga, a contratilidade miocárdica e a FC, além de aumentarem a oferta de oxigênio ao miocárdio, pela vasodilatação coronária que promovem. A vasodilatação coronária é semelhante e independe do agente usado. Os di-hidropiridínicos ocasionam maior vasodilatação arterial periférica e tendem a produzir taquicardia reflexa (mais evidente com a nifedipina de ação curta); o verapamil e o diltiazem tendem a causar bradicardia por reduzirem o cronotropismo e o dromotropismo, podendo levar a bloqueios atrioventriculares (mais evidente com verapamil). Em pacientes com comprometimento da função ventricular esquerda e/ou alterações na condução $\mathrm{AV}$, esses medicamentos devem geralmente ser evitados. Outro efeito colateral, mas que costuma aparecer apenas após uso prolongado desses agentes, é a retenção hídrica.

Para controlar os sintomas, ${ }^{200,201}$ os antagonistas dos canais de cálcio são tão eficientes quanto os betabloqueadores; entretanto, não reduzem a incidência de angina refratária, infarto ou óbito - ao contrário, parecem acentuar a incidência dessas complicações, como sugerido por metanálise. ${ }^{202}$ Até o momento, foram avaliados na Al apenas os representantes de primeira geração. Essas ações deletérias foram observadas com todas as classes de antagonistas do cálcio ${ }^{135,136,203}$ testados nessa indicação, mas inexistem dados conclusivos em relação aos di-hidropiridínicos. Por outro lado, em pacientes com IAMSSST, existem evidências de que o diltiazem e o verapamil (que não se associam à taquicardia reflexamente induzida) possam ter efeito protetor. $^{204,205}$ Esses agentes podem ser usados para controlar sintomas isquêmicos refratários em pacientes já em uso de nitratos e betabloqueadores em doses adequadas, ou em pacientes que não toleram o uso destes medicamentos (principalmente nos casos de contraindicação), ou, ainda, nos casos de angina variante (Prinzmetal). Contudo, não é recomendado o emprego rotineiro de antagonistas dos canais de cálcio, sendo contraindicado, em particular, o uso isolado da nifedipina de ação rápida.

Antagonistas dos canais de cálcio - Sumário de recomendações e evidências

Pacientes com risco intermediário e alto. Uso de derivado não di-hidropiridínico em casos de contraindicação aos betabloqueadores e sem disfunção ventricular esquerda.

Pacientes com angina variante (Prinzmetal).

Di-hidropiridínicos de ação prolongada na presença de isquemia refratária para pacientes em uso adequado de nitratos e betabloqueadores e sem disfunção ventricular.

Derivados di-hidropiridínicos de início de ação rápida para pacientes de alto risco, já em uso adequado de betabloqueadores.

Derivados di-hidropiridínicos de início de ação rápida em pacientes sem uso adequado de betabloqueadores.

\section{Antiplaquetários}

\section{1. Ácido Acetilsalicílico}

O AAS é o antiplaquetário de excelência, devendo ser sempre prescrito, exceto em casos de intolerância ou eventos adversos. ${ }^{206-209}$

Sua importância no tratamento das SCASSST está embasada, fundamentalmente, em estudos publicados nos anos 1980, ${ }^{210,211}$ que, em sua maioria, dispõem de um número relativamente pequeno de pacientes, com baixa incidência de desfechos, mas que, de forma geral, evidenciaram nítido impacto tanto na redução de IAM não fatal quanto na mortalidade nos curto e médio prazos.

A posologia preconizada do AAS é de 150 a 300mg para a dose de ataque, seguida por 75 a 100mg ao dia para a dose de manutenção. O estudo CURRENT OASIS-7 testou, em um de seus braços, a hipótese do uso de dose alta de manutenção do AAS em pacientes com SCA (cerca de $70 \%$ de pacientes sem supra de ST). Não houve diferença entre a dose de manutenção habitual (75 a 100mg ao dia) e a dose elevada (300 a 325mg/dia) na ocorrência de eventos cardiovasculares graves (mortalidade, IAM não fatal ou AVC, $p=0,61$ ). Também não houve diferença em relação à ocorrência de sangramentos graves $(p=0,90) \cdot{ }^{212}$

\subsection{Inibidores do Receptor $\mathrm{P}^{2} \mathrm{Y}_{12}\left(\mathrm{iP}_{2} \mathrm{Y}_{12}\right)$}

Os derivados tienopiridínicos (clopidogrel e prasugrel) são fármacos antagonistas da ativação plaquetária mediada pelo difosfato de adenosina (ADP), que agem bloqueando de maneira irreversível o receptor $\mathrm{P}_{2} \mathrm{Y}_{12}$ plaquetário; $\mathrm{e}$ também reduzem o nível de fibrinogênio circulante e bloqueiam parcialmente os receptores de glicoproteína Ilb/ Illa, dificultando sua ligação ao fibrinogênio e ao fator de von Willebrand. Em conjunto com o ticagrelor (derivado da ciclopentiltriazolopirimidina - "não tienopiridínico"), que é um inibidor reversível da agregação plaquetária induzida por ADP, estes são, atualmente, os três iP2 $\mathrm{Y}_{12}$ plaquetários disponíveis para uso no Brasil (preferencialmente em associação ao AAS).

\subsubsection{Clopidogrel}

No contexto de SCASSST, o primeiro grande estudo clínico - CURE (Clopidogrel in Unstable angina to prevent Recurrent Events) - testou o papel do clopidogrel em adição ao AAS em mais de 12 mil pacientes, sendo acompanhados por 3 a 12 meses (média de 9 meses). Ao final do seguimento, houve redução de 20\% (RR 0,80; IC 95\% 0,72-0,89; p = 0,00005) na incidência dos eventos (óbito cardiovascular, IAM ou AVC) a favor do grupo clopidogrel + AAS em relação ao grupo AAS + placebo, à custa de um aumento na incidência de sangramentos no grupo clopidogrel + AAS (RR 1,38, $p=0,001) .{ }^{213}$ Os efeitos benéficos da dupla antiagregação (DAP) ocorreram tanto em pacientes de alto risco como naqueles de risco intermediário ou baixo. Outras análises do estudo CURE demonstraram que a DAP também teria benefícios tanto nos pacientes submetidos à revascularização miocárdica cirúrgica como nos submetidos ao tratamento medicamentoso isolado. ${ }^{214}$ 
Quando os pacientes com SCASSST são tratados com ICP, o duplo bloqueio da agregação plaquetária torna-se imperativo, tanto com base em estudo que focalizou primariamente o contexto da ICP ${ }^{215}$ como também em trabalhos que abordaram as SCA per se. Nesta última condição, se inserem o subestudo do CURE (PCI-CURE), prospectivamente desenvolvido, ${ }^{151}$ e o estudo CREDO (Center for Research on Education Outcomes). ${ }^{156}$

Por conta das importantes limitações do clopidogrel, relacionadas ao seu metabolismo e interações medicamentosas, o fármaco foi testado também com dose dobrada no estudo CURRENT OASIS-7. ${ }^{216}$ Neste estudo, 25.086 pacientes com SCA (71\% sem supra de ST) e programação de estratificação invasiva foram randomizados para receber dose em dobro do clopidogrel (600mg de ataque seguido por 150mg ao dia por 6 dias e $75 \mathrm{mg}$ ao dia após a primeira semana) ou a posologia habitual (300mg de ataque seguidos por $75 \mathrm{mg}$ ao dia). Ao final de 30 dias, não houve diferença significativa na ocorrência do desfecho primário composto de óbito cardiovascular, IAM não fatal ou AVC (HR 0,94; 4,2\% vs. $4,4 \%, p=0,30)$. No entanto, a dose dobrada de clopidogrel foi associada a aumento significativo na incidência de sangramentos maiores (HR 1,24; 2,5\% vs. 2\%, $p=0,01$ ). Em análise pré-especificada, ${ }^{212}$ considerando-se apenas os pacientes submetidos à ICP ( $\mathrm{n}=17.263)$, demonstrou-se redução de $14 \%$ na incidência do desfecho composto primário do estudo aos 30 dias de evolução (HR 0,86; 3,9\% vs. 4,5\%, $p=0,039$, número necessário para tratar $[\mathrm{NNT}]=167$ ), além de redução significativa de trombose definitivamente comprovada de stents (HR 0,54; 0,7\% vs. 1,3\%, p=0,0001), porém à custa de maior incidência de sangramentos graves (HR 1,$41 ; 1,6 \%$ vs. $1,1 \%, p=0,009, \mathrm{NNH}=200$ ). Considerando o NNT elevado, recomenda-se a avaliação cautelosa do risco individual prévio de sangramento para guiar uma decisão de dose neste contexto.

A "má resposta" (ou "resistência" para alguns) ao clopidogrel, expressão utilizada para caracterizar os pacientes que não atingem o nível de inibição plaquetária esperado, é identificada por meio de ensaios laboratoriais in vitro que quantificam a intensidade da agregabilidade plaquetária mediada pela via do ADP. Dados consistentes associam a má resposta ao clopidogrel à maior incidência de eventos trombóticos, principalmente em pacientes submetidos à ICP com implante de stent. ${ }^{217-219}$ Atualmente, três principais fatores estão relacionados com a má resposta ao clopidogrel: 1) variabilidade genética, caracterizada por polimorfismos associados às enzimas do citocromo P450 envolvidas no processo de metabolização hepática, notadamente a CYP2C19;20 2) alteração no processo de absorção intestinal do medicamento relacionado com a expressão da glicoproteína $\mathrm{P}$ nas células epiteliais intestinais; ${ }^{221} 3$ ) utilização concomitante de outros fármacos que podem interferir no metabolismo hepático mediado por enzimas do citocromo P450, como, por exemplo, o cetoconazol (que inibe o citocromo P450 e reduz a ação do clopidogrel) e a rifampicina (que estimula o citocromo P450 e acentua a ação do clopidogrel).

A associação dos inibidores de bomba de prótons (IBP) ao clopidogrel merece destaque. Diversos estudos in vitro indicam a ocorrência de redução na inibição plaquetária induzida por clopidogrel quando da associação deste ao IBP, e sugerem que isso seria especialmente frequente com o omeprazol. ${ }^{222-225}$ Entretanto, os estudos que a analisaram com a ocorrência de eventos isquêmicos mostraram resultados conflitantes ${ }^{226-228}$ e encontraram associação entre aumento de eventos isquêmicos e uso concomitante de clopidogrel + IBP. Já uma subanálise do estudo TRITON (Optimizing Platelet Inhibition with Prasugrel Thrombolysis in Miocardial Infarction) não encontrou qualquer associação ${ }^{229} \mathrm{e}$, interessantemente, subanálise similar do estudo PLATO (Platelet Inhibition and Patient Outcomes) ${ }^{230}$ encontrou aumento na incidência de eventos isquêmicos tanto no grupo clopidogrel quanto no grupo ticagrelor, quando utilizados em conjunto com IBP. Mais recentemente, análise do estudo TRILOGY demonstrou que, entre pacientes com SCA manejados sem revascularização do miocárdio, o uso de IBP não resultou em resposta antiplaquetária diferente entre prasugrel versus clopidogrel, mas foi associado com menor incidência de infarto no grupo prasugrel. ${ }^{228}$

O único estudo clínico randomizado que testou diretamente tal hipótese, o COGENT (Clopidogrel and the Optimization of Gastrointestinal Events), ${ }^{231}$ avaliou 3.761 pacientes com indicação de dupla terapia antiagregante por pelo menos 12 meses (um grupo recebendo clopidogrel e omeprazol versus um grupo recebendo clopidogrel e placebo). Entretanto, tal estudo foi interrompido precocemente por questões de financiamento e não teve o seguimento previsto dos pacientes (consequentemente, obteve-se número bastante reduzido de eventos), o que comprometeu de forma importante seu poder estatístico. De qualquer modo, até a finalização do número de pacientes randomizados no estudo, não foi verificada diferença na incidência de eventos isquêmicos (4,9\% no grupo clopidogrel + omeprazol vs. 5,7\% no grupo clopidogrel + placebo, $p=0,96)$. Como esperado, demonstrou-se maior incidência de sangramentos digestivos no grupo placebo (2,9\% vs. $1,1 \%$, com $p<0,001)$. Assim, um contingente apreciável de médicos e pesquisadores sugere que, em princípio, o uso de IBP (principalmente omeprazol), em conjunto com o clopidogrel, deva ser evitado. Os pacientes com maior risco de sangramento gastrintestinal (antecedente de hemorragia digestiva, úlcera péptica diagnosticada, infecção por $H$. pylori, idade $\geq 65$ anos, uso concomitante de anticoagulantes ou esteroides) podem empiricamente receber bloqueadores dos receptores $\mathrm{H} 2$ (p. ex., ranitidina). Caso seja necessário o uso de um IBP, sugere-se o pantoprazol, cujo metabolismo via CYP P450 é menos pronunciado.

Portanto, o uso do clopidogrel está indicado para as SCASSST de risco moderado e alto para novos eventos isquêmicos. A administração consiste em uma dose de ataque de 300mg e manutenção com $75 \mathrm{mg}$ ao dia. Em pacientes submetidos à ICP e com baixo risco de sangramento, podese considerar a dose de ataque de $600 \mathrm{mg}$, com manutenção de 150mg nos primeiros 7 dias e $75 \mathrm{mg}$ ao dia após esse prazo. O tempo de uso do medicamento deve ser de 12 meses, independentemente do tratamento recebido (clínico, percutâneo ou cirúrgico). Quando houver indicação de revascularização cirúrgica eletiva, o clopidogrel deverá ser 
suspenso pelo menos 5 dias antes do procedimento devido ao risco de sangramento. Não há demonstração de que o ajuste da terapia antiplaquetária guiada por métodos de avaliação da agregabilidade plaquetária seja superior à terapia antiplaquetária padrão, portanto, essa estratégia não deve ser utilizada rotineiramente, sendo reservada para situações especiais. ${ }^{232-233}$

Por conta das limitações do clopidogrel, novos fármacos foram desenvolvidos no sentido de se obterem bloqueios de agregação plaquetária mais rápidos, mais efetivos e mais consistentes.

\subsubsection{Prasugrel}

O prasugrel é um tienopiridínico de geração mais recente e que cumpre tais objetivos. Isso ocorre basicamente porque esse medicamento tem um metabolismo mais simples em relação ao clopidogrel, com apenas uma fase de metabolização hepática. Como consequência, seu metabólito ativo atinge pico plasmático em apenas 30min, além de apresentar menor interação com medicações metabolizadas pelo citocromo P450. ${ }^{234}$

O estudo TRITON incluiu 13.608 pacientes com SCA, sem uso recente de tienopiridínico, anatomia coronariana conhecida (nos pacientes com SCASSST) e ICP planejada. Desses pacientes, $74 \%$ se apresentaram com SCASSST de risco moderado ou alto para complicações isquêmicas/trombóticas. Foram excluídos indivíduos plaquetopênicos, anêmicos ou com risco alto de sangramento. Os pacientes foram randomizados para clopidogrel (ataque de 300mg e manutenção de $75 \mathrm{mg}$ ao dia) ou prasugrel (60mg de ataque e manutenção de 10mg ao dia) após realização da coronariografia e indicação de ICP, sendo que o seguimento médio da população foi de 14,5 meses. O desfecho primário de eficácia do estudo, composto de óbito cardiovascular, (re)infarto e AVC, apresentou redução de 19\% no grupo prasugrel (RR 0,81; 12,1\% vs. 9,9\%, p < 0,001), em comparação com o grupo tratado com clopidogrel. Com relação aos desfechos secundários de eficácia, o grupo tratado com prasugrel apresentou 24\% de redução de IAM (RR 0,76; 9,5\% vs. $7,3 \%, p<0,001)$, 34\% de diminuição da necessidade de revascularização urgente (RR 0,76; 3,7\% vs. 2,5\%, p < 0,001) e $52 \%$ de redução de trombose de stent (RR 0,48; $2,4 \%$ vs. $1,1 \%, p<0,001)$.

A análise dos desfechos de segurança do TRITON revelou, no grupo prasugrel, aumento de $32 \%$ na incidência de sangramento maior pelo critério TIMI não relacionado com a cirurgia de revascularização (RR 1,32; 1,8\% vs. 2,4\%, p = 0,03), $52 \%$ de aumento de sangramento ameaçador à vida (RR 1,52; $0,9 \%$ vs. $1,4 \%, p=0,01$ ), além de um aumento significativo de sangramentos fatais (RR 4,$1 ; 0,1 \%$ vs. $0,4 \%, p<0,002$ ).

O benefício líquido total do estudo mostrou que o prasugrel foi inferior ao clopidogrel em indivíduos com passado de AVC ou AIT prévio (RR 1,54, p =0,04), foi neutro em indivíduos com $>75$ anos de idade ou peso $<60 \mathrm{~kg}$, e superior em indivíduos sem passado de AVC ou AIT, com $<75$ anos de idade e peso $>60 \mathrm{~kg}($ RR 0,8; $\mathrm{p}<0,001) \cdot{ }^{154}$

Aplicando a nova classificação de IAM ao material científico do TRITON-TIMI, Morrow et al. demonstraram que o prasugrel se mostrou mais eficaz que o clopidogrel na redução de diversos tipos de infarto. ${ }^{235}$
Subanálises do estudo evidenciaram resultados favoráveis ao prasugrel em pacientes diabéticos ${ }^{236}$ e também naqueles submetidos à cirurgia de revascularização miocárdica. ${ }^{237}$

O prasugrel também foi avaliado no estudo TRILOGY (TaRgeted platelet Inhibition to cLarify the Optimal strateGy), que incluiu 9.326 pacientes com SCASSST e um fator de risco adicional (idade mínima de 60 anos, diabetes melito, antecedente de IAM, ICP ou revascularização miocárdica), submetidos ou não à coronariografia, mas com indicação específica de tratamento clínico (sem revascularização miocárdica após o evento índice para entrada no estudo). Os pacientes foram randomizados para clopidogrel (300mg de ataque com $75 \mathrm{mg}$ ao dia de manutenção) ou prasugrel (30mg de ataque com manutenção de $10 \mathrm{mg}$ ao dia se idade $<75$ anos, ou $5 \mathrm{mg}$ ao dia se idade $\geq 75$ anos ou peso $<60 \mathrm{~kg}$ ), tendo sido acompanhados em média por 17 meses; o tempo médio de uso da medicação foi de 15 meses. ${ }^{238}$

Com relação ao desfecho primário de eficácia, composto de morte cardiovascular, IAM ou AVC, não houve diferença significativa entre os grupos prasugrel e clopidogrel $(p=0,21)$. Tampouco foram detectadas diferenças significativas entre os grupos no que se refere aos desfechos principais de segurança (sangramento grave ou ameaçador à vida pelo critério GUSTO ou sangramento grave pelo critério TIMI).

Finalmente, no TRILOGY, aproximadamente um terço dos pacientes foi submetido a análises de agregabilidade plaquetária e, apesar de um claro bloqueio mais efetivo da agregabilidade plaquetária no grupo prasugrel, não se conseguiu demonstrar significativa associação entre reatividade plaquetária e ocorrência de eventos isquêmicos/ trombóticos. ${ }^{238}$

Assim como para o clopidogrel, o prasugrel, caso indicado, deve ser em princípio continuado por 12 meses. Salienta-se que a necessidade de suspensão do prasugrel é de pelo menos 7 dias antes de revascularização miocárdica eletiva.

\subsubsection{Ticagrelor}

O ticagrelor também é inibidor da agregação plaquetária induzida por ADP, via bloqueio do receptor $\mathrm{P}_{2} \mathrm{Y}_{12}$, porém não pertence à classe dos tienopiridínicos. O ticagrelor é uma ciclopentiltriazolopirimidina (CPTP) com meia-vida de cerca de $12 \mathrm{~h}$ e que, ao contrário dos tienopiridínicos, exerce bloqueio reversível dos receptores $\mathrm{P}_{2} \mathrm{Y}_{12}$ e não depende da metabolização hepática para o início de sua ação. Com tais características, o ticagrelor exerce efeito antiagregante plaquetário mais intenso, rápido e consistente em relação ao clopidogrel. ${ }^{239}$

No estudo PLATO, ${ }^{152}$ cerca de 18 mil pacientes admitidos por SCA de risco intermediário e alto com até $24 \mathrm{~h}$ do início dos sintomas foram randomizados para receber ticagrelor $180 \mathrm{mg}$ de ataque seguidos por $90 \mathrm{mg}$ a cada $12 \mathrm{~h}$ de manutenção) ou clopidogrel (300mg de ataque seguidos por $75 \mathrm{mg}$ ao dia de manutenção). Os pacientes que foram submetidos à ICP receberam dose adicional de $90 \mathrm{mg}$ de ticagrelor e poderiam, a critério do investigador, receber dose adicional de 300mg de clopidogrel. Todos os pacientes, exceto se houvesse contraindicação, receberam AAS, e a medicação do estudo foi mantida durante 12 meses, independentemente da estratégia 
de tratamento empregada (revascularização percutânea, cirúrgica ou tratamento clínico exclusivo). Nos pacientes com indicação de CRVM, o clopidogrel deveria ser suspenso 5 dias antes do procedimento, e o ticagrelor, em um intervalo de 24 a $72 \mathrm{~h}$ antes da cirurgia. O desfecho primário de eficácia do estudo foi composto de óbito por causas vasculares, (IAM não fatal ou AVC em 12 meses; o desfecho primário de segurança foi a ocorrência de sangramento grave pelo critério do próprio estudo. Do número total de pacientes incluídos, a prevalência de SCASSST foi de aproximadamente $60 \%$, sendo cerca de $43 \%$ dos pacientes com IAM sem supradesnível de ST e 17\% daqueles com Al de risco intermediário e alto. A mediana de idade dos pacientes incluídos foi de 62 anos e 15\% tinham mais de 75 anos. Aproximadamente $64 \%$ dos pacientes foram submetidos à ICP e 10\%, à CRVM, permanecendo os demais em tratamento clínico exclusivo. Ao final do estudo, o uso do ticagrelor levou à redução significativa de $16 \%$ na incidência do desfecho primário composto de eficácia (RR 0,84; 9,8\% vs. $11,7 \%, p<0,001)$. Nas análises isoladas dos componentes do desfecho composto (metas secundárias principais), evidenciaram-se reduções significativas nas incidências de IAM (RR 0,84; 5,8\% vs. 6,9\%, p=0,005) e óbitos por causas vasculares (RR 0,$79 ; 4,0 \%$ vs. 5,1\%, p < 0,001), não havendo diferenças significativas em relação à incidência de AVC ( $p$ $=0,22$ ). Em relação ao desfecho primário de segurança, não se observou diferença significativa na incidência de sangramento grave avaliado tanto pelo critério elaborado pelo próprio estudo ( $\mathrm{HR}=1,04 ; \mathrm{p}=0,43$ ) quanto pelo critério TIMI $(H R=1,03, p=0,57)$. Apesar de não haver diferença na incidência de sangramento fatal $(H R=0,87 ; p=0,66)$ ou na necessidade de transfusões ( $H R=1 ; p=0,96)$, o uso de ticagrelor levou a um aumento absoluto discreto, mas significativo, na incidência de sangramento intracraniano fatal $(0,1$ vs. 0,$01 ; p=0,02)$ e na incidência de sangramento maior não relacionado à $\operatorname{CRVM}(4,5 \%$ vs. $3,8 \%, p=0,03)$. Outros efeitos adversos apresentaram maior incidência no grupo ticagrelor. Houve aumento significativo na ocorrência de dispneia (RR 1,84; 13,8\% vs. 7,8\%, p < 0,001), que, em geral, foi transitória e levou à suspensão do medicamento em menos de $1 \%$ dos pacientes. Existe controvérsia se este efeito colateral seria explicado por aumento nos níveis plasmáticos de adenosina ou não. ${ }^{240-242}$ Também houve aumento na incidência de bradicardia transitória, com elevação significativa na ocorrência de pausas ventriculares $>3$ segundos nos primeiros 7 dias de uso da medicação (5,8\% vs. $3,6 \%, p=0,01)$, mas que perde tal significância após 30 dias de utilização do medicamento (2,1\% vs. 1,7\%, $p=0,52) \cdot{ }^{243}$ Não houve diferença entre os grupos, no global da população estudada, quanto à necessidade de implante de MP, ocorrência de síncope ou bloqueio cardíaco. ${ }^{243}$ Houve elevação dos níveis de creatinina (10\% vs. 8\%) e de ácido úrico (14\% vs. $7 \%$ ), que foram revertidos 1 mês após o final do tratamento. ${ }^{244}$

O banco de dados o PLATO propiciou a publicação de diversas análises de subgrupos pré-especificados, como, por exemplo: diabéticos ${ }^{245}$ doença renal crônica, ${ }^{246}$ AVC prévio, ${ }^{247}$ utilização de IBP, ${ }^{230}$ estratégia invasiva ou conservadora inicial, ${ }^{248}$ revascularização miocárdica cirúrgica, ${ }^{249}$ recorrência de eventos, ${ }^{250}$ custo-efetividade, ${ }^{251}$ entre outros. De forma resumida, sugere-se que o ticagrelor seja custo-efetivo e que os resultados das subanálises realizadas ficaram muito próximos aos demonstrados na publicação original, com toda a população incluída. O medicamento deve ser suspenso pelo menos 3 dias antes de um procedimento cirúrgico de revascularização miocárdica eletiva.

Mais recentemente, foi publicado estudo (ISAR-REACT 5) multicêntrico, não cego, que comparou o uso de ticagrelor (180mg na chegada ao hospital seguido de 90mg 2 vezes/dia) versus prasugrel (60mg na sala de hemodinâmica seguido de $10 \mathrm{mg}$ ou $5 \mathrm{mg}$ nos $\geq 75$ anos ou $<60 \mathrm{~kg}$ ) em 4.018 pacientes com SCA que seriam submetidos a tratamento invasivo precoce $(41,1 \%$ de IAM com supra e 58,9\% de SCASSST). O desfecho primário, composto de morte, IAM ou AVC em 1 ano de seguimento, ocorreu em 184 pacientes (9,3\%) no grupo ticagrelor e em 137 pacientes $(6,9 \%)$ no grupo prasugrel (HR 1,36; IC 95\%, 1,09 a 1,70; $p=0,006)$; o sangramento maior (desfecho de segurança) foi semelhante em ambos os grupos $(5,4 \%$ no grupo ticagrelor vs. $4,8 \%$ no grupo prasugrel - HR, 1,12; 95\% Cl, 0,83 a 1,51; p =0,46). Ressaltam-se algumas limitações no estudo: estudo foi aberto (não cego); $90 \%$ dos contatos com os pacientes foram realizados de forma telefônica (83\%) ou por carta (7\%); ambas as medicações não foram dispensadas pelo estudo (paciente precisava adquiri-las por conta própria); a estratificação invasiva na SCASSST foi feita de forma bastante rápida, o que não é nossa prática; ocorrência do desfecho primário (6,9\%) no grupo prasugrel foi mais baixa que no estudo TRITON TIMI 38 (9,9\%) e bem abaixo do que se imaginava neste grupo (12,9\%) durante o cálculo amostral. ${ }^{252}$

\subsection{Terapia antiplaquetária ajustada por testes de agregação plaquetária ou por testes genéticos}

Três estudos clínicos randomizados buscaram demonstrar o impacto clínico de terapias antiplaquetárias diferenciadas em pacientes com má resposta ao clopidogrel. O estudo GRAVITAS (Gauging Responsiveness With A Verify Now AssayImpact On Thrombosis And Safety) ${ }^{232}$ avaliou se uma dose elevada de clopidogrel (600mg de ataque seguidos por 150mg/ dia de manutenção) seria superior à terapia padrão (75mg/ dia sem dose de ataque adicional) na prevenção de eventos cardiovasculares após a ICP e implante de stent farmacológico. Os pacientes a serem randomizados foram selecionados de acordo com a presença de elevada reatividade plaquetária com o uso do clopidogrel, avaliada pelo método laboratorial do VerifyNow ${ }^{\circledR} \mathrm{P}_{2} \mathrm{Y}_{12}$; dos 5.429 pacientes avaliados inicialmente, 2.214 (40,8\%) apresentaram hiper-reatividade plaquetária (pela via ADP) e foram incluídos no estudo (40\% com diagnóstico de SCASSST). Apesar de uma redução absoluta de $22 \%$ no número de pacientes que mantinham hiper-reatividade plaquetária $\left(P 2 Y_{12}\right.$ reactionunit $[\mathrm{PRU}] \geq$ 230), o tratamento com dose alta de clopidogrel não foi capaz de reduzir o risco de óbito por causas cardiovasculares, IAM não fatal ou trombose de stent em 6 meses de evolução após a ICP (HR 1,01, IC 95\% 0,58 a 1,76, p = 0,97). Tampouco houve aumento de hemorragias graves na comparação entre os grupos. No estudo ARCTIC, ${ }^{233} 2.440$ pacientes com programação de ICP e implante de stent farmacológico (27\% com SCASSST) foram randomizados para duas distintas 
estratégias de antiagregação plaquetária: uma convencional, em que a administração de AAS e iP2Y $\mathrm{Y}_{12}$ utilizava a posologias habitualmente empregadas, e outra na qual as doses eram ajustadas de acordo com os resultados da agregabilidade plaquetária obtidos pelo método laboratorial do VerifyNow ${ }^{\circledR}$ Aspirinand $\mathrm{P}_{2} \mathrm{Y}_{12}$. A randomização, a avaliação da reatividade plaquetária e a intervenção, quando indicadas ao grupo de terapia monitorada, foram realizadas antes do procedimento programado para implante do stent. A incidência de hiperreatividade plaquetária nos pacientes em uso de clopidogrel foi de $34,5 \%$ e a resistência ao AAS foi observada em $7,6 \%$ dos mesmos. No grupo de terapia monitorada, nova avaliação da função plaquetária foi realizada 2 e 4 semanas após o implante do stent, e novos ajustes terapêuticos foram realizados quando necessário. Nessa nova avaliação, houve redução significativa de aproximadamente $50 \%$ ( $15,6 \%$ vs. $34,5 \%$ no momento da ICP; $p<0,001$ ) no número de pacientes com hiper-reatividade plaquetária definida como valor de PRU $\geq 235$ ou $15 \%$ ou menos de inibição plaquetária em comparação com valores de controle. No entanto, o desfecho primário composto de óbito por qualquer causa, IAM, AVC, AIT, revascularização coronária de urgência ou trombose de stent em até 1 ano foi de $34,6 \%$ nos pacientes que receberam terapia monitorada e $31,1 \%$ naqueles tratados de forma convencional (HR 1,13; IC $95 \%$ 0,98 a 1,29; $p=0,10)$. A taxa de eventos hemorrágicos graves também não diferiu significativamente entre os grupos. No estudo ANTARTIC, pacientes idosos (idade $\geq 75$ anos) submetidos à ICP após SCA foram randomizados para uma estratégia guiada por testes de agregação plaquetária versus estratégia convencional. Todos os pacientes eram inicialmente tratados com prasugrel $5 \mathrm{mg}$, e, no grupo de terapia guiada, a dose poderia ser incrementada para $10 \mathrm{mg}$ em caso de inibição plaquetária inadequada (definido como PRU $\geq$ 208) ou desescalonada para clopidogrel $75 \mathrm{mg}$ em caso de inibição plaquetária excessiva (definido como PRU $\leq 85$ ). O desfecho foi composto de morte cardiovascular, AVC, infarto, revascularização urgente, trombose de stent ou sangramento clinicamente relevante em 12 meses (HR 1,00, IC 95\% 0,78 a 1,29). ${ }^{253}$ Desse modo, a terapêutica antiplaquetária guiada por testes de agregabilidade só deve ser utilizada em casos selecionados.

Em relação aos testes genéticos, o estudo POPULAR Genetics testou a terapia guiada pela avaliação do polimorfismo do citocromo 2C19. Neste estudo, 2.488 pacientes com SCA foram randomizados para uma estratégia padrão com uso de ticagrelor ou prasugrel versus uma estratégia personalizada, em que os pacientes não portadores de polimorfismos, levando à perda de função do 2C19 (e, portanto, com metabolização normal do clopidogrel), recebiam clopidogrel em vez dos outros dois antiplaquetários. A estratégia personalizada foi não inferior à convencional para o desfecho composto de morte, infarto, AVC, trombose de stent ou sangramento maior, ao mesmo tempo em que reduziu sangramento maior (HR 0,78; IC 95\% 0,61 a 0,98; $p=0,04) .{ }^{254}$ Já o estudo TAILOR $\mathrm{PCI}$ incluiu pacientes submetidos à ICP (aproximadamente $80 \%$ com SCA e $60 \%$ apresentando SCASSST) e avaliou a estratégia de terapia guiada por genotipagem. Tal estratégia não foi superior ao tratamento convencional na redução do desfecho composto de morte cardiovascular, infarto, AVC, trombose de stent ou isquemia grave recorrente (HR 0,66; IC 95\% 0,43-1,02; $p=0,06)$ em pacientes carreadores do alelo que leva à perda de função do 2C19 (aproximadamente $35 \%$ dos pacientes incluídos). ${ }^{255}$ Novos estudos, inclusive com análise de custo-efetividade, são necessários para confirmar tais resultados antes de uma decisão definitiva quanto ao rotineiro uso da genotipagem.

\section{Antiplaquetários - Sumário de recomendações e evidências}

AAS (162-300mg em dose de ataque, com dose de manutenção de $81-100 \mathrm{mg} / \mathrm{dia}$ ) em todos os pacientes, salvo contraindicações, independentemente da estratégia de tratamento, continuando por tempo indeterminado.

Tienopiridínicos em pacientes com intolerância ao AAS

Uso de terapia antiplaquetária dupla por 12 meses após 0 evento agudo (independentemente da estratégia inicial clínico, percutâneo ou cirúrgico), salvo contraindicações.

Clopidogrel (300mg em dose de ataque, com manutenção de $75 \mathrm{mg} / \mathrm{dia}$ ) em adição ao AAS, em pacientes portadores de SCASSST de risco intermediário ou alto por 12 meses, em pacientes com risco muito alto de sangramento, em uso concomitante de anticoagulantes orais ou quando prasugrel ou ticagrelor não estiverem disponíveis.

Ticagrelor (180mg de ataque seguidos por 90mg 2 vezes/ dia) em pacientes portadores de SCASSST de risco intermediário ou alto, independente da estratégia de tratamento posterior (clínico, cirúrgico ou percutâneo), preferencialmente ao clopidogrel, por 12 meses.

Prasugrel $60 \mathrm{mg}$ de ataque seguidos por $10 \mathrm{mg}$ ao dia em pacientes portadores de SCASSST de risco moderado ou alto, com anatomia coronariana conhecida, tratados com ICP e sem fatores de risco para sangramento (idade $\geq 75$ anos; com < 60kg; AVC ou AIT prévios), preferencialmente ao clopidogrel, por 12 meses.

Clopidogrel $600 \mathrm{mg}$ em dose de ataque seguidos por $150 \mathrm{mg}$ ao dia por 7 dias e dose posterior de $75 \mathrm{mg}$ ao dia), em adição ao AAS, em pacientes submetidos à ICP com alto risco de eventos isquêmicos e baixo risco de sangramento.

\begin{tabular}{llll}
\hline $\begin{array}{l}\text { Reinício de ticagrelor, prasugrel ou clopidogrel após } \\
\text { cirurgia de revascularização miocárdica, assim que seguro. }\end{array}$ & Ila & B \\
\hline $\begin{array}{l}\text { Uso de testes de agregabilidade plaquetária ou testes } \\
\text { genéticos (genotipagem) em casos selecionados. }\end{array}$ & IIb & B \\
\hline $\begin{array}{l}\text { Combinação de AAS com outros anti-inflamatórios não } \\
\text { esteroidais (AINE). }\end{array}$ & III & C \\
\hline $\begin{array}{l}\text { Utilização de prasugrel em pacientes com histórico de AIT } \\
\text { ou AVC prévio ou pacientes com SCASSST sem anatomia } \\
\text { conhecida. }\end{array}$ & III & B \\
\hline
\end{tabular}

\section{Antitrombínicos}

\subsection{Heparina Não Fracionada}

Entre os anticoagulantes injetáveis, a HNF foi a primeira sintetizada. A heparina é um polissacarídeo sulfatado com uma faixa de peso molecular de 3.000 a 30.000Da (média, 15.000Da). Sua ação se deve a inativação da trombina e fator ativado X (fator Xa) por um mecanismo dependente da antitrombina (AT). A heparina se liga à AT por meio de um pentassacarídeo de alta afinidade e, para inibir a 
trombina, esta ligação se faz tanto à AT quanto à enzima de coagulação. Ao inativar a trombina, previne a formação de fibrinas e inibe a ativação induzida pelas trombinas de plaquetas e dos fatores V e VIII. Sua resposta variável se faz pela ligação independente da AT de heparina a proteínas plasmáticas, pelas proteínas liberadas pelas plaquetas e células endoteliais, ocasionando a resistência à heparina e uma resposta farmacológica variável. Por essa razão, é importante o monitoramento por meio do tempo de ativação da tromboplastina (TTPa). Devido à sua meia-vida curta, a HNF deve ser administrada com uma infusão intravenosa contínua para garantir níveis estáveis de anticoagulação. ${ }^{256,257}$

As evidências para o uso de HNF no tratamento do IAMSSST são provenientes de estudos randomizados e metanálises. Eikelboom JW et al., em uma metanálise de seis estudos randomizados, comprovaram que o uso de HNF, ou heparinas de baixo peso molecular (HBPM), reduz os desfechos cardiovasculares maiores nas SCA. ${ }^{182}$ A HNF permanece um anticoagulante amplamente utilizado no IAMSSST quando a cineangiocoronariografia ocorre nas primeiras $2 \mathrm{~h}$ da chegada ao hospital, apesar de evidências consistentes de maior risco de sangramento em comparação com outros antitrombóticos. ${ }^{191}$

O regime terapêutico proposto para o uso de HNF deve ser ajustado ao peso corporal. Deve-se administrar por via intravenosa uma dose inicial de 60 unidades $/ \mathrm{kg}$, e seguir a infusão de 12 unidades $/ \mathrm{kg} /$ hora. A intensidade e o ajuste da anticoagulação é realizado pelo monitoramento de TTPa. A primeira amostra de sangue deve ser coletada na terceira hora de infusão e, posteriormente, a cada $6 \mathrm{~h}$, até que a faixa-alvo seja atingida, a partir do que se pode coletar a cada $24 \mathrm{~h}$. O intervalo terapêutico é estreito, por isso deve ser mantido valores de TTPa entre 1,5 e 2,0 vezes. ${ }^{198}$

Durante intervenção coronariana percutânea, deve ser administrada uma dose de HNF para manter o tempo de coagulação ativado (TCA) entre 250 e 350 segundos. A titulação da dose deve ser orientada pelo peso corporal. A administração de um bolus de 70-100UI/kg de HNF é suficiente para uma anticoagulação adequada. Na vigência de uso concomitante de inibidores dos receptores IIb/IIla, a dose inicial deve ser de 60-70Ul/ $\mathrm{kg} .{ }^{258}$

Os efeitos colaterais mais frequentes da HNF são os sangramentos maiores ou menores, que ocorrem principalmente quando o tempo de coagulação está acima da faixa terapêutica. A HNF pode desencadear uma reação imunológica intensa, a trombocitopenia induzida por heparina $(\mathrm{TIH})$ - condição clínica que pode ser fatal, pois induz, concomitantemente, sangramento e trombose. ${ }^{258}$

Na vigência de sangramentos que ameaçam a vida, ou na necessidade de cirurgia de urgência, o uso de um reversor do efeito anticoagulante é imperativo O reversor específico do efeito da HNF é o sulfato de protamina. Uma vez que a meia-vida da HNF é de aproximadamente 1 a 1,5h, a dose de protamina necessária para reverter o efeito da HNF deve se basear na dose total de HNF administrada nas últimas 2 a 3h. Aproximadamente $1 \mathrm{mg}$ neutraliza 100 unidades de HNF. Recomenda-se uma infusão IV lenta para evitar hipotensão arterial e bradicardia. ${ }^{258}$

\subsection{Heparinas de Baixo Peso Molecular}

Durante investigações para melhor compreensão da estrutura da heparina convencional (HNF), verificou-se que suas cadeias de polissacarídeos podem sofrer despolimerização por meio de vários processos físicos e químicos para obter compostos também heterogêneos, porém de mais baixo peso molecular, que recebem o nome genérico de heparinas fracionadas ou de baixo peso molecular (HBPM). ${ }^{256,257}$

As formas de heparina de baixo peso molecular são constituídas de cadeias curtas de polissacarídeos, o que resulta em um efeito anticoagulante mais previsível quando comparada à HNF. A HBPM tem várias vantagens potenciais sobre HNF: ${ }^{257}$

- Maior atividade antifator Xa em relação ao fator Ila. Proporciona uma inibição mais efetiva na geração de trombina.

- Promove uma inibição maior do que as HNF na via do fator tecidual.

- Induz menos frequentemente plaquetopenia.

- Administração via subcutânea por sua grande biodisponibilidade.

- Promove uma anticoagulação previsível em virtude de menor ligação em proteínas plasmáticas.

- Não necessita de monitoramento de níveis plasmáticos.

A fraxiparina, dalteparina e a enoxaparina são exemplos de HBPM que foram testadas em SCA. A enoxaparina permaneceu como fármaco eleito para o uso nesse contexto, devido ao maior corpo de dados experimentais; e os estudos prévios evidenciaram que a fraxiparina e a nadroparina são similares à HNF.

Dois estudos foram publicados (TIMI 11B e ESSENCE) comparando a enoxaparina com a HNF, em termos de eficácia clínica e segurança, no tratamento de pacientes com AI e IAM sem supradesnível de ST. Em resumo, demonstraram pela primeira vez que uma HBPM (no caso, a enoxaparina) era superior à HNF, além de demonstrar que não existe benefício adicional com a utilização do medicamento após a fase de hospitalização (TIMI 11B); durante a fase ambulatorial, ocorreu hemorragia importante em 1,5\% do grupo tratado com placebo e $2,9 \%$ no grupo tratado com enoxaparina ( $p$ $=0,021) \cdot{ }^{259,260}$ Talvez mais importante, a análise conjunta dos dois estudos demonstrou diminuição significativa na incidência de eventos "duros", óbito ou (re)infarto, a favor da enoxaparina em relação à HNF, sendo essas vantagens ainda perceptíveis 1 ano após o tratamento inicial. ${ }^{261}$

O estudo SINERGY foi desenhado para definir o uso da enoxaparina comparada com a HNF em pacientes com SCASSST de alto risco. Foram randomizados 10.027 pacientes, cujo objetivo primário foi o composto de morte cardiovascular, IAM, AVC e revascularização de urgência. Os resultados demonstraram para o braço da enoxaparina que a taxa de eventos foi de 14,0\% (696/4.993); nos pacientes randomizados à HNF, a taxa de eventos foi 14,5\% (722/4.985) (RR, 0,96; IC 95\%, 0,861,06). Em relação aos achados de segurança, observouse mais sangramento com enoxaparina, com aumento estatisticamente significativo no sangramento maior $(9,1 \%$ 
vs. $7,6 \%, p=0,008$ ), (critérios TIMI) e um incremento não significativo de sangramento graves (critérios GUSTO) $(2,7 \%$ vs. $2,2 \%, p=0,08)$ e transfusões de sangue $(17,0 \%$ vs. $16,0 \%, p=0,16)$. A conclusão dos autores foi que a enoxaparina não foi superior à HNF, tampouco, não foi inferior para o tratamento de pacientes de alto risco com SCASSST. ${ }^{262} \mathrm{~A}$ enoxaparina é uma alternativa segura e eficaz à HNF; as vantagens da conveniência do uso por via subcutânea e o fato de não necessitar de monitoramento da anticoagulação rotineiramente devem ser considerados com o excesso modesto de sangramento maior. Outra consideração originada de uma análise não pré-especificada foi a que devemos evitar a troca de classes de anticoagulantes durante o manejo da fase hospitalar dos pacientes com SCA. ${ }^{262}$

A dose de enoxaparina é de $1 \mathrm{mg} / \mathrm{kg}$ administrado por via subcutânea (SC) duas vezes ao dia. Na idade superior a 75 anos, a dose deve ser reduzida para $0,75 \mathrm{mg} / \mathrm{kg}$ duas vezes ao dia. Em pacientes com a taxa de filtração glomerular estimada (TFGe) igual ou inferior a $30 \mathrm{~mL} / \mathrm{min} / 1,73 \mathrm{~m}^{2}$, a dose deve ser reduzida pela metade, sendo então administrado $1 \mathrm{mg} /$ kg (SC) uma vez ao dia. Quando a TFGe chegar em $15 \mathrm{~mL} /$ $\mathrm{min} / 1,73 \mathrm{~m}^{2}$, devemos evitar o uso de enoxaparina. Uma alternativa nessa condição é a HNF, pois tem metabolismo exclusivamente hepático. Nos pacientes pré-tratados com enoxaparina, não é recomendado o uso de enoxaparina adicional durante a intervenção coronariana percutânea se a última injeção SC de enoxaparina tiver sido administrada $8 \mathrm{~h}$ antes do procedimento. Um bolus adicional $0,3 \mathrm{mg} / \mathrm{kg}$ IV é recomendado se a última dose SC de enoxaparina tiver sido administrada $\geq 8 \mathrm{~h}$ antes da angioplastia. ${ }^{263}$

\subsection{Fondaparinux}

O fondaparinux é um pentassacarídeo sintético, constituído por uma sequência de açúcares ( $\mathrm{B}$ C D F) - a menor sequência capaz de se ligar diretamente a trombina. Esta descoberta foi um marco no desenvolvimento farmacológico das heparinas. Forneceu as ferramentas para o conhecimento da biologia e para o avanço da farmacologia dessa classe de medicamentos. Permitiu o conhecimento de que o bloqueio seletivo e direto do fator Xa promove um importante efeito antitrombótico, abrindo o caminho para o desenvolvimento dos novos anticoagulantes orais diretos. ${ }^{264}$ Pentassacarídeo sintético que se liga seletivamente à trombina leva à inibição do fator Xa. Devido à sua discreta interação com componentes do plasma, possui ação anticoagulante previsível e pouca variabilidade individual. Apresenta boa biodisponibilidade, favorecendo a administração por via subcutânea. Atinge seu pico plasmático rapidamente em $2 \mathrm{~h}$, e tem meia-vida longa de $17 \mathrm{~h}$, o que permite o uso de dose única diária. A eliminação do fondaparinux é exclusivamente pelos rins, sendo necessário o monitoramento renal. Quando TFGe for menor que 20/mL/1,73m², devemos suspender seu uso. ${ }^{265}$

O estudo clínico que testou a eficácia e a segurança do fondaparinux em pacientes com SCASSST em comparação com a enoxaparina foi OASIS-5. Ensaio clínico foi desenhado para avaliar se o fondaparinux preservaria os benefícios antiisquêmicos da enoxaparina enquanto reduziria o sangramento em pacientes com SCA. Foram randomizados 20.078 pacientes com SCASSST que receberam fondaparinux $(2,5 \mathrm{mg} / \mathrm{dia})$ ou enoxaparina $(1 \mathrm{mg} / \mathrm{kg}$, duas vezes ao dia) por uma média de exposição de 6 dias. O desfecho composto primário de eficácia foi: morte cardiovascular, IAM ou isquemia refratária no 9o dia. O sangramento maior foi o desfecho primário de segurança, e sua combinação o benefício clínico líquido. Pacientes foram seguidos por até 6 meses. Os resultados demostraram que a taxa de eventos do desfecho composto de eficácia foi semelhante nos dois grupos (579 com fondaparinux [5,8\%] vs. 573 com enoxaparina [5,7\%]; RR: 1,01 no grupo fondaparinux; 95\% (IC 90-1.13; p para não inferioridade $=0,007) \cdot{ }^{194}$ Subanálises do estudo foram publicadas na sequência, sendo a principal aquela que analisou os 12.715 pacientes submetidos à angiografia durante a hospitalização (6.238 tratados por ICP). Durante o andamento do OASIS 5 (após relatos de alguns centros sobre a incidência de trombose de cateteres) ocorreu uma emenda ao protocolo que orientava a lavagem dos cateteres de hemodinâmica com 200UI de HNF previamente ao procedimento. Entre os pacientes submetidos à ICP, o fondaparinux mostrou eficácia similar à enoxaparina para o desfecho primário em 9 dias (6,2\% vs. 6,3\%; RR 1,09; $p=0,79)$, com redução na incidência de sangramentos graves $(10,4 \%$ vs. $8,2 \%$; $R R=0,78 ; p=0,004)$; entretanto, registrouse maior incidência de trombose de cateteres ( $0,4 \%$ vs. $0,9 \%$ ), sendo essa complicação associada a taxas mais elevadas de AVC e IAM. ${ }^{266,267}$

\begin{tabular}{|c|c|c|}
\hline Uso rotineiro de HNF. & 1 & A \\
\hline Uso rotineiro de HBPM. & 1 & A \\
\hline $\begin{array}{l}\text { Uso de fondaparinux } 2,5 \mathrm{mg} \mathrm{SC}, 1 \text { vez ao dia por } 8 \text { dias ou } \\
\text { até a alta hospitalar. }\end{array}$ & I & B \\
\hline $\begin{array}{l}\text { Aos pacientes em uso de fondaparinux, administrar HNF } 85 \mathrm{UI} / \\
\mathrm{kg} I \mathrm{IV} \text {, no momento da ICP, ou } 60 \mathrm{UI} / \mathrm{kg} \text { àqueles que estiverem } \\
\text { recebendo IGPs IIb/llla. }\end{array}$ & 1 & B \\
\hline $\begin{array}{l}\text { Uso de enoxaparina preferencialmente à HNF, a não ser que } \\
\text { cirurgia de revascularização miocárdica esteja planejada } \\
\text { para as próximas } 24 \mathrm{~h} \text {. }\end{array}$ & Ila & A \\
\hline $\begin{array}{l}\text { Considerar interrupção da anticoagulação após a ICP, } \\
\text { exceto se houver outra indicação para mantê-la. }\end{array}$ & Ila & C \\
\hline Troca de heparinas (HNF e enoxaparina). & III & B \\
\hline
\end{tabular}

\section{Associação de Antiplaquetários e Anticoagulantes Orais Diretos em Situações Especiais}

Nos últimos anos, os quatro DOAC foram estudados no cenário de fibrilação atrial em pacientes submetidos à angioplastia, e passaram a ser ótimas opções ao uso da varfariana.

Os estudos clínicos que testaram o uso dos DOAC no contexto de DAC (crônica e aguda) associada à fibrilação atrial apresentaram os seguintes resultados quando comparados com a terapia tríplice (AAS + clopidogrel + varfarina):

- Estudo PIONNER AF-PCl utilizou rivaroxabana 15mg (reduzido para $10 \mathrm{mg}$ no pacientes com "clearance de creatinina" entre 30 a $50 \mathrm{~mL} ; \mathrm{min}$ ) + iP2Y ${ }_{12}$ (clopidogrel/ 
ticagrelor) por 12 meses e foi associado a menores taxas de sangramentos clinicamente significantes (meta primária); sendo que o componente de eficácia (morte cardiovascular, infarto e AVC) foi semelhante (desfecho secundário). ${ }^{268}$

- Estudo REDUAL PCl utilizou dabigatrana 110mg ou

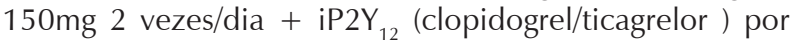
12 meses e foi associado a menores taxas de sangramentos clinicamente significantes (meta primária), sendo o " $p$ " significativo para não inferioridade em ambos os grupos com dabigatrana e significativo para superioridade somente no grupo dabigatrana 110mg; a terapia dupla (ambos os grupos dabigatrana) foi não inferior à terapia tríplice em relação ao desfecho composto de eventos tromboembólicos. ${ }^{269}$

- Estudo AUGUSTUS utilizou apixabana 5mg 2 vezes/ dia (ou 2,5mg 2 vezes/dia caso houver duas ou mais características - idade $>80$ anos, peso $<60 \mathrm{~kg}$ ou creatinina $>1,5)+\mathrm{iP} \mathrm{Y}_{12}$ (clopidogrel) e foi associado a menor taxa de sangramento (meta primária) e menor taxa de morte ou hospitalização (desfecho secundário) sem diferença significativa na incidência de eventos isquêmicos. Ressaltase que, no estudo da apixabana, foram incluídos também pacientes que apresentavam SCA sem realização de ICP. ${ }^{270}$

- Estudo ENTRUST AF-PCI utilizou a edoxabana 60mg em associação a iP2Y ${ }_{12}(n=751)$ e, no outro grupo, varfarina associada à dupla antiagregação plaquetária (DAPT $=\mathrm{AAS}+\mathrm{iP}_{2 Y_{12}}$ ), totalizando 1.506 pacientes. $\mathrm{O}$ desfecho primário foi o de sangramento maior, $(H R=0,83$; IC 95\% $0,65-1,05 ; p=0,0010$ para não inferioridade e $p=0,1154$ para superioridade). Para o desfecho secundário de morte cardiovascular, AVC, embolia sistêmica, IAM e trombose de stent, não houve diferença significativa. ${ }^{271}$

Cerca da metade dos pacientes era portadora de SCA, e o uso do clopidogrel como iP2 $2 \mathrm{Y}_{12}$ foi bem mais frequente que o ticagrelor. Esses estudos tiveram, sempre, como objetivo primário, o desfecho de segurança (sangramento). Com diferentes desenhos, demonstraram segurança dos DOAC em relação à varfarina quando associados a antiplaquetários; e os desfechos isquêmicos (como desfechos secundários) não apresentaram diferenças significativas. ${ }^{272} \mathrm{O}$ tempo total de utilização da terapia tripla, seja com os DOACs ou com varfarina, e de suspensão de AAS deverá ser feito conforme o risco de eventos isquêmicos e o risco de eventos hemorrágicos ${ }^{273}$

\section{Hipolipemiantes}

Vários estudos comprovam os benefícios das terapias para a redução do colesterol em pacientes em prevenção secundária. ${ }^{274,275}$ Nos pacientes de alto risco, o benefício é independente dos níveis basais do LDL-C. ${ }^{276}$ Estudo de Dondo et al. com mais de 389 mil pacientes com SCASSST e seguimento médio de 2,2 anos mostrou que a não aderência ao tratamento com estatinas foi um dos fatores de maior impacto relacionados à redução da sobrevida. Se as diretrizes fossem aplicadas e seguidas corretamente, a aderência ao uso das estatinas, juntamente com a realização de angiografia coronária quando indicada, reabilitação cardiovascular e cessação do tabagismo, poderia evitar $28,9 \%$ dos óbitos. ${ }^{277}$
As metas lipídicas variam conforme as diretrizes, porém, nos últimos anos, foi incorporada uma estratégia de redução mais rigorosa dos níveis de LDL, sendo preconizados, em 2017, pela Diretriz brasileira sobre dislipidemias e prevenção da aterosclerose, níveis de LDL menores que $50 \mathrm{mg} / \mathrm{dL}$ e não $\mathrm{HDL}<80 \mathrm{mg} / \mathrm{dL}$ nos pacientes classificados de muito alto risco. ${ }^{278}$ Quando as estatinas não são toleradas em doses maiores, uma opção é a associação da ezetimiba. ${ }^{279}$

Admite-se que o ideal seja iniciar terapia redutora de lípides desde a hospitalização, desde que não haja contraindicação. O estudo SECURE-PCI avaliou o uso de dose de ataque de atorvastatina $80 \mathrm{mg}$ antes da coronariografia em 4.191 pacientes com SCA submetidos à estratégia invasiva. O uso da dose de ataque não reduziu desfechos cardiovasculares maiores em 30 dias comparado ao placebo (HR 0,88; IC $95 \% 0,69$ a 1,$11 ; p=0,27)$, embora tenha havido possível benefício no subgrupo de pacientes que foram submetidos à ICP (HR 0,72; IC 95\% 0,54 a 0,96; p = 0,02). ${ }^{280}$

Hipolipemiantes - Sumário de recomendações e evidências

Iniciar tratamento precoce com dose alta de estatina em todos os pacientes, independentemente dos níveis de LDL, desde que não existam contraindicações.

Associar ezetimiba em pacientes em uso de dose máxima tolerada de estatina se os níveis de LDL não atingirem as metas estabelecidas

\section{Inibidores do Sistema Renina- Angiotensina-Aldosterona}

Este grupo de fármacos é muito importante no tratamento de hipertensão arterial, insuficiência cardíaca e alguns grupos de pacientes com DAC. Não há evidências conclusivas de benefícios na utilização precoce dos mesmos em pacientes com SCASSST, mas alguns estudos sugerem que podem ser úteis na fase crônica após o episódio agudo. O estudo HOPE (The Heart Outcomes Prevention Evaluation) ${ }^{281}$ incluiu pacientes de alto risco para eventos cardiovasculares, frequentemente com doença arterial aterosclerótica importante (geralmente atingindo o território coronário) e independentemente da fase em que se encontravam e mostrou benefício com o uso de ramipril (dose alvo de $10 \mathrm{mg} /$ dia) a longo prazo. Em 5 anos de seguimento observou-se redução do risco relativo de óbito em $26 \%$ ( $p$ $<0,001)$; infarto, 20\% ( $<<0,001)$; e AVC, 32\% ( $<<$ $0,001)$. Resultados similares também foram demonstrados em pacientes com coronariopatia crônica com o uso de perindopril. ${ }^{282}$

O benefício é maior nos pacientes com disfunção de ventrículo esquerdo (VE), e IAM anterior, em que colaboram na melhora do remodelamento cardíaco, melhora da função do VE, com diminuição da progressão para insuficiência cardíaca. ${ }^{283}$

O objetivo do tratamento é chegar a maior dose tolerável das medicações, até captopril 50mg de 8/8h (podendo ser substituído na sequência por ramipril $10 \mathrm{mg} / \mathrm{dia}$ ou enalapril $20 \mathrm{mg} /$ dia $12 / 12 \mathrm{~h}$ ), losartana 50mg 12/12h ou valsartana $320 \mathrm{mg} / \mathrm{dia}$. 
No caso dos antagonistas de aldosterona, o estudo EPHESUS mostrou redução de mortalidade com uso do eplerrenone (não disponível em nosso meio) em pacientes com IAM (com ou sem supra de ST) e disfunção ventricular esquerda apresentando sintomas de IC ou diabetes (RR 0,85; IC 95\% 0,75-0,96; $p=0,008)$, sendo o benefício evidente já nos primeiros 30 dias de tratamento. ${ }^{284,285}$ Previamente, o estudo RALES já havia demonstrado diminuição da mortalidade em pacientes com insuficiência cardíaca crônica e fração de ejeção do ventrículo esquerdo (FEVE) $\leq 35 \%$. $^{286}$ Dessa maneira, o uso da espironolactona (antagonista de aldosterona disponível em nosso meio), dose-alvo de $25 \mathrm{mg}$ uma vez ao dia (podendo ser aumentada para 50mg após 8 semanas de tratamento se houver sinais de progressão da insuficiência cardíaca sem hipercalemia). O uso do bloqueador de aldosterona está contraindicado em pacientes com disfunção renal importante $(\mathrm{Cr}>2,5 \mathrm{mg} / \mathrm{dL})$ ou níveis de $\mathrm{K}>5,5 \mathrm{mEq} / \mathrm{L}$. Deve haver monitoramento cuidadoso de $\mathrm{K}$ e função renal, sobretudo quando do uso concomitante com IECA/BRA.

Inibidores do sistema renina-angiotensina-aldosterona - Sumário de recomendações e evidências

Administrar inibidores da enzima de conversão da angiotensina (IECA) a pacientes de risco intermediário e alto com disfunção ventricular esquerda, hipertensão arterial ou diabetes melito.

Administrar bloqueadores dos receptores da angiotensina II a pacientes de risco intermediário e alto com contraindicação aos IECA.

Uso de espironolactona em pacientes com SCASSST, FEVE $\leq 35 \%$, e sintomas de IC ou histórico de diabetes.

Administrar IECA a todos os pacientes de risco intermediário e alto.

\section{Estratificação de Risco com os Métodos Complementares}

Em pacientes com SCA, a estratificação de risco deve ser um processo contínuo, desde a avaliação clínica inicial, passando pelos exames subsidiários já discutidos nestas Diretrizes, e culminando com os métodos complementar expostos a seguir.

\section{Exames Não Invasivos para Diagnóstico de Isquemia e Avaliação Prognóstica}

Os exames funcionais são indicados para avaliação da isquemia miocárdica e são fundamentais para a tomada de decisão em alguns casos, principalmente no diagnóstico e prognóstico dos pacientes com risco intermediário e alto. Na abordagem terapêutica conservadora, utilizam-se mais os métodos não invasivos prognósticos.

\subsection{Teste Ergométrico}

Na fase de hospitalização, os parâmetros medidos no teste determinam o grau residual de isquemia e servem para avaliar o desempenho cardíaco. A isquemia residual é estimada por meio do comportamento do segmento ST durante o exercício ou na fase de recuperação e da presença de dor anginosa. O desempenho cardíaco é avaliado por meio do comportamento da pressão arterial e do duplo produto. O desempenho cardíaco e a resposta autonômica relacionada com o comportamento da redução da FC na fase de recuperação têm apresentado melhor correlação com mortalidade em comparação com outros parâmetros. Seu valor preditivo negativo é muito elevado, de $98 \%$ a 100\%, embora com valor preditivo positivo modesto de aproximadamente $50 \%$, sendo os TE anormais infrequentes na população indicada para esse procedimento estratificado nas unidades de dor torácica. ${ }^{287-289}$

Os principais preditores independentes de sobrevida livre de eventos (morte e IAM) em 1 ano, em análise de regressão multivariada, foram o número de derivações com depressão do segmento ST e a carga máxima alcançada. Quanto à segurança, o TE em pacientes estabilizados tem a incidência de $0,5 \%$ de complicações (óbito ou IAM) em até 24h após o exame. . $^{290-292}$

Com o objetivo de estimar o prognóstico e auxiliar na decisão clínica em pacientes de risco intermediário, o TE está indicado a esse grupo de pacientes 24 a 48h após completa estabilização clínica (estabilidade hemodinâmica, ausência de isquemia ativa clínica ou eletrocardiográfica, de novas ondas Q, de sinais clínicos de insuficiência cardíaca e marcadores de lesão miocárdica normais) e desde que haja capacidade para o exercício. ${ }^{51,198}$

Assim, o TE como estratégia precoce $(<48 \mathrm{~h})$ é contraindicado formalmente a pacientes de alto risco. Entretanto o TE realizado após 48h de plena estabilização do quadro clínico, ainda durante a internação, poderá ser indicado a pacientes submetidos à cinecoronariografia, quando é necessária avaliação funcional de lesão conhecida ou estabelecimento de risco antes da alta hospitalar e para orientar adequadamente programas de reabilitação cardíaca. ${ }^{293,294}$

Teste ergométrico - Sumário de recomendações e evidências

Realização de teste ergométrico em pacientes de risco intermediário, 24 a 48h após completa estabilização clínica, desde que sem sintomas isquêmicos ativos, sem sinais de insuficiência cardíaca ou comprometimento hemodinâmico, com ECG de repouso sem isquemia, e marcadores de necrose miocárdica normais.

Realização de teste ergométrico em pacientes de alto risco após $48 \mathrm{~h}$.

Realização de teste ergométrico em pacientes de alto risco antes de $48 \mathrm{~h}$.

11.2. Métodos ecocardiográficos (isquemia, viabilidade estresse, contraste/ microbolhas, strain etc.)

\subsubsection{Ecocardiograma transtorácico}

A nova análise da alteração contrátil do VE pode, de fato, ajudar na determinação de diagnóstico e prognóstico da SCA. ${ }^{295-299} \mathrm{O}$ índice de motilidade segmentar (WMSI; do inglês, wallmotion score index) é o parâmetro de referência 
para expressar a função segmentar do VE, e seu valor de normalidade é 1 (o VE é dividido em 16 ou 17 segmentos que recebem classificação com base no espessamento sistólico); valores entre 1 e 1,6 evidenciam alteração contrátil de grau discreto; enquanto valores de WMSI superiores a 1,6 apontam maior acometimento e pior prognóstico. Obviamente, a ausência de alterações da contratilidade segmentar no ETT de repouso não exclui a presença de DAC. ${ }^{300}$

Vale lembrar que a avaliação da função ventricular pelo ETT, na fase aguda da isquemia, pode estar comprometida pelo fenômeno do stunning (atordoamento) miocárdico. Após um período de 2 semanas, pode ocorrer melhora acentuada da função ventricular. ${ }^{301}$

Com as novas tecnologias desenvolvidas nos aparelhos de ecocardiografia, como speckle-tracking 2D, tem sido possível, por meio da análise do strain global longitudinal (SGL) das paredes do VE, diagnosticar precocemente alterações isquêmicas em pacientes com alteração de troponina, porém sem alteração do ECG ou ecocardiograma de repouso ( $25 \%$ a $75 \%$ dos paciente com SCA têm ecocardiograma normal). ${ }^{302}$

O SGL (quando $<16,5 \%$ ) pode complementar algoritmos diagnósticos existentes e agir como marcador adjunto precoce de isquemia. ${ }^{303}$ Publicação recente propõe que o SGL seja uma ferramenta utilizada na procura de pacientes candidatos à estratégia invasiva. ${ }^{304}$ Pequenos centros têm utilizado SGL rotineiramente na unidade de emergência e há registros de alteração do padrão de strain $(<18 \%)$ antes mesmo da alteração da troponina. ${ }^{305}$

Em circunstâncias especiais, quando a janela acústica é subótima, precisa ser complementado pelo exame de ecocardiografia contrastada por microbolhas, a fim de melhor se delimitar os bordos endocárdicos ou de avaliar eventuais defeitos de perfusão miocárdica. ${ }^{306}$

Ecocardiograma transtorácico - Sumário de recomendações e evidências

Avaliação da função ventricular global e segmentar.

Diagnóstico diferencial de causas alternativas de dor torácica: estenose aórtica grave, cardiomiopatia hipertrófica, embolia pulmonar, dissecção de aorta, pericardite e presença de tumores cardíacos.

Dor torácica com instabilidade hemodinâmica e suspeita de origem cardíaca.

Suspeita de complicações mecânicas no infarto do miocárdio: aneurisma do ventrículo esquerdo, ruptura de parede livre ou músculo papilar, comunicação interventricular, derrame pericárdico.

Cálculo do SGL por meio do speckle tracking como adjunto aos algoritmos existentes de diagnóstico e classificação de risco em pacientes com suspeita de doença coronariana.

\subsubsection{Ecocardiografia de estresse}

A ecocardiografia sob estresse permite a verificação das anormalidades regionais transitórias da contração, indicativas de isquemia induzida tanto por exercício quanto farmacologicamente. ${ }^{307}$
O ecocardiograma sob estresse é um preditor independente de morte cardiovascular, de valor adicional aos demais métodos e pode evitar a cinecoronariografia. Seu uso pode ser recomendado para estratificação de risco de pacientes em unidades de dor torácica, especialmente quando o ECG não define o diagnóstico e o teste ergométrico é submáximo, de realização não factível ou com resultado inconclusivo, uma vez aliviada a dor por pelo menos $24 \mathrm{~h}$ em pacientes de baixo a moderado risco e sem alterações isquêmicas evidentes no ECG e marcadores de necrose. ${ }^{307,308}$

Respostas de melhora de contração segmentar em áreas dissinérgicas, com doses iniciais de dobutamina (5 a 10g/ $\mathrm{kg} / \mathrm{min})$, identificam viabilidade miocárdica nessas regiões "atordoadas" pela isquemia pregressa. ${ }^{307-309}$

$\begin{aligned} & \text { Ecocardiograma de estresse - Avaliação pelo ecocardiograma sob } \\ & \text { estresse - Sumário de recomendações e evidências }\end{aligned}$
$\begin{aligned} & \text { Pacientes com angina instável ou SCASSST de baixo risco } \\ & \text { controlada clinicamente* antes de decidir a estratégia } \\ & \text { invasiva. }\end{aligned}$

\subsubsection{Avaliação da perfusão miocárdica pela ecocardiografia}

Em pacientes com dor torácica aguda e ECG não diagnóstico, o uso da ecocardiografia com contraste aumenta a sensibilidade para o diagnóstico da SCA. ${ }^{310}$

Pacientes com perfusão e função miocárdica normais ao repouso têm bom prognóstico, enquanto a presença de defeitos de perfusão ao repouso identifica um subgrupo de alto risco para a SCA. ${ }^{306,311}$

Os agentes de contraste ecocardiográfico são soluções contendo microbolhas de gás do tamanho das hemácias, cuja interface com o meio líquido é altamente refringente, melhorando o sinal ecocardiográfico do meio que as contém. Por este método, à beira de leito, pode-se avaliar a microcirculação miocárdica, pois as microbolhas são marcadores microvasculares que se comportam como as hemácias, portanto, não atingem áreas de obstrução microvascular. Desta forma, áreas com infarto não apresentam este contraste e são facilmente detectadas pela ecocardiografia. ${ }^{306}$ Por meio dessa modalidade ecocardiográfica, 
obtém-se simultânea e instantaneamente as alterações da contração segmentar do VE e da perfusão miocárdica. ${ }^{312}$

O contraste ecocardiográfico possibilita uma melhor definição das margens endocárdicas, permitindo uma avaliação mais adequada do espessamento miocárdico parietal e das funções contrátil global e segmentar do VE em repouso e sob estresse. Adicionalmente, os agentes de contraste permitem medida mais acurada dos volumes ventriculares e da FEVE, principalmente em casos de imagens subótimas, e têm comprovada utilidade na definição de alterações da anatomia. ${ }^{306,313}$

Defeitos regionais de perfusão transitórios extensos durante o estresse são indicativos de DAC grave. Respostas de melhora de contração segmentar em áreas dissinérgicas e com perfusão presente, durante doses iniciais da infusão de dobutamina (5 a $10 \mu \mathrm{g} / \mathrm{kg} / \mathrm{min}$ ), identificam viabilidade miocárdica nessas regiões "atordoadas" pela isquemia pregressa.

Em suma, em pacientes com dor torácica atendidos no centro de emergência, a ecocardiografia contrastada em repouso adiciona dados de diagnóstico e prognóstico a esses pacientes. Se o preenchimento completo do miocárdio pelo contraste (perfusão) for observado dentro de 4 segundos, isso identifica pacientes com motilidade e perfusão normais, portanto, de baixo risco. Já quando a perfusão é normal, mas há alteração segmentar do movimento de parede, identifica miocárdio atordoado, enquanto um defeito fixo de perfusão mapeia toda a área em risco durante a lesão isquêmica aguda. ${ }^{314,315}$ Nos pacientes com IAM, a ecocardiografia sob estresse com contraste miocárdico identifica não somente as áreas de infarto ou de atordoamento em repouso, mas pode identificar as áreas isquêmicas à distância pela análise das alterações transitórias da motilidade e perfusão miocárdicas.

11.2.3.1. Avaliação da perfusão miocárdica pelo ecocardiograma | Sumário de recomendações e evidências

Perfusão miocárdica pelo ecocardiograma - Sumário de recomendações e evidências

Ecocardiografia transtorácica contrastada para melhora do sinal Doppler em pacientes com imagem subótima ou ecocardiografia transtorácica contrastada para delineamento de margens endocárdicas durante a Ila B ecocardiografia sob estresse em pacientes com imagens subótimas em repouso.

Ecocardiograma sob estresse com microbolhas em pacientes com risco intermediário nos quais persistem dúvidas após a realização de teste ergométrico.

Ecocardiograma sob estresse com microbolhas em pacientes com alto risco.

\subsection{Métodos de Cardiologia Nuclear}

A cintilografia miocárdica de perfusão (CMP) é indicada fundamentalmente aos casos de impossibilidade de realização do teste ergométrico e a pacientes nos quais há dificuldades para a interpretação adequada do ECG de esforço. Uma das principais indicações da CMP é a possibilidade da realização das técnicas não invasivas mais utilizada no cenário da Al de baixo risco. Permite avaliar os pacientes incapazes de realizar esforço físico por meio do estresse farmacológico e apresenta melhor correlação com os dados anatômicos em comparação com o teste ergométrico.

A CMP e a ventriculografia nuclear radioisotópica têm um grande valor diagnóstico e prognóstico nas coronariopatias aguda e crônica. ${ }^{316-318}$ Uma das principais indicações da CMP é a possibilidade da realização precoce nas SCA, com ampla margem de segurança, empregando-se agentes vasodilatadores como o dipiridamol e a adenosina. Em relação a outros exames, a CMP mostrou-se superior nessa aplicação. Deve ser ainda destacada a possibilidade de, sincronizando-se o estudo cintilográfico tomográfico com o ECG (gated-SPECT), avaliar-se a função sistólica regional e medir-se a FE ventricular com exame único. ${ }^{319}$ Os vários estudos são consistentes na demonstração de que pacientes com diagnóstico de Al que apresentem cintilografia normal durante estresse pertencem a subgrupo com risco notadamente reduzido de eventos graves, de cerca de 1\% em 1 ano; enquanto a detecção de defeitos reversíveis expressa prognóstico desfavorável, com taxa de eventos da ordem de $20 \%$ para o mesmo prazo de seguimento. ${ }^{320-323}$

A tomografia por emissão de pósitrons (PET; positron emission tomography) é uma técnica não invasiva de doença coronariana obstrutiva que apresenta acurácia bastante elevada para detecção de isquemia miocárdica e viabilidade miocárdica. Sua utilidade foi demonstrada para avaliação diagnóstica e prognóstica da DAC. Além disso, possibilita a avaliação muito precisa da reserva do fluxo coronariano por quantificação absoluta. Essa informação pode ser útil na avaliação de quadro de infarto em pacientes sem obstruções coronárias significativas (MINOCA). ${ }^{324,325}$ No Brasil, temos dificuldade para obter os radiotraçadores (rubídio e amônia) que permitem essa quantificação, mas novas gamacâmaras de detectores de cádmio-zinco-telúrio (CZT) também têm mostrado possibilidade de realizar quantificação da reserva de fluxo com traçadores de tecnécio. ${ }^{326}$

Cintilografia miocárdica de perfusão - Sumário de recomendações e evidências

Em pacientes com risco intermediário, nos quais persistem dúvidas após a realização de TE, ou impossibilitados de submeter-se ao TE.

Para identificação da presença/extensão de isquemia em pacientes que não podem realizar cateterismo, ou quando os resultados deste não são suficientes para o estabelecimento de condutas.

Após o cateterismo, para identificação da artéria relacionada com o evento (região a ser revascularizada), e/ ou estratificação complementar de risco.

Em pacientes com regiões ventriculares dissinérgicas, em que se torna necessário comprovar ou excluir a presença de miocárdio viável para guiar a conduta terapêutica.

Como primeira opção na avaliação de isquemia, mesmo em pacientes em que o TE seja factível e interpretável.

Angiocardiografia nuclear em pacientes de risco

intermediário e alto para identificação de envolvimento do ventrículo direito.

Em pacientes de alto risco antes das primeiras $48 \mathrm{~h}$ de estabilização do paciente. 


\subsection{Ressonância Magnética Cardiovascular}

A ressonância magnética cardiovascular (RMC) é um método bastante útil para a avaliação cardíaca morfológica e funcional, fornecendo informações diagnósticas e prognósticas importantes tanto na doença isquêmica quanto nas miocardiopatias não isquêmicas. O exame é capaz de fornecer informações precisas sobre os aspectos morfológicos do coração, a quantificação dos volumes, a massa e a função ventricular global e regional, a avaliação de isquemia miocárdica (pela análise da contratilidade segmentar sob estresse com dobutamina e sem uso de contraste ou pela técnica de perfusão miocárdica sob estresse com vasodilatadores, como o dipiridamol e a adenosina, e com uso de contraste com base em gadolínio) e a avaliação da fibrose/necrose miocárdica pela técnica do realce tardio miocárdico. ${ }^{327}$ Todas essas informações são fornecidas de maneira integrada em um único exame. O método ainda permite, com a combinação destas e de outras formas de aquisição de imagem, a visualização do pericárdio e dos grandes vasos e a análise de fluxos e função valvar.

Vários estudos clínicos e metanálises mostram que a ressonância cardíaca é um método altamente acurado para a detecção de isquemia miocárdica, mesmo em comparação com o ecocardiograma de estresse, ${ }^{328}$ a cintilografia miocárdica ${ }^{329,330}$ ou a reserva de fluxo fracional (fractional flow reserve - FFR). ${ }^{331}$

A avaliação da viabilidade miocárdica pela técnica do realce tardio também já foi estudada e validada nas SCA e fornece importantes informações diagnósticas e prognósticas, além de ser considerada por muitos o padrão-ouro para a avaliação de viabilidade miocárdica e detecção de infartos. ${ }^{332-336}$ Estudos uni e multicêntricos demonstraram que a RMC é uma técnica extremamente sensível para detecção e localização do infarto, mesmo os pequenos infartos subendocárdicos, ${ }^{337-339}$ que também têm importância prognóstica demonstrada, talvez pela sua frequente associação a estenoses coronárias críticas e que podem passar despercebidos tanto à avaliação clínica quanto a outros exames diagnósticos. ${ }^{340-342}$ Adicionalmente, a medida da área infartada obtida pela RMC tem grande impacto prognóstico independente de outros fatores clínicos, tendo sido, em alguns estudos, mais importante que a própria FEVE. ${ }^{343,344}$ Utilizando técnicas de identificação de zonas de edema associadas à mensuração das zonas de realce tardio, pode-se obter também a taxa de miocárdio preservado, elemento que tem valor prognóstico, em especial em pacientes submetidos a tratamento trombolítico. ${ }^{345}$

A técnica do realce tardio também permite a detecção de áreas de hipossinal (áreas escuras) no meio da área de hipersinal (infarto), o que se relaciona com áreas de obstrução microvascular (no-reflow phenomenon) e também acrescenta informação prognóstica nessa população. ${ }^{343-347}$

Além dessas aplicações, a ressonância é bastante útil na diferenciação das miocardiopatias isquêmicas das não isquêmicas, ${ }^{327,348}$ sendo utilizada para o diagnóstico de miocardite ${ }^{349,350}$ e síndrome de Takotsubo. ${ }^{351,352}$ Ademais, na situação de elevação de marcadores de necrose miocárdica e cateterismo "normal", a RMC pode confirmar a presença do infarto, que poderia estar relacionado com espasmo ou síndromes trombofílicas, entre outros. Outros diagnósticos diferenciais em que a RMC pode ajudar são a hipertrofia ventricular esquerda (primária da cardiomiopatia hipertrófica ou secundária) e a pericardite aguda isolada, sem miocardite associada.

Pela sua sensibilidade em encontrar áreas de infarto e de realizar o diagnóstico de outras anormalidades cardíacas, a ressonância tem sido preconizada para a avaliação de pacientes com quadro de infarto em pacientes sem obstruções coronárias significativas (MINOCA). Nesta condição, o exame permitiu a diferenciação correta entre processos inflamatórios e necrose isquêmica real, mesmo na ausência de placas de ateroma significativa, e pode fornecer dados fundamentais para a condução desses casos. Tal abordagem pode ser particularmente relevante no caso de mulheres que apresentam maior incidência deste evento. ${ }^{353}$

Nos casos de DAC confirmada, a RMC pode ainda ajudar a definir a coronária relacionada com o infarto em casos nos quais este achado não é claro no cateterismo, como, por exemplo, em pacientes com lesões triarteriais graves e ECG inespecífico. Nessa situação, a RMC pode ainda diferenciar infartos antigos de infartos recentes, relacionados com o quadro atual. Finalmente, a RMC pode fornecer imagens de alta resolução para a avaliação de complicações mecânicas pós-infarto, como ruptura do VE, insuficiência mitral, extensão do infarto para o ventrículo direito e comunicação interventricular (CIV). ${ }^{340,354}$

\section{Ressonância magnética cardiovascular - Sumário de recomendações} e evidências Na avaliação da função ventricular, da presença/extensão
da área de necrose e viabilidade.

Na pesquisa de eventuais alterações mecânicas.

Avaliação de pacientes com apresentação clínica de SCA, sem obstruções coronárias significativas.

No diagnóstico diferencial de pacientes que apresentam quadro clínico compatível com coronariopatia aguda, porém com ECG apresentando alterações inespecíficas e marcadores bioquímicos de necrose negativos.

Como adjuvante no diagnóstico de SCA, principalmente nos pacientes com probabilidade intermediária ou alta.

\section{Cinecoronariografia e Avaliações Coronárias Intravasculares (FFR, IVUS, OCT)}

A coronariografia comumente utilizada para diagnosticar e definir o tratamento para os pacientes com IAMCSST pode apresentar dificuldades em mostrar a lesão culpada na Al e no IAMSSST. Tal dificuldade ocorre especialmente porque este exame não é $100 \%$ sensível às rupturas de placas. ${ }^{355} \mathrm{O}$ fator desencadeador das SCA vai desde doença obstrutiva aterosclerótica (que pode ser incipiente, com placa rota ou não), espasmo, embolia, hematoma coronário intramural, dissecção espontânea da coronária até dissecção aórtica.

Barcarawi et al. demonstraram, em uma metanálise recente, que, para os pacientes com SCASSST, a abordagem invasiva precoce de rotina resultou em uma menor incidência de eventos cardiovasculares maiores (definidos por cada um dos estudos incluídos) quando comparada com a estratégia invasiva 
tardia (RR 0,65, IC 95\% 0,49-0,87; $p=0,003)$, sendo que este benefício persistiu apenas em pacientes com um escore GRACE > $140 .{ }^{356}$ Contudo, nesse estudo, não houve diferenças significativas na mortalidade por todas as causas, mortalidade cardiovascular, infarto do miocárdio ou eventos hemorrágicos entre os grupos. O tratamento invasivo precoce também foi associado a menor risco de desfechos isquêmicos no estudo SWEDEHEART. ${ }^{357}$

O rumo terapêutico a ser tomado, especialmente o momento da avaliação invasiva, depende não só do diagnóstico anatômico e funcional mas também das comorbidades, apresentação clínica, fragilidade, estado cognitivo e expectativa de vida do paciente e especialmente da estratificação de risco, pois quando se trata de pacientes de "muito alto risco", esses casos devem ser avaliados rapidamente, em menos de $2 \mathrm{~h}$, sendo em até $72 \mathrm{~h}$ para os pacientes de "risco intermediário", o que é apresentado no Tabela 2.1. ${ }^{358}$

A estratégia invasiva permite o diagnóstico da DAC subjacente, a identificação da lesão, a orientação para o tratamento com medicamentos antitrombóticos e a avaliação da anatomia coronariana para ICP ou CRVM, pois até $40 \%$ desses pacientes com SCASSST demonstram múltiplas placas com morfologia complexas, sendo que até um quarto dos pacientes apresenta uma coronária com oclusão aguda.

A Sociedade Europeia de Cardiologia e a Associação Europeia de Cirurgia Cardiotorácica (ESC/EACTS) consideram a FFR o atual padrão diagnóstico para a avaliação funcional da gravidade da lesão em pacientes com estenose de grau intermediário (tipicamente em torno de $40 \%$ a 50\%) sem evidência de isquemia em testes não invasivos ou naqueles com doença multiarterial. Nesta Diretriz, a introdução da razão instantânea de ondas livres (iFR), uma nova medida que não requer hiperemia induzida por adenosina, está incluída na recomendação como classe IA. As diretrizes consideram o FFR e o iFR como equivalentes.
Para a doença do tronco da coronária esquerda (TCE), a avaliação funcional por FFR ou iFR pode ser tecnicamente complexa, e as evidências que sustentam seu uso nesse cenário são escassas. Consequentemente, a ultrassonografia intracoronária (USIC) é uma recomendação da classe IlaB e a revascularização deve ser excluída quando a área luminal mínima for $>6 \mathrm{~mm}^{2}$. Para todas as lesões fora do TCE, a avaliação funcional é preferível à imagem intracoronariana. O uso do USIC e da tomografia de coerência óptica (OCT; optial coherence tomography) é recomendado para otimizar o implante de stent (classe llaB).

A avaliação da FFR necessita da administração de adenosina para obter hiperemia máxima e estável, diferente da razão instantânea de onda livre (iwFR), que avalia os índices de repouso derivados apenas dos gradientes de repouso, ou seja, da pressão coronariana distal para aórtica $(\mathrm{Pd} / \mathrm{Pa})$. O estudo iFR-SWEDEHEART, que avaliou a revascularização guiada por iFR, tinha $17,5 \%$ dos pacientes com SCA no momento desta avaliação e demostrou que esta estratégia foi considerada não inferior à estratégia de revascularização guiada por FFR em relação à taxa de eventos cardíacos adversos maiores e eventos até 12 meses após o procedimento. ${ }^{359}$

O estudo DEFINE-FLAIR, ${ }^{360}$ que avaliou 2.492 pacientes com DAC, mostrou que a revascularização coronariana guiada pelo iRF foi não inferior à revascularização guiada pelo FFR com relação ao risco de eventos cardíacos adversos maiores em 1 ano, ainda com o benefício que o iFR foi mais econômico quando comparado com o FFR. O ponto de corte para definir uma lesão como hemodinamicamente significativa foi: iFR $\leq$ 0,89 e $F F R \leq 0,8$.

A OCT utiliza luz infravermelha para fornecer imagens in vivo transversais de alta resolução da artéria coronária. Esta técnica de imagem permite uma avaliação detalhada da morfologia da placa em pacientes com SCA e pode ajudar a entender os mecanismos subjacentes, incluindo ruptura ou

Tabela 2.1 - Seleção da estratégia de tratamento da SCASSST de acordo com a estratificação de risco inicial

\begin{tabular}{|ccc|}
\hline Avaliação invasiva na SCASSST & & Risco intermediário \\
\hline Muito alto risco & Alto risco & DM ou insuficiência renal \\
\hline $\begin{array}{c}\text { Instabilidade hemodinâmica ou choque } \\
\text { cardiogênico }\end{array}$ & Troponina positiva & ICC ou FEVE < 40\% \\
\hline $\begin{array}{c}\text { Angina recorrente ou persistente refratária ao } \\
\text { tratamento clínico }\end{array}$ & Alteração dinâmica ST/T & Angina pós-IAM \\
\hline Arritmia ventricular maligna ou PCR & GRACE >140 & ICP ou CRVM prévios \\
\hline Complicações mecânicas & & GRACE 109-140 ou sintomas recorrentes ou \\
\hline IC aguda & teste funcional positivo \\
\hline Alterações dinâmicas ST/T recorrentes & Invasiva precoce \\
\hline (menor que 24h) & IA & Invasiva \\
\hline Invasiva imediata & IA & I \\
\hline
\end{tabular}

Fonte: adaptada de Neumann FJ, et al.358

CRVM: cirurgia de revascularização do miocárdio; DM: diabetes melito; GRACE: Global Registry of Acute Coronary Events; ICP: intervenção coronária percutânea; PCR: parada cardiorrespiratória; IAM: infarto agudo do miocárdio; FEVE: fração de ejeção de ventrículo esquerdo. 
erosão da placa e calcificação. Portanto, é útil para otimizar a intervenção coronária percutânea e avaliar a resposta vascular à intervenção coronária e terapia farmacológica. ${ }^{361}$

Ao identificar trombo e delinear a ruptura ou erosão da placa, a OCT é útil na identificação de lesões e os mecanismos subjacentes na SCA, especialmente quando as lesões são ambíguas na angiografia. ${ }^{362}$

Pacientes com quadro de SCA, lesão única na artéria culpada sem doença difusa no mesmo vaso considerado responsável pela SCA e com indicação de angioplastia e implante de stent foram avaliados pelo estudo DOCTORS. ${ }^{363}$ Esse estudo foi desenhado com o objetivo de avaliar a eficácia da OCT na otimização da intervenção coronária percutânea entre pacientes com SCASSST e demonstrou que a subexpansão do stent foi comum, aproximadamente $42 \%$, e foi um preditor independente de resultados adversos. Concluiu afirmando que a intervenção com OCT resulta em um maior benefício funcional, avaliado por FFR após a intervenção, em comparação à intervenção guiada por angiografia de rotina nesses pacientes com diagnóstico de SCASSST.

Apesar de os dados de longo prazo demonstrarem melhor resultado para tratamento da DAC com o auxílio da avaliação fisiológica, o FFR e o iFR permanecem subutilizados na prática atual. ${ }^{364}$ Mesmo assim, avanços adicionais em outras abordagens alternativas de FFR, incluindo TC coronariana não invasiva (FFRCT), angiografia invasiva (angioFFR) e tomografia de coerência óptica (FFROCT), já estão sendo realizados guiados por algoritmos de inteligência artificial e ferramentas robustas que permitem a intervenção detalhada pré-procedimento.

Estudo hemodinâmico e cineangiocoronariográfico - Sumário de recomendações e evidências

Nos pacientes de muito alto risco, realização da cineangiocoronariografia imediata.

Nos pacientes de alto risco, realização da cineangiocoronariografia precoce (em até 24h).

Nos pacientes de risco intermediário ou que apresentam recorrência de sintomas, ou ainda que têm teste não invasivo positivo para isquemia, realização da cineangiocoronariografia em até $72 \mathrm{~h}$.

\section{Revascularização miocárdica (cirurgia de revascularização miocárdica e intervenção coronária percutânea)}

A diferença entre o tratamento da Al e do IAMSSST em relação à DAC crônica é a decisão rápida da indicação de revascularização, evitando assim complicações cardiovasculares. ${ }^{365-367}$ A estratificação de risco é fundamental para a escolha adequada do tratamento conservador ou invasivo. Os escores mais usados são o TIMI e GRACE. ${ }^{28,368}$

$\mathrm{Na}$ escolha do tratamento, a angiografia coronária determina a estratégia anatômica, cuja revascularização deve ser imediata nos casos de angina refratária e instabilidade elétrica ou hemodinâmica. Além disso, as abordagens mais precoces têm desfechos favoráveis e estão indicadas nos pacientes de alto risco. ${ }^{28,368-370}$ Em uma coorte de 363.500 pacientes diabéticos com IAMSSST, a estratégia de avaliação invasiva precoce foi utilizada em 164.740 pacientes (45,3\%). Em uma análise ajustada por escore de propensão, 21.681 diabéticos foram pareados em cada braço. Houve uma associação de menor mortalidade intra-hospitalar com a estratégia invasiva para o IAMSSST, mas não para a $\mathrm{AI}(2,2 \%$ vs. 3,8\%; RR 0,57, IC 95\%; 0,50-0,63, p < 0,01). ${ }^{371}$

As estratégias invasivas incluem a angioplastia ou a cirurgia de revascularização miocárdica. ${ }^{372}$ Uma ferramenta fundamental para esta decisão é baseada da anatomia coronária utilizando-se o SYNTAX Score. ${ }^{373}$ Pacientes com SYNTAX Score $>22$ (intermediário ou alto) têm maior benefício a longo prazo com a revascularização cirúrgica. ${ }^{374,375}$

Aproximadamente $5 \%$ a $10 \%$ dos pacientes com SCASSST necessitam de $\mathrm{CRVM}^{376}$ e representam um subgrupo desafiador devido às suas características de alto risco em comparação com pacientes submetidos à revascularização miocárdica eletiva. ${ }^{377}$

Em pacientes com isquemia em curso ou instabilidade hemodinâmica com indicação de CRVM, a cirurgia deve ser realizada o quanto antes, e não adiada como consequência da exposição ao tratamento antiplaquetário.

Na ausência de dados randomizados, o tempo ideal para revascularização miocárdica deve ser determinado individualmente. O risco de eventos isquêmicos, possivelmente relacionados à terapia antiplaquetária subótima enquanto aguarda a cirurgia é < 0,1\%, enquanto o de complicações hemorrágicas perioperatórias associadas a inibidores de plaquetas é $>10 \% .{ }^{378}$

Se o quadro clínico do paciente possibilitar a espera da cirurgia, sugere-se que a antiagregação plaquetária seja suspensa em tempo hábil. Dependendo do tipo e da dosagem do agente, deve-se aguardar a redução do seu efeito, por exemplo, 5 dias antes do procedimento cirúrgico para o clopidogrel, 5 dias para o ticagrelor e 7 dias para o prasugrel. Nesta situação, o tempo de espera para a cirurgia poderia ser abreviado testando-se a agregação plaquetária diariamente para verificar se o paciente recuperou ou não a inibição e liberá-lo com segurança para a cirurgia. Um estudo brasileiro está testando esta hipótese (NCT 02516267).

Atualmente, o manuseio cirúrgico na coronariopatia aguda sem supradesnivelamento do segmento ST é semelhante ao da doença estável. Portanto, após discussão com o Heart Team e indicação cirúrgica apropriada, o mais importante seria avaliar o momento ideal para a realização do procedimento. Isso estaria mais relacionado com a repercussão sistêmica do evento agudo em relação à otimização ao quadro clínico do paciente, na procura pelos melhores resultados. Isso significa que pacientes poderiam ir para cirurgia na mesma internação de forma imediata (urgência/emergência), aguardar a redução da ação de antiagregantes plaquetários ou obter alta hospitalar com data agendada para a cirurgia.

Quando há urgência ou emergência, dá-se preferência ao uso de enxertos venosos aos arteriais. A cirurgia poderá ser realizada com ou sem o auxílio da circulação extracorpórea, de acordo com as condições técnicas pertinentes a cada caso. Em pacientes em vigência de choque cardiogênico, a revascularização completa por meio de procedimento de angioplastia constitui-se como opção inicial; porém, diante 
de sua limitação, a cirurgia poderá ser indicada de acordo com avaliação multiprofissional. ${ }^{358}$

Os pacientes operados em 1 a 2 dias e 3 a 7 dias após o IAM tiveram uma taxa de mortalidade semelhante, sugerindo que, para alguns pacientes, seria possível reduzir o intervalo IAM-CRVM, sem comprometimento dos resultados. Nos pacientes operados no primeiro dia após o IAM, observou-se maior índice de mortalidade. ${ }^{379}$

Estudo realizado em pacientes acima dos 80 anos, portadores de IAMSSST e AI realizado em 16 centros na Noruega, denominado After Eighty Study, foram randomizados para a estratégia invasiva (ATC ou CRVM + tratamento clínico otimizado) versus estratégia conservadora com tratamento clínico otimizado isolado. Os desfechos maiores ocorreram em 93 pacientes $(40,6 \%)$ de 229 pacientes no grupo de estratégia invasiva e em $140(61,4 \%)$ de 228 pacientes no grupo da estratégia não invasiva (RR 0,53 [IC 95\% 0,41-0,69], $\mathrm{p}=0,0001)$. Não houve diferença quanto as complicações hemorrágicas entre os dois grupos. ${ }^{380}$

Estudo multicêntrico com 1.810 casos com IAM sem supra de ST e Al, dentro das 48h do início da dor, comparou também a estratégia invasiva com a conservadora. No primeiro ano, não houve diferença quanto aos desfechos primários de infarto e morte. Porém, em 5 anos de evolução, a estratégia invasiva teve um índice significativamente menor desses desfechos. ${ }^{381}$

Uma revisão sistemática incluindo 8.915 pacientes, sendo 4.545 submetidos à estratégia invasiva e 4.370 a uma estratégia conservadora, também observou a redução de mortalidade com a estratégia invasiva no período de 6 a 12 meses. ${ }^{382}$ Técnicas mais avançadas auxiliam a estratificação de risco e a abordagem terapêutica dos pacientes, como a fração de reserva de fluxo (FFR) e o ultrassom intracoronário. ${ }^{383-385}$

Revascularização miocárdica (cirurgia de revascularização miocárdica e intervenção coronária percutânea) - Sumário de recomendações e evidências

ICP ou CRVM nas lesões de múltiplos vasos, de acordo com o quadro clínico e o Escore SYNTAX.

Revascularização (ICP) de rotina em lesões não

relacionadas ao IAM no choque cardiogênico.

\section{Parte 3 - Recomendações na Alta e Cuidados Pós-Alta Hospitalar}

\section{Mudança de Estilo de Vida}

A prevenção secundária é parte fundamental no cuidado de pacientes pós-SCA. Esta etapa compreende mudanças no estilo de vida, reabilitação cardiovascular, educação quanto aos fatores de risco e promoção da melhor adesão ao tratamento. Apesar de eficácia comprovada na prevenção de desfechos cardiovasculares, sua implementação ainda é subótima. ${ }^{386,387}$ Pacientes e familiares devem ser orientados de forma clara e compreensível quanto aos benefícios comprovados pelas evidências científicas. ${ }^{388-390}$ Aumentar a abrangência da prevenção secundária é importante objetivo nesta população de pacientes.
Orientação adequada deve ser dada ao paciente quanto ao retorno às suas atividades laborais e sexuais e quanto à capacidade de conduzir veículos, trabalhando a reinserção do paciente paulatinamente à sua rotina. Além disso, atenção especial deve ser dispensada às questões psicossociais e socioeconômicas do paciente, incluindo atenção ao risco de depressão e isolamento social. ${ }^{391-398}$

\subsection{Cessação do Tabagismo}

Este item ocupa destaque especial na mudança de estilo de vida do paciente. O abandono do tabagismo é medida muito efetiva para a redução da mortalidade em pacientes pós-SCASSST. ${ }^{399} \mathrm{O}$ cigarro tem cerca de 7.000 componentes químicos, dos quais muitos interferem diretamente nas doenças cardiovasculares, além de 69 deles serem carcinogênicos. ${ }^{400} \mathrm{O}$ cigarro interfere no sistema cardiovascular de várias formas, aumentando a frequência cardíaca e a demanda de oxigênio pelo miocárdico, além de diminuir a sua oferta. ${ }^{401}$ Aumenta a incidência de morte súbita, ${ }^{402}$ o risco de trombose, inflamação, vasoconstrição e aumento da oxidação do LDL colesterol. ${ }^{403}$ Estima-se que o risco de fibrilação atrial aumente 1,5 a 2 vezes entre os tabagistas. ${ }^{404}$

Em pacientes após SCASSST, o encaminhamento a um programa de cessação do tabagismo e a utilização de agentes farmacológicos, incluindo nicotina (adesivos ou goma), são comprovadamente úteis. ${ }^{405} \mathrm{Em}$ estudo observacional com 12.656 pacientes, Parasuraman et al. identificaram que pacientes tabagistas, comparados com ex-tabagistas e pessoas que nunca fumaram, foram submetidos à intervenção coronariana em idade mais precoce, e a intervenção esteve mais associada a uma SCA. Ex-tabagistas tiveram resultados semelhantes ao grupo de pessoas que nunca fumaram. ${ }^{406}$

A abordagem para abandono do tabagismo deve ocupar papel central na estratégia de reabilitação do paciente, o quanto mais precoce possível, sendo o ideal ainda na fase hospitalar. Familiares que residem na mesma casa do paciente também devem ser encorajados a participar de programas com vistas à cessação do tabagismo, reforçando, desta maneira, o empenho do paciente, além de diminuir o risco do fumo passivo. ${ }^{407}$

A estratégia de abordagem da dependência a nicotina consiste em quatro etapas. O primeiro passo é determinar a dependência. Utiliza-se mais comumente o teste de Fagerström (Tabela 3.1). As etapas seguintes consistem em aconselhamento, tratamento medicamentoso e comportamental e seguimento clínico.

Para prevenir recaídas, é importante identificar as situações de alto risco e agir para enfrentá-las. As estratégias consistem, basicamente, em evitar, escapar, distrair e adiar. Deve-se evitar festas, ingestão de álcool ou cafeína, encontro com fumantes, pelo menos durante as primeiras semanas de parada.

O uso de medicações como bupropiona, vareniclina e a suplementação de nicotina podem aumentar as chances de abstinência, associadas a outras terapias como grupos de apoio e aconselhamento, psicoterapia e abstinência de álcool.

A bupropiona é um antidepressivo de ação ansiolítica que diminuiu os sintomas de abstinência ao desejo de fumar em vários estudos. Um deles, que comparou a cessação do tabagismo entre pacientes com tratamento de bupropiona 
Tabela 3.1 - Questionário de tolerância de fagerström

\begin{tabular}{l}
\hline Quantos cigarros você fuma por dia? \\
\hline (0) menos de 11 \\
\hline (1) de 11 a 20 \\
\hline (2) de 21 a 30 \\
\hline (3) mais de 30 \\
\hline 2. Quanto tempo depois de acordar você fuma o primeiro cigarro? \\
\hline (0) mais de 60min \\
\hline (1) entre 31 e 60min \\
\hline (2) entre 6 e 30 min \\
\hline (3) menos de 6min \\
\hline 3. Você tem dificuldade de ficar sem fumar em locais proibidos? \\
\hline (0) não \\
\hline (1) sim \\
\hline 4. 0 primeiro cigarro da manhã é o que traz mais satisfação? \\
\hline (0) não \\
\hline (1) sim \\
\hline 5. Você fuma mais nas primeiras horas da manhã do que no restante \\
do dia? \\
\hline (0) não \\
\hline (1) sim \\
\hline 6 . Você fuma mesmo quando acamado por doença? \\
\hline (0) não \\
\hline (1) sim \\
\hline Interpretação do resultado (soma dos pontos obtidos em cada questão): \\
0 a 2 pontos = muito baixa dependência física \\
a a pontos = baixa dependência física \\
5 pontos = média dependência fisica \\
6 a 7 pontos = elevada dependência física \\
8 a 10 = muito elevada dependência física \\
\hline \\
\hline
\end{tabular}

Fonte: adaptada de Ranney $L$ et al. ${ }^{407}$

300mg/dia versus placebo, mostrou abstinência de 44,2\% versus $9,2 \%$ em favor da bupropiona. ${ }^{408}$ Em levantamento da literatura, foi encontrado que a bupropiona parece ser mais efetiva em pacientes que abandonaram e/ou falharam no tratamento com a terapia de reposição de nicotina. ${ }^{409}$ Por outro lado, dois estudos em fumantes hospitalizados por eventos coronarianos agudos não encontraram aumentos na cessação do tabagismo em fumantes que receberam bupropiona versus placebo. ${ }^{410,411}$

A reposição de nicotina é tratamento eficaz e apresenta benefícios no abandono ao tabagismo. Em um estudo, o uso de alguma forma de reposição de nicotina levou a um aumento da abstinência em até 60\% (RR: 1,60; IC 95\%: 1,53 a 1,68) quando comparada ao placebo. O aumento da eficácia do tratamento ocorre na associação de modos de reposição de nicotina se comparado com apenas um modo (RR: 1,34; IC 95\%: 1,18 a 1,51). ${ }^{412} \mathrm{~A}$ reposição de longa duração mais utilizada são os adesivos transdérmicos e as de curta duração são a goma de mascar, sprays nasais e inaladores, alguns ainda não disponíveis no Brasil.
A vareniclina é um agonista parcial do receptor nicotínico e, ao substituir a ação da nicotina, reduz a intensidade dos sintomas de abstinência. Sua ligação ao receptor reduz também os efeitos de recompensa e prazer associados ao cigarro, o que pode reduzir alguns dos efeitos da privação. Sua eficácia foi demonstrada em seis estudos clínicos envolvendo um total de 3.659 fumantes crônicos. ${ }^{413-416}$ A vareniclina duplicou as taxas de abstinência em relação ao placebo (RR: 2,24; IC 95\%: 2,06 a 2,43). ${ }^{417}$ Estudo envolvendo mais de 8.000 fumantes comparou o uso de vareniclina, bupropiona, adesivos de nicotina e placebo, randomizados na razão de $1: 1: 1: 1$, e encontrou maior taxa de abstinência do grupo vareniclina, em 6 meses, do que todos nos outros grupos. ${ }^{418} \mathrm{Em}$ um estudo randomizado em pacientes com coronariopatia crônica, o uso de vareniclina mostrou aumento da chance de abstinência contínua em 1 ano, em comparação com o placebo (OR: 3,14; IC 95\%: 1,94 a 5,11$).{ }^{419}$ Dois estudos randomizados em fumantes com SCA encontraram taxas mais altas de abstinência contínua em 24 semanas e mais alta prevalência de abstinência em 52 semanas naqueles que tomaram vareniclina versus placebo. ${ }^{420,421}$ A vareniclina tem como uma de suas principais limitações o alto custo e a ocorrência de náusea como efeito colateral limitante em alguns pacientes.

A associação entre os métodos parece ser mais efetiva que o tratamento isolado. Em recente metanálise envolvendo quatro estudos, a associação entre vareniclina e bupropiona mostrou maiores taxas de abstinência em 6 meses quando comparada à vareniclina em monoterapia. Os efeitos eram mais observados nos tabagistas com alto grau de dependência e nos com alta carga tabágica. O benefício, entretanto, não se manteve no seguimento de 12 meses. O uso da associação aumentou significativamente os sintomas de ansiedade nos pacientes. ${ }^{422}$ Portanto, a associação entre os métodos parece ser segura e mais efetiva quando são utilizadas vareniclina ou bupropiona em associação com a terapia de reposição de nicotina.

A bupropiona e a vareniclina também parecem ser seguras para pacientes com doenças cardiovasculares. O achado de alguns estudos aumentando a ocorrência de eventos neuropsiquiátricos em usuários dessas medicações levou a Food and Drug Administration (FDA) a exigir um aviso em bula sobre esses riscos. Após novos estudos, esse risco foi reavaliado, sendo retirada a observação em bula pela própria FDA em 2016. .23 $^{23}$

Uma polêmica questão na abordagem do tabagista é a substituição do cigarro tradicional por cigarro com menor quantidade de nicotina ou por dispositivos vaporizadores de nicotina, estes últimos conhecidos como cigarros eletrônicos. ${ }^{424}$ Ambas as estratégias são classificadas apenas como potenciais controles de danos.

A avaliação dos cigarros com menor quantidade de nicotina apresentou pouca efetividade, visto que os tabagistas, em geral, compensam a menor concentração de nicotina do cigarro com o consumo maior de cigarros diários, ou outras formas de adição de nicotina. ${ }^{425}$ Já os dispositivos vaporizadores de nicotina, que aparentemente expõem o paciente a menor quantidade 
de agentes cancerígenos que o cigarro tradicional, tem por outro lado a grande variabilidade de combinações de substâncias tóxicas, além do explosivo aumento do uso por jovens, principalmente nos EUA. ${ }^{426}$ No Brasil, a venda desse tipo de dispositivo encontra-se proibida. Recentemente, várias mortes nos EUA foram relacionadas ao uso desses dispositivos, por problemas pulmonares agudos, advindos de substâncias inaladas. O número de doentes relacionados ao Vaping atingiu um total de 2.807 que necessitou de hospitalização, além de 68 mortes confirmadas pelo Center for Disease Control (CDC; Centro de Controle de Doenças dos EUA). Até o presente momento, não há evidências que suportem o uso dessas estratégias, sendo o uso de cigarros eletrônicos, em particular, potencialmente perigoso.

Cessação do tabagismo - Sumário de recomendações e evidências

Recomenda-se cessar o tabagismo e evitar exposição a ambientes com fumantes, tanto no trabalho quanto no lar.

Acompanhamento no longo prazo, encaminhamento a programas específicos ou farmacoterapia (incluindo reposição de nicotina) são úteis quando associados às clássicas estratégias não farmacológicas.

Uso de estratégias contra o tabagismo para controle de danos como cigarros com menor concentração de nicotina.

Uso de dispositivos vaporizadores de nicotina para controle de danos e estratégia para abandono do tabagismo em pacientes resistentes

\subsection{Recomendações Alimentares}

Os pacientes que tiveram SCASSST classificam-se, obviamente, como de muito alto risco cardiovascular e, portanto, uma redução considerável nos valores do colesterol é absolutamente indispensável. Além da terapia com estatinas, que é suportada por diversas metanálises ${ }^{427,428}$ e estudos randomizados, ${ }^{429-432}$ a terapia dietética é ponto de central importância e traz expressivo número de evidências. ${ }^{433,434}$

É recomendada uma dieta padrão que enfatiza a ingestão de vegetais, frutas, grãos integrais, leguminosas, fontes de proteínas saudáveis (produtos lácteos, aves com baixo teor de gordura [sem pele], peixe/frutos do mar e nozes) e óleos vegetais não tropicais. Deve-se evitar a ingestão de doces, bebidas açucaradas e o próprio açúcar, além do excesso de carnes vermelhas.

O estudo PREDIMED testou o uso de uma dieta do tipo mediterrânea, mostrando redução em eventos cardiovasculares, especialmente AVC. ${ }^{435}$

Esse padrão alimentar deve ser ajustado para requisitos calóricos apropriados, padrões culturais, preferências alimentares e terapia nutricional para outras condições incluindo diabetes. A ingestão calórica deve ser ajustada para evitar ganho de peso e em caso de pacientes com sobrepeso/obesidade, para promover perda de peso. O uso de suplementos alimentares vitamínicos ou antioxidantes não deve ser prescrito de rotina para prevenção secundária. ${ }^{436}$

\section{Reabilitação Cardiovascular}

O exercício físico reduz a aterogênese, promove ação anti-inflamatória, melhora a função endotelial, diminui o tônus simpático, aumenta o $\mathrm{HDL}$, reduz a pressão arterial e a resistência à insulina, dentre outros efeitos benéficos, não devendo ser negado ao paciente após SCA. ${ }^{437}$ Nos programas de reabilitação cardiovascular, a atividade física está inserida no contexto terapêutico. O sedentarismo é problema de ordem mundial e está entre os principais fatores de risco passíveis de intervenção na prevenção primária, sendo ainda mais importante no âmbito da prevenção secundária de eventos coronarianos

O processo de reabilitação cardiovascular do paciente acometido por SCA inicia-se ainda durante a internação, na fisioterapia hospitalar, com o processo de deambulação precoce e a realização de movimentos passivos e ativos dos principais grupos musculares. Ainda durante o período da internação, o paciente deve ser orientado sobre escalas de percepção do esforço (p. ex., escala de BORG), que será útil na sua orientação após a alta.

Na ocasião da alta, é importante que todo paciente receba orientação adequada sobre a prática de atividade física que, inicialmente, no domicílio, deverá ser de leve intensidade, como continuidade aos exercícios que já vinham sendo realizados na fase intra-hospitalar (fase 1), e sobre como se monitorar. Deve ser indicada avaliação precoce em programa formal de reabilitação ou, quando não disponível, ser o paciente orientado sobre programa de exercícios que possam ser acompanhados pelo fisioterapeuta ou educador físico, de acordo com os limites propostos pelo médico (fase 2).

Alguns estudos demonstram que pacientes encaminhados a programas de exercício após um evento coronariano agudo cursaram com melhor qualidade de vida, menor recorrência de sintomas e de novos eventos cardiovasculares. ${ }^{438-440}$

Apesar dos efeitos positivos bem determinados dos programas de reabilitação, o encaminhamento sistemático e a aderência ainda são um grande desafio. ${ }^{441}$ Falta de educação médica continuada em reabilitação cardíaca, falta de conhecimento sobre a segurança dos programas (taxa de eventos de 1 para cada 112 mil pacientes/hora) e dificuldade de tornar esses programas custo-efetivos são parte importante do problema.

\subsection{Orientação sobre Atividade Física na Ocasião da Alta}

O primeiro passo na avaliação do paciente para programa de reabilitação cardiovascular, após avaliação clínica e dos exames complementares disponíveis, será o de verificar se existe alguma contraindicação absoluta à prática de atividade física. ${ }^{442,443}$ A Tabela 3.2 enumera as contraindicações para a prática de atividade física regular.

De posse dos dados clínicos com foco na ocorrência de angina, classificação funcional, função ventricular, presença de lesões coronárias residuais e de arritmias, segue-se com a classificação do risco para a prática de atividade física no cardiopata. Esta classificação é útil na determinação do nível de suporte a ser ofertado durante o programa e a necessidade de monitoramento durante as sessões de exercícios. ${ }^{442,443}$ 
Tabela 3.2 - Classificação de risco para exercício em pacientes cardiopatas

\begin{tabular}{|c|c|c|}
\hline Baixo risco & Risco moderado & Alto risco \\
\hline $\begin{array}{l}\text { - FEVE > 50\% } \\
\text { - Ausência de arritmias complexas } \\
\text { - Ausência de sintomas de insuficiência cardíaca } \\
\text { congestiva } \\
\text { - Ausência de angina com o esforço ou no } \\
\text { período de recuperação } \\
\text { - Ausência de lesão valvular grave ou moderada } \\
\text { - Capacidade funcional } \geq 7 \text { METS }\end{array}$ & $\begin{array}{l}\text { - FEVE: } 40 \% \text { a } 49 \% \\
\text { - Sinais/sintomas, incluindo angina em níveis } \\
\text { moderados de exercício ( } 5 \text { a 6,9 METS) ou no } \\
\text { período de recuperação } \\
\text { - Lesão valvar moderada }\end{array}$ & $\begin{array}{l}\text { - FEVE < } 40 \% \\
\text { - Sobreviventes de parada cardíaca ou morte } \\
\text { súbita } \\
\text { - Arritmias ventriculares complexas em repouso } \\
\text { ou no exercício } \\
\text { - Doença valvular grave } \\
\text { - Cardiopatia congênita não corrigida } \\
\text { - Capacidade funcional <5 METS } \\
\text { Infradesnível do segmento ST isquêmico durante } \\
\text { exercício > } 2 \mathrm{~mm}\end{array}$ \\
\hline
\end{tabular}

FEVE: fração de ejeção do ventrículo esquerdo.

Pacientes de baixo risco podem iniciar exercícios físicos em ambiente não necessariamente supervisionado pelo médico acompanhado pelo fisioterapeuta ou educador físico. Já os de risco moderado, se disponível, preferencialmente, devem iniciar o programa de exercícios em ambiente com supervisão médica e com recursos de suporte avançado de vida e evoluir para programa externo semissupervisionado, caso não apresentem intercorrências após 12 semanas de exercícios. Quando um programa de reabilitação cardiovascular formal e sob supervisão médica no local não é disponível, estes podem ser realizados sob supervisão do educador físico ou fisioterapeuta, obedecendo a limites predeterminados de segurança de acordo com a avaliação do cardiologista. O local e a equipe devem ter capacitação ao menos em suporte básico de vida e um desfibrilador externo automático disponível nas proximidades. Os pacientes de alto risco são preferencialmente conduzidos em ambiente sob supervisão médica, com equipe de fisioterapia e/ou educação física treinada em suporte básico de vida e com recursos locais para suporte avançado de vida.

Em todas as situações, o monitoramento da frequência cardíaca deve ser estimulado como guia da intensidade do esforço. A necessidade de monitoramento eletrocardiográfico é definida caso a caso pela equipe médica do programa de reabilitação.

As zonas de exercício de segurança podem ser definidas idealmente com base em uma prova funcional (teste cardiopulmonar ou teste ergométrico), ou, em casos específicos, podem ser guiadas apenas pela percepção do esforço. Os exercícios aeróbicos devem ser mantidos, em geral, com a frequência cardíaca entre a indicada pelo limiar anaeróbico e pelo ponto de compensação respiratória, quando disponível um teste cardiopulmonar (zona em que, apesar da produção de ácido láctico, não há acidose metabólica descompensada, relacionando-se assim a uma menor chance de eventos arrítmicos ou de sobrecarga cardiovascular). Quando um teste cardiopulmonar não for disponível, pode-se trabalhar entre $70 \%$ e $85 \%$ da frequência cardíaca ( $F C$ ) máxima atingida em um teste ergométrico ou $50 \%$ a $80 \%$ da $\mathrm{FC}$ de reserva adicionada à $\mathrm{FC}$ de repouso, em que: $\mathrm{FC}$ de reserva $=\mathrm{FC}$ pico esforço - FC repouso. Nos pacientes que apresentem alteração eletrocardiográfica ou sintomas sugestivos de isquemia ao esforço, o limite deve estar, em geral, em 10 batimentos a menos que o de início do sintoma ou da alteração de ST. Em casos específicos e sob supervisão médica, o paciente pode ser treinado no limite de isquemia.

O médico deve idealmente determinar os seguintes parâmetros para o exercício:

- Frequência semanal.

- Intensidade (utilizando a escala de Borg e a frequência cardíaca ou a carga determinada em um teste cardiopulmonar ou no teste ergométrico).

- Modalidade (p. ex., caminhada, bicicleta, remo).

- Duração da sessão.

- Exercícios resistidos devem também ser estimulados. Recomendar 40\% a 60\% da contração voluntária máxima (baixa a moderada intensidade), 8 a 15 repetições, 1 a 3 séries. ${ }^{443,444}$

\section{Reabilitação cardiopulmonar - Sumário de recomendações e evidências}

Orientação sobre atividade física na ocasião da alta e programas de reabilitação cardíaca devem ser estimulados em todos os pacientes após SCA.

A intensidade e o grau de supervisão do programa de reabilitação devem ser estabelecidos de acordo com a classificação de risco do paciente.

Reabilitação cardiopulmonar nas seguintes condições (a menos que devidamente resolvidas): infarto agudo do miocárdio com $<72 \mathrm{~h}$; angina instável em curso; arritmias complexas graves não controladas; insuficiência cardíaca descompensada; lesão de tronco de coronária esquerda grave instável ou com indicação de intervenção; hipertensão arterial descompensada (sistólica $>190 \mathrm{mmHg}$ ou diastólica $>120 \mathrm{mmHg}$ ).

\section{Medicamentos a Serem Prescritos por Ocasião da Alta Hospitalar}

\subsection{Antitrombóticos}

\section{A. Troca de Antiplaquetários}

A abordagem de como selecionar o segundo antiplaquetário a ser usado em conjunto com o AAS já foi feita previamente. Por ocasião da alta hospitalar, contudo, 
pode ser necessária a troca do segundo antiplaquetário por algum motivo, entre os quais:

- Custo.

- Efeitos adversos limitantes (p. ex., dispneia com o ticagrelor, sangramento em vigência dos fármacos mais potentes como ticagrelor e prasugrel).

- Preferência do paciente por usar medicações com tomada única diária (p. ex., prasugrel, se tratado com ICP e sem AVC/AIT prévio) em vez de duas vezes por dia (ticagrelor).

A transição de clopidogrel para ticagrelor foi a única estudada em trabalho com poder suficiente para avaliar desfechos clínicos, apesar de o estudo não ter sido desenvolvido com este objetivo. No estudo PLATO, 46\% dos pacientes randomizados para receber ticagrelor haviam sido pré-tratados com clopidogrel (dose de 300 a 600mg). ${ }^{152}$ A segurança e a eficácia do ticagrelor não foram afetadas pelo uso prévio de clopidogrel. ${ }^{248}$ Já no estudo TRITONTIMI-38, que avaliou o uso de prasugrel, a utilização prévia de outro inibidor $\mathrm{P}_{2} \mathrm{Y}_{12}$ foi considerada critério de exclusão para o estudo. ${ }^{154}$ As outras trocas entre inibidores $\mathrm{P}_{2 \mathrm{Y}_{12}}$ (p. ex., entre ticagrelor e prasugrel ou de ticagrelor/ prasugrel para clopidogrel) foram avaliadas por estudos de farmacodinâmica e por registros observacionais, os quais servem mais como geradores de hipótese, uma vez que não foram desenhados para avaliar desfechos clínicos da forma adequada. ${ }^{445-449}$ Dessa forma, existem menos evidências para embasar tais trocas.

No paciente com SCA há menos de 30 dias, recomendamos que, caso seja necessária a troca entre agentes $\mathrm{P}_{2} \mathrm{Y}_{12}$, seja seguido o esquema da Figura 3.1. ${ }^{450,451}$

Assim, como regra geral, em todos cenários de troca de antiplaquetários $\mathrm{P}_{2} \mathrm{Y}_{12}$ ainda na fase aguda da doença coronariana ( $<30$ dias), deve-se utilizar dose de ataque da nova medicação, seguida de dose de manutenção. Exceção a esta regra se faz quando a mudança é em função de descalonamento da terapia com prasugrel ou ticagrelor, para clopidogrel, devido a sangramento ou de risco de sangramento aumentado.

Quanto ao horário de administração do novo fármaco, recomenda-se esperar $24 \mathrm{~h}$ após a administração do primeiro medicamento. Exceção a esta regra se faz quando o medicamento a ser substituído é o clopidogrel.

Nos casos em que o paciente tenha apresentado SCA há mais de 30 dias e seja necessária a troca entre agentes, recomenda-se o esquema da Figura 3.2.

Neste cenário, há algumas diferenças:

- Em todas as situações, recomenda-se aguardar 24h entre a última dose da medicação prévia para então iniciarse a medicação nova.

- Dose de ataque do novo agente é recomendada somente quando o fármaco a ser substituído é o ticagrelor. Estudos clínicos demonstraram maior reatividade plaquetária nas primeiras $48 \mathrm{~h}$ quando da transição de ticagrelor para clopidogrel ${ }^{448,449}$ ou para prasugrel. ${ }^{447}$ Essa diferença se deve ao fato de o ticagrelor ser um bloqueador reversível do $\mathrm{P}_{2} \mathrm{Y}_{12}$, enquanto os tienopiridínicos (clopidogrel e prasugrel) são bloqueadores não reversíveis.
Mudança de inibidores P2Y $_{12}$ - Sumário de recomendações e evidências

Em pacientes admitidos com SCA nos quais foi administrado clopidogrel e que se deseja trocar para ticagrelor nos primeiros 30 dias, deve ser feita dose de ataque de $180 \mathrm{mg}$ deste, independentemente do momento e da dose do clopidogrel administrada.

Em relação às outras trocas entre inibidores $P 2 Y_{12}$ orais, as mesmas devem ser consideradas em casos de efeitos adversos ou outros fatores, e seguir os esquemas recomendados por esta Diretriz.

\section{B. Duração da Dupla Terapêutica Antitrombótica}

\section{B.1. Além de 12 Meses}

\section{B.1.1. Antiplaquetários}

Os estudos que avaliaram o uso de clopidogrel, prasugrel e ticagrelor em pacientes com SCA mantiveram a dupla terapêutica antiplaquetária (DAP) por um tempo médio de 12 meses. Assim, este é o tempo padrão recomendado, independentemente da estratégia terapêutica adotada (tratamento clínico, angioplastia ou cirurgia de revascularização miocárdica). No caso de pacientes tratados clinicamente, as opções de antiplaquetários são apenas o ticagrelor e o clopidogrel, visto que o prasugrel não se mostrou superior ao clopidogrel neste cenário. ${ }^{452}$

O uso de DAP é uma forma muito eficaz de se prevenir trombose de stent. O risco de trombose de stent tardia (entre 1 mês e 1 ano da implantação do dispositivo) e muito tardia ( $>1$ ano após a angioplastia) vem diminuindo consideravelmente com o uso dos stents farmacológicos mais modernos. Assim, a manutenção de DAP além de 1 ano após evento de SCA e angioplastia parece carregar um aumento do risco de sangramento mais deletério do que o potencial benefício relacionado à prevenção de tromboses muito tardias de stent. Contudo, o estudo PEGASUS demonstrou que, em pacientes com histórico de infarto $>1$ ano e critérios de alto risco adicionais (diabetes, idade $>65$ anos, doença renal crônica, doença coronária multiarterial ou dois ou mais infartos prévios), o uso prolongado de DAP com AAS e ticagrelor reduziu a incidência de desfechos isquêmicos, incluindo novos casos de infarto não relacionados com trombose de stent e de AVC, em relação à monoterapia com AAS (HR 0,84; IC 95\% 0,74 a 0,95; p = 0,004 e HR 0,85; IC 95\% 0,75 a 0,96; $p=0,008$, para as doses de 60mg e 90mg, respectivamente). ${ }^{453} \mathrm{O}$ uso da DAP além de 12 meses estaria, portanto, mais associado à proteção sistêmica contra eventos trombóticos do que à prevenção de tromboses mais tardias de stent. Tal argumento foi reforçado por subanálise do mesmo estudo em que os pacientes sem histórico de angioplastia com stent tiveram benefício similar na redução de eventos isquêmicos cardiovasculares quando comparados a pacientes com angioplastia prévia. ${ }^{454} \mathrm{~A}$ diminuição de desfechos cardiovasculares foi antagonizada por um aumento do número de sangramento maiores (HR 2,32; IC 95\% 1,68 a 3,21; $p<0,001$ e HR 2,69, IC 95\% 1,96 a 3,70; $p<0,001$, para as doses de 60 e $90 \mathrm{mg}$, respectivamente). Não houve 


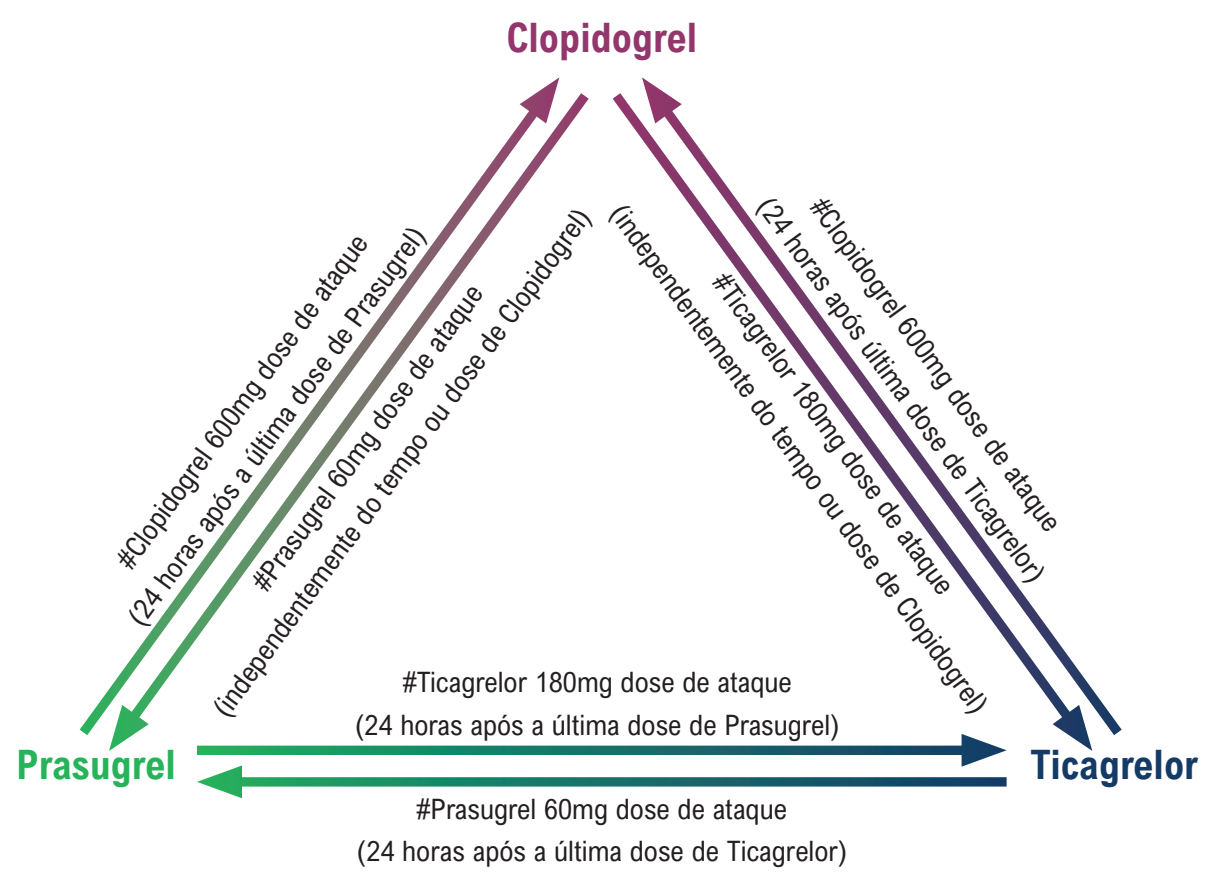

Figura 3.1 - Recomendações em relação à troca de inibidores $P 2 Y_{12}$ em pacientes nos primeiros 30 dias após síndrome coronariana aguda. Recomenda-se dose de ataque do novo agente de forma rotineira. *Se estiver havendo descalonamento da terapia com prasugrel ou ticagrelor para clopidogrel devido a sangramento ou a risco de sangramento aumentado, pode-se considerar fazer apenas a dose de manutenção do clopidogrel. Adaptada de Valgimigli et al. ${ }^{451}$

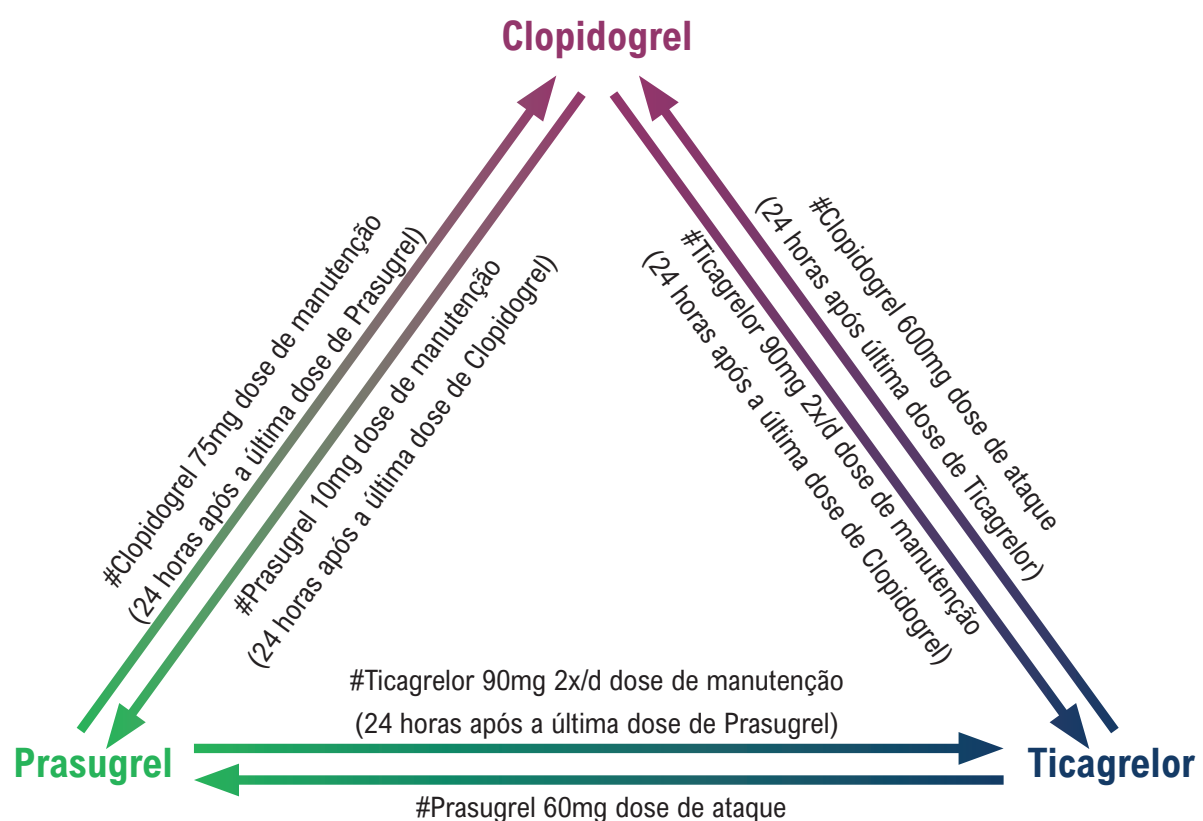

\#Prasugrel 60mg dose de ataque

(24 horas após a última dose de Ticagrelor)

Figura 3.2 - Recomendações em relação à troca de inibidores $P 2 Y_{12}$ em pacientes após 30 dias de síndrome coronariana aguda. *Se estiver havendo descalonamento da terapia com ticagrelor para clopidogrel devido a sangramento ou a risco de sangramento aumentado, pode-se considerar fazer apenas a dose de manutenção do clopidogrel. Adaptado de Valgimigli et al. ${ }^{451}$ 
aumento de sangramento fatal ou de hemorragia intracraniana com o ticagrelor. O grupo que usou a dose mais elevada de ticagrelor (90mg, 2 vezes/dia) não teve benefícios adicionais em relação à redução do risco isquêmico e apresentou maiores taxas de sangramento. A dose de 60mg, portanto, é a aprovada para esta indicação, em casos selecionados de pacientes após 1 ano de IAMSSST que toleraram a DAP no primeiro ano.

O DAPT trial foi outro estudo que avaliou o uso de terapia antiplaquetária dupla por tempo superior a 12 meses. ${ }^{455}$ Todos os pacientes incluídos haviam sido submetidos à angioplastia com stent farmacológico e cerca de um terço teve a angioplastia realizada no contexto de uma SCASSST. Nesse estudo, os pacientes usavam DAP pelo tempo padrão de 12 meses e, caso tivessem sido bem aderentes aos antiplaquetários e não tivessem apresentado sangramentos relevantes, eram então randomizados para continuar com a terapia dupla por mais 18 meses ou continuar apenas com o AAS em associação a placebo. De forma similar ao PEGASUS, foi notada redução de eventos isquêmicos, mas este benefício foi contrabalanceado pelo aumento do risco de sangramento. Neste estudo, houve a redução de um caso de trombose de stent para cada 100 pacientes tratados com DAP prolongada, mas ao custo da ocorrência de um evento de sangramento moderado ou importante em cada 111 pacientes submetidos a este mesmo tratamento. No DAPT trial, os inibidores $\mathrm{P}_{2} \mathrm{Y}_{12}$ usados foram o clopidogrel $(65,2 \%$ dos casos) e o prasugrel (34,8\% dos pacientes).

Metanálise com > 32.000 pacientes antes da publicação do PEGASUS encontrou aumento significativo na incidência de infarto no grupo que usou DAP por 12 meses (em comparação com $>12$ meses $\mathrm{OR}=1,57$, IC 95\% 1,30 a 1,90), com menor incidência de sangramento (OR =0,65, IC 95\% 0,52 a 0,81). ${ }^{456}$ Metanálise posterior, incluindo o PEGASUS, encontrou diminuição significativa de mortalidade por qualquer causa a favor do grupo com DAP por $>12$ meses (HR $=0,89$, IC 95\% 0,79 a 0,99). ${ }^{457}$ Conclui-se assim que os três inibidores da $\mathrm{P}_{2} \mathrm{Y}_{12}$ disponíveis no Brasil (clopidogrel, ticagrelor e prasugrel) têm potencial em reduzir eventos isquêmicos quando usados associados a AAS por período superior a 12 meses, porém com aumento do risco de sangramento. Fazse necessário, portanto, avaliar de formada individualizada o risco do paciente tanto em relação a eventos isquêmicos quanto em relação a sangramentos. Escores clínicos permitem estimar, com parâmetros mais objetivos, o risco isquêmico e o risco hemorrágico conforme as características clínicas do paciente. Podem, portanto, auxiliar na tomada de decisão quanto à duração da DAP.

O estudo PRECISE-DAPT (Predicting bleeding complications in patients undergoing stent implantation and subsequent dual antiplatelet therapy) avaliou 14.963 pacientes que haviam sido submetidos à angioplastia e gerou um escore constituído de cinco variáveis (idade, clearance de creatinina, hemoglobina, contagem de leucócitos e história de sangramento espontâneo) para predizer o risco de sangramento neste cenário. ${ }^{458}$ Além de ser avaliado nesta população, o escore foi validado em um grupo de mais de 14.000 pacientes. Pacientes com escore baixo $(<25)$ apresentaram benefício com a DAP prolongada, demonstrando redução do desfecho isquêmico composto (IAM, trombose definitiva de stent, AVC e necessidade de revascularização de órgão-alvo), com NNT de 65, sem aumentar significativamente o risco de sangramento. Por outro lado, em pacientes com escore alto ( $\geq 25)$, a DAPT prolongada foi associada a maior risco de sangramento (NNH 38), sem proporcionar benefício em relação à prevenção quanto a desfechos isquêmicos. Vale ressaltar, no entanto, que este escore foi derivado de estudos randomizados com ICP (com ou sem SCA), e não exclusivamente de uma população com SCA, em que o risco de eventos isquêmicos tende a ser maior comparado a pacientes com DAC estável.

O escore DAPT (Tabela 3.3) foi derivado de uma coorte do trial de mesmo nome. ${ }^{459}$ Nesta análise, pacientes com escore de risco alto $(\geq 2)$ apresentaram importante redução de desfechos isquêmicos com o uso de DAPT por 30 meses (NNT de 34), à custa de um pequeno aumento no risco de sangramento (NNH de 272). Por outro lado, pacientes com escore baixo $(<2)$ não mostraram redução do risco isquêmico com a DAP prolongada e ainda evoluíram com aumento considerável no risco de sangramento ( $\mathrm{NNH}$ de 64).

Tabela 3.3 - Escore DAPT (Dual Antiplatelet Therapy) trial

\begin{tabular}{lll}
\hline Variáveis & Pontos \\
\hline Idade $\geq 75$ anos & -2 \\
\hline Idade entre 65 e 74 anos & -1 \\
\hline Idade $<65$ anos & 0 \\
\hline Tabagismo atual & 1 \\
\hline Diabetes melito & 1 \\
\hline IAM na apresentação inicial & 1 \\
\hline ICP ou IAM prévio & 1 \\
\hline Diâmetro do stent $<3$ mm & 1 \\
\hline Stent eluído com paclitaxel & 2 \\
\hline IC ou FEVE < 30\%
\end{tabular}

IAM: infarto agudo do miocárdio; ICP: intervenção coronária percutânea; IC: insuficiência cardíaca; FEVE: fração de ejeção do ventrículo esquerdo. 


\section{B.1.2. Anticoagulantes}

O estudo COMPASS incluiu > 27.000 pacientes com doença coronariana crônica para utilizarem rivaroxabana $2,5 \mathrm{mg} 2$ vezes/dia + AAS 100mg $1 \mathrm{vez} /$ dia $(\mathrm{n}=9152)$ ou rivaroxabana $5 \mathrm{mg} 2$ vezes/dia $(n=9117)$ ou AAS 100mg/dia ( $\mathrm{n}=9126)$. Em um prazo médio de acompanhamento de 23 meses, demonstrou superioridade do grupo rivaroxabana + AAS sobre AAS isolado (HR =0,76, IC 95\% 0,66 a 0,86 para o desfecho primário composto de óbito CV, IAM ou AVC), à custa de aumento na incidência de sangramento $(\mathrm{HR}=$ 1,70, IC 95\% 1,40 a 2,05). Importante: houve diminuição significativa na incidência de óbito por qualquer causa $(\mathrm{HR}=$ 0,82, IC 95\% 0,71 a 0,96) e ausência de diferença significativa na incidência de sangramento fatal ou intracerebral. ${ }^{460}$ Considerando apenas os pacientes incluídos nos grupos rivaroxabana + AAS e AAS isolado, 2.423 apresentavam história de IAM < 2 anos, 3.279 entre 2 e 5 anos, e $5673>$ 5 anos. A comparação entre os grupos apresentou $\mathrm{HR}=0,70$ para pacientes com IAM $<2$ anos, HR $=0,81$ para aqueles com IAM entre 2 e 5 anos, e HR $=0,72$ para aqueles com $>5$ anos (P-interação $=0,93)^{\cdot 461}$

\section{B.2. Menos de 12 Meses}

O uso de monoterapia com ticagrelor foi avaliado no estudo GLOBAL LEADERS ${ }^{462}$ em 15.968 pacientes submetidosàa ICP (34\% com SCASSST). Os grupos recebiam AAS + ticagrelor por 1 mês, seguido de ticagrelor monoterapia por 23 meses, ou DAP padrão com AAS + clopidogrel (coronariopatia estável) ou AAS + ticagrelor (coronariopatia aguda) por 12 meses, seguido de monoterapia com AAS monoterapia por mais 12 meses. Ao final de 2 anos de seguimento, a meta principal do estudo (óbito por qualquer causa ou infarto) foi similar nos dois grupos (RR 0,87, IC 95\% 0,75 a 1,01). A meta secundária principal (sangramento BARC 3 ou 5) também foi similar entre os grupos ( $R R=0,97$, IC 95\% 0,78 a 1,20). Análise secundária em publicação posterior encontrou diminuição significativa na incidência da meta primária do estudo em pacientes com coronariopatia aguda e ICP em mais de uma coronária. ${ }^{463}$

Já o estudo TWILIGHT avaliou se, em pacientes submetidos à ICP e com características clínicas e angiográficas de alto risco de trombose ou sangramento, a descontinuação precoce de AAS seria segura. ${ }^{464}$ Foram incluídos 7.119 pacientes (4.614 com SCASSST), todos tratados por 3 meses após a ICP com AAS e ticagrelor. Após este período, foram randomizados para continuar a DAP ou para o uso de monoterapia com ticagrelor por mais 9 meses. O desfecho principal do estudo foi sangramento BARC 2, 3 ou 5. Ao final do seguimento, o grupo monoterapia com ticagrelor apresentou redução de 44\% (HR 0,56; IC 95\%: 0,45-0,68; p < 0,001) no desfecho principal do estudo, sem que isso fosse acompanhado de aumento no risco isquêmico (desfecho secundário, estudo sem poder amostral para esta conclusão).

O’Donoghue et al., em metanálise recém-publicada, analisando monoterapia com $\mathrm{iP}_{2} \mathrm{Y}_{12}$ versus DAP em aproximadamente 17.000 pacientes com coronariopatia aguda, encontraram HR de 0,50 (IC 95\% 0,41 a 0,61) para sangramento, e de 0,85 (IC 95\% 0,70 a 1,03) para MACE. 465

\begin{tabular}{|c|c|c|c|c|}
\hline \multicolumn{5}{|c|}{$\begin{array}{l}\text { Duração de dupla terapêutica antitrombótica em pacientes } \\
\text { SCASSST em ritmo sinusal - Sumário de recomendações e }\end{array}$} \\
\hline \multicolumn{4}{|c|}{$\begin{array}{l}\text { Após SCASSST, é recomendado que a DAPT seja mantida } \\
\text { por } 12 \text { meses, independentemente da estratégia clínica } \\
\text { adotada (angioplastia, cirurgia de revascularização } \\
\text { miocárdica ou tratamento clínico). }\end{array}$} & A \\
\hline \multicolumn{4}{|c|}{$\begin{array}{l}\text { Em pacientes com SCASSST e risco aumentado de } \\
\text { sangramento, pode-se considerar manter o tempo de } \\
\text { dupla antiagregação plaquetária por apenas } 6 \text { meses, } \\
\text { suspendendo-se o inibidor } \mathrm{P}^{2} \mathrm{Y}_{12} \text { após este período, } \\
\text { independentemente da estratégia clínica adotada } \\
\text { (angioplastia, cirurgia de revascularização miocárdica ou } \\
\text { tratamento clínico) }\end{array}$} & B \\
\hline \multicolumn{3}{|c|}{$\begin{array}{l}\text { Em pacientes com SCASSST submetidos à ICP, pode-se } \\
\text { considerar manter a DAPT por } 3 \text { meses seguido de } \\
\text { monoterapia com iP2Y }{ }_{12} \text {, (preferencialmente ticagrelor). }\end{array}$} & Ila & A \\
\hline \multicolumn{3}{|c|}{$\begin{array}{l}\text { Associar uma segunda medicação antitrombótica (ver } \\
\text { tabela abaixo) ao AAS após os } 12 \text { meses de DAP em } \\
\text { pacientes com alto risco isquêmico e baixo risco de } \\
\text { sangramento. }\end{array}$} & Ila & A \\
\hline \multicolumn{5}{|c|}{ Opções de terapia antitrombótica/antiplaquetária estendida } \\
\hline Fármaco & Trial & Dose & \multicolumn{2}{|l|}{ Indicação } \\
\hline Clopidogrel & DAPT & $75 \mathrm{mg}$ por dia & \multicolumn{2}{|c|}{$\begin{array}{l}\text { Pós- } \\
\text { angioplastia que } \\
\text { tolerou DAP por } \\
1 \text { ano }\end{array}$} \\
\hline Prasugrel & DAPT & $\begin{array}{l}10 \mathrm{mg} \text { por dia } \\
(5 \mathrm{mg} \text { se peso }< \\
60 \mathrm{~kg} \text { ou idade }> \\
75 \text { anos) }\end{array}$ & \multicolumn{2}{|c|}{$\begin{array}{l}\text { Pós- } \\
\text { angioplastia que } \\
\text { tolerou DAP por } \\
1 \text { ano }\end{array}$} \\
\hline Ticagrelor & $\begin{array}{l}\text { PEGASUS- } \\
\text { TIMI-54 }\end{array}$ & $\begin{array}{l}\text { 60mg } 2 \text { vezes/ } \\
\text { dia }\end{array}$ & \multicolumn{2}{|c|}{$\begin{array}{l}\text { Pós-infarto com } \\
\text { risco isquêmico } \\
\text { aumentado }\end{array}$} \\
\hline Rivaroxabana & COMPASS & $\begin{array}{l}2,5 \mathrm{mg} 2 \text { vezes/ } \\
\text { dia }\end{array}$ & \multicolumn{2}{|c|}{$\begin{array}{l}\text { Pacientes } \\
\text { coronariopatas } \\
\text { ou com } \\
\text { doença arterial } \\
\text { periférica } \\
\text { com alto risco } \\
\text { trombótico }\end{array}$} \\
\hline
\end{tabular}

Atenção especial deve ser dada quando da prescrição de antiplaquetários a pacientes admitidos com SCA que, durante a internação hospitalar, são submetidos à cirurgia de revascularização miocárdica. Subanálises dos estudos CURE, ${ }^{466}$ PLATO $^{249}$ e TRITON ${ }^{237}$ mostraram que pacientes submetidos à revascularização cirúrgica parecem se beneficiar de forma similar aos outros indivíduos incluídos nestes trials. Dessa forma, o tienopiridínico deve ser reintroduzido assim que considerado seguro após a revascularização cirúrgica.

\section{Manejo de Antiagregantes no Paciente que Necessita de Anticoagulação Cronicamente}

A evidência que existe sobre o assunto se restringe praticamente a pacientes com fibrilação atrial (FA). A incidência de FA em pacientes com SCASSST varia de 5\% a $23 \% .{ }^{467}$ A terapia padrão para SCA é o uso de DAP por pelo menos 12 meses, com objetivo de prevenção de eventos isquêmicos. Em pacientes com FA e escore $\mathrm{CHA}_{2} \mathrm{DS}_{2} \mathrm{VASC} \geq 2$, 
é recomendado o uso de anticoagulação crônica, com objetivo de prevenção de eventos tromboembólicos. Quando um paciente apresenta essas duas situações associadas, surge a questão de qual a melhor combinação de antiagregantes e antitrombóticos, qual a melhor dose e qual a duração ideal de cada etapa do tratamento. Essas perguntas foram avaliadas em uma série de estudos clínicos de fase 3.

O primeiro desses estudos foi o trial WOEST, ${ }^{468}$ que recrutou 573 pacientes com FA em uso de anticoagulantes e que foram submetidos à angioplastia. Os pacientes foram então randomizados em dois grupos: um que usava clopidogrel associado ao anticoagulante e outro que usava terapia tripla (anticoagulante + clopidogrel + AAS). Observou-se que a terapia dupla foi associada a menor risco de sangramentos em 1 ano (19,4\% vs. 44,4\%, HR 0,36 , IC 95\% 0,26-0,50, p < 0,0001) sem que isso estivesse associado a maior risco de eventos isquêmicos.

O primeiro estudo randomizado a avaliar o uso de DOAC no contexto de terapia dupla e tripla no paciente com FA submetido à angioplastia foi o PIONEER AF-PCI. ${ }^{268}$ Neste, foram comparadas três estratégias antitrombóticas: rivaroxabana $15 \mathrm{mg}$ /dia associada a um inibidor $\mathrm{P}_{2} \mathrm{Y}_{12}$; terapia tripla com DAP e rivaroxabana em baixas doses $(2,5 \mathrm{mg} 12 / 12 \mathrm{~h})$; terapia tripla com DAP e antagonista da vitamina $\mathrm{K}$. As estratégias com rivaroxabana mostraram causar menor risco de sangramento do que a terapia tripla com antagonistas da vitamina K. Não houve diferença de desfechos isquêmicos, mas o tamanho amostral de 2.124 pacientes não gerava poder suficiente para este desfecho. Uma crítica a este estudo foi o fato de as doses reduzidas de rivaroxabana utilizadas não serem as aprovadas para tratamento antitrombótico na FA.

No ano seguinte, foi publicado o estudo RE-DUAL PCI, que randomizou 2.725 pacientes com FA submetidos à angioplastia. ${ }^{269}$ Terapia dupla com dabigatrana em diferentes doses (150mg 2 vezes/dia e 110mg 2vezes/ dia) associada a inibidor da $\mathrm{P} 2 \mathrm{Y}_{12}$ foi comparada a terapia tripla com varfarina. No grupo da terapia tripla, o AAS era mantido por 1 mês nos casos que haviam recebido stent não farmacológico, e por 3 meses no grupo tratado com stent farmacológico. Os dois esquemas com dabigatrana causaram menor risco de sangramentos do que o esquema com varfarina na terapia tripla. Adicionalmente, demonstrou-se que não existe interação entre inibidores de bomba de próton e o efeito do medicamento, na medida em que o uso dessa classe de medicamentos não influenciou os resultados principais do estudo. ${ }^{469} \mathrm{O}$ desenho do RE-DUAL PCI e do PIONEER AF-PCI não permitia avaliar se a redução do risco de sangramento observado com a terapia dupla era secundária à substituição de antagonistas da vitamina $\mathrm{K}$ por DOAC ou ao fato de se excluir o AAS do tratamento.

Para responder a esse questionamento, no ano de 2019, foi publicado o estudo AUGUSTUS, ${ }^{270}$ que randomizou 4.614 pacientes com FA que haviam sido submetidos à ICP ou apresentado SCA nos últimos 14 dias. O estudo usou um desenho fatorial $2 \times 2$ de forma que os pacientes foram randomizados em grupos que compararam apixabana $5 \mathrm{mg}$ 2 vezes por dia à varfarina, e grupos que compararam AAS a placebo. Todos os pacientes recebiam um inibidor $\mathrm{P} 2 \mathrm{Y}_{12^{\prime}}$ sendo utilizado o clopidogrel em mais de $90 \%$ dos casos. Foram estudados, portanto, quatro grupos: (1) inibidor $\mathrm{P}_{2} \mathrm{Y}_{12}+$ varfarina + AAS; (2) inibidor $\mathrm{P}_{2} \mathrm{Y}_{12}+$ varfarina + placebo; (3) inibidor $\mathrm{P}_{2} \mathrm{Y}_{12}+$ apixabana + AAS; (4) inibidor $\mathrm{P}_{2} \mathrm{Y}_{12}+$ apixabana + placebo. Na comparação entre apixabana e varfarina, notou-se menor risco de sangramento com o uso do DOAC. A cada 24 pacientes tratados com apixabana, evitou-se um sangramento clinicamente relevante durante o período do estudo. Já na comparação de AAS versus placebo, foi demonstrado que o uso de AAS aumentou o risco de sangramento. A cada 14 pacientes tratados com terapia tripla incluindo AAS, houve um sangramento relevante a mais no período de 6 meses. Não houve aumento de desfechos isquêmicos com o uso de terapia dupla em relação à terapia tripla neste estudo, devendo-se considerar que a amostra não foi calculada objetivando este desfecho. Importante salientar que, no AUGUSTUS, os pacientes foram randomizados em média 6 dias após a ICP ou a SCA. Dessa forma, os pacientes receberam ao menos um breve curso de AAS e terapia tripla, antes da randomização. Outro dado relevante sobre este estudo é que ele também incluiu pacientes com FA e SCA tratada clinicamente (cerca de um quarto dos pacientes incluídos).

O estudo ENTRUST randomizou 1.506 pacientes portadores de FA e submetidos à angioplastia coronariana, com seguimento de 12 meses. ${ }^{271} \mathrm{O}$ delineamento comparou a terapia dupla com edoxabana $60 \mathrm{mg} /$ dia associada a clopidogrel $75 \mathrm{mg} /$ dia à terapia tripla tradicional (varfarina e dupla antiagregação plaquetária com AAS e clopidogrel). A terapia dupla com edoxabana foi não inferior em relação ao desfecho primário sangramento. Este foi, portanto, o único ensaio clínico que não demonstrou, no que se refere ao desfecho sangramento, superioridade da terapia dupla com DOAC sobre a terapia tripla com varfarina.

Uma possível preocupação em se utilizar terapia dupla no paciente com FA submetido à angioplastia seria o aumento do risco isquêmico, principalmente de trombose de stent. Os cinco trials citados previamente (WOEST, PIONEER AF-PCl, RE-DUAL PCl, AUGUSTUS e ENTRUST) foram desenhados para mostrar redução de sangramento com o uso de terapia antitrombótica menos agressiva. Nenhum deles, contudo, tinha poder suficiente para se avaliar de forma adequada aumento de risco isquêmico. Para avaliar esse aspecto, duas metanálises foram desenvolvidas, ambas demonstrando que, em comparação com varfarina + DAP, o uso de dupla terapêutica antitrombótica diminui eventos hemorrágicos sem aumentar eventos. ${ }^{272,470,471}$ Entretanto, ao comparar dupla ou tripla terapêutica antitrombótica, Gargiulo et al. ${ }^{472}$ demonstraram diminuição significativa de sangramento à custa de aumento significativo na incidência de trombose de stent ( $R R=1,59$, IC 95\% 1,01 a 2,50) e uma tendência a aumento de IAM, com o uso da dupla terapêutica antitrombótica, sugerindo que alguns pacientes de muito alto risco de eventos isquêmicos, principalmente se com baixo risco de eventos hemorrágicos, podem se beneficiar da terapêutica antitrombótica tripla por até 30 dias apos o evento-índice (Figura 3.3). 


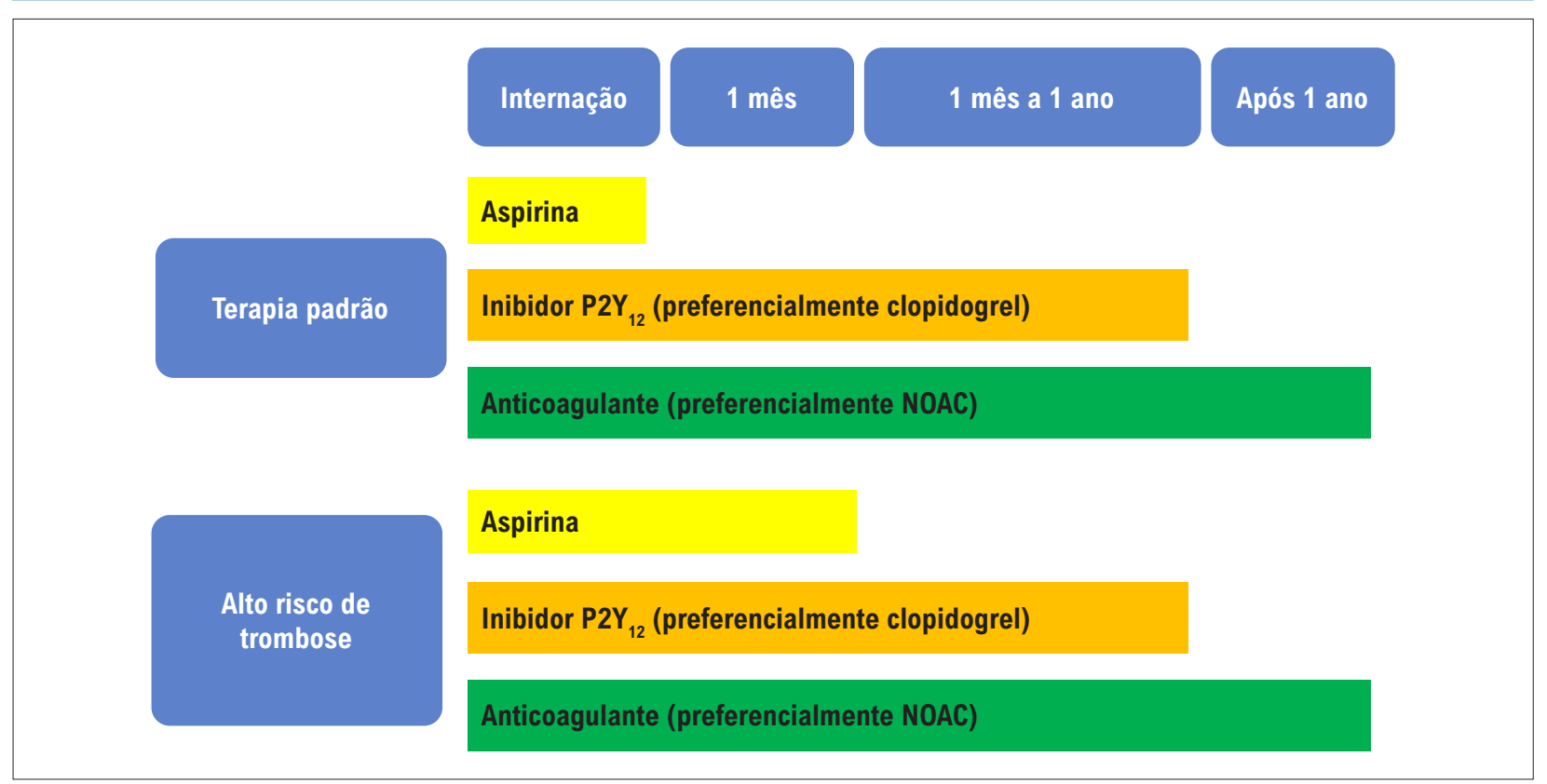

Figura 3.3-Esquema antitrombótico proposto para pacientes com síndrome coronariana aguda sem supra de ST e que apresentam FA com indicação de anticoagulação.

Escolha de terapia antitrombótica em pacientes após SCA e que apresentam FA com indicação de anticoagulação - Sumário de recomendações e evidências

A utilização de DOAC deve ser preferida em relação à varfarina

0 clopidogrel deve ser 0 inibidor $\mathrm{P} 2 \mathrm{Y}_{12}$ preferido, uma vez que é o que foi mais estudado nesse contexto

0 uso de terapia tripla deve ser mantido o menor tempo possível devido ao alto risco de sangramento associado.

Quando optado pelo uso da varfarina, deve-se almejar um INR entre 2 e 2,5 .

0 AAS deve ser usado em doses baixas, preferencialmente $\leq 100 \mathrm{mg} / \mathrm{dia}$.

Durante a internação hospitalar, deve-se utilizar terapia tripla com AAS + inibidor ${\mathrm{P} 2 \mathrm{Y}_{12}}_{+}$anticoagulante.

Após a alta hospitalar, a rotina é manter inibidor $\mathrm{P}_{2 \mathrm{Y}_{12}} \mathrm{e}$ anticoagulante até 12 meses do evento. Após 12 meses do evento, retira-se 0 inibidor $P 2 Y_{12}$, mantendo-se apenas 0 anticoagulante.

Em pacientes com risco isquêmico aumentado, pode-se manter a terapia tripla por um período maior.

0 uso de inibidores de bombas de prótons como profilaxia de úlcera de estresse nesse grupo de pacientes deve ser considerado como primeira escolha devido ao risco elevado de sangramento gastrintestinal.

\subsection{Inibidores do Sistema Renina-Angiotensina- Aldosterona}

Em pacientes pós-SCA, recomenda-se o uso de inibidores de ECA para aqueles com disfunção sistólica de VE/insuficiência cardíaca, hipertensão arterial sistêmica ou diabetes. Bloqueadores dos receptores de angiotensina (BRA) podem ser usados em pacientes intolerantes aos inibidores de ECA.
Antagonistas de mineralocorticoides estão indicados nos pacientes pós-SCA que apresentam FEVE $\leq 40 \%$ associada a evidências de insuficiência cardíaca ou a diabetes. ${ }^{283}$

No manejo da hipertensão arterial dos pacientes, após internação por SCA e a longo prazo, há de se ter um cuidado especial ao adequado controle da pressão sanguínea, conforme as recomendação da Diretriz Brasileira de Hipertensão Arterial. ${ }^{473}$ No entanto, é importante considerar a relevância da curva J, não obstante, toda a polêmica de sua existência e papel. Os dados do estudo ONTARGET ${ }^{474,4475}$ demonstraram que reduções excessivas da pressão arterial sistólica (PAS) foram associadas ao aumento de eventos isquêmicos, sendo observado que o valor de PAS de $126 \mathrm{mmHg}$ teve a menor ocorrência de IAM. Análise do estudo TNT ${ }^{476}$ avaliou o impacto dos níveis de pressão arterial em mais de 10.000 pacientes coronariopatas. Foi observada associação com mais eventos isquêmicos quando a PAS atingiu níveis inferiores a 110-120mmHg e a pressão arterial diastólica (PAD), abaixo de 60-70mmHg. Entretanto, o estudo SPRINT, que randomizou 9.361 pacientes não diabéticos e com alto risco cardiovascular para uma meta de controle intensivo (PAS $<120 \mathrm{mmHg}$ ) versus uma meta convencional (PAS $<140 \mathrm{mmHg}$ ), mostrou que o tratamento intensivo reduziu o desfecho composto de morte cardiovascular, infarto, AVC, SCA ou insuficiência cardíaca (HR 0,75; IC 95\% 0,64 a 0,89; p < 0,001), além de ter reduzido mortalidade por todas as causas (HR 0,73; IC 95\% 0,60 a $0,90 ; p=0,003)$. Houve aumento na incidência de eventos adversos de quedas, síncope, hipotensão e insuficiência renal aguda no grupo intensivo. Neste estudo, não houve aumento na incidência de infarto nem de SCA com o tratamento intensivo. Entretanto, o estudo incluiu menos de $20 \%$ de pacientes com doença cardiovascular manifesta. ${ }^{477}$ Não existem estudos semelhantes especificamente em pacientes com histórico de SCA. Por conta disso, em virtude do potencial 
de piora da isquemia, recomenda-se cautela em reduzir a PA, devendo-se evitar uma PAD inferior a $60 \mathrm{mmHg}$, a fim de evitar redução da pressão de perfusão coronária.

Uso de inibidores do sistema renina-angiotensina-aldosterona nos pacientes pós-síndrome coronariana aguda sem supradesnivel do segmento ST - Sumário de recomendações e evidências

0 uso de inibidores da ECA está recomendado por tempo indeterminado em pacientes com disfunção sistólica do VE, insuficiência cardíaca, hipertensão arterial sistêmica ou diabetes. Os bloqueadores do receptor de angiotensina devem ser utilizados em pacientes intolerantes aos inibidores da ECA.

Espironolactona está recomendada em pacientes com FEVE $\leq 40 \%$ associada à insuficiência cardíaca ou a diabetes.

\subsection{Betabloqueadores}

O uso de betabloqueadores a longo prazo é recomendado em pacientes com insuficiência cardíaca e fração de ejeção $\leq 40 \%$. Já em pacientes com função sistólica de ventrículo esquerdo preservada, os dados são menos robustos. As evidências favoráveis ao uso dessas medicações surgiram no início dos anos 1980, quando o tratamento das SCA era bastante distinto do atual. ${ }^{478,479} \mathrm{O}$ uso de betabloqueadores em pacientes com SCASSST e sem insuficiência cardíaca não foi avaliado por ensaios clínicos randomizados. Os dados disponíveis nessa população vêm de estudos observacionais que sugerem não ser útil o uso de betabloqueador a longo prazo pós-IAM. ${ }^{480,481}$ Experiência nacional especificamente analisando pacientes com SCASSST seguidos por aproximadamente 17 anos sugere benefício no uso do betabloqueador a longo prazo na população com disfunção ventricular esquerda, mas não naqueles com fração de ejeção normal. ${ }^{137}$ Atualmente, o estudo DANBLOCK (NCT 03778554) está randomizando pacientes com infarto do miocárdio recente e $\mathrm{FE}>40 \%$ para avaliar se o uso de betabloqueadores reduz desfechos isquêmicos no contexto da terapia atual de SCA. Os resultados devem estar disponíveis em 2023.

Uso de betabloqueadores em pacientes pós-síndrome coronariana aguda sem supradesnivel do segmento ST - Sumário de recomendações e evidências

0 uso de betabloqueadores é recomendando por tempo indeterminado em pacientes com disfunção ventricular esquerda. Deve-se usar os agentes com comprovada eficácia neste cenário.

\subsection{Antidiabéticos}

Mais de $30 \%$ dos pacientes admitidos com SCASSST apresentam diabetes. ${ }^{482} \mathrm{O}$ tratamento desta comorbidade sofreu grandes mudanças nos últimos anos com o advento de medicamentos que não apenas diminuem os níveis glicêmicos, mas também reduzem a incidência de desfechos cardiovasculares. Há evidências de que o controle mais intensivo da hemoglobina glicada ( $\mathrm{HbA1C}$ ) em pacientes diabéticos reduz o risco de complicações microvasculares. ${ }^{483,484}$
O impacto sobre eventos macrovasculares foi mais heterogêneo, parecendo haver benefício no seguimento de longo prazo (> 10 anos), desde que seja realizado precocemente após o diagnóstico. ${ }^{485}$ Com base nos achados em relação a eventos microvasculares, recomenda-se um alvo de $\mathrm{HbA} 1 \mathrm{C}$ inferior a 7\% na maioria dos pacientes diabéticos. É importante notar, contudo, que este número serve como um princípio geral, mas deve ser individualizado para cada paciente. No estudo ACCORD, por exemplo, a adoção de um controle glicêmico mais agressivo, além de não trazer redução de desfechos cardiovasculares maiores, foi associada a uma maior mortalidade total, levando à interrupção precoce do estudo. ${ }^{486}$ Os pacientes incluídos no estudo apresentavam diabetes de longa duração (10 anos, em média), além da prevalência de doença cardiovascular elevada (cerca de $35 \%)$. Por isso, em pacientes com baixa expectativa de vida, diabetes de longa duração, histórico de hipoglicemias graves, doença microvascular ou macrovascular avançada, alvos menos rigorosos de $\mathrm{HbA} 1 \mathrm{C}$ (p. ex., < 8\%) podem ser considerados. De modo inverso, em pacientes com diabetes de início recente, sem comorbidades relevantes e com bom entendimento da doença, alvos mais intensivos (p. ex., HbA1C $<7 \%$ ) podem ser almejados.

Uma vez determinados os alvos glicêmicos a serem atingidos, é necessário escolher os medicamentos a serem usados. Todo paciente com diagnóstico de diabetes deve receber metformina a menos que esta esteja formalmente contraindicada. ${ }^{487}$ Trata-se de uma medicação de baixo custo, amplamente disponível na rede pública, com efeitos favoráveis na redução de peso e controle glicêmico, além de potencialmente reduzir a incidência de eventos cardiovasculares. ${ }^{484}$ Além disso, os estudos randomizados que surgiram nos últimos anos mostrando redução de desfechos cardiovasculares com os novos antidiabéticos utilizaram como terapia de base a metformina em mais de $70 \%$ a $80 \%$ dos pacientes.

Os principais efeitos colaterais da metformina são relacionados ao trato gastrintestinal (sensação de empachamento, dor abdominal, diarreia) e podem ser evitados com a progressão mais lenta da dose. Pacientes com clearance de creatinina abaixo de $30 \mathrm{~mL} / \mathrm{min}$ têm contraindicação formal ao fármaco. ${ }^{488}$ Pacientes que fazem uso crônico de metformina apresentam maior incidência de baixos níveis de vitamina $\mathrm{B}_{12}$, devendo-se considerar o monitoramento desta nesta população, principalmente se houver anemia ou neuropatia associadas. ${ }^{489}$

Em pacientes com histórico de coronariopatia, recomendase considerar terapia com inibidores da SGLT2 ou agonistas do receptor GLP1, independentemente dos níveis de HbA1C. Recomenda-se que se opte por alguma das medicações que já mostraram ter benefício na redução de eventos cardiovasculares em estudos de fase 3 .

A decisão da escolha entre inibidores da SGLT2 e agonistas dos receptores GLP1 depende de vários fatores, entre os quais expomos alguns na Tabela 3.4. Ambas as classes de medicações mostraram ter benefícios similares em relação à redução de desfechos cardiovasculares maiores em pacientes de prevenção secundária. ${ }^{490} \mathrm{O}$ ideal é que seja feita uma decisão compartilhada com o paciente pesando aspectos 
Tabela 3.4 - Fatores a serem considerados para decidir qual o melhor novo antidiabético no paciente coronariopata

\begin{tabular}{|c|c|c|}
\hline & iSGLT2 & GLP1-RA \\
\hline Modo de administração & $\begin{array}{l}\text { VO } \\
\text { Administração diária }\end{array}$ & $\begin{array}{l}\text { SC (já existe semaglutida VO, mas ainda não está } \\
\text { disponível no Brasil) } \\
\text { Administração diária ou semanal }\end{array}$ \\
\hline Vantagens & $\begin{array}{l}\text { Reduz MACE } \\
\text { Reduz morte cardiovascular (empagliflozina) } \\
\text { Reduz IC } \\
\text { Reduz (discretamente) PA } \\
\text { Previne progressão de nefropatia }\end{array}$ & $\begin{array}{l}\text { Reduz MACE } \\
\text { Reduz morte cardiovascular (liraglutida) } \\
\text { Perda de peso } \\
\text { Previne progressão de nefropatia (liraglitida) }\end{array}$ \\
\hline Precauções & $\begin{array}{l}\mathrm{ClCr}<30 \mathrm{~mL} / \mathrm{min} / 1,73 \mathrm{~m}^{2} \\
\text { Histórico de infecções genitais } \\
\text { Histórico de cetoacidose } \\
\text { Osteoporose/Fraturas (canagliflozina) } \\
\text { Doença arterial periférica (canagliflozina) }\end{array}$ & $\begin{array}{l}\mathrm{ClCr}<30 \mathrm{~mL} / \mathrm{min} / 1,73 \mathrm{~m}^{2} \\
\text { Náuseas } \\
\text { História de pancreatite } \\
\text { Retinopatia (semaglutida) }\end{array}$ \\
\hline
\end{tabular}

práticos como via de administração (VO vs. SC) e preço, bem como os benefícios clínicos demonstrados pelos estudos randomizados. Vale ressaltar que, em virtude do benefício além do controle glicêmico, estes medicamentos devem ser prescritos o quanto antes após a SCA, uma vez que pacientes diabéticos com SCA constituem um grupo de muito alto risco, evitando-se a inércia terapêutica. Em uma subanálise do estudo DECLARE de pacientes com IAM prévio, o uso da dapagliflozina em relação ao placebo reduziu o composto de morte CV, infarto e AVC isquêmico (principalmente à custa de redução de reinfarto), e este benefício pareceu ser maior quanto mais próximo da fase aguda do evento coronário. ${ }^{491}$

É importante enfatizar que, no caso da dapagliflozina, o estudo DAPA-HF mostrou benefício cardiovascular em pacientes com insuficiência cardíaca e fração de ejeção do VE inferior a $40 \%$ independentemente da presença de diabetes. ${ }^{492}$ Nesse trial, 55\% dos pacientes apresentavam coronariopatia como causa da IC e a redução observada de $23 \%$ no desfecho composto de piora de IC e morte cardiovascular ocorreu independentemente dos níveis de $\mathrm{HbA} 1 \mathrm{C}$ do paciente. Dessa forma, em pacientes com disfunção de VE por coronariopatia e com diabetes associado, os inibidores da SGLT2 têm mais evidências de benefícios do que os agonistas de receptores GLP1.

Outro cenário em que os iSGLT2 mostraram benefício foi no de pacientes diabéticos com doença renal crônica. No estudo CREDENCE, o uso de canagliflozina na dose de 100mg por dia mostrou reduzir progressão de nefropatia em pacientes diabéticos que apresentavam ClCr entre 30 e 90mL/ min associado a proteinúria (relação albumina sobre creatina urinária $\geq 300 \mathrm{mg} / \mathrm{g}$ ). ${ }^{493} \mathrm{O}$ desfecho primário de doença renal terminal, elevação superior a 2 vezes nos níveis de creatinina ou morte de causas renais ou cardiovasculares foi reduzido em 30\% com o uso do iSGLT2 (HR 0,70; IC 95\% 0,59 a 0,82; $p=0,00001)$.

A maioria dos outros antidiabéticos mostrou-se neutra em relação a eventos cardiovasculares. Contudo, em alguns casos, houve piora de desfechos. No estudo SAVOR-TIMI 53, o uso do inibidor de DPP-4 saxagliptina foi testado contra o placebo em uma população de 16.492 pacientes diabéticos. ${ }^{494}$ Além de não ter havido redução de desfechos cardiovasculares com a medicação, observou-se aumento na taxa de internações por insuficiência cardíaca (de 2,8\% para 3,5\%, HR 1,27; IC
95\% 1,07 a 1,51; $p=0,007)$. Esta medicação deve, portanto, ser evitada em pacientes com IC.

Manejo ambulatorial de pacientes diabéticos com passado de síndrome coronariana aguda - Sumário de recomendações e evidências

Alvo de hemoglobina glicada $<7 \%$ deve ser usado na maioria dos pacientes diabéticos visando à redução de eventos microvasculares.

0 alvo de hemoglobina glicada deve ser individualizado, levando em conta características como presença de comorbidades, expectativa de vida e duração do DM

Metformina é o fármaco de escolha para o tratamento inicial de diabetes, salvo contraindicações.

Em pacientes após SCA, deve-se considerar a associação de um iSGLT2 ou de um GLP1-RA que comprovadamente têm benefícios cardiovasculares independentemente dos niveis de hemoglobina glicada.

Em pacientes com insuficiência cardíaca ou com nefropatia (CICr entre 30 e $90 \mathrm{~mL} / \mathrm{min}$ e/ou com proteinúria), os iSGLT2 são a opção de escolha.

Uso de saxagliptina e pioglitazona em pacientes diabéticos com insuficiência cardíaca.

\subsection{Hipolipemiantes}

O tratamento com estatinas deve ser iniciado precocemente, preferencialmente com agentes de alta potência (i. e., rosuvastatina 20 a $40 \mathrm{mg}$ ou atorvastatina 40 a $80 \mathrm{mg}$ ). Nos pacientes que já usavam esta medicação, o tratamento não deve ser interrompido. Caso a estatina usada previamente seja de baixa ou moderada potência, a modificação para estatinas de alta potência deve ser considerada.

No seguimento ambulatorial, deve-se atentar às metas terapêuticas de LDL-c e não HDL-c, respectivamente, < $50 \mathrm{mg} / \mathrm{dL}$ e $<80 \mathrm{mg} / \mathrm{dL}$. Caso as metas não sejam atingidas e o paciente ainda não esteja em uso de estatinas de alta potência, recomenda-se que se prescreva uma medicação deste grupo. Se, mesmo assim, os alvos de LDL não forem atingidos, recomenda-se a associação com ezetimiba 10mg/ dia. Se após essas medidas o LDL continuar acima da meta, deve-se considerar o uso dos inibidores da PCSK9. 
O primeiro estudo avaliando desfechos clínicos associados a inibidores da PCSK9 foi o FOURIER, ${ }^{495}$ publicado em 2017. Foram avaliados 27.564 pacientes com histórico de doença cardiovascular que mantinham LDL $\geq 70 \mathrm{mg} / \mathrm{dL}$ apesar do uso de estatinas. Os indivíduos eram randomizados para receberem evolocumab (140mg SC a cada 2 semanas ou 420mg SC 1 vez por mês, de acordo com a preferência do paciente) ou placebo. Observou-se no grupo evolucumab uma redução significativa do desfecho composto de morte cardiovascular, IAM, AVC, necessidade de revascularização coronária ou internação devido à Al. Este desfecho ocorreu em 11,3\% dos pacientes do grupo controle e em 9,8\% do grupo evolocumab ao longo de um seguimento médio de 26 meses. Não houve diferença de mortalidade.

Em 2018, foi publicado o estudo ODISSEY-OUTCOMES que avaliou o uso do alirocumab em pacientes com passado de SCA no ano anterior à inclusão. ${ }^{496}$ Os pacientes apresentavam LDL $\geq 70 \mathrm{mg} / \mathrm{dL}$ apesar de estarem usando estatinas de alta potência e eram randomizados para receber alirocumab $75 \mathrm{mg}$ SC a cada 2 semanas ou placebo. Em um seguimento médio de 2,8 anos, foi observada uma redução de 14,4\% no desfecho composto de morte por coronariopatia, IAM, AVC e hospitalização por AI. Neste trial houve uma aparente redução de mortalidade global (de 4,1\% para 3,5\%), embora não tenha havido redução de morte CV. Os benefícios da nova medicação foram mais proeminentes em pacientes com LDL basal acima de 100mg/ dL. Enquanto no grupo geral a redução de risco absoluto de mortalidade foi de $0,6 \%$, no grupo com LDL acima de 100mg/ $\mathrm{dL}$, foi de $1,7 \%$.

Um dado relevante é que, no ODISSEY-OUTCOMES, o inibidor de PCSK9 foi iniciado em média 2,6 meses após o episódio de SCA. Já nos pacientes com histórico de infarto do estudo FOURIER (cerca de $80 \%$ da população total), o evolocumab foi iniciado em média 3,4 anos após o último IAM. Ou seja, com base nas evidências desses estudos, o uso de inibidores de PCSK9, via de regra, deve ser aventado no acompanhamento ambulatorial de pacientes infartados e não na fase aguda intra-hospitalar.

Outro hipolipemiante que mostrou redução de eventos cardiovasculares no contexto de prevenção secundária foi a suplementação de ômega 3 à base de EPA (icosapentaetil 4g/dia). Tal estratégia foi avaliada no estudo REDUCEIT, que randomizou pacientes de alto risco (prevenção secundária ou diabetes com outro fator de risco associado), os quais apresentavam hipertrigliceridemia apesar do uso de estatinas. ${ }^{497}$ A maioria dos pacientes $(70,7 \%)$ era de prevenção secundária. Foi observada uma redução no desfecho primário composto de morte cardiovascular, IAM, AVC, necessidade de revascularização ou $\mathrm{Al}$ de $22 \%$ para $17,2 \%$. Houve redução de morte cardiovascular de 5,2\% para 4,3\% (IC 0,66 a 0,98; p $=0,03)$. A cada 21 pacientes tratados durante o seguimento médio de 4,9 anos do estudo, um evento cardiovascular foi prevenido. Uma crítica feita ao REDUCE-IT foi a de que o placebo utilizado (óleo mineral) aumentou o LDL 5mg/dL a mais do que o grupo que usou o EPA. Isso poderia ter aumentado o risco de eventos no grupo placebo.

Deve ser enfatizado que, no estudo REDUCE-IT, foi utilizado um tipo de formulação específica de ômega 3 que contava apenas com EPA (icosapenta-etil), o qual não teve impacto relevante sobre o LDL no trial (aumento de $2 \mathrm{mg}$ / $\mathrm{dL}$ ). Há evidências de que formulações de ômega 3 contendo ácido docosa-hexaenoico (DHA) elevam níveis de LDL. ${ }^{498}$ Assim, a diretriz recomenda que, em caso de uso de ômega 3 no paciente pós-SCA, seja utilizada a formulação usada no REDUCE-IT. Esta não está disponível no Brasil até a data da publicação desta Diretriz.

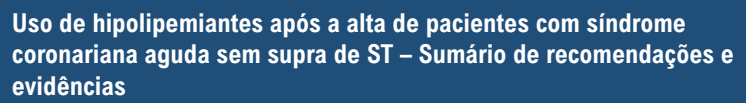

Em indivíduos com diagnóstico prévio de SCA, o LDL-c deve ser reduzido para $<50 \mathrm{mg} / \mathrm{dL}$ e o não HDL-c para < $80 \mathrm{mg} / \mathrm{dL}$.

Sempre que possível e tolerado, deve-se dar preferência para 0 uso de estatina de alta intensidade.

Ezetimiba deve ser associada quando a meta do LDL-c não for atingida com o tratamento com estatinas na dose máxima tolerada.

Inibidores da PCSK9 podem ser considerados em pacientes em tratamento otimizado com estatinas na maior dose tolerada, associado ou não à ezetimiba, e que não tenham alcançado as metas de LDL-c ou não HDL-c recomendadas.

\subsection{Outros Medicamentos}

Pacientes pós-SCA apresentam risco aumentado de sangramento devido ao uso de terapia antitrombótica. O trato gastrintestinal é o sítio mais frequente de sangramentos clinicamente relevantes em pacientes usando terapia antiplaquetária crônica. ${ }^{499}$ Uma forma de reduzir o risco destes eventos gastrintestinais é o uso de protetores gástricos. Inibidores de bombas de prótons se mostraram mais eficazes que antagonistas de receptores $\mathrm{H} 2$ em estudos observacionais. ${ }^{500}$ Contudo, alguns estudos sugeriram que o uso de inibidores de bombas de prótons em conjunto com o clopidogrel poderia reduzir a atividade antiplaquetária deste (in vitro). ${ }^{225,226} \mathrm{O}$ estudo randomizado COGENT (ver Parte 2) mostrou que a associação de omeprazol ao clopidogrel reduziu o risco de complicações gastrintestinais sem aumento aparente de eventos isquêmicos (embora a interrupção precoce do estudo não consiga excluir um aumento de eventos isquêmicos com o omeprazol). ${ }^{231}$

Recomenda-se, portanto, o uso de inibidores de bomba de prótons em pacientes que usam DAP e que tenham risco aumentado de sangramento (história de sangramento gastrintestinal, história de doença ulcerosa péptica, uso de anticoagulantes, uso crônico de AINE, uso crônico de corticosteroides ou que apresentem dois ou mais dos seguintes fatores: idade $\geq 65$ anos, dispepsia, doença do refluxo gastresofágico, infecção por Helicobacter pylori, uso crônico de álcool).

Os pacientes devem ser orientados após a alta para que, caso apresentem dor anginosa em repouso, utilizem nitrato sublingual (dinitrato, mononitrato ou nitroglicerina), desde que não existam contraindicações. Importante orientar que, caso a dor não melhore em 3 a 5 min, o paciente ou seu acompanhante deve acionar o serviço de emergência. 
Infecções virais e bacterianas podem servir de gatilho para desencadear um evento cardiovascular agudo em pacientes cardiopatas. Há evidências de que a vacinação para influenza e para pneumococo podem reduzir internações e até mesmo mortalidade nestes pacientes. ${ }^{501}$ Desta forma, recomenda-se a vacinação anual para influenza em pacientes portadores de coronariopatia. O ideal é que a vacina seja administrada na época da campanha vacinal (abril e maio). Em relação à vacina pneumocócica, recomenda-se a aplicação de uma dose da "Pneumo 23" com reforço após 5 anos. ${ }^{502}$ Um estudo randomizado brasileiro em andamento está testando se a vacina anti-influenza durante a hospitalização por SCA em dose dobrada é superior à vacinação em dose convencional 30 dias após o evento, a fim de reduzir desfechos cardiovasculares (NCT 04001504).

A terapia direcionada a reduzir a inflamação na placa tem começado a trazer resultados promissores. No estudo CANTOS, em pacientes com infarto prévio (a partir de 30 dias após o evento-índice) e proteína C-reativa elevada, o canaquinumabe, um anticorpo monoclonal anti-interleucina $1-\beta$, reduziu os eventos cardiovasculares maiores, ou seja, o composto de morte CV, reinfarto ou AVC (HR 0,88; IC 95\% 0,79 a 0,97; $p=$ $0,02) \cdot{ }^{503}$ Entretanto, houve aumento de morte por infecção. O custo proibitivo fez que com este medicamento não tenha sido incorporado à prática clínica para esta indicação. Já a colchicina, um medicamento amplamente disponível e de baixo custo, na dose de $0,5 \mathrm{mg}$ uma vez ao dia, reduziu de maneira significativa o desfecho composto de morte $\mathrm{CV}$, reinfarto, hospitalização por Al com necessidade de revascularização, AVC ou parada cardíaca reanimada (HR 0,77; IC 95\% 0,61 a 0,96; $p=0,02$ ) em pacientes com IAM recente (até 30 dias do evento-índice). Houve aumento na incidência de pneumonia. ${ }^{504}$ A Figura 3.4 traz um resumo dos medicamentos que são recomendados após alta por SCASSST.

Outras intervenções farmacológicas em pacientes após a alta por uma síndrome coronariana aguda - Sumário de recomendações e evidências

Orientar o paciente a usar nitrato sublingual caso apresente dor torácica em repouso, desde que não apresente contraindicações à medicação.

Vacinação contra influenza e pneumococo, a fim de reduzir morbimortalidade.

Uso de inibidores de bomba de prótons em pacientes em uso de DAP e que apresentem risco aumentado de sangramento (história de sangramento gastrintestinal, história de doença ulcerosa péptica, uso de anticoagulantes, uso crônico de AINE, uso crônico de corticosteroides ou que tenham dois ou mais dos seguintes fatores: idade $\geq 65$ anos, dispepsia, doença do refluxo gastresofágico, infecção por Helicobacter pylori, uso crônico de álcool).

\section{Rastreamento Clínico Pós-alta}

Os pacientes de baixo risco e os revascularizados após SCASSST têm, por recomendação de uma reavaliação precoce, entre 2 e 6 semanas inicialmente. Naqueles pacientes com maior gravidade, recomenda-se a avaliação dentro de 14 dias. ${ }^{505}$ Obviamente que esses prazos devem levar em consideração as particularidades de cada situação, uma vez que as intercorrências dos procedimentos, condições de acesso ao serviço de saúde e características individuais de cada paciente são muito variáveis.

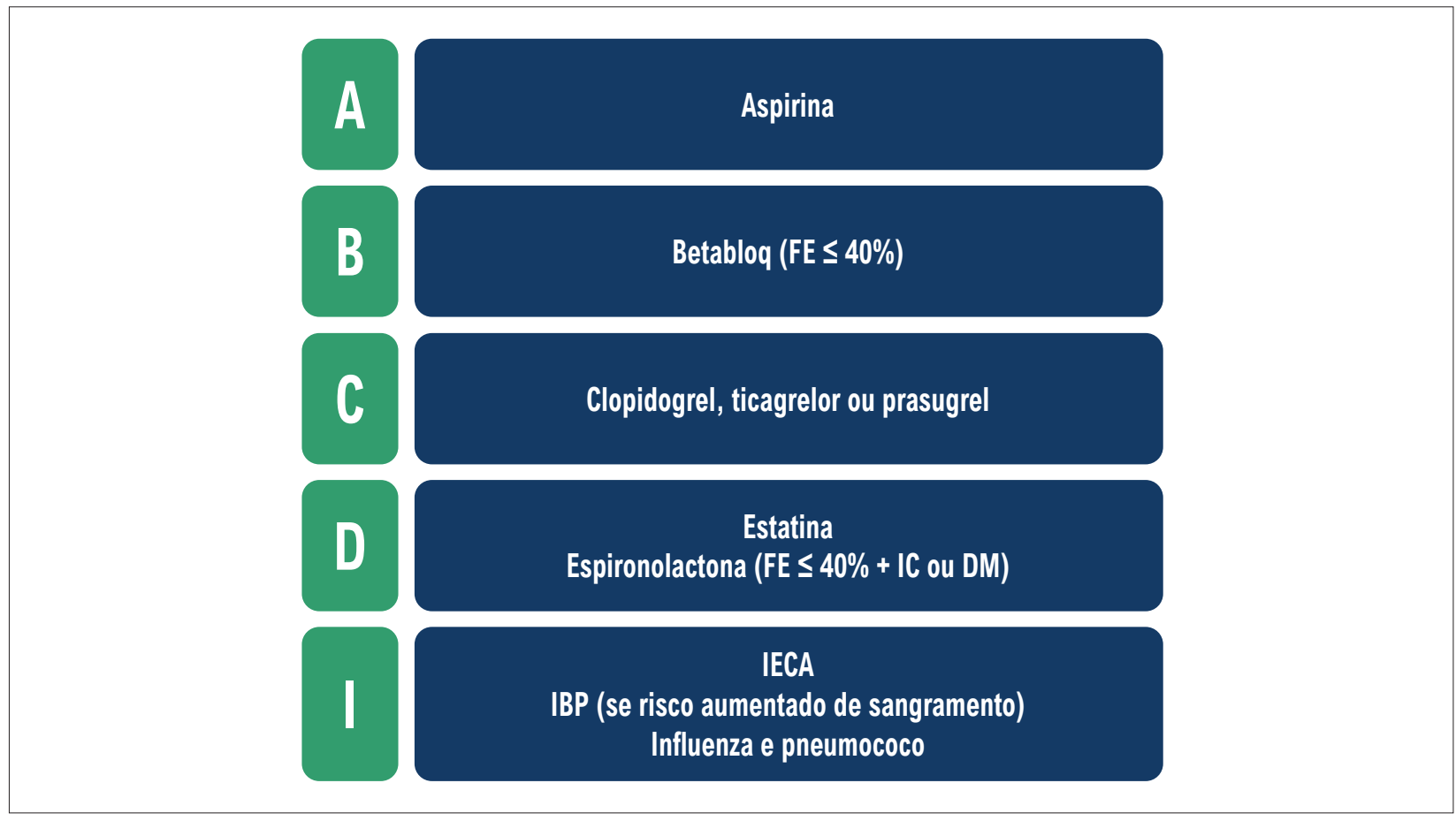

Figura 3.4 - Resumo da prescrição de alta pós-sindrome coronariana aguda sem supradesnivel de ST 
O risco de complicações existe mesmo em pacientes assintomáticos e, portanto, a avaliação deste risco se aplica a pacientes sintomáticos e assintomáticos.

Após revascularização e/ou após SCA estabilizada nos primeiros 12 meses, os pacientes devem ser monitorados com mais vigilância, porque correm maior risco por complicações e porque estão sujeitos a alterações no tratamento farmacológico. ${ }^{506}$ Portanto, são recomendadas pelo menos duas visitas no primeiro ano de acompanhamento, sendo a primeira, idealmente, dentro de 3 meses.

Em um paciente com disfunção sistólica do VE antes do procedimento de revascularização ou após a SCA, uma reavaliação da função do VE deve ser considerada 8 a 12 semanas após a intervenção. ${ }^{507,508}$

A função cardíaca pode ter melhorado devido a mecanismos como recuperação de atordoamento do miocárdio ou hibernação, que pode ser revertida por revascularização ou por outro lado piorado em virtude de outras comorbidades, como valvopatias, arritmias ou inflamações etc. Esses achados precisam ser identificados e tratados. ${ }^{509}$

De forma similar, provas não invasivas de isquemia podem ser realizadas após revascularização, para identificação de isquemia residual e também servindo de referência para comparativos subsequentes. ${ }^{509}$ Essa abordagem deve ser individualizada, uma vez que cada situação de revascularização traz consigo peculiaridades anatômicas e difere muito de paciente para paciente. Ressaltamos que as recomendações são, em sua maioria, baseadas em opiniões de especialistas.

Em pacientes que estejam assintomáticos há mais de 1 ano, uma reavaliação pelo menos anual é recomendada. ${ }^{509}$ Deve-se avaliar o estado clínico geral do paciente e adesão ao tratamento medicamentoso, bem como o perfil de risco estabelecidos pelos escores. Exames laboratoriais que incluem perfil lipídico, função renal, um hemograma completo e também biomarcadores devem ser realizados pelo menos a cada 2 anos. ${ }^{507,508}$

O perfil lipídico e o status glicêmico devem ser avaliados periodicamente e, apesar de não haver evidências que suportem a periodicidade dessa avaliação, de forma geral, recomenda-se uma avaliação anual. ${ }^{509}$

Alguns biomarcadores de inflamação parecem estar associados como marcadores de eventos. A proteína C-reativa de alta sensibilidade parece ser o de maior evidência em múltiplos estudos, mesmo em pacientes em prevenção primária. NT-proBNP, fator de Von Willenbrand e interleucina- 6, também parecem ser preditores de eventos. ${ }^{510}$ Escores estabelecidos com associação de biomarcadores (LDL, NT-proBNP, troponina T, produtos de degradação de fibrina), mostraram-se com melhor poder de reclassificação e aumento da estatística-C do que os escores com base em modelos clínicos, e podem ser promissoras ferramentas de predição de eventos em pacientes coronariopatas. ${ }^{511,512}$ No entanto, a falta de evidências mais robustas deve limitar a utilização desses biomarcadores a casos selecionados, e não é aplicada de rotina.

Um ECG deve ser solicitado em cada visita para determinar o ritmo e a frequência cardíaca. O ecocardiograma pode ser benéfico para avaliar a função do VE (diastólica e sistólica), status valvar e dimensões cardíacas em pacientes aparentemente assintomáticos a cada 3 a 5 anos. Da mesma forma, pode ser benéfico avaliar não invasivamente a presença de isquemia silenciosa em um paciente aparentemente assintomático a cada 3 a 5 anos, preferencialmente com exames de estresse com imagens. ${ }^{513}$

A angioTC de coronárias não deve ser utilizada para avaliação em virtude da falta de informações funcionais. Em casos específicos, ela pode ajudar na avaliação da patência de coronárias e enxertos. ${ }^{512}$

Para pacientes com histórico de SCASSST e/ou já revascularizados, com sintomas inequívocos de angina, de acordo com a grande maioria das evidências, a estratificação invasiva é a melhor opção. Para pacientes que tenham sintomas duvidosos, a utilização de exames de estresse com imagem é recomendada. ${ }^{513}$

Rastreamento clínico pós-alta - Sumário de recomendações e evidências

Pacientes assintomáticos

Uma visita periódica a um cardiologista (preferencialmente em até 3 meses), para reavaliar qualquer alteração potencial no risco da situação dos pacientes, com avaliação clínica das medidas de modificação do estilo de vida, adesão aos alvos fatores de risco e o desenvolvimento de comorbidades que podem afetar tratamentos e resultados.

Em pacientes com sintomas leves ou inexistentes recebendo tratamento médico, nos quais a estratificação de risco não invasiva indica um alto risco, e para quem a revascularização é considerada para melhorar 0 prognóstico, a angiografia coronária invasiva (FFR, quando necessário e disponível) é recomendada.

Pacientes de alto risco, submetidos à revascularização há cerca de 6 meses, podem realizar estratificação de risco por exame de imagem sob estresse.

Em pacientes submetidos à revascularização de alto risco (p. ex., tronco de coronária esquerdo desprotegido), podese considerar nova angiografia, independentemente dos sintomas.

Exame de imagem com estresse de rotina em pacientes revascularizados de forma percutânea há mais de 1 ano e cirurgicamente há mais de 5 anos.

Uso de angioTC de coronária como rotina para estratificação isoladamente.

Uso de angiografia coronariana apenas para estratificação de risco em paciente assintomático.

\section{Pacientes assintomáticos}

Avaliação do status da doença coronária em pacientes com deterioração da função sistólica do VE sem causa identificável.

Realização de exame de imagem com estresse (preferencialmente) em pacientes com sintomas novos e/ ou piora dos sintomas prévios.

Realização de angiografia (com FFR ou iFR, se necessário) em pacientes com sintomas inequívocos de coronariopatia, principalmente se refratários ao tratamento medicamentoso, ou que se enquadrarem no perfil de alto risco.

Angiografia em pacientes com achados de alto risco em exames de imagem com estresse.

Em paciente revascularizado previamente, deve fazer exame de imagem sob estresse em detrimento de teste ergométrico isolado 12 


\section{Referências}

1. Goodacre S, Cross E, Arnold J, Angelini K, Capewell S, Nicholl J. The health care burden of acute chest pain. Heart. 2005;91(2):229-30.

2. Barstow C, Rice M, McDivitt JD. Acute Coronary Syndrome: Diagnostic Evaluation. Am Fam Physician. 2017;95(3):170-7.

3. Gibler WB, Racadio JM, Hirsch AL, Roat TW. Continuum of Care for Acute Coronary Syndrome: Optimizing Treatment for ST-Elevation Myocardial Infarction and Non-St-Elevation Acute Coronary Syndrome. Crit Pathw Cardiol. 2018;17(3):114-38.

4. Thygesen K, Alpert JS, Jaffe AS, Chaitman BR, Bax JJ, Morrow DA, et al. Fourth universal definition of myocardial infarction (2018). Eur Heart J. 2019;40(3):237-69.

5. Pasupathy S, Air T, Dreyer RP, Tavella R, Beltrame JF. Systematic review of patients presenting with suspected myocardial infarction and nonobstructive coronary arteries. Circulation. 2015;131(10):861-70. Erratum in: Circulation. 2015;131(19):e475.

6. Scalone G, Niccoli G, Crea F. Editor's Choice- Pathophysiology, diagnosis and management of MINOCA: an update. Eur Heart J. Acute Cardiovasc Care. 2019;8(1):54-62

7. Niccoli G, Camici PG. Myocardial infarction with non-obstructive coronary arteries: what is the prognosis?. Eur HeartJ Suppl. 2020;22(Suppl E):E40-5.

8. Tamis-Holland JE, Jneid H, Reynolds HR, Agewall S, Brilakis ES, Brown TM, et al. Contemporary Diagnosis and Management of Patients With Myocardial Infarction in the Absence of Obstructive Coronary Artery Disease: A Scientific Statement From the American Heart Association. Circulation. 2019;139(18):e891-e908

9. Planer D, Mehran R, Ohman EM, White HD, Newman JD, Xu K, et al. Prognosis of patients with non-ST- segment-elevation myocardial infarction and nonobstructive coronary artery disease: propensity-matched analysis from the Acute Catheterization and Urgent Intervention Triage Strategy trial. Circ Cardiovasc Interv. 2014;7(3):285-93.

10. Pasupathy S, Tavella R, Beltrame JF. Myocardial Infarction With Nonobstructive Coronary Arteries (MINOCA): The Past, Present, and Future Management. Circulation. 2017 Apr 18;135(16):1490-3.

11. Effects of tissue plasminogen activator and a comparison of early invasive and conservative strategies in unstable angina and non-Q-wave myocardial infarction. Results of the TIMI IIIB Trial. Thrombolysis in Myocardial Ischemia. Circulation. 1994 Apr;89(4):1545-56.

12. Theroux P, Fuster V. Acute coronary syndromes: unstable angina and nonQ-wave myocardial infarction. Circulation. 1998 Mar 31;97(12):1195-206.

13. Zaacks SM, Liebson PR, Calvin JE, Parrillo JE, Klein LW. Unstable angina and non-Q wave myocardial infarction: does the clinical diagnosis have therapeutic implications? J Am Coll Cardiol. 1999 Jan;33(1):107-18.

14. Calvin JE, Klein LW, VandenBerg BJ, Meyer P, Ramirez-Morgen LM, Parrillo JE. Clinical predictors easily obtained at presentation predict resource utilization in unstable angina. Am Heart J. 1998 Sep;136(3):373-81.

15. Kong DF, Blazing MA, $\mathrm{O}^{\prime}$ Connor $\mathrm{CM}$. The health care burden of unstable angina. Cardiol Clin. 1999 May;17(2):247-61.

16. Roffi M, Patrono C, Collet JP, Mueller C, Valgimigli M, Andreotti F, et al. 2015 ESC Guidelines for the management of acute coronary syndromes in patients presenting without persistent ST-segment elevation: Task Force for the Management of Acute Coronary Syndromes in Patients Presenting without Persistent ST-Segment Elevation of the European Society of Cardiology (ESC). Eur Heart J. 2016;37(3):267-315

17. Naghavi M, Wang H, Lozano R, Davis A, Liang X, Zhou M, et al; GBD 2013Mortality and Causes of Death Collaborators. Global, regional, and national age-sex specific all-cause and cause-specific mortality for 240 causes of death, 1990-2013: a systematic analysis for the Global Burden of Disease Study 2013. Lancet. 2015;385(9963):117-71.
18. Brasil.Ministério da Saúde. Informação em saúde: Estatísticas vitais. [Citado em 2020 fev 26]. Disponível em: http://datasus.saude.gov.br/).

19. Franken M, Giugliano RP, Goodman SG, Baracioloi L, Godoy LC, Furtado RHM, et al. Performance of acute coronary syndrome approaches in Brazil. A report from the BRACE (Brazilian Registry in Acute Coronary syndromEs) [published online ahead of print, 2019 Aug 10]. Eur Heart J Qual Care Clin Outcomes. 2019;qcz045.

20. Libby P. Mechanisms of Acute Coronary Syndromes and Their Implications for Therapy. N Engl J Med. 2013;368(21):2004-13.

21. Ibáñez B, Heusch G, Ovize M, Van de Werf F. Evolving therapies for myocardial ischemia/reperfusion injury. J Am Coll Cardiol.2015; 65(14):1454-71.

22. The Principal Investigators of CASS and Their Associates. The National Heart, Lung and Blood Institute Coronary Artery Surgery Study: historical background, design, methods, the registry, the randomized trial, clinical database. Circulation. 1981;63(suppl I):I-1-I-81.

23. Stone PH, Thompson B, Anderson HV, Kronenberg MW, Gibson RS, Rogers WJ, et al. Influence of race, sex, and age on management of unstable angina and non-Q-wave myocardial infarction: The TIMI III registry. JAMA. 1996 Apr 10;275(14):1104-12.

24. Nicolau JC, Franci A, Barbosa CJ, Baracioli LM, Franken M, Furtado RH, e al. Influence of proven oral therapies in the very old with acute coronary syndromes: A 15 year experience. Int J Cardiol. 2015 Nov 1;198:213-5.

25. Kleiman NS, Anderson HV, Rogers WJ, Theroux P, Thompson B, Stone PH Comparison of outcome of patients with unstable angina and non-Q-wave acute myocardial infarction with and without prior coronary artery bypass grafting (Thrombolysis in Myocardial Ischemia III Registry). Am J Cardiol. 1996 Feb $1 ; 77(4): 227-31$

26. Barbash GI, Reiner J, White HD, Wilcox RG, Armstrong PW, Sadowski $Z$, et al. Evaluation of paradoxic beneficial effects of smoking in patients receiving thrombolytic therapy for acute myocardial infarction: mechanism of the "smoker's paradox" from the GUSTO-I trial, with angiographic insights. Global Utilization of Streptokinase and Tissue-Plasminogen Activator for Occluded Coronary Arteries. J Am Coll Cardiol. 1995 Nov $1 ; 26(5): 1222-9$

27. Barbash GI, White HD, Modan M, Diaz R, Hampton JR, Heikkila J, et al. Significance of smoking in patients receiving thrombolytic therapy for acute myocardial infarction. Experience gleaned from the International Tissue Plasminogen Activator/Streptokinase Mortality Trial. Circulation. 1993 Jan;87(1):53-8

28. Antman EM, Cohen M, Bernink PJ, McCabe CH, Horacek T, Papuchis G, et al. The TIMI risk score for unstable angina/non-ST elevation MI: A method for prognostication and therapeutic decision making. JAMA. 2000 Aug $16 ; 284(7): 835-42$

29. Braunwald E, Jones RH, Mark DB, Brown J, Brown L, Cheitlin MD, et al. Diagnosing and managing unstable angina. Agency for Health Care Policy and Research. Circulation. 1994 Jul;90(1):613-22.

30. Yeghiazarians Y, Braunstein JB, Askari A, Stone PH. Unstable angina pectoris. N Engl J Med. 2000 Jan 13;342(2):101-14.

31. Braunwald E, Califf RM, Cannon CP, Fox KA, Fuster V, Gibler WB, et al. Redefining medical treatment in the management of unstable angina. Am Med. 2000 Jan;108(1):41-53.

32. Bosch X, Theroux P, Pelletier GB, Sanz G, Roy D, Waters D. Clinical and angiographic features and prognostic significance of early postinfarction angina with and without electrocardiographic signs of transient ischemia. Am J Med. 1991 Nov;91(5):493-501.

33. Gottlieb SO, Weisfeldt ML, Ouyang P, Mellits ED, Gerstenblith G. Silent ischemia predicts infarction and death during 2 year follow-up of unstable angina. J Am Coll Cardiol. 1987 Oct;10(4):756-60. 
34. Armstrong PW, Fu Y, Chang WC, Topol EJ, Granger CB, Betriu A, et al. Acute coronary syndromes in the GUSTO-IIb trial: prognostic insights and impact of recurrent ischemia. The GUSTO-IIb Investigators. Circulation. $1998 \mathrm{Nov}$ 3;98(18):1860-8.

35. Cannon CP, McCabe CH, Stone PH, Rogers WJ, Schactman M, Thompson BW, etal. The electrocardiogram predicts one-year outcome of patients with unstable angina and non-Q wave myocardial infarction: results of the TIMI III Registry ECG Ancillary Study. Thrombolysis in Myocardial Ischemia. J Am Coll Cardiol. 1997 Jul;30(1):133-40.

36. Lee TH, Goldman L. Serum enzyme assays in the diagnosis of acute myocardial infarction. Recommendations based on a quantitative analysis. Ann Intern Med. 1986 Aug; 105(2):221-33.

37. Newby LK, Christenson RH, Ohman EM, Armstrong PW, Thompson TD, Lee $\mathrm{KL}$, et al. Value of serial troponin $\mathrm{T}$ measures for early and late risk stratification in patients with acute coronary syndromes. The GUSTO-Ila Investigators. Circulation. 1998 Nov 3;98(18):1853-9.

38. Amsterdam EA, Kirk JD, Bluemke DA, Diercks DE, Farkouh ME, Garvey JE, et al. Testing of low-risk patients presenting to the emergency department with chest pain. A Scientific Statement From the American Heart Association. Circulation. 2010;122(17):1756-776.

39. Ohman EM, Armstrong PW, Christenson RH, Granger CB, Katus HA, Hamm CW, et al. Cardiac troponin T levels for risk stratification in acute myocardial ischemia. GUSTO IIA Investigators. N Engl J Med. 1996 Oct 31;335(18):1333-41.

40. Jaffe AS, Ravkilde J, Roberts R, Naslund U, Apple FS, Galvani M, etal. It's time for a change to a troponin standard. Circulation. 2000 Sep 12;102(11):1216-20.

41. Reichlin T, Hochholzer W, Bassetti S, Steuer S, StelzigC, Hartwiger S, etal. Early diagnosis of myocardial infarction with sensitive cardiac troponin assays. N Engl J Med. 2009;361(9):858-67.

42. Giannitsis E, Kurz K, Hallermayer K, Jarausch J, Jaffe AS, Katus HA. Analytical validation of a high-sensitivity cardiac troponin T assay. Clin Chem. 2010;56(2):254-61.

43. Mueller C. Biomarkers and acute coronary syndromes: an update. Eur Heart]. 2014;35(9):552-6.

44. Westermann D, Neumann J, Sörensen N, Blankenberg S. Highsensitivity assays for troponin in patients with cardiac disease. Nat Rev Cardiol.2017;14(8):472-83.

45. Stoyanov KM, Hund H, Biener M, Gandowitz J, Riedle C, Lohr J, et al. RAPIDCPU: a prospective study on implementation of the ESC 0/1-hour algorithm and safety of discharge after rule-out of myocardial infarction. Eur Heart] Acute Cardiovasc Care. 2020;9(1):39-51.

46. Boeddinghaus J, Nestelberger T, Twerenbold R, Wildi K, Badertscher P, Cupa J, et al. Direct Comparison of 4 Very Early Rule-Out Strategies for Acute Myocardial Infarction Using High-Sensitivity Cardiac Troponin I. Circulation. 2017 Apr 25;135(17):1597-11.

47. Mair J,Morandell D, Genser N, Lechleitner P, Dienst F, Puschendorf B. Equivalent earlysensitivities of myoglobin, creatine kinase $\mathrm{MB}$ mass, creatine kinase isoform ratios, and cardiac troponins I and T for acute myocardial infarction. Clin Chem. 1995 Sep;41(9):1266-72.

48. Costa TN, Strunz CM, Nicolau JC, Gutierrez PS. Comparison of MB fraction of creatine kinase mass and troponin I serum levels with necropsy findings in acute myocardial infarction. Am J Cardiol. 2008 Feb 1;101(3):311-4.

49. Lin JC, Apple FS, Murakami M,Luepker RV. Rates of positive cardiac troponin I and creatine kinase MB mass among Patients Hospitalized for Suspected Acute Coronary Syndromes. Clin Chem. 2004;50(2):333-8.

50. Amsterdam EA, Kirk JD, Diercks DB, Lewis WR, Turnipseed SD. Immediate exercise testing to evaluate low-risk patients presenting to the emergency department with chest pain. J Am Coll Cardiol. 2002;40(2):251-6. 165.

51. Meneghelo RS, Araújo CG, Stein R, Mastrocolla LE, Albuquerque PF, Serra SM, et al; Sociedade Brasileira de Cardiologia. III Diretrizes da Sociedade Brasileira de Cardiologia sobre teste ergométrico. Arq Bras Cardiol. 2010;95(5 Suppl 1):1-26.
52. Peels $\mathrm{CH}$, Visser CA, Kupper AJ, Visser FC, Roos JP. Usefulness of twodimensional echocardiography for immediate detection of myocardial ischemia in the emergency room. Am J Cardiol. 1990 Mar 15;65(11):68791.

53. Sabia P, Abbott RD, Afrookteh A, Keller MW, Touchstone DA, Kaul S. Importance of two-dimensional echocardiographic assessment of left ventricular systolic function in patients presenting to the emergency room with cardiac-related symptoms. Circulation. 1991 Oct;84(4):1615-24.

54. Feigenbaum $\mathrm{H}$. Role of echocardiography in acute myocardial infarction. Am J Cardiol. 1990 Nov 20;66(18): $17 \mathrm{H}-22 \mathrm{H}$.

55. Parisi AF. The case for echocardiography in acute myocardial infarction. J Am Soc Echocardiogr. 1988 May; 1(3):173-8.

56. Reeder GS, Seward JB, Tajik AJ. The role of two-dimensional echocardiography in coronary artery disease: a critical appraisal. Mayo Clin Proc. 1982 Apr;57(4):247-58.

57. Gibson RS, Bishop HL, Stamm RB, Crampton RS, Beller GA, Martin RP. Value of early two dimensional echocardiography in patients with acute myocardial infarction. Am J Cardiol. 1982 Apr 1;49(5):1110-9.

58. Visser CA, Lie KI, Kan G, Meltzer R, Durrer D. Detection and quantification of acute, isolated myocardial infarction by two dimensional echocardiography. Am J Cardiol. 1981 May;47(5):1020-5.

59. Heger JJ, Weyman AE, Wann LS, Rogers EW, Dillon JC, Feigenbaum H. Cross-sectional echocardiographic analysis of the extent of left ventricular asynergy in acute myocardial infarction. Circulation. 1980 Jun;61(6):1113-

60. Ryan T, Vasey CG, Presti CF, O'Donnell JA, Feigenbaum H, Armstrong WF Exercise echocardiography: detection of coronary artery disease in patients with normal left ventricular wall motion at rest. J Am Coll Cardiol. 1988 May; 11(5):993-9.

61. Sawada SG, Ryan T, Conley MJ, Corya BC, Feigenbaum H, Armstrong WF Prognostic value of a normal exercise echocardiogram. Am Heart J. 1990 Jul;120(1):49-55.

62. Cheitlin MD, Alpert JS, Armstrong WF, Aurigemma GP, Beller GA, Bierman FZ, et al. ACC/AHA Guidelines for the Clinical Application of Echocardiography. A report of the American College of Cardiology/ American Heart Association Task Force on Practice Guidelines (Committee on Clinical Application of Echocardiography). Developed in collaboration with the American Society of Echocardiography. Circulation. 1997 Mar 18;95(6):1686-744.

63. Ersbø\|l M, Valeur N, Mogensen UM, Andersen MJ, Møller JE, Velazquez EJ, Hassager C,et al. Prediction of all-cause mortality and heart failure admissions from global left ventricular longitudinal strain in patients with acute myocardial infarction and preserved left ventricular ejection fraction. J Am Coll Cardiol. 2013 Jun 11;61(23):2365-73.

64. Lin SS, Lauer MS, Marwick TH. Risk stratification of patients with medically treated unstable angina using exercise echocardiography. Am J Cardiol. 1998 Sep 15;82(6):720-4.

65. Colon PJ, III, Guarisco JS, Murgo J, Cheirif J. Utility of stress echocardiography in the triage of patients with atypical chest pain from the emergency department. Am J Cardiol. 1998 Nov 15;82(10):1282-4, A10.

66. Markman Filho B, Almeida MC, Markman M, Chaves A, Moretti M, Ramires JA, Cesar LA. Stratifying the risk in unstable angina with dobutamine stress echocardiography. Arq Bras Cardiol. 2006; 87(3):294-9.

67. Jain D, Thompson B, Wackers FJ, Zaret BL. Relevance of increased lung thallium uptake on stress imaging in patients with unstable angina and non-Q wave myocardial infarction: results of the Thrombolysis in Myocardial Infarction (TIMI)-IIIB Study. J Am Coll Cardiol. 1997 Aug;30(2):421-9.

68. Geleijnse ML, Elhendy A, van Domburg RT, Cornel JH, Rambaldi R, Salustri A, et al. Cardiac imaging for risk stratification with dobutamine-atropine stress testing in patients with chest pain. Echocardiography, perfusion scintigraphy, or both? Circulation. 1997 Jul 1;96(1):137-47. 
69. Kontos MC, Jesse RL, Schmidt KL, Ornato JP, Tatum JL. Value of acute rest sestamibi perfusion imaging for evaluation of patients admitted to the emergency department with chest pain. J Am Coll Cardiol. 1997 Oct:30(4):976-82.

70. Kapetanopoulos A, Heller GV, Selker HP, Ruthazer R, BeshanskyJR, Feldman $J$ A, etal. Acute resting myocardial perfusion imaging in patients with diabetes mellitus: results from the Emergency Room Assessment of Sestamibi for Evaluation of Chest Pain (ERASE Chest Pain) trial. J Nucl Cardiol. 2004 Sep;11(5):570-7.

71. Hendel RC, Berman DS, Di Carli MF, Heidenreich PA, Henkin RE, Pellikka PA, Pohost GM, et al. ACCF/ASNC/ACR/AHA/ASE/SCCT/SCMR/SNM 2009 appropriate use criteria for cardiac radionuclide imaging. Circulation. 2009 Jun 9:119(22):e561-87;

72. Klocke FJ, Baird MG, Lorell BH, Bateman TM, Messer JV, Berman DS, et al; American College of Cardiology; American Heart Association; American Society for Nuclear Cardiology. American College of Cardiology; American Heart Association Task Force on Practice Guidelines; American Society for Nuclear Cardiology. ACC/AHA/ASNC guidelines for the clinical use of cardiac radionuclide imaging: A report of the American College of Cardiology/American Heart Association Task Force on Practice Guidelines (ACC/AHA/ASNC Committee to Revise the 1995 Guidelines for the clinical use of cardiac radionuclide imaging). J Am Coll Cardiol. 2003;42(7):1318-33.

73. Notghi A, Low CS. Myocardial perfusion scintigraphy: past, present and future. Br J Radiol.2011;84(Spec 3):S229-36.

74. Wackers FJ, Brown KA, Heller GV, Kontos MC, Tatum JL, Udelson JE, et al. American Society of Nuclear Cardiology position statement on radionuclide imaging in patients with suspected acute ischemic syndromes in the emergency department or chest pain center. J Nucl Cardiol. 2002;9(2):246-50.

75. Budoff MJ, Dowe D, Jollis JG,Gitter M, Sutherland J, Halamert E, et al. iagnostic performance of 64-multidetector row coronary computed tomographic angiography for evaluation of coronary artery stenosis in individuals without known coronary artery disease: results from the prospective multicenter ACCURACY (Assessment by Coronary Computed Tomographic Angiography of Individuals Undergoing Invasive Coronary Angiography) trial. J Am Coll Cardiol. 2008;52(21):1724-32.

76. Miller JM, Rochitte CE, Dewey M, Arbab-Zadeh A, Gottlieb NH, Clouse ME, et al. Diagnostic performance of coronary angiography by 64-row CT. N Engl J Med 2008;359(22):2324-36.

77. Meijboom WB, Meijs MF, Schuijf JD, Cramer MJ, Mollet NR, van Mieghem CA, et al. Diagnostic accuracy of 64-slice computed tomography coronary angiography: a prospective, multicenter, multivendor study. J Am Coll Cardiol. 2008;52(25):2135-44

78. Hoffmann U, Ferencik M, Udelson JE, Picard MH, Truong QA, Patel MR, et al.; PROMISE Investigators. Prognostic Value of Noninvasive Cardiovascular Testing in Patients With Stable Chest Pain: Insights From the PROMISE Trial (Prospective Multicenter Imaging Study for Evaluation of Chest Pain). Circulation. 2017;135(24):2320-32.

79. Collet C, Onuma Y, Andreini D, Sonck J, Pompilio G, Mushtaq S, et al. Coronary computed tomography angiography for heart team decisionmaking in multivessel coronary artery disease. Eur Heart J. 2018 Nov 1;39(41):3689-98

80. Goldstein JA, Chinnaiyan KM, Abidov A, Achenbach S, Berman DS, Hayes SW, et al. The CT-STAT (Coronary Computed Tomographic Angiography for Systematic Triage of Acute Chest Pain Patients to Treatment) trial. J Am Coll Cardiol. 2011:58(14):1414-22.

81. Litt HI, Gatsonis C, Snyder B, et al. CT angiography for safe discharge of patients with possible acute coronary syndromes. N Engl J Med. 2012;366(15):1393-403.

82. Hoffmann U, Truong QA, Schoenfeld DA, Chou ET, Woodard PK, Nagurney $\mathrm{JT}$, et al. Coronary CT angiography versus standard evaluation in acute chest pain. N Engl J Med 2012;367(4):299-308.
83. Hulten E, Pickett C, Bittencourt MS, Villines Tc, Petrillo S, Di Carlo MF et al. Outcomes After Coronary Computed Tomography Angiography in the Emergency Department: A Systematic Review and Meta-Analysis of Randomized, Controlled Trials. J Am Coll Cardiol. 2013;61(8):880-92.

84. Schertler T, Frauenfelder T, Stolzmann P, Scheffel H, Desbiolles L, Marincek B, Kaplan V, Kucher N, Alkadhi H. Triple rule-out CT in patients with suspicion of acute pulmonary embolism: findings and accuracy. Acad Radiol. 2009 Jun;16(6):708-17.

85. Takakuwa KM, Halpern EJ, Shofer FS. A time and imaging cost analysis of low-risk ED observation patients: a conservative 64-section computed tomography coronary angiography "triple rule-out" compared to nuclear stress test strategy. Am J Emerg Med. 2011 Feb;29(2):187-95.

86. Sara L, Szarf G, Tachibana A, Shiozaki AA, Villa AV, de Oliveira AC, de Albuquerque AS, etal. II Guidelines on Cardiovascular Magnetic Resonance and Computed Tomography of the Brazilian Society of Cardiology and the Brazilian College of Radiology. Arq Bras Cardiol. 2014 Dec;103(6 Suppl 3):1-86.

87. Goehler A, Mayrhofer T, Pursnani A, Ferencik M, Lumish HS, Barth C, et al. Long-term health outcomes and cost-effectiveness of coronary $\mathrm{CT}$ angiography in patients with suspicion for acute coronary syndrome. Cardiovasc Comput Tomogr. 2020 Jan-Feb;14(1):44-54

88. Fox KA, Dabbous OH, Goldberg RJ, Pieper KS, Eagle KA, Van der Wef F, et al. Prediction of risk of death and myocardial infarction in the six months after presentation with acute coronary syndrome: prospective multinational observational study (GRACE). BMJ. 2006;333(7578):1091.

89. Granger CB, Goldberg RJ, Dabbous O, et al. Predictors of hospital mortality in the Global Registryof Acute Coronary Events. Arch Intern Med. 2003;163(19):2345-53.

90. Fox KAA, FitzGerald G, Puymirat E, Huang W, Carruthers K, Simon T, et al. Should patients with acute coronary disease be stratified for management according to their risk? Derivation, external validation and outcomes using the updated GRACE risk score. BMJ Open. 2014;4(2):e004425.

91. Braunwald E, Antman EM, Beasley JW, Califf RM, Cheitlin MD, Hochman IS, et al. ACC/AHA guidelines for the management of patients with unstable angina and non-ST-segment elevation myocardial infarction. A report of the American College of Cardiology/American Heart Association Task Force on Practice Guidelines (Committee on the Management of Patients With Unstable Angina). J Am Coll Cardiol. 2000 Sep;36(3):970-1062.

92. Subherwal S, Bach RG, Chen AY, Gage BF, Rao SV, Newby LK,et al. Baseline risk of major bleeding in non-ST-segment-elevation myocardial infarction: the CRUSADE (Can Rapid risk stratification of Unstable angina patients Suppress ADverse outcomes with Early implementation of the ACC/AHA Guidelines) Bleeding Score. Circulation. 2009;119(14):1873-82.

93. Nicolau JC, Moreira HG, Baracioli LM, Serrano CV Jr, Lima FG, Franken M et al. The bleeding risk score as a mortality predictor in patients with acute coronary syndrome. Arq Bras Cardiol. 2013 Dec;101(6):511-8.

94. Mehran R, Pocock SJ, Nikolsky E, Clayton T, Dangas GD, Kirtane AJ,et al. A risk score to predict bleeding in patients with acute coronary syndromes. J Am Coll Cardiol. 2010;55(23):2556-66.

95. Collet JP, Thiele H, Barbato E, Barthélémy O, Bauersachs J, Bhatt DL, et al ESC Scientific Document Group. 2020 ESC Guidelines for the management of acute coronary syndromes in patients presenting without persistent STsegment elevation. Eur Heart J. 2020 Aug 29:ehaa575.

96. Six AJ, Backaus BE, Kelder SC, Chest pain in the emergency room: value of the Heart score. Neth Heart J.2008;16(6):191-6.

97. Than M, Cullen L, Aldous S, Goodacre S, Frampton CM, Troughton R, et al. 2-Hour accelerated diagnostic protocol to assess patients with chest pain symptoms using contemporary troponins as the only biomarker: the ADAPT trial. J Am Coll Cardiol. 2012;59(23):2091-8.

98. Than M,Flaws D, Sanders S, Doust J, Glasziou P, Kline J, et al Development and validation of the Emergency Department Assessment of Chest pain Score and $2 \mathrm{~h}$ accelerated diagnostic protocol. Emerg Med Australas.2014;26(1):34-44 
99. Greenslade JH et al. Diagnostic Accuracy of a New High-Sensitivity Troponin I Assay and Five Accelerated Diagnostic Pathways for Ruling Out Acute Myocardial Infarction and Acute Coronary Syndrome. Ann Emerg Med. 2018;71(4):439-51.e3.

100. Santi L, Farina G, Gramenzi A, Trevisani F, Baccini M, Bernardi M, et al. The HEART score with high-sensitive troponin $T$ at presentation: ruling out patients with chest pain in the emergency room. Intern EmergMed. 2017;12(3):357-64.

101. Carlton EW, Cullen L, Than M, Gamble J, Khattab A, Greaves K. A novel diagnostic protocol to identify patients suitable for discharge after a single highsensitivity troponin. Heart. 2015;101(13):1041-6.

102. Aarts GWA, Camaro C, van Geuns RJ, et al. Acute rule-out of non-ST-segment elevation acute coronary syndrome in the (pre) hospital setting by HEART score assessment and a single point-of-care troponin: rationale and design of the ARTICA randomised trial. BMJ Open. 2020;10(2): e034403.

103. Backus BE, SixAJ, Kelder JC, Mast TP, van den Akker F, MastEG, MonninkSH, van Tooren RM, Doevendans PA. Chest pain in the emergency room: a multicenter validation of the HEART Score. Crit Pathw Cardiol. 2010 Sep;9(3):164-9.

104. Backus BE, Six AL, Kelder SC,Bosschaert EG, Mast A, Mosterd RF, et al. A prospective validation of the Heartscore for chest pain patients at the emergency departament. Int J Cardiol. 2013; 168:2153-8.

105. Six Aj, Cullen L,Backus BE, Greenslade J, Parsonage W, Aldous S, et al. The HEART score for the assessment of patients with chest pain in the emergency department: a multinational validation study.Crit Pahtw Cardiol. 2013:12(3):121-6.

106. Van Den Berg P, Body R. The HEART score for early rule out of acute coronary syndromes in the emergency department: a systematic review and meta-analysis. Eur Heart J Acute Cardiovasc Care. 2018; 7(2): 111-9.

107. Poldervaart JM, Langedijk M, Backus BE, Dekker IMC, Six AJ, Doevendans PA, Hoes AW, Reitsma JB. Comparison of the GRACE, HEART and TIMI score to predict major adverse cardiac events in chest pain patients at the emergency department. Int J Cardiol. 2017 Jan 15;227:656-61.

108. Sakamoto JT, Liu N, Koh ZX, Fung NX, Heldeweg ML, Ng JC. Comparing HEART, TIMI, and GRACE scores for prediction of 30-day major adverse cardiac events in high acuity chest pain patients in the emergency department. Int J Cardiol. 2016 Oct 15;221:759-64.

109. Mahler SA, Riley RF, Hiestand BC, Russell GB, Hoekstra JW, Lefebvre CW, et al. The HEART Pathway randomized trial: identifying emergency department patients with acute chest pain for early discharge. Circ Cardiovasc Qual Outcomes. 2015;8(2):195-203.

110. Stopyra JP, Riley RF, Hiestand BC, Russell G, Holkstra JW, Lefebvre CW, et al. The HEART Pathway Randomized Controlled Trial One-year Outcomes. Acad Emerg Med. 2019;26(1):41-50.

111. Reinhardt SW, Lin CJ, Novak E, Brown DL. Noninvasive Cardiac Testing vs Clinical Evaluation Alone in Acute Chest Pain: A Secondary Analysis of the ROMICAT-II Randomized Clinical Trial. JAMA Intern Med. 2018:178(2):212-9.

112. O'Neill L, Smith K, Currie P,Elder Dhj, Wei J, Lang CC. et al. Nurse-led Early Triage (NET) study of chest pain patients: a long term evaluation study of a service development aimed at improving the management of patients with non-ST-elevation acute coronary syndromes. Eur J Cardiovasc Nurs. 2014; 13(3):253-60.

113. Roche TE, Gardner G, Jack L. The effectiveness of emergency nurse practitioner service in the management of patients presenting to rural hospitals with chest pain: a multisite prospective longitudinal nested cohort study. BMC Health Serv Res. 2017; 17(1): 445.

114. Stub D, Smith K, Bernard S, Nehme Z, Stephenson M, Bray JE, eet al. Air versus oxygen in ST-segment-elevation myocardial infarction. Circulation 2015;131(24):2143-50.

115. Hofmann R, James SK, Jernberg T, Lindahl B, Erlinge D, Witt N, et al. Oxygen Therapy in Suspected Acute Myocardial Infarction. N Engl J Med. 2017 Sep 28:377(13):1240-9.
116. Hobl EL, Stimpfl T, Ebner J, Schoergenjofer C, Derhaschnig U, Plassman RS, et al. Morphine decreases clopidogrel concentrations and effects: a randomized, double-blind, placebo-controlled trial. J Am Coll Cardiol. 2014;63(7):630-5.

117. Thomas MR, Morton AC, Hossain R, Chen b, Luo L, Shahari NN, et al. Morphine delays the onset of action of prasugrel in patients with prior history of ST-elevation myocardial infarction. Thromb Haemost. 2016; 116(7):96-102.

118. Kubica J, Adamski P, Ostrowska M, Sikora J, Kubica JM, Srooka WD, et al. Morphine delays and attenuates ticagrelor exposure and action in patients with myocardial infarction: the randomized, double-blind, placebo-controlled IMPRESSION trial. Eur HeartJ. 2016;37(3):245-52.

119. Meine TJ, Roe MT, Chen AY, Patel MR, Washam JB, Ohman EM, et al; CRUSADE Investigators. Association of intravenous morphine use and outcomes in acute coronary syndromes: results from the CRUSADE Quality Improvement Initiative. Am Heart). 2005;149(6):1043-9.

120. Duarte GS, Nunes-Ferreira A, Rodrigues FB, Pinto FJ, Ferreira JJ, Costa J, et al. Morphine in acute coronary syndrome: systematic review and meta-analysis. BMJ Open. 2019;9(3):e025232.

121. Furtado RHM, Nicolau JC, Guo J, Im K, White JA, Sabatine MS, et al Morphine and Cardiovascular Outcomes Among Patients With Non-ST-Segment Elevation Acute Coronary Syndromes Undergoing Coronary Angiography. J Am Coll Cardiol. 2020 Jan 28;75(3):289-300.

122. Dixon RA, Edwards IR, Pilcher J. Diazepam in immediate post-myocardial infarct period. A double blind trial. Br Heart J.1980 May;43(5):535-40.

123. Gislason GH, Jacobsen S, Rasmussen JN, Rasmussen S, Bucch P, Fribens $\mathrm{J}$, et al. Risk of death or reinfarction associated with the use of selective cyclooxygenase- 2 inhibitors and nonselective nonsteroidal antiinflammatory drugs after acute myocardial infarction. Circulation. 2006;113(25):2906-13.

124. Conaway DG, O'Keefe JH, Reid KJ, Spertus J. Frequency of undiagnosed diabetes mellitus in patients with acute coronary syndrome. Am J Cardiol. 2005;96(3):363-5.

125. Goyal A, Mahaffey KW, Garg J, Nicolau JC, Hochman JS, Weaver WD, Theroux P, Oliveira GB, Todaro TG, Mojcik CF, Armstrong PW, Granger CB. Prognostic significance of the change in glucose level in the first $24 \mathrm{~h}$ after acute myocardial infarction: results from the CARDINAL study. Eur Heart J. 2006 Jun;27(11):1289-97.

126. Nicolau JC, Serrano CV Jr, Giraldez RR, Baracioli LM, Moreira HG, Lima F, et al. In patients with acute myocardial infarction, the impact of hyperglycemia as a risk factor for mortality is not homogeneous across age-groups. Diabetes Care. 2012 Jan;35(1):150-2.

127. Finfer S, Chittock DR, Su SY, Bleir D, Foster D, Dhingra V, et al. Intensive versus conventional glucose control in critically ill patients. N Engl J Med. 2009;360(13):1283-97.

128. DePace NL, Herling IM, Kotler MN, Hakki AH, Spielman SR, Segal BL. Intravenous nitroglycerin for rest angina. Potential pathophysiologic mechanisms of action. Arch Intern Med. 1982 Oct;142(10):1806-9.

129. Kaplan K, Davison R, Parker M, Przybylek J, Teagarden JR, Lesch M. Intravenous nitroglycerin for the treatment of angina at rest unresponsive to standard nitrate therapy. Am J Cardiol.1983 Mar 1;51(5):694-8.

130. Roubin GS, Harris PJ, Eckhardt I, Hensley W, Kelly DT. Intravenous nitroglycerine in refractory unstable angina pectoris. Aust N Z J Med. 1982 Dec;12(6):598-602.

131. Curfman GD, Heinsimer JA, Lozner EC, Fung HL. Intravenous nitroglycerin in the treatment of spontaneous angina pectoris: a prospective, randomized trial. Circulation. 1983 Feb;67(2):276-82.

132. Dellborg M, Gustafsson G, Swedberg K. Buccal versus intravenous nitroglycerin in unstable angina pectoris. Eur J Clin Pharmacol. 1991;41(1):5-9.

133. Gottlieb SO, Weisfeldt ML, Ouyang P, Achuff SC, Baughman KL, Traill TA, et al. Effect of the addition of propranolol to therapy with nifedipine for unstable angina pectoris: a randomized, double-blind, placebo-controlled trial. Circulation. 1986 Feb;73(2):331-7. 
134. Telford AM, Wilson C. Trial of heparin versus atenolol in prevention of myocardial infarction in intermediate coronary syndrome. Lancet. 1981 Jun 6;1(8232):1225-8.

135. Lubsen J, Tijssen JG. Efficacy of nifedipine and metoprolol in the early treatment of unstable angina in the coronary care unit: findings from the Holland Interuniversity Nifedipine/metoprolol Trial (HINT). Am J Cardiol. 1987 Jul 15;60(2):18A-25A

136. Yusuf S, Wittes J, Friedman L. Overview of results of randomized clinical trials in heart disease. II. Unstable angina, heart failure, primary prevention with aspirin, and risk factor modification. JAMA. 1988 Oct 21;260(15):2259-63.

137. Nicolau JC, Furtado RHM, Baracioli LM, Lara LM, Dalçóquio TF, Scanavini Junior MA, et al. The Use of Oral Beta-Blockers and Clinical Outcomes in Patients with Non-ST-Segment Elevation Acute Coronary Syndromes: a LongTerm Follow-Up Study. Cardiovasc Drugs Ther. 2018 Oct;32(5):435-42.

138. Chen ZM, Pan HC, Chen YP, Peto R, Collins R, Jiang LX, et al. Early intravenous then oral metoprolol in 45,852 patients with acute myocardial infarction: randomised placebo-controlled trial. Lancet. 2005 Nov 5;366(9497):162232.

139. Kontos MC, Diercks DB, Ho PM, Wang TY, Chen AY, Roe MT. Treatment and outcomes in patients with myocardial infarction treated with acute $\beta$-blocker therapy: results from the American College of Cardiology's NCDR( $(\mathbb{B})$. Am Heart J. 2011 May;161(5):864-70

140. Crea F, Libby P. Acute Coronary Syndromes: The Way Forward From Mechanisms to Precision Treatment. Circulation. 2017 Sep 19;136(12):115566.

141. Bhatt DL, Hulot JS, Moliterno DJ, Harrington RA. Antiplatelet and anticoagulation therapy for acute coronary syndromes. Circ Res. 2014;114(12):1929-43.

142. Lüscher TF, Steffel J, Eberli FR, Joner M, Nakazawa G, Tanner FC, et al. Drugeluting stent and coronary thrombosis: biological mechanisms and clinical implications. Circulation. 2007 Feb 27;115(8):1051-8.

143. Bellemain-Appaix A, Kerneis M, O'Connor SA, Silvain J, Cucherat M, Beygui $\mathrm{F}$, et al. Reappraisal of thienopyridine pretreatment in patients with non-ST elevation acute coronary syndrome: a systematic review and meta-analysis. BMJ.2014;349:g6269.

144. Golwala H, BhattDL. The Timing of P2Y12 Inhibitor Initiation in the Treatment of ACS? Does the Evidence Exist in This Era? Prog Cardiovasc Dis. 2018 JanFeb:60(4-5):471-7.

145. Dworeck C, Redfors B, Angerås O, Haraldsson I, Odenstedt J, loanes D, et al. Association of Pretreatment With P2Y12 Receptor Antagonists Preceding Percutaneous Coronary Intervention in Non-ST-Segment Elevation Acute Coronary Syndromes With Outcomes. JAMA Netw Open. 2020;3(10):e2018735.

146. Wiviott SD, Trenk D, Frelinger AL, O'Donoghue M, Neumann FJ, Michelson AD, et al. PRINCIPLE-TIMI 44 Investigators. Prasugrel compared with high loading- and maintenance-dose clopidogrel in patients with planned percutaneous coronary intervention: the Prasugrel in Comparison to Clopidogrel for Inhibition of Platelet Activation and AggregationThrombolysis in Myocardial Infarction 44 trial. Circulation. 2007 Dec 18;116(25):2923-32.

147. Gurbel PA1, Bliden KP, Butler K, Tantry US, Gesheff T, Wei C, etal. Randomized double-blind assessment of the ONSET and OFFSET of the antiplatelet effects of ticagrelor versus clopidogrel in patients with stable coronary artery disease: the ONSET/OFFSET study. Circulation. 2009 Dec 22;120(25):2577-85.

148. Bonello L, Laine M, Camoin-Jau L, Noirot F, Guieu R, Dignet-George F, et al. Onset of optimal P2Y12-ADP receptor blockade after ticagrelor and prasugrel intake in Non-ST elevation acute coronary syndrome. Thromb Haemost. 2015:114(4):702-7.

149. Singh S, Singh M, Grewal N, Khosla S. Comparative Efficacy and Safety of Prasugrel, Ticagrelor, and Standard-Dose and High-Dose Clopidogrel in Patients Undergoing Percutaneous Coronary Intervention: A Network Metaanalysis. Am J Ther. 2016;23(1):e52-e62.
150. Yusuf S, Bijsterveld N, Moons A. Effects of clopidogrel in addition to aspirin in patients with acute coronary syndromes without ST-segment elevation: the clopidogrel in unstable angina to prevent recurrent events trial investigators. New Engl J Med. 2001; 345(7):494-502 .

151. Mehta SR, Yusuf S, Peters RJ, Bertrand ME, Lewis BS, Natarajan MK, et al. Effects of pretreatment with clopidogrel and aspirin followed by long-term therapy in patients undergoing percutaneous coronary intervention: the PCI-CURE study. Lancet. 2001;358(9281):527-33

152. Wallentin L, Becker RC, Budaj A, Cannon CP, Emmanuelson H, Held C, et al. Ticagrelor versus clopidogrel in patients with acute coronary syndromes. N Engl J Med. 2009;361(1):1045-57.

153. Cannon CP, Harrington RA, James S, Ardissino D, Becker RC, Emanuelsson $\mathrm{H}$ et al. PLATelet inhibition and patient Outcomes (PLATO) investigators. Comparison of ticagrelor with clopidogrel in patients with a planned invasive strategy for acute coronary syndromes (PLATO): a randomised double-blind study. Lancet. 2010; 375(9791): 283-93.

154. Wiviott SD, Braunwald E, McCabe CH, Montalescot G, Ruzyllo W, Gottlieb $\mathrm{S}$, Neumann FJ, et al. Prasugrel versus clopidogrel in patients with acute coronary syndromes. N Engl J Med. 2007; 357(20): 2001-15.

155. Di Sciascio MG, Patti G, Pasceri V, Gatto L. Effectiveness of in-laboratory high-dose clopidogrel loading versus routine pre-load in patients undergoing percutaneous coronary intervention. J Am Coll Cardiol.2010;56(7):550-7.

156. Steinhubl SR, Berger PB, Mann JT 3rd, Fry ET, Delago A, Wilmer CH, et al. Early and sustained dual oral antiplatelet therapy following percutaneous coronary intervention: a randomized controlled trial. JAMA. 2002;288(19):2411-20.

157. Montalescot G, Bolognese L, Dudek D, Goldstein P, Hamm C, Tanguay J-F, ten Berg JM, et al. Pretreatment with prasugrel in non-ST-segment elevation acute coronary syndromes. N Engl J Med. 369(11):999-1010.

158. Tarantini G, Mojoli M, Varbella F,Caporale R, Riggatieri S, Condo G, et al. Timing of Oral P2Y12 Inhibitor Administration in Non-ST Elevation Acute Coronary Syndrome. J Am Coll Cardiol. 2020;S0735-1097(20)36444-5.

159. Nairooz R, Valgimigli M, Rochlani Y, Pothineni NV, Raina S, Sardar P, et al. Meta-analysis of clopidogrel pretreatment in acute coronary syndrome patients undergoing invasive strategy. Int J Cardiol. 2017 Feb 15;229:82-9.

160. Komosa A, Lesiak M, Krasiński Z, Grygier M, Siniawski A, Skorupski W, et al. Optimal Timing of P2Y12 Inhibitor Loading in Patients Undergoing PCI: A Meta-Analysis. Thromb Haemost. 2019 Jun;119(6):1000-20.

161. Topol EJ, Moliterno DJ, Herrmann HC, Powers ER, Grines CL, Cohen DJ, et al. the TARGET Investigators. Comparison of two platelet glycoprotein Ill/IIla inhibitors, tirofiban and abciximab, for the prevention of ischemic events with percutaneous coronary revascularization. N Engl J Med. 2001:344(25):1888-94.

162. Valgimigli M, Biondi-Zoccai G, Tebaldi M, van't Hof AWJ, Campo G, Hamm C, et al.T irofiban as adjunctive therapy for acute coronary syndromes and percutaneous coronary intervention: a meta-analysis of randomized trials. Eur Heart J. 2010;31(1):35-49.

163. Cannon CP, Weintraub WS, Demopoulos LA, Vicari R, Frey MJ, Lakkis N, et al. Comparison of early invasive and conservative strategies in patients with unstable coronary syndromes treated with the glycoprotein IIb/IIla inhibitor tirofiban. N Engl J Med 2001 Jun 21;344(25):1879-87.

164. Novel dosing regimen of eptifibatide in planned coronary stent implantation (ESPRIT): a randomised, placebo-controlled trial. Lancet 2000 Dec 16;356(9247):2037-44.

165. Platelet Receptor Inhibition in Ischemic Syndrome Management (PRISM) Study Investigators. A comparison of aspirin plus tirofiban with aspirin plus heparin for unstable angina. N Engl J Med. 1998 May 21;338(21):1498-505

166. International, randomized, controlled trial of lamifiban (a platelet glycoprotein IIb/IIla inhibitor), heparin, or both in unstable angina. The PARAGON Investigators. Platelet IIb/Illa Antagonism for the Reduction of Acute coronary syndrome events in a Global Organization Network. Circulation. 1998 Jun 23:97(24):2386-95. 
167. Platelet Glycoprotein IIb/IIla in Unstable Angina: Receptor Suppression Using Integrilin Therapy (PURSUIT) Trial Investigators. Inhibition of platelet glycoprotein IIb/IIla with eptifibatide in patients with acute coronary syndromes. N Engl J Med. 1998 Aug 13;339(7):436-43.

168. Mukherjee D, Mahaffey KW, Moliterno DJ, Harrington RA, Yadav JS, Pieper $\mathrm{KS}$, et al. Promise of combined low-molecular-weight heparin and platelet glycoprotein Ilb/Illa inhibition: results from Platelet Ilb/IIla Antagonist for the Reduction of Acute coronary syndrome events in a Global Organization Network B (PARAGON B). Am Heart J. 2002 Dec;144(6):995-1002.

169. Simoons ML. Effect of glycoprotein Ilb/Illa receptor blocker abciximab on outcome in patients with acute coronary syndromes without early coronary revascularisation: the GUSTO IV-ACS randomised trial. Lancet. 2001 Jun 16;357(9272):1915-24.

170. Boersma E, Harrington RA, Moliterno DJ, White H, Theroux P, Van de WF, et al. Platelet glycoprotein Ilb/Illa inhibitors in acute coronary syndromes: a meta-analysis of all major randomised clinical trials. Lancet. 2002 Jan 19;359(9302):189-98.

171. EPIC Investigators. Use of a monoclonal antibody directed against the platelet glycoprotein IIb/IIla receptor in high-risk coronary angioplasty. N Engl J Med. 1994 Apr 7;330(14):956-61.

172. Randomised placebo-controlled trial of abciximab before and during coronary intervention in refractory unstable angina: the CAPTURE Study. Lancet. 1997 May 17;349(9063):1429-35. Erratum in: Lancet 1997 Sep 6;350(9079):744.

173. Platelet glycoprotein IIb/IIla receptor blockade and low-dose heparin during percutaneous coronary revascularization. The EPILOG Investigators. N Engl J Med. 1997 Jun 12;336(24):1689-96.

174. EPISTENT Investigators. Randomised placebo-controlled and balloonangioplasty-controlled trial to assess safety of coronary stenting with use of platelet glycoprotein-IIb/Illa blockade. Lancet. 1998 Jul 11;352(9122):8792.

175. Randomised placebo-controlled trial of effect of eptifibatide on complications of percutaneous coronary intervention: IMPACT-II. Integrilin to Minimise Platelet Aggregation and Coronary Thrombosis-II. Lancet. 1997 May 17;349(9063):1422-8.

176. Effects of platelet glycoprotein IIb/Illa blockade with tirofiban on adverse cardiac events in patients with unstable angina or acute myocardial infarction undergoing coronary angioplasty. The RESTORE Investigators. Randomized Efficacy Study of Tirofiban for Outcomes and REstenosis. Circulation. 1997 Sep 2;96(5):1445-53.

177. O'Shea JC, Hafley GE, Greenberg S, Hasselblad V, Lorenz TJ, Kitt MM, et al. Platelet glycoprotein Ilb/llla integrin blockade with eptifibatide in coronary stent intervention: the ESPRIT trial: a randomized controlled trial. JAMA. 2001 May 16;285(19):2468-73.

178. Karvouni E, Katritsis DG, Ioannidis JP. Intravenous glycoprotein IIb/ IIla receptor antagonists reduce mortality after percutaneous coronary interventions. J Am Coll Cardiol. 2003 Jan 1;41(1):26-32.

179. Kastrati A, Mehilli J, Neumann FJ, Dotzer F, Ten BJ, Bollwein H, et al. Abciximab in patients with acute coronary syndromes undergoing percutaneous coronary intervention after clopidogrel pretreatment: the ISAR-REACT 2 randomized trial. JAMA. 2006 Apr 5;295(13):1531-8.

180. Stone GW, Bertrand ME, Moses JW, Ohman EM, Lincoff AM, Ware JH, et al. Routine upstream initiation vs deferred selective use of glycoprotein llb/ Illa inhibitors in acute coronary syndromes: the ACUITY Timing trial. JAMA. 2007 Feb 14;297(6):591-602.

181. Giugliano RP, White JA, Bode C, Armstrong Pw, Montalescot G, Lewis BS, et al. et al. Early versus delayed, provisional eptifibatide in acute coronary syndromes. N Engl J Med 2009;360(21):2176 -90.

182. Eikelboom JW, Anand SS, Malmberg K, Weitz JI, Ginsberg JS, Yusuf S. Unfractionated heparin and low-molecular-weight heparin in acute coronary syndrome without ST elevation: a meta-analysis. Lancet. 2000 Jun 3;355(9219):1936-42.
183. Spinler SA, Mahaffey KW, Gallup D, Levine GM, Ferguson JJ, Rao SV,et al. Relationship between renal function and outcomes in high-risk patients with non-ST-segment elevation acute coronary syndromes: results from SYNERGY. Int J Cardiol. 2010;144(1):36-41.

184. Bazinet A, Almanric K, Brunet C,Martineau J, Turcotte I, Caron S, et al. Dosage of enoxaparin among obese and renal impairment patients. Thromb Res. $2005 ; 116(1): 41-50$.

185. Garcia DA, Baglin TP, Weitz JI, Samama MM. Parenteral anticoagulants: Antithrombotic Therapy and Prevention of Thrombosis, 9th ed: American College of Chest Physicians Evidence-Based Clinical Practice Guidelines. Chest. 2012 May;141(2 Suppl):e24S-e43S.

186. Lalama JT, Feeney ME, Vandiver JW, Beavers KD, Walter LN, McClintic JR. Assessing an enoxaparin dosing protocol in morbidly obese patients. J Thromb Thrombolysis. 2015;39(4):516-21.

187. Lee YR, Palmere PJ, Burton CE, Benavides TM. Stratifying Therapeutic Enoxaparin Dose in Morbidly Obese Patients by BMI Class: A Retrospective Cohort Study. Clin Drug Investig. 2020;40(1):33-40.

188.Spinler SA, Ou FS, Roe MT, Gibler WB, Ohman EM, Pollack CV,et al. Weight-based dosing of enoxaparin in obese patients with non-ST-segment elevation acute coronary syndromes: results from the CRUSADE initiative. Pharmacotherapy. 2009 Jun;29(6):631-8.

189. Chua D, Tataru A. Enoxaparin Dosing for Acute Coronary Syndromes in Obese Patients-Should There be a Maximum Dose. J Cardio Cardiovasc Med. 2016;1:002.

190. White HD, Kleiman NS, Mahaffey KW, Lokhnygina Y, Pieper K, Cheswell K. et al. Efficacy and safety of enoxaparin compared with unfractionated heparin in high-risk patients with non-ST-segment elevation acute coronary syndrome undergoing percutaneous coronary intervention in the Superior Yield of the New Strategy of Enoxaparin, Revascularization and Glycoprotein IIb/IIla Inhibitors (SYNERGY) trial [published correction appears in Am Heart J. 2007 Feb;153(2):327]. Am Heart J. 2006;152(6):1042-50.

191. Silvain J, Beygui F, Barthelemy O, Pollack C, Jr., Cohen M, Zeymer U, et al. Efficacy and safety of enoxaparin versus unfractionated heparin during percutaneous coronary intervention: systematic review and meta-analysis. BMJ. 2012;344:e553.

192. Petersen JL, Mahaffey KW, Hasselblad V, Antman EM, Cohen M, Goodman SG, et al. Efficacy and bleeding complications among patients randomized to enoxaparin or unfractionated heparin for antithrombin therapy in nonST-segment elevation acute coronary syndromes: a systematic overview. JAMA. 2004; 292(1): 89-96.

193. Califf RM, Petersen JL, Hasselblad V, Mahaffey KW, Ferguson JJ. A perspective on trials comparing enoxaparin and unfractionated heparin in the treatment of non-ST-elevation acute coronary syndromes. Am Heart). 2005 Apr;149(4 Suppl):S91-9.

194. Yusuf S, Mehta SR, Chrolavicius S, Afzal R, Pogue J, Granger CB, et al. Comparison of fondaparinux and enoxaparin in acute coronary syndromes. N Engl J Med. 2006 Apr 6;354(14):1464-76.

195. Karthikeyan G, Mehta SR, Eikelboom JW. Fondaparinux in the treatment of acute coronary syndromes: evidence from OASIS 5 and 6 . Expert Rev Cardiovasc Ther. 2009 Mar;7(3):241-9.

196. Serrano Jr. CV, Soeiro AM, Leal TCAT, Godoy LC, Biselli B, Hata LA et al. Posicionamento sobre Antiagregantes Plaquetários e Anticoagulantes em Cardiologia - 2019. Arq Bras Cardiol. 2019; 113(1):111-34.

197. Mason PJ, Shah B, Tamis-Holland JE,BittJA, Cohen MG, Safirstein J, et al. An Update on Radial Artery Access and Best Practices for Transradial Coronary Angiography and Intervention in Acute Coronary Syndrome: A Scientific Statement From the American Heart Association. Circ Cardiovasc Interv. 2018;11(9):e000035. doi:10.1161/HCV.0000000000000035

198. Amsterdam EA, Wenger NK, Brindis RG, Casey DE, Ganisats TG, Holmes DR, et al. 2014 AHA/ACC Guideline for the management of patients with non-ST-elevation acute coronary syndromes. Circulation. 2014;130(25):e344-e426. 
199. Borzak S, Cannon CP, Kraft PL, Douthat L, Becker RC, Palmeri ST etal. Effects of Prior Aspirin and Anti-Ischemic Therapy on Outcome of Patients With Unstable Angina. Am J Cardiol.1998;81(6):678-81.

200. Theroux P, Taeymans Y, Morissette D, Bosch X, Pelletier GB, Waters DD. A randomized study comparing propranolol and diltiazem in the treatment of unstable angina. J Am Coll Cardiol. 1985;5(3):717-22.

201. Parodi O, Simonetti I, Michelassi C, Carpeggiani C, Biagini A, L'Abbate A, et al. Comparison of verapamil and propranolol therapy for angina pectoris at rest: a randomized, multiple-crossover, controlled trial in the coronary care unit. Am J Cardiol. 1986;57(11):899-906.

202. Held PH, Yusuf S, Furberg CD. Calcium channel blockers in acute myocardial infarction and unstable angina: an overview. BMJ. 1989;299(6709):1187-92.

203. Smith NL Reiber GE, Psaty BM, Heckbert SR, Siscovick DS, Ritchie JL, et al. Health outcomes associated with beta-blocker and diltiazem treatment of unstable angina. J Am Coll Cardiol. 1998;32(5):1305-11.

204. Yusuf S, Held P, Furberg C. Update of effects of calcium antagonists in myocardial infarction or angina in light of the second Danish Verapamil Infarction Trial (DAVIT-II) and other recent studies. Am J Cardiol. 1991;67(15):1295-7.

205. Boden WE, van Gilst WH, Scheldewaert RG, Starkey IR, Carlier MF, Julian DG, et al. Diltiazem in acute myocardial infarction treated with thrombolytic agents: a randomised placebo-controlled trial. Incomplete Infarction Trial of European Research Collaborators Evaluating Prognosis post-Thrombolysis (INTERCEPT). Lancet. 2000;355(9217):1751-6.

206. De Luca G, Verdoia M, Binda G, Schaffer A, Suryapranata H, Marino P. Aspirin desensitization in patients under-going planned or urgent coronary stent implantation: a single-center experience. Int J Cardiol. 2013;167(2):561-3.

207. Rossini R, Angiolillo DJ, Musumeci G, Scuri P, Invernizzi P, Bass TA, etal. Aspirin desensitization in patients undergoing percutaneous coronary interventions with stent implantation. Am J Cardiol. 2008;101(6):786-9.

208. Page NA, Schroeder WS. Rapid desensitization protocols for patients with cardiovascular disease and aspirin hypersensitivity in an era of dual antiplatelet therapy. Ann Pharmacother. 2007;41(1):61-7.

209. McMullan KL, Wedner HJ. Safety of aspirin desensitization in patients with reported aspirin allergy and cardiovascular disease. Clin Cardiol. 2013;36(1):25-30

210. Risk of myocardial infarction and death during treatment with low dose aspirin and intravenous heparin in men with unstable coronary artery disease. The RISC Group. Lancet. 1990;336(8719):827-30.

211. Theroux P, OuimetH, McCans J, Latour JG, Joly P, Levy G, et al. Aspirin, heparin, or both to treat acute unstable angina. N Engl J Med. 1988;319(17):1105-11.

212. Mehta SR, Tanguay JF, Eikelboom JW, JollySS, J oyner CD, Granger CB, et al; CURRENT-OASIS 7 trial investigators. Double-dose versus standarddose clopidogrel and high-dose versus low-dose aspirin in individuals undergoing percutaneous coronary intervention for acute coronary syndromes (CURRENT-OASIS 7): a randomised factorial trial. Lancet. 2010;376(9748):1233-43.

213. Yusuf S, Mehta SR, Zhao F, Gersh BJ, Commerford PJ, Blumenthal M, et al; Clopidogrel in Unstable angina to prevent Recurrent Events Trial Investigators. Early and late effects of clopidogrel in patients with acute coronary syndromes. Circulation. 2003;107(7):966-72

214. Peters RJ, Mehta SR, Fox KA, Zhao F, Lewis BS, Kopecky SL, et al; Clopidogrel in Unstable angina to prevent Recurrent Events (CURE) Trial Investigators. Effects of aspirin dose when used alone or in combination with clopidogrel in patients with acute coronary syndromes: observations from the Clopidogrel in Unstable angina to prevent Recurrent Events (CURE) study. Circulation. 2003;108(14):1682-7.

215. Leon MB, Baim DS, Popma JJ, Gordon PC, Cutlip DE, Ho KK, et al. A clinical trial comparing three antithrombotic-drug regimens after coronary-artery stenting. Stent Anticoagulation Restenosis Study Investigators. N Engl J Med.1998;339(23):1665-71
216. Mehta SR, Bassand JP, Chrolavicius S, Diaz R, Eikelboom JW, Fox KA, et al CURRENT-OASIS 7 Investigators. Dose comparisons of clopidogrel and aspirin in acute coronary syndromes. N Engl J Med. 2010;363(10):93042. Erratum in: N Engl J Med. 2010;363(16):1585.

217. Breet NJ, van Werkum JW, Bouman HJ, Kelder JC, Ruven HJ Bal ET, et al. Comparison of platelet function tests in predicting clinical outcome in patients undergoing coronary stent implantation. JAMA. 2010;303(8):754-62. Erratum in: JAMA. 2010;303(13):1257. JAMA. 2011;305(21):2174. JAMA. 2011;305(21):2172-3.

218. Buonamici P, Marcucci R, Migliorini A, Gensini GF, Santin A, Paniccia R, et al. Impact of platelet reactivity after clopidogrel administration on drugeluting stent thrombosis. J Am Coll Cardiol. 2007; 49(24): 2312-7.

219. Price MJ, Endemann S, Gollapudi RR, Valencia R, Stinis CT, Levisay JP, et al. Prognostic significance of postclopidogrel platelet reactivity assessed by a point-of-care assay on thrombotic events after drug-eluting stent implantation. Eur Heart J. 2008;29(8):992-1000.

220. Mega JL, Simon T, Collet JP, Anderson IL, Antman EM, Bliden K, et al. Reduced-function CYP2C19 genotype and risk of adverse clinical outcomes among patients treated with clopidogrel predominantly for PCI: a metaanalysis. JAMA. 2010;304(16):1821-30.

221. Taubert D, von Beckerath N, Grimberg G, Lazar A, Jung N, Goeser T, et al. Impact of P-glycoprotein on clopidogrel absorption. Clin PharmacolTher. 2006;80(5):486-501

222. Angiolillo DJ, Gibson CM, Cheng S, Ollier C, Nicolas O, Bergougnan $\mathrm{L}$, et al. Differential effects of omeprazole and pantoprazole on the pharmacodynamics and pharmacokinetics of clopidogrel in healthy subjects: randomized, placebo-controlled, crossover comparison studies. Clin PharmacolTher. 2011;89(1): 65-74.

223. Cuisset T, Frere C, Quilici J, Poyet R, Gaborit B, Bali L, et al Comparison of omeprazole and pantoprazole influence on a high 150mg clopidogrel maintenance dose the PACA (Proton Pump Inhibitors And Clopidogrel Association) prospective randomized study. J Am Coll Cardiol. 2009;54(13):1149-53.

224. Frelinger AL 3rd, Lee RD, Mulford DJ, Wu J, Nudurupati S, Nigam A, et al. A randomized, 2-period, crossover design study to assess the effects of dexlansoprazole, lansoprazole, esomeprazole, and omeprazole on the steady-state pharmacokinetics and pharmacodynamics of clopidogrel in healthy volunteers.J Am Coll Cardiol. 2012;59(14):1304-11. Erratum in J Am Coll Cardiol. 2012;60(6):566-7

225. Gilard M, Arnaud B, Cornily JC, Le Gal G, Lacut K, Le Calvez $\mathrm{G}$, et al. Influence of omeprazole on the antiplatelet action of clopidogrel associated with aspirin: the randomized, double-blind OCLA (OmeprazoleCLopidogrel Aspirin) study. J Am Coll Cardiol. 2008;51(3):256-60.

226. Ho PM, Maddox TM, Wang L, Fihn SD, Jesse RL, Peterson ED et al. Risk of adverse outcomes associated with concomitant use of clopidogrel and proton pump inhibitors following acute coronary syndrome. JAMA. 2009;301(9):937-44.

227. Juurlink DN, Gomes T, Ko DT, Szmitko PE, Austin PC, Tu JV, et al. A population-based study of the drug interaction between proton pumpinhibitors and clopidogrel. CMAJ. 2009;180(7):713-8.

228. Nicolau JC, Bhatt DL, Roe MT, Lokhnygina Y, Neely B, Corbalán $\mathrm{R}$, et al. TRILOGY ACS investigators. Concomitant proton-pump inhibitor use, platelet activity, and clinical outcomes in patients with acute coronary syndromes treated with prasugrel versus clopidogrel and managed without revascularization: insights from the Targeted Platelet Inhibition to Clarify the Optimal Strategy to Medically Manage Acute Coronary Syndromes trial. Am Heart J. 2015;170(4):683-694.

229. O'Donoghue ML, Braunwald E, Antman EM, Murphy SA, Bates ER, Rozenman Y, et al. Pharmacodynamic effect and clinical efficacy of clopidogrel and prasugrel with or without a proton-pump inhibitor: na analysis of two randomised trials. Lancet. 2009;374(9694):989-97. 
230. Goodman SG, Clare R, Pieper KS, Nicolau JC, Storey RF, Cantor WJ, et al . Association of proton pump inhibitor use on cardiovascular outcomes with clopidogrel and ticagrelor: insights from the platelet inhibition and patient outcomes trial. Circulation. 2012;125(8):978-86.

231. Bhatt DL, Cryer BL, Contant CF, Cohen M, Lanas A, Schnitzer TJ, et al; COGENT Investigators. Clopidogrel with or without omeprazole in coronary artery disease. N Engl J Med. 2010;363(20):1909-17.

232. Price MJ, Berger PB, Teirstein PS, Tanguay JF, Angiolillo DJ, Spriggs D, et al; GRAVITAS Investigators. Standard- vs high-dose clopidogrel based on platelet function testing after percutaneous coronary intervention: the GRAVITAS randomized trial. JAMA. 2011;305(11):1097-105. Erratum in JAMA. 2011 Jun 1;305(21);2174.

233. Collet JP, Cuisset T, Rangé G, Cayla G, Elhadad S, Pouillot C, et al; ARCTICInvestigators. Bedside monitoring to adjust antiplatelet therapy for coronary stenting. N Engl J Med. 2012;367(22):2100-9.

234. Jakubowski JA, Winters KJ, Naganuma H, Wallentin L. Prasugrel: a novel thienopyridine antiplatelet agent: a review of preclinical and clinical studies and the mechanistic basis for its distinct antiplatelet profile. Cardiovasc Drug Rev. 2007;25(4):357-74.

235. Morrow DA, Wiviott SD, White HD, Nicolau JC, Bramucci E, Murphy SA, et al. Effect of the novel thienopyridine prasugrel compared with clopidogrel on spontaneous and procedural myocardial infarction in the Trial to Assess Improvement in Therapeutic Outcomes by Optimizing Platelet Inhibition with Prasugrel-Thrombolysis in Myocardial Infarction 38: an application of the classification system from the universal definition of myocardial infarction. Circulation. 2009;119(21):2758-64.

236. Wiviott SD, Braunwald E, Angiolillo DJ, Meisel S, Dalby AJ, Verheugt FW, et al; TRITON-TIMI 38 Investigators. Greater clinical benefit of more intensive oral antiplatelet therapy with prasugrel in patients with diabetes mellitus in the trial to assess improvement in therapeutic outcomes by optimizing platelet inhibition with prasugrel-Thrombolysis in Myocardial Infarction 38. Circulation. 2008;118(16):1626-36.

237. Smith PK, Goodnough LT, LevyJH, Poston RS, Short MA, Weerakkody GJ, et al. Mortality benefit with prasugrel in the TRITON-TIMI 38 coronary artery bypass grafting cohort: risk-adjusted retrospective data analysis. J Am Coll Cardiol. 2012,31;60(5):388-96.

238. Gurbel PA, Erlinge D, Ohman EM, Neely B, Neely M, Goodman SG, et al. Platelet function during extended prasugrel and clopidogrel therapy for patients with ACS treated without revascularization: the TRILOGY ACS platelet function substudy. JAMA. 2012;308(17):1785-94.

239. Ohman J, Kudira R, Albinsson S, Olde B, Erlinge D. Ticagrelor induces adenosine triphosphate release from human red blood cells. Biochem Biophys Res Commun. 2012;418(4):754-8.

240. Bonello L, Laine M, Kipson N, Mancini J, Helal O, Fromonot], et al. Ticagrelor increases adenosine plasma concentration in patients with an acute coronary syndrome. J Am Coll Cardiol 2014;63(9):872-7.

241. Orme RC, Parker WAE, Thomas MR, Judge HM, Baster K, Sumaya W, et.al. Study of Two Dose Regimens of Ticagrelor Compared with Clopidogrel in Patients Undergoing Percutaneous Coronary Intervention for Stable Coronary Artery Disease (STEEL-PCI). Circulation 2018;138(13):1290-300.

242. Ortega-Paz L, Brugaletta S, Ariotti S, Akkerhuis KM, Karagiannis A, Windecker S, et al. HI-TECH investigators. Adenosine and Ticagrelor Plasma Levels in Patients With and Without Ticagrelor-Related Dyspnea . Circulation 2018;138(6):646-48.

243. Scirica BM, Cannon CP, Emanuelsson H, Michelson EL, Harrington RA, Husted S, et al.; PLATO Investigators. The incidence of bradyarrhythmias an clinical bradyarrhythmic events in patients with acute coronary syndromes treated with ticagrelor or clopidogrel in the PLATO (Platelet Inhibition and Patient Outcomes) trial: results of the continuous electrocardiographic assessment substudy. J Am Coll Cardiol. 2011;57(19):1908-16.

244. Nilsen DW. Potential benefits of ticagrelor beyond platelet inhibition. Cardiology. 2013;125(1):31-3.
245. ames S, Angiolillo DJ, Cornel JH, Erlinge D, Husted S, Kontny F, et al; PLATO Study Group. Ticagrelor vs. clopidogrel in patients with acute coronary syndromes and diabetes: a substudy from the PLATelet inhibition and patient Outcomes (PLATO) trial. Eur Heart J. 2010;31(24):3006-16.

246. James S, Budaj A, Aylward P, Buck KK, Cannon CP, Cornel JH, et al. Ticagrelor versus clopidogrel in acute coronary syndromes in relation to renal function: results from the Platelet Inhibition and Patient Outcomes (PLATO) trial. Circulation. 2010;122(11):1056-67.

247. James SK, Storey RF, Khurmi NS, Husted S, Keltai M, Mahaffey KW, et al; PLATO Study Group. Ticagrelor versus clopidogrel in patients with acute coronary syndromes and a history of stroke or transient ischemic attack. Circulation. 2012;125(23):2914-21.

248. Cannon CP, Harrington RA, James S, Ardissino D, Becker RC, Emanuelsson $\mathrm{H}$, et al; PLATelet inhibition and patient Outcomes Investigators. Comparison of ticagrelor with clopidogrel in patients with a planned invasive strategy for acute coronary syndromes (PLATO): a randomised double-blind study. Lancet. 2010;375(9711):283-93.

249. Held C, Asenblad N, Bassand JP, Becker RC, Cannon CP, Claeys MJ, et al. Ticagrelor versus clopidogrel in patients with acute coronary syndromes undergoing coronary artery bypass surgery: results from the PLATO (Platelet Inhibition and Patient Outcomes) trial. J Am Coll Cardiol. 2011;57(6):672-84.

250. Kohli P, Wallentin L, Reyes E, Horrow J, Husted S, Angiolillo DJ, etal. Reduction in first and recurrent cardiovascular events with ticagrelor compared with clopidogrel in the PLATO Study. Circulation. 2013;127(6):673-80.

251. Nikolic E, Janzon M, Hauch O, Wallentin L, Henriksson M; PLATO Health Economic Substudy Group. Cost-effectivenessof treating acute coronary syndrome patients with ticagrelor for 12 months: results from the PLATO study. Eur Heart J. 2013;34(3):220-8.

252.Schüpke S, Neumann FJ, Menichelli M, Mayer K, Bernlochner I, Wöhrle J, et al., ISAR-REACT 5 Trial Investigators Ticagrelor or Prasugrel in Patients with Acute Coronary Syndromes N Engl J Med 2019;381(16):1524-34.

253. Cayla G, Cuisset T, Silvain J, Leclercq F, Manzo-Silberman S, Saint-Etienne C, et al.ANTARCTIC investigators. Platelet function monitoring to adjust antiplatelet therapy in elderly patients stented for an acute coronary syndrome (ANTARCTIC): an open-label, blinded-endpoint, randomised controlled superiority trial. Lancet. 2016;388(10055):2015-22.

254. Claassens DMF, Vos GJA, Bergmeijer TO, Hermanides RS, van 't Hof AWJ, van der Harst P, et al. A Genotype-Guided Strategy for Oral P2Y 12 Inhibitors in Primary PCI. N Engl J Med. 2019;381(17):1621-31.

255. Pereira NL, Farkouh ME, So D. Effect of Genotype-Guided Oral P2Y12 Inhibitor Selection vs Conventional Clopidogrel Therapy on Ischemic Outcomes After Percutaneous Coronary Intervention: The TAILOR-PCI Randomized Clinical Trial JAMA. 2020;324(8):761-77

256. Hirsh J, Warkentin TE, Shaughnessy SG, Annand SS. Heparin and LowMolecular-Weight Heparin, Mechanisms of Action, Pharmacokinetics, Dosing, Monitoring, Efficacy, and Safety. Chest. 2001; 119(1 Suppl):64S-94S.

257. Hirsh J, Anand SS, Halperin JL, Fuster V. Mechanism of Action and Pharmacology of Unfractionated Heparin. Arterioscler Thromb Vasc Biol. 2001;21(7):1094-96.

258. Lee MS, Wali AU, Menon V, Berkowitz SD, Thompson TD, Califf RM, et al. The determinants of activated partial thromboplastin time, relation of activated partial thromboplastin time to clinical outcomes, and optimal dosing regimens for heparin treated patients with acute coronary syndromes: are view of GUSTO-IIlb. J Thromb Thrombolysis 2002;14(2):91-101.

259. AntmanEM, McCabe CH, Gurfinkel EP, Turpie AG, Bernink PJ, Salein D, et al. Enoxaparin prevents death and cardiac Ischemic events in unstable angina/ non-Q-wave myocardial infarction: results of theThrombolysis in Myocardial Infarction (TIMI) 11B trial. Circulation. 1999;100(15):1593-601.

260. Cohen M, Demers C, Gurfinkel EP, Turpie AGG, Fromell GJ, Goodman $\mathrm{S}$, et al. A Comparison of Low-Molecular-Weight Heparin with Unfractionated Heparin for Unstable Coronary Artery Disease. N Engl J Med. 1997:337(7), 447-52. 
261. Antman EM, Cohen M, Radley D, McCabeC, Rush J, PremmereurJ, Braunwald E. Assessment of the Treatment Effect of Enoxaparin for Unstable angina/ non-Q-wave Myocardial Infarction. TIMI 11B-ESSENCE Meta-Analysis. Circulation. 1999;100(15), 1602-8.

262. Ferguson JJ, Califf RM, Antman EM, Cohen M, Grines CL, Goodman S, et al. Enoxaparin VS unfractionated heparin in high risk patients with non-STsegment elevation acute coronary syndromes managed with na intended early invasive strategy: primary results of the SYNERGY randomized trial. JAMA. 2004;292(1):45-54.

263. Collet JP, Montalescot G, Lison L, Choussat R, Ankri A, Drobinski G, et al. Percutaneous coronary intervention after subcutaneous enoxaparin pretreatment in patients with unstable angina pectoris. Circulation. 2001;103(5):658-63.

264. Petitou M, Casu B, Lindahl U. 1976-1983, a critical period in the history of heparin: the discovery of the antithrombin binding site. Biochimie. 2003;85(12):83-9.

265. Holbrook A, Schulman S, Witt DM, Vandnivick PO, Fish J, Kovacs MJ, et al. Evidence-based management of anticoagulant therapy: Antithrombotic Therapy and Prevention of Thrombosis, 9th ed: American College of Chest Physicians Evidence-Based Clinical Practice Guidelines. Chest. 2012;141(2 Suppl):e152S-e184S.

266. Zhang Y, Zhang M, Tan L, Pan N, Zhang L. The clinical use of Fondaparinux: A synthetic heparin pentasaccharide. Prog Mol Biol Transl Sci. 2019;163:41-53.

267. Mehta SR, Granger CB, Eikelboom JW, Bassand JP, Wallentin L,Faxon DP, et al. Efficacy and Safety of Fondaparinux Versus Enoxaparin in Patients With Acute Coronary Syndromes Undergoing Percutaneous Coronary Intervention: Results From the OASIS-5 Trial. J Am Coll Cardiol 2007;50(18):1742-51

268. Gibson CM, Mehran R, Bode C, Halpecin J, Verheugt FW, Goose P, Prevention of bleeding in patients with atrial fibrillation undergoing PCI. N Engl J Med. 2016;375(25):2423-34.

269. Cannon CP, Bhatt DL, Oldgren J, Thomas L, Ansell J, Fonarow GC, et al. Dual antithrombotic therapy with dabigatran after $\mathrm{PCl}$ in atrial fibrillation. N Engl J Med. 2017;377(25):1513-24.

270. Lopes RD, Heizer G, Aronson R, Vora AN, Massaro T, Mehran R, et al Antithrombotic Therapy After Acute Coronary Syndrome or PCl in Atrial Fibrillation. N Engl J Med. 2019;380(16):1509-24.

271. Vranckx P, Valgimigli M, Eckardt L, Tijsssen J, Lewatter T, Gargiuo G, et al. Edoxaban-based Versus Vitamin K Antagonist-Based Antithrombotic Regimen After Successful Coronary Stenting in Patients With Atrial Fibrillation (ENTRUST-AF PCI): A Randomised, Open-Label, Phase 3b Trial. Lancet, 2019;394 (10206), 1335-43.

272. Lopes RD, Hong H, Harskamp RE, Bhatt DL, Mehran R, Cannon CP, et al. Optimal Antithrombotic Regimens for Patients with Atrial Fibrillation Undergoing Percutaneous Coronary Intervention: an Updated Network Meta-analysis. JAMA Cardiol. 2020;5(5):582-589.

273. Collet JP, Thiele H, Barbato E, Barthélémy O, Bauersachs J, Bhatt DL, et al ESC Scientific Document Group, 2020 ESC Guidelines for the management of acute coronary syndromes in patients presenting without persistent STsegment elevation: The Task Force for the management of acute coronary syndromes in patients presenting without persistent ST-segment elevation of the European Society of Cardiology (ESC). Eur HeartJ. 2020 Aug 20 ehaa575 [online]

274. Cannon CP, Braunwald E, McCabe CH, Rader DJ, Rouleau IL, Belder R, et.al. Intensive versus moderate lipid lowering with statins after acute coronary syndromes. N Engl J Med 2004;350:1495-15042.

275. Sacks FM, Pfeffer MA, Moye LA, Rouleau JL, Rutherford JD, Cole TG, et al. The effect of pravastatin on coronary events after myocardial infarction in patients with average cholesterol levels. Cholesterol and Recurrent Events Trial investigators. N Engl J Med. 1996;335(14):1001-9.

276. Heart Protection Collaborative Group. MRC/BHF Heart Protection Study of cholsterol lowering with simvastatin in 20,536 high-risk individuals: a randomised placebo-controlled trial. Lancet. 2002;360(9326):7-22.
277. Dondo TB, Hall M, Timmis AD, Gilthorpe MS, Alabas AO, Batin PD, et al Excess Mortality and Guideline-Indicated Care Following non-ST-elevation Myocardial Infarction. Eur Heart J Acute Cardiovasc Care, 2107;6 (5), $412-20$

278. Faludi AA, Izar MCO, Saraiva JFK, Bianco HT, Chacra APM, Bertoluci MC et al. Diretriz brasileira baseada em evidências sobre prevenção de doenças cardiovasculares em pacientes com diabetes: posicionamento da Sociedade Brasileira de Diabetes (SBD), da Sociedade Brasileira de Cardiologia (SBC) e da Sociedade Brasileira de Endocrinologia e Metabologia (SBEM). Arq Bras Cardiol. 2017; 109(6 Supl.1):1-31

279. Cannon CP, Blazing MA, Giugliano RP, McCagg A, White JA, Theroux P, et.al. IMPROVE-IT Investigators. Ezetimibe added to statin therapy after acute coronary syndromes. N Engl J Med. 2015;372:2387-97.

280. Berwanger O, Santucci EV, de Barros e Silva PGM, Jesuíno IA, Damiani LP, Barbosa LM, et al. Effect of Loading Dose of Atorvastatin Prior to Planned Percutaneous Coronary Intervention on Major Adverse Cardiovascular Events in Acute Coronary Syndrome. JAMA. 2018;319(13):1331-40.

281. Yusuf S, Sleight P, Pogue J, Bosch J, Davies R, Dagenais G. Effects of na angiotensin-converting-enzyme inhibitor, ramipril, on cardiovascular events in high-risk patients. The Heart Outcomes Prevention Evaluation Study Investigators. N Engl J Med. 2000;342(3):145-53. Erratum in N Engl J Med. 2000;342(10):748 Erratum: N Engl J Med. 2000;342(18):1376.

282. Fox KM; EURopean trial On reduction of cardiac events with Perindopril in stable coronary Artery disease Investigators. Efficacy of perindopril in reduction of cardiovascular events among patients with stable coronary artery disease: randomised, double-blind, placebo-controlled, multicentre trial (the EUROPA study). Lancet. 2003; 362(9386):782-8.

283. Hoedemaker NPG, Damman P, Ottervanger JP, Dambrink JHE, Gosselink ATM, Kedhi E, et.al. Trends in Optimal Medical Therapy Prescription and Mortality After Admission for Acute Coronary Syndrome: A 9-year Experience in a Real-World Setting. Eur Heart J Cardiovasc Pharmacother,2018; 4(2):102-10.

284. Pitt B, Remme W, Zannad F, Neaton J, Martinez F, Roniker B, etal. Eplerenone, a selective aldosterone blocker, in patients with left ventricular dysfunction after myocardial infarction. N Engl J Med. 2003 Apr 3;348(14):1309-21. Erratum in: N Engl J Med. 2003; 348(22):2271.

285. Carillo S, Zhang Y, Fay R, Angioi M, Vincent J, Sutradhor SC, et al. Heart failure with systolic dysfunction complicating acute myocardial infarction - differential outcomes but similar eplerenone efficacy by ST-segment or non-ST-segment elevation: A post hoc substudy of the EPHESUS trial. Arch Cardiovasc Dis. 2014 Mar;107(3):149-57.

286. Pitt B, Zannad F, Remme WJ, Cody R, Castaigne A, Perez A, Palensky J, Wittes J. The effect of spironolactone on morbidity and mortality in patients with severe heart failure. Randomized Aldactone Evaluation Study Investigators. N Engl J Med. 1999 Sep 2;341(10):709-17.

287. Gibbons RJ, Balady GJ, Bricker JT, Chaitman BR, Fletcher GF, Froelicher $\mathrm{VF}$, et al; American College of Cardiology/American Heart Association Task Force on Practice Guidelines (Committee to Update the 1997 Exercise Testing Guidelines). ACC/AHA 2002 guideline update for exercise testing: summary article: a report of the American College of Cardiology/American Heart AssociationTask Force on Practice Guidelines (Committee to Update the 1997 ExerciseTesting Guidelines). Circulation. 2002;106(14):1883-92.

288. Gibler WB, Cannon CP, Blomkalns AL, Char DM, Drew BJ, Hollander JE, et al American Heart Association Council on Clinical Cardiology (Subcommittee on Acute Cardiac Care); Council on Cardiovascular Nursing, and Quality of Care and Outcomes Research Interdisciplinary Working Group; Society of Chest Pain Centers. Practical implementation of the guidelines for unstable angina/non-ST-segment elevation myocardial infarction in the emergency department: a scientific statement from the American Heart Association Councilon Clinical Cardiology (Subcommittee on Acute Cardiac Care), Councilon Cardiovascular Nursing, and Quality of Care and Outcomes Research Interdisciplinary Working Group, in Collaboration With the Society of Chest Pain Centers. Circulation. 2005:111(20):2699-710. 
289. Amsterdam EA, Kirk JD, Diercks DB, Lewis WR, Turnipseed SD. Early exercise testing in the management of low risk patients in chest pain centers. Prog Cardiovasc Dis. 2004;46(5):438-52.

290. Mark DB, HlatkyMA, Harrell FEJr, Lee KL, Califf RM, Pryor DB. Exercise treadmill score for predicting prognosis in coronary artery disease. Ann Intern Med. 1987;106(6):793-800.

291. Stein RA, Chaitman BR, Balady GJ, Fleg JL, Limacher MC, Pina IL, etal. Safety and utility of exercise testing in emergency room chest pain centers: an advisory from the Committee on Exercise, Rehabilitation, and Prevention, Council on Clinical Cardiology, American Heart Association. Circulation. 2000;102(12):1463-7.

292. Larsson H, Areskog M, Areskog NH, Nylander E, Nyman I, Swahn E, et al. Should the exercise test $(\mathrm{ET})$ be performed at discharge or one month later after an episode of unstable angina or non-Q-wave myocardial infarction? Int J Card Imaging. 1991;7(1):7-14.

293. Hermann LK, Weingart SD, Duvall WL, Henzlova MJ. The limited utility of routine cardiac stress testing in emergency department chest pain patients younger than 40 years. Ann Emerg Med. 2009;54(1):12-6

294. Natsui S, Sun BC, Shen E, Wu YL, Redberg RF, Lee MS, et al. Evaluation of Outpatient Cardiac Stress Testing After Emergency Department Encounters for Suspected Acute Coronary Syndrome. Ann Emerg Med. 2019 Aug; 74(2):216-23.

295. Sabia P, Afrookteh A, Touchstone DA, Keller MW, Esquivel L, Kaul S. Value of regional wall motion abnormality in the emergency room diagnosis of acute myocardial infarction: a prospective study using two-dimensional echocardiography. Circulation. 1991;84(3 Suppl):185-92.

296. Stein JH, Neumann A, Preston LM, VandenBerg BJ, Parrillo JE, Calvin JE, et al. Improved risk stratification in unstable angina: identification of patients at low risk for in hospital cardiac events by admission echocardiography. Clin Cardiol. 1998;21(10):725-30.

297. Horowitz RS, Morganroth J, Parrotto C, Chen CC, Soffer I, Pauletto FJ. Immediate diagnosis of acute myocardial infarction by two-dimensional echocardiography. Circulation. 1982;65(2):323-9.

298. Kontos MC, Arrowood JA, Paulsen WH, Nixon JV. Early echocardiography can predict cardiac events in emergency department patients with chest pain. Ann Emerg Med. 1998;31(5):550-7.

299. Barberato SH, Romano MMD, BeckALS, Rodrigues ACT, Almeida ALC, Assunção BMBL, et al. Position Statement on Indications of Echocardiography in Adults - 2019. Arq Bras Cardiol. $2019 ; 113(1): 135-81$.

300. Campos FO, Zielinsky P, Ortiz I, Maciel BC, Andrade JL, Mathias W Jr, et al; Brazilian Society of Cardiology. [Guideline for indication and utilization of echocardiography in clinical practice]. Arq Bras Cardiol. 2004;82(Suppl 2):11-34.

301. Atici A, Ali Barman H, Durmaz E, Demir K, Cakmak R, Tugrul S, et al. Predictive value of global and territorial longitudinal strain imaging in detecting significant coronary artery disease inpatients with myocardial infarction without persistent ST-segment elevation. Echocardiography. 2019; 36(3):425-622.

302. Solomon SD, Glynn RJ, Greaves S, Ajani U, Rouleau JL, Menapace RF, et al. Recovery of venricular function after myocardial infarction in the reperfusion era: The healing and early after local therapy study. Ann Intern Med. 2001; 134(6): $451-8$.

303. Liou K, Negishi K, Ho S, Russell EA, Cranney G, Ooi SY. Detectionof Obstructive Coronary Artery Disease Using Peak Systolic Global Longitudinal Strain Derived by Two-Dimensional Speckle-Tracking: A Systematic Review and Meta-Analysis. J Am Soc Echocardiogr.2016;29(8):724-35 e4.

304. Marques-Alves P, Espirito-Santo N, Baptista R, Teixeira R, Martins R, Gonçalvrs $\mathrm{F}$, et al. Two-dimensional speckle-tracking global longitudinal strain in highsensitivity troponin-negative low-risk patients with unstable angina: a "resting ischemia test"? Int J Cardiovasc Imaging. 2017; 34(4):561-8.

305. Dahlslett T, Karlsen S, Grenne B, Eek C, Sjoli B, Skustad H, et al. Early assessment of strain echocardiography can accurately exclude significant coronary artery stenosis in suspected non-ST-segment elevation acute coronary syndrome. J Am Soc Echocardiogr. 2014;27(5):512-9.
306. Porter TR, Mulvagh SL, Abdelmoneim SS, Becher H, Belcik JT, Bierig M, et.al. Clinical Applications of Ultrasonic Enhancing Agents in Echocardiography: 2018 American Society of Echocardiography Guidelines Update. J Am Soc Echocardiogr. 2018; 31(3):241-74.

307.Pellikka PA, Olson AA, Chaudhry FA, Chen MH, Marshall JE, Porter TR, Sawada SG, Guidelines for Performance, Interpretation, and Application of Stress Echocardiography in Ischemic Heart Disease: From the American Society of Echocardiography. J Am Soc Echocardiogr.2020;33(1):1-41.

308. Sicari R, Landi P, Picano E, Pirelli S, Chiaranda G, Previtali M, et al. Exerciseelectrocardiography and/or pharmacological stress echocardiography for non-invasive risk stratification early after uncomplicated myocardial infarction: a prospective international large scale multicentre study. Eur Heart J. 2002;23(13):1030-7.

309. Montalescot G, Sechtem U, Achenbach S, Andreotti F, Arden C, Budaj A, et al. $2013 \mathrm{ESC}$ guidelines on the management of stable coronary artery disease: the Task Force on the management of stable coronary artery disease of the European Society of Cardiology. Eur HeartJ. 2013;34(38):2949-3003.

310. Picano E, Mathias WJr, Pingitore A, Bigi R, Previtali M. Safety and tolerability of dobutamine-atropine stress echocardiography: a prospective, multicentre study. Echo Dobutamine International Cooperative Study Group. Lancet. 1994:344(8931):1190-2.

311. Caldas MA, Tsutsui JM, Kowatsch I, Andrade JL, Nicolau JC, Ramires JF, et al. Value of myocardial contrast echocardiography for predicting left ventricular remodeling and segmental functional recovery after anterior wall acute myocardial infarction. J Am Soc Echocardiogr. 2004;17(9):923-32.

312. Mathias W Jr, Arruda AL, Andrade JL, Filho OC, Porter TR. Endocardial borderdeline action during dobutamine infusion using contrast echocardiography. Echocardiography. 2002;19(2):109-14.

313. Porter TR, Abdelmoneim S, Belcik JT, McCulloch ML, Mulvagh SL, Olson JJ, et al. Guidelines for the cardiac sonographer in the performance of contrast echocardiography: a focused update from the American Society of Echocardiography. J Am Soc Echocardiogr. 2014;27(8):797-810.

314. Tsutsui JM, Elhendy A, Xie F, O'Leary EL, McGrain AC, Porter TR. Safety of dobutamine stress real-time myocardial contrast echocardiography. J Am Coll Cardiol. 2005;45(8):1235-42.

315. Tsutsui JM, Xie F, O'Leary EL, Elhendy A, Anderson JR, McGrain AC, et al.Diagnostic accuracy and prognostic value of dobutamine stress myocardial contrast echocardiography in patients with suspected acute coronary syndromes. Echocardiography. 2005;22(6):487-95.

316. Brown KA. Evaluation of the unstable angina patient in 2005: is there still a role for non invasive risk stratification? J Nucl Cardiol. 2005;12(1):9-11.

317. Amanullah AM. Noninvasive testing in the diagnosis and management of unstable angina. Int J Cardiol. 1994;47(2):95-103.

318. Miller DD. Risk stratification in unstable angina pectoris. In: Zaret BL, Beller GA. (eds) Nuclear cardiology: stateoftheartand future directions. Saint Louis: Mosby Inc; 1999. p. 490-9.

319. Stratmann HG, Younis LT, Wittry MD, Amato M, Miller DD. Exercise technetium-99m myocardial tomography for the risk stratification of men with medically treated unstable angina pectoris. Am J Cardiol. 1995;76(4):236-40

320. Freeman MR, Chisholm RJ, Armstrong PW. Usefulness of exercise electrocardiography and thallium scintigraphy in unstable angina pectoris in predicting the extent and severity of coronary artery disease. Am J Cardiol. 1988;62(17):1164-70. Erratum in: Am J Cardiol 1989;63(5):392.

321. Zhu YY, Chung WS, Botvinick EH, Dae MW, Lim AD, Ports TA, et al. Dipyridamole perfusion scintigraphy: the experience with its application in one hundred seventy patients with known or suspected unstable angina. Am Heart J. 1991;121(1 Pt 1):33-43.

322. Brown KA. Prognosticvalueof thallium-201 myocardial perfusion imaging in patients with unstable angina who respond to medical treatment. J Am Coll Cardiol. 1991:17(5):1053-7. 
323. Madsen JK, Stubgaard M, Utne HE, Hansen JF, van Duijvendijk K, Reiber $\mathrm{JH}$, et al. Prognosis and thallium-201 scintigraphy in patients admitted with chest pain without confirmed acute myocardial infarction. Br Heart J. 1988;59(2):184-9

324. Beanlands RS, Nichol G, Huszti E, Humen D, Racine N, Freeman M, et al. F-18-fluorodeoxyglucose positron emission tomography imaging-assisted management of patients with severe left ventricular dysfunction and suspected coronary disease: A randomized, controlled trial (PARR-2). J Am Coll Cardiol. 2007;50(2):2002-12.

325.Ziadi MC, Dekemp RA, Williams KA, Guo A, Chow BJ, Renaud JM, et al. Impaired myocardial flow reserve on rubidium-82 positron emission tomography imaging predicts adverse outcomes in patients assessed for myocardial ischemia. J Am Coll Cardiol.2011;58(7):740-8.

326. de Souza ACDAH, Gonçalves BKD, Tedeschi AL, Lima RSL. Quantification of Myocardial Flow Reserve Using aGamma Camera With Solid-State Cadmium-Zinc-Telluride Detectors: Relation to Angiographic Coronary Artery Disease. J Nucl Cardiol. 2019; Jun 20. Doi 10.1007/s12350-01901775-z. ahead of print

327. Hundley WG, Bluemke DA, Finn JP, Flamm SD, Fogel MA, Friedrich MG, et al; American College of Cardiology Foundation Task Force on Expert Consensus Documents. ACCF/ACR/AHA/NASCI/SCMR 2010 expert consensus documenton cardiovascular magnetic resonance: a report of the American College of Cardiology Foundation Task Force on Expert Consensus Documents. Circulation. 2010;121(22):2462-508.

328. Nagel E, Lehmkuhl HB, Bocksch W, Klein C, Vogel U, Frantz E, et al. Non invasive diagnosis of ischemia-induced wall motion abnormalities with the use of high-dose dobutamine stress MRI: comparison with dobutamine stress echocardiography. Circulation. 1999;99(6):763-70.

329. Jaarsma C, Leiner T, Bekkers SC, Crijns HJ, Wildberger JE, Nagel E, et al. Diagnostic performance of noninvasive myocardial perfusion imaging using single-photon emission computed tomography, cardiac magnetic resonance, and pósitron emission tomography imaging for the detection of obstructive coronary artery disease: a meta-analysis. J Am Coll Cardiol. 2012;59(19):1719-28

330. Schwitter J, Wacker CM, Wilke N, Al-Saadi N, Sauer E, Huettle K, et al; MR-IMPACT Investigators. MR-IMPACT II: Magnetic Resonance Imaging for Myocardial Perfusion Assessment in Coronary artery diseaseTrial: perfusion-cardiac magnetic resonance vs. single-photon emission computed tomography for the detection of coronary artery disease: a comparative multicentre, multivendor trial. Eur Heart J. 2013;34(10):775-81

331. Watkins S, McGeoch R, Lyne J, Steedman T, Good R, McLaughlin MJ, et al. Validation of magnetic resonance myocardial perfusion imaging with fractional flow reserve for the detection of significant coronary heart disease. Circulation. 2009;120(22):2207-13.

332. Steel K, Broderick R, Gandla V, Larose E, Resnic F, Jerosch-Herold M, et al. Complementary prognostic values of stress myocardial perfusion and late gadolinium enhancement imaging by cardiac magnetic resonance in patients with known or suspected coronary artery disease. Circulation. 2009;120(14):1390-400.

333. Kim RJ, Wu E, Rafael A, Chen EL, Parker MA, Simonetti O, et al. The use of contrast-enhanced magnetic resonance imaging to identify reversible myocardial dysfunction. N Engl J Med. 2000;343(20):1445-53.

334. Choi KM, Kim RJ, Gubernikoff G, Vargas JD, Parker M, Judd RM. Transmural extent of acute myocardial infarction predicts long-term improvement in contractile function. Circulation. 2001;104(10):1101-7.

335. Wagner A, Mahrholdt H, Holly TA, Elliott MD, Regenfus M, Parker M, et al. Contrast-enhanced MRI androutine single photon emission computed tomography (SPECT) perfusion imaging for detection of subendocardial Myocardial infarcts: an imaging study. Lancet. 2003;361(9355):374-9.

336. Cheong BY, Muthupillai R, Wilson JM, Sung A, Huber S, Amin S, et al. Prognostic significance of delayed-enhancement magnetic resonance imaging: survival of 857 patients with and without left ventricular dysfunction. Circulation. 2009;120(21):2069-76.
337. Wu E, Judd RM, Vargas JD, Klocke FJ, Bonow RO, Kim RJ. Visualisation of presence, location, and transmural extent of healed Q-wave and non-Q wave myocardial infarction. Lancet. 2001;357(9249):21-8

338. Kim RJ, Albert TS, Wible JH, Elliott MD, Allen JC, Lee JC, et al Performance of delayed-enhancement magnetic resonance imaging with gadoversetamide contrast for the detection and assessment of myocardial infarction: na international, multicenter, double-blinded, randomized trial. Circulation.2008;117(5):629-37.

339. Kim HW, Farzaneh-Far A, Kim RJ. Cardiovascular magneticresonance in patients with myocardial infarction: current and emerging applications. J Am Coll Cardiol. 2009:55(1):1-16

340. Eitel I, de Waha S, Wöhrle J, Fuernau G, Lurz P, Pauschinger M, et al. Comprehensive prognosis assessment by CMR imaging after STsegment elevation myocardial infarction. J Am Coll Cardiol. 2014 Sep 23;64(12):1217-26

341. Schelbert EB, Cao JJ, Sigurdsson S, Aspelund T, Kellman P, Aletras AH, et al. Prevalence and prognosis of unrecognized myocardial infarction determined by cardiac magnetic resonance in older adults. JAMA. 2012;308(9):890-6.

342. Kwong RY, Chan AK, Brown KA, Chan CW, Reynolds HG, Tsang S, et al. Impact of unrecognized myocardial scar detected by cardiac magnetic resonance imaging on event-free survival in patients presenting with signs or Symptoms of coronary artery disease. Circulation. 2006;113(23):273343. Erratum in Circulation. 2006:114(8):e365.

343. Wu KC, Zerhouni EA, Judd RM, Lugo-Olivieri CH, Barouch LA, Schulman $\mathrm{SP}$, et al. Prognostic significance of microvascular obstruction by magnetic resonance imaging in patients with acute myocardial infarction. Circulation. 1998;97(8):765-72.

344. Kelle S, Roes SD, Klein C, Kokocinski T, de Roos A, Fleck E, et al. Prognostic value of myocardial infarct size and contractile reserve using magnetic resonance imaging. J Am Coll Cardiol. 2009;54(19):1770-7.

345. Kendziora B, Dewey M. Prognostic value of the myocardial salvage index measured by $\mathrm{T} 2$-weighted and $\mathrm{T} 1$-weighted late gadolinium enhancement magnetic resonance imaging after ST-segment elevation myocardial infarction: A systematic review and meta-regression analysis. PLoS One. 2020 Feb 13;15(2):e0228736.

346. Rochitte CE. Microvascular obstruction the final frontier for a complete myocardial reperfusion. J Am Coll Cardiol. 2008;51(23):2239-40.

347. Klug G, Mayr A, Schenk S, Esterhammer R, Schocke M, Nocker M, et al. Prognostic value at 5 years of microvascular obstruction after acute myocardial infarction assessed by cardiovascular magnetic resonance. J Cardiovasc Magn Reson. 2012;14(1):46.

348. Mahrholdt H, Wagner A, Judd RM, Sechtem U, Kim RJ. Delayed enhancement cardiovascular magneticresonance assessment of non ischaemic cardiomyopathies. Eur Heart J. 2005;26(15):1461-74.

349. Friedrich MG, Sechtem U, Schulz-Menger J, Holmvang G, Alakija P, Cooper LT, et al; International Consensus Group on Cardiovascular Magnetic Resonance in Myocarditis. Cardiovascular magnetic resonance in myocarditis: A JACC White Paper. J Am Coll Cardiol. 2009;53(17):1475-87.

350. Gannon MP, Schaub E, Grines CL, Saba SG. State of the Art: Evaluation and Prognostication of Myocarditis Using Cardiac MRI. J Magn Reson Imaging, 2019:49 (7), e122-e131

351. Athanasiadis A, Schneider B, Sechtem U. Role of cardiovascular magnetic resonance in takotsubo cardiomyopathy. Heart Fail Clin. 2013;9(2):167-76.

352. Scally C, Abbas H, Ahearn T, Srinivasan J, Mezincescu A, Rudd A, et al. Myocardial and Systemic Inflammation in Acute Stress-Induced (Takotsubo) Cardiomyopathy. Circulation. 2019;139 (13):1581-92.

353. Vidal-Perez R, Abou Jokh Casas C, Agra-Bermejo RM, Alvarez-Alvarez B, Grapsa J, Fontes-Carvalho R, et al. Myocardial infarction with nonobstructive coronary arteries: A comprehensive review and future research directions. World J Cardiol. 2019 Dec 26;11(12):305-15 
354. Perazzolo Marra M, Lima JA, Iliceto S. MRI in acute myocardial infarction. Eur Heart J. 2011;32(3):284-93

355. Sandoval Y, Jaffe AS. Type 2 Myocardial Infarction: JACC Review Topic of the Week. J Am Coll Cardiol. 2019 Apr 16;73(14):1846-60.

356. Barbarawi, M, Kheiri, B, Zayed, Y, Barbarawi O, Chahine A, Haykal $\mathrm{T}$, et al. Meta - analysis of optimal timing of coronary intervention in nonST - elevation acute coronary syndrome. Catheter Cardiovasc Interv. 2020; 95(2): 185-93.

357. Lindholm D, Alfredsson J, Angerås O, Bohm F, Calais F, Koul S, et al. Timing of percutaneous coronary intervention in patients with non-ST-elevation myocardial infarction: a SWEDEHEART study. Eur Heart J Qual Care Clin Outcomes. 2017;3(1):53 - 60 .

358. Neumann FJ, Sousa-Uva M, Ahlsson A, Alfonso F, Banning AP, Benedetto $U$, et al. 2018 ESC/EACTS Guidelines on myocardial revascularization Eur Heart J. 2019;40(2): 87-165.

359. Götberg M, Christiansen EH, Gudmundsdottir I J, Sandhall L, Danielewicz M, Jakobsen L, et al. Instantaneous Wave-free Ratio versus Fractional Flow Reserve to Guide PCI. N Engl J Med .2017;376(19):1813-23.

360. Davies JE, Sen S, Dehbi HM, Al-Lamee R, Petraco R, Nijjer S S, et al. Use of the Instantaneous Wave-free Ratio or Fractional Flow Reserve in PCI. N Engl J Med. 2017;376(19), 1824-34

361. Matsuo Y, Kubo T, Akasaka T. The use of optical coherence tomography in acute coronary syndrome. Expert Rev Cardiovasc Ther. 2016;14(5):649-57.

362. Ali ZA, Galougahi, KK, Maehara A, Shlofmitz RA, Ben-Yehuda O, Mintz GS, Stone GW. Intracoronary Optical Coherence Tomography 2018. JACC: Cardiovasc Interv. 2017;10(24), 2473-87.

363. Meneveau N, Souteyrand G, Motreff P, Caussin C, Amabile N, Ohlmann P, et al. Optical Coherence Tomography to Optimize Results of Percutaneous Coronary Intervention in Patients with Non-ST-Elevation Acute Coronary Syndrome: Results of the Multicenter, Randomized DOCTORS Study (Does Optical Coherence Tomography Optimize Results of Stenting). Circulation. 2016;134(13):906 - 17.

364. Chowdhury M, Osborn EA. Physiological assessment of coronary lesions in 2020. Curr Treat Options Cardiovasc Med. 2020; 22(1):2.

365. Choudhry NK, Singh JM, Barolet A, Tomlinson GA, Detsky AS. How should patients with unstable angina and non-ST-segment elevation myocardial infarction be managed? A meta-analysis of randomized trials. Am J Med. 2005;118(5):465-74.

366. Damman P, van Geloven N, Wallentin L, Lagerqvist B, Fox KA, Clayton $\mathrm{T}$, et al. Timing of angiography with a routine invasive strategy and longterm outcomes in non-ST-segment elevation acute coronary syndrome: a collaborative analysis of individual patient data from the FRISC II (Fragmin and Fast Revascularization During Instability in Coronary Artery Disease), ICTUS (Invasive Versus Conservative Treatment in Unstable Coronary Syndromes), and RITA-3 (Intervention Versus Conservative Treatment Strategy in Patients With Unstable Angina or Non-ST Elevation Myocardial Infarction) Trials. JACC Cardiovasc Interv. 2012;5(2):191-9.

367.Zimarino M, Curzen N, Cicchitti V, De Caterina R. The adequacy of myocardial revascularization in patients with multivessel coronary artery disease. Int J Cardiol. 2013;168(3):1748-57.

368. Granger CB, Goldberg RJ, Dabbous O, Pieper KS, Eagle KA, Cannon CP, et al. Predictors of hospital mortality in the Global Registry of Acute Coronary Events. Arch Intern Med 2003;163:2345-53138.

369. Judd E, Hollander JE, Than M, Mueller C. State-of-the-Art Evaluation of Emergency Department Patients Presenting With Potential Acute Coronary Syndromes. Circulation 2016;134:547-564.

370. Damman P, Hirsch A, Windhausen F, Tijssen JGP, Winter RJ, ICTUS Investigators. 5-year clinical outcomes in the ICTUS (Invasive versus Conservative Treatment in Unstable coronary Syndromes) trial a randomized comparison of an early invasive versus selective invasive management in patients with non-ST-segment elevation acute coronary syndrome. J Am Coll Cardiol. 2010;55:858-64.
371. Mahmoud AN, Elgendy IY, Mansoor H, Xuerong W, Mojadid MK, Bavry AA, et al. Early invasive strategy and in-hospital survival of diabetics with non-st-elevation Myocardial infarction: a contemporary national insight. JACC. $2017 ;(69): 182$

372. Sianos G, Morel MA, Kappetein AP, Morice MC, Colombo A, Dawkins K, et al. The SYNTAX Score: an angiographic tool grading the complexity of coronary artery disease. Eurolntervention. 2005;1(2):219-27.

373. Mohr FW, Morice MC, Kappetein AP, Feldman TE, Ståhle E, Colombo A, et al. Coronary artery bypass graft surgery versus percutaneous coronary intervention in patients with three-vessel disease and left main coronary disease: 5-year follow-up of the randomised, clinical SYNTAX trial. Lancet. 2013;381(9867):629-38.

374. Jones EL, Craver JM, Guyton RA, Bone DK, Hatcher CR Jr, Riechwald N. Importance of complete revascularization in performance of the coronary bypass operation. Am J Cardiol. 1983;51(1):7-12.

375. Bundhun PK, Sookharee Y, Bholee A, Huang F. Application of the SYNTAX score in interventional cardiology: A systematic review and meta-analysis. Medicine (Baltimore). 2017;96(28):e7410.

376. Ranasinghe I, Alprandi-Costa B, Chow V, Elliott JM, Waites J, Counsell JT, et al. Risk stratification in the setting of non-ST elevation acute coronary syndromes 1999-2007. Am J Cardiol 2011;108:617-624.

377. Fukui T, Tabata M, Morita S, Takanashi S. Early and long-term outcomes of coronary artery bypass grafting in patients with acute coronary syndrome versus stable angina pectoris. J Thorac Cardiovasc Surg 2013;145:1577-1583.

378. Malm CJ, Hansson EC, Akesson J, Andersson M, Hesse C, Shams Hakimi $\mathrm{C}$, et al. Preoperative platelet function predicts perioperative bleeding complications in ticagrelor-treated cardiac surgery patients: A prospective observational study. Br J Anaesth 2016;117:309-315.

379. Nichols EL, McCullough JN, Ross CS, Kramer RS, Westbrook BM, Klemperer JD, et al. Optimal Timing From Myocardial Infarction to Coronary Artery Bypass Grafting on Hospital Mortality. Ann of Thorac Surg. 2017;103:(1)162-171.

380. Tegn N, Abdelnoor M, Aaberge L, Endresen K, Smith P, Aakhus S, et al. After Eighty study investigators. Invasive versus conservative strategy in patients aged 80 years or older with non-ST-elevation myocardial infarction or unstable angina pectoris (After Eighty study): an open-label randomised controlled trial. Lancet. 2016;387(10023):1057-1065.

381. Fox KA, Poole-Wilson P, Clayton TC, Henderson RA, Shaw TRD, Wheatley DJ, et al. 5-year outcome of an interventional strategy in non-ST-elevation acute coronary syndrome: the British Heart Foundation RITA 3 randomised trial. Lancet. 2005;366(9489):914-20.

382. Fanning JP, Nyong J, Scott IA, Aroney CN, Walters DL. Routine Invasive Strategies Versus Selective Invasive Strategies for Unstable Angina and nonST Elevation Myocardial Infarction in the Stent Era. Cochrane Database Syst Rev. 2016;(5):CD004815.

383. Smits PC, Abdel-Wahab M, Neumann FJ, Boxma-de Klerk BM, Lunde K, Schotborgh CE, et al. Fractional Flow Reserve-Guided Multivessel Angioplasty in Myocardial Infarction. N Engl J Med, 2017;376(13):1234-44.

384. Choi KH, Song YB, Lee JM, Lee SY, Park TK, Yang JH, et al. Impact of Intravascular Ultrasound-Guided Percutaneous Coronary Intervention on Long-Term Clinical Outcomes in Patients Undergoing Complex Procedures. JACC Cardiovasc Interv, 2019;12(7):607-20.

385. Gao XF, Wang ZM, Wang F, Gu Y, Ge Y, et al. Intravascular Ultrasound Guidance Reduces Cardiac Death and Coronary Revascularization in Patients Undergoing Drug-Eluting Stent Implantation: Results From a Meta-Analysis of 9 Randomized Trials and 4724 Patients. Int J Cardiovasc Imaging. 2019;35(2):239-47.

386. Nicolau JC, Franken M, Lotufo PA, Carvalho AC, Marin-Neto JA, Gallego $\mathrm{F}$, et al. Use of demonstrably effective therapies in the treatment of acute coronary syndromes:comparison between different Brazilian regions. Analysis of the Brazilian Registry on Acute Coronary Syndromes (BRACE). Arq Bras Cardiol. 2012;98(4):282-9. 
387. Coleman EA. Falling through the cracks: challenges and opportunities for improving transitional care for persons with continuous complex care needs. J Am Geriatr Soc. 2003;51(4):549-55

388. Coleman EA, Boult C, American Geriatrics Society Health Care Systems Committee. Improving the quality of transitional care for persons with complex care needs. J Am Geriatr Soc. 2003;51(4):556-7.

389. Coleman EA, Mahoney E, Parry C. Assessing the quality of preparation for posthospital care from the patient's perspective: the care transitions measure. Med Care. 2005;43(3):246-55.

390. Smith SC Jr, Benjamin EJ, Bonow RO, Braun LT, Creager MA, Franklin BA, et al. AHA/ACCF secondary prevention and risk reduction therapy for patients with coronary and other atherosclerotic vascular disease: 2011 update: a guideline from the American Heart Association and American College of Cardiology Foundation. Circulation. 2011;124(22):2458-73.

391. Bernheim SM, Spertus JA, Reid KJ, Bradley E, Desai RA, Peterson ED, et al. Socioeconomic disparities in outcomes after acute myocardial infarction. Am Heart J. 2007;153(2):313-9.

392. Rahimi AR, Spertus JA, Reid KJ,Bernheim SM, Krumholz HM. Financial barriers to health care and outcomes after acute myocardial infarction. JAMA. 2007;297(10):1063-72.

393. Smolderen KG, Spertus JA, Reid KJ, Buchanan DM, Krumholz HM, Denollet J, et al. The association of cognitive and somatic depressive symptoms with depression recognition and outcomes after myocardial infarction. Circ Cardiovasc Qual Outcomes. 2009;2(4):328-37.

394. Taylor RS, Brown A, Ebrahim S, Jollife J, Noorani H, Becky KR, et al. Exercisebased rehabilitation for patients with coronary heart disease: systematic review and meta-analysis of randomized controlled trials. Am J Med. 2004:116(10):682-92.

395. Leon AS, Franklin BA, Costa F, Balady GB, Berra KA, Stewart KJ, et al. Cardiac rehabilitation and secondary prevention of coronary heart disease: an American Heart Association scientific statement from the Council on Clinical Cardiology (Subcommittee on Exercise, Cardiac Rehabilitation, and Prevention) and the Council on Nutrition, Physical Activity, and Metabolism (Subcommittee on Physical Activity), in collaboration with the American Association of Cardiovascular and Pulmonary Rehabilitation. Circulation. 2005; 111(3):369-76.

396. Suaya JA, Stason WB, Ades PA, Normand ST, Shepard DS, et al. Cardiac rehabilitation and survival in older coronary patients. J Am Coll Cardiol. 2009:54(1):25-33.

397. lestra JA, Kromhout D, van der Schouw YT, Grobbee DE, Boshuizen HC, van Staveren WA. Effect size estimates of lifestyle and dietary changes on all-cause mortality in coronary artery disease patients: a systematic review. Circulation . 2005;112(6)924-34.

398. Anderson L1, Thompson DR, Oldridge N, Zwisler AD, Rees K, Martin $\mathrm{N}$, Taylor RS. Exercise-based cardiac rehabilitation for coronary heart disease. Cochrane Database Syst Rev. 2016 Jan 5;67(1):1-12.

399. Critchley JA, Capewell S. Mortality risk reduction associated with smoking cessation in patients with coronary heart disease: a systematic review. JAMA 2003;290(1):86-97.

400. National Center for Chronic Disease Prevention and Health Promotion(US Office on Smoking and Health . The health consequences of smoking - 50 years of progress: a report of the Surgeon General. Atlanta (GA): Centers for Disease Control and Prevention,(US) ;2014.

401. Kalkhoran S, Benowitz N, Rigotti N. Prevention and Treatment of Tobacco Use.JACC Health Promotion Series. J Am Coll Cardiol. 2018;72(9):1030-45.

402. Goldenberg I, Jonas M, Tenenbaum A, Boyoko V, Matetzky S, Shotan A, et al. Current smoking, smoking cessation, and the risk of sudden cardiac death in patients with coronary artery disease. Arch Intern Med. 2003;163(19):2301-5.

403. Messner B, Bernhard D. Smoking and cardiovascular disease: mechanisms of endothelial dysfunction and early atherogenesis. Arterioscler Thromb Vasc Biol. 2014;34(3):509-15.
404. Chamberlain AM, Agarwal SK, Folsom AR, et al. (2011) Smoking and incidence of atrial fibrillation: results from the Atherosclerosis Risk in Communities (ARIC) study. Heart Rhythm.2011;8(8):1160-6.

405. Daly LE, Mulcahy R, Graham IM, Hickey N. Long term effect on mortality of stopping smoking after unstable angina and myocardial infarction. Br Med J (Clin Res Ed). 1983;287(6388):324-6.

406. Parasuraman S, Zaman AG, Egred M, Bagnall A, Broadhurst PA, Ahmed J, et al. Smoking status and mortality outcomes following percutaneous coronary intervention. Eur J Prev Cardiol. 2020 Feb 3; 2047487320902325

407. Ranney L, Melvin C, Lux L, McClain E, Lohr KN. Systematic review: smoking cessation intervention strategies for adults and adults in special populations. Ann Intern Med. 2006;145(11):845-56.

408. Ford ES, Ajani UA, Croft JB, Critchley JA, Labarthe DR, Kottke TE, et al. Explaining the decrease in U.S. deaths from coronary disease, 1980-2000. N Engl J Med. 2007;356(23):2388-98.

409. Lindson N, Klemperer E, Hong B, Ordóñez-Mena JM, Aveyard P. Smoking reduction interventions for smoking cassation. Cochrane Database Syst Rev. 2019 Sep 30;9(9):CD013183.

410. Eisenberg MJ, Grandi SM, Gervais A, O'Loughlin J, Paradis G, Rinfret S, et al. Bupropion for smoking cessation in patients hospitalized with acute myocardial infarction: a randomized, placebo-controlled trial. J Am Coll Cardiol 2013; 61(5):524-32.

411. Planer D, Lev I, Elitzur Y, Sharon N, Ouzan E, Pugatsch T, et al. Bupropion for smoking cessation in patients with acute coronary syndrome. Arch Intern Med. 2011;171(12):1055-60.

412. Stead LF, Perera R, Bullen C,Mant D, Hartman-Boyce J, Cahill K, et al. Nicotine replacement therapy for smoking cessation. Cochrane Database Syst Rev.2018;5(5):CD000146

413. Wilson K, Gibson N, Willan A, Cook D. Effect of smoking cessationon mortality after myocardial infarction: meta-analysis of cohortstudies. Arch Intern Med. 2000;160(7):939-44.

414. Agency for Health Care Research and Quality. (AHRQ). Clinical Practice Guidelines: Smoking Cessation. No 18. AHCPR Publication No.96-0692; 1996.

415. Jorenby DE, Hays JT, Rigotti NA, Azoulay S, Watsky EJ, Williams KE, et al Varenicline Phase 3 Study Group. Efficacy of varenicline, analpha4beta2 nicotinic acetylcholine receptor partial agonist, vs placeboor sustainedrelease bupropion for smoking cessation: a randomized controlled trial. JAMA. 2006;296(1):56-63. Erratum in JAMA. 2006;296(11):1355.

416. Gonzales D, Rennard SI, Nides M, Oncken C, Azoulay S, Billing CB, et al. Varenicline, an alpha4beta2 nicotinic acetylcholine receptor partial agonist, vs sustained-release bupropion and placebo for smoking cessation: a randomized controlled trial. JAMA. 2006;296(1):47-55.

417. Cahill K, Stead LF, Lancaster T. Nicotine receptor partial agonists for smoking cessation. Sao Paulo Med J.2012;130(5):346-7. (Cochrane Highlights)

418. Anthenelli RM, Benowitz NL, West R, Russ C, McRae T, Lawrence D, et al. Neuropsychiatric safety and efficacy of varenicline, bupropion, and nicotine patch in smokers with and without psychiatric isorders EAGLES): a double-blind, randomised, placebo-controlled clinical trial. Lancet.2016; 387(10037):P2507-20.

419. Rigotti NA, Pipe AL, Benowitz NL, Arteaga C, Garza D, Tonstad S. Efficacy and safety of varenicline for smoking cessation in patients with cardiovascular disease: a randomized trial. Circulation. 2010; 121(2):221-9.

420. Eisenberg MJ, Windle SB, Roy N, Old W, Grondin FR, Bata I, et al. Varenicline for smoking cessation in hospitalized patients with acute coronary syndrome. Circulation. 2016; 133(1):21-30.

421. Windle SB, Dehghani P, Roy N, Old W, Grondin FR, Bhata I, et al. Smoking abstinence 1 year after acute coronary syndrome: follow-up from a randomized controlled trial of varenicline in patients admitted to hospital. CMAJ.2018;190(12):E347-E354. 
422. Zhong Z, Zhao S, Zhao Y, Xia S. Combination therapy of varenicline and bupropion in smoking cessation: A meta-analysis of the randomized controlled trials. Compr Psychiatry. 2019; 95:152125.

423. Kalkhoran S, Benowitz NL, Rigotti N. Prevention and Treatment of Tobacco Use. J Am Coll Cardiol. 2018;72(23):2964-979.

424. Benowitz NL,Donny EC, Hatsukami DK. Reduced nicotine content cigarettes, e-cigarettes and the cigarette end game. Addiction.2017; 112(1):6-7.

425. Hatsukami DK, Donny EC, Koopmeiners JS, Benowitz NL. Compensatory smoking from gradual and immediate reduction in cigarette nicotine content. Cancer Epidemiol Biomarkers Prev.2015; 24(2):472-6.

426. MacDonald A, Middlekauff HR. Electronic cigarettes and cardiovascular health: what do we know so far? Vasc Health Risk Manag. 2019 jun 21;15:159-74.

427. Baigent C, Blackwell L, Emberson J, Efficacy and safety of more intensive lowering of LDL cholesterol: a meta-analysis of data from 170,000 participants in 26 randomised trials. Lancet. 2010;376: 1670-81.

428. Collins R, Reith C, Emberson J,Bhala N, Peto R, Barnes EH, et al. Interpretation of the evidence for the efficacy and safety of statin therapy. Lancet. 2016;388(9753):2532-61.

429. Amarenco P, Bogousslavsky J, Callahan A 3rd,Goldstein LB, Hennerici M, Rudolph $\mathrm{AE}$, et al. High-dose atorvastatin after stroke or transiente ischemic attack. N Engl J Med. 2006;355(6):549-59.

430. Athyros VG, Papageorgiou AA, Mercouris BR, Athyros VV, Symeonidis AN, Basayannis EO, et al. Treatment with atorvastatin to the National Cholesterol Educational Program goal versus 'usual' care in secondary coronary heart disease prevention. The GREek Atorvastatin and Coronary-heart-disease Evaluation (GREACE) study. Curr Med Res Opin. 2002;18(4):220-8

431. Kjekshus J, Apetrei E, Barrios V, Bohm M, Cleland JG, Cornel JH, et al. Rosuvastatin in older patients with systolic heart failure. N Engl J Med. 2007;357(22):2248-61.

432. Tavazzi L, Maggioni AP, Marchioli R, Barlera S, Franzosi MG, Latini R, et al. Effect of rosuvastatin in patients with chronic heart failure (the GISSI-HF trial): a randomised, double-blind, placebo-controlled trial. Lancet. 2008; 372(9645):1231-9

433. Eckel RH, Jakicic JM, Ard JD, de Jesus JM, Houston Miller N, Hubbard VS, et al. et al. $2013 \mathrm{AHA} /$ ACC guideline on lifestyle management to reduce cardiovascular risk: a report of the American College of Cardiology/American Heart Association Task Force on Practice Guidelines. Circulation. 2014;129(25 Suppl 2):S76-99.

434. Jensen MD, Ryan DH, Apovian CM, Ard JD, Comuzzie AG, Donato KA, Hu FB, et al. $2013 \mathrm{AHA} / \mathrm{ACC} / \mathrm{TOS}$ guideline for the management of overweight and obesity in adults: a report of the American College of Cardiology/American Heart Association Task Force on Practice Guidelines and The Obesity Society.J Am Coll Cardiol. 2014;63(25 Pt B):2985-3023.

435. Estruch R, Ros E, Salas-Salvadó J, Covas MI, Corella D, Arós F, et al. Primary Prevention of Cardiovascular Disease with a Mediterranean Diet Supplemented with Extra-Virgin Olive Oil or Nuts. N Engl J Med. 2018 Jun 21;378(25):e34.

436. Bjelakovic G, Nikolova D, Gluud LL,Simonetti RG, Gluud C. Mortality in randomized trials of antioxidant supplements for primary and secondary prevention: systematic review and meta-analysis. JAMA. 2007; 297(8):842-57.

437. Carvalho T, Milani M, Ferraz AS, Silveira AD, Herdy AH, Hossri CAC, et al. Diretriz Brasileira de Reabilitação Cardiovascular - 2020. Arq Bras Cardiol. 2020; 114(5):943-87.

438. Kureshi F, Kennedy KF, Jones PG, Thomas RJ, Arnold S V., Sharma P, et al. Association between cardiac rehabilitation participation and health status outcomes after acute myocardial infarction. JAMA Cardiol. 2016;1 (9):980-8.

439. Suaya JA, Shepard DS, Normand S-LT, Ades PA, Prottas J, Stason WB. Use of Cardiac Rehabilitation by Medicare Beneficiaries After Myocardial Infarction or Coronary Bypass Surgery. Circulation. 2007 Oct 9;116(15):1653 LP-1662.
440.Sunamura M, Ter Hoeve N, van den Berg-Emons RJG, Boersma E, van Domburg RT, Geleijnse ML. Cardiac rehabilitation in patients with acute coronary syndrome with primary percutaneous coronary intervention is associated with improved 10-year survival. Eur Heart J Qual Care Clin Outcomes. 2018 Jul;4(3):168-72.

441. Ades PA, Keteyian SJ, Wright JS, Hamm LF, Lui K, Newlin K, et al. Increasing Cardiac Rehabilitation Participation From 20\% to 70\%: A Road Map From the Million Hearts Cardiac Rehabilitation Collaborative. Mayo Clin Proc. 2017;92(2):234-42.

442. Correia LC, Garcia G, Kalil F, Ferreira F, Carvalhal M, Oliveira R,et al. Prognostic value of TIMI score versus GRACE score in ST-segment elevation myocardial infarction. Arq Bras Cardiol. 2014 Aug;103(2):98-106.

443. Fletcher GF, Ades PA, Kligfield P, Arena R, Balady GJ, Bittner VA, et al. Exercise standards for testing and training: A scientific statement from the American heart association. Circulation. 2013;128(8):873-934.

444. Costa RVC, Braga AMW, Carlos A. Arquivos Brasileiros de Cardiologia I CONSENSO NACIONAL DE REABILITAÇÃO CARDIOVASCULAR. Arq Bras Cardiol. 1997;69(4):267-91.

445. Loh JP, Pendyala LK, Kitabata H, Torguson R, Chen F, Kent KM, et al. Safety of reloading prasugrel in addition to clopidogrel loading in patients with acute coronary syndrome undergoing percutaneous coronary intervention. Am J Cardiol.2013;111(6):841-5.

446.Zettler ME, Peterson ED, McCoy LA, Effron MB, Anstrom KJ, Henry TD, et al. Switching of adenosine diphosphate receptor inhibitor after hospital discharge among myocardial infarction patients: Insights from the Treatment with Adenosine Diphosphate Receptor Inhibitors: Longitudinal Assessment of Treatment Patterns and Events after. Am Heart J. 2017J Jan ; 183:62-8.

447. Angiolillo DJ, Curzen N, Gurbel P, Vaitkus P, Lipkin F, Li W, et al. Pharmacodynamic evaluation of switching from ticagrelor to prasugrel in patients with stable coronary artery disease: Results of the swap-2 study (switching anti platelet-2). J Am Coll Cardiol. 2014;63(15):1500-9.

448. Pourdjabbar A, Hibbert B, Chong AY, Le May MR, Labinaz M, Simard $\mathrm{T}$, et al. A randomised study for optimising crossover from ticagrelor to clopidogrel in patients with acute coronary syndrome. Thromb Haemost. 2017;117(2):303-10.

449. Franchi F, Rollini F, Rios JR, Rivas A, Agarwal M, Kureti M, et al. Pharmacodynamic effects of switching from ticagrelor to clopidogrel in patients with coronary artery disease results of the SWAP-4 study. Circulation. 2018;137(23):2450-62.

450. Angiolillo DJ, Rollini F, Storey RF, Bhatt DL, James S, Schneider DJ, et al. International expert consensus on switching platelet $\mathrm{P} 2 \mathrm{Y} 12$ receptorinhibiting therapies. Circulation. 2017;136(20):1955-75.

451. Valgimigli M, Bueno H, Byrne RA, Collet JP, Costa F, Jeppsson A, et al. 2017 ESC focused update on dual antiplatelet therapy in coronary artery disease developed in collaboration with EACTS. Eur Heart J. 2017;53(1):213-54.

452. Roe MT, Armstrong PW, Fox KAA, White HD, Prabhakaran D, Goodman SG, et al. Prasugrel versus clopidogrel for acute coronary syndromes without revascularization. N Engl J Med. 2012;367(14):1297-309.

453. Bonaca MP, Bhatt DL, Cohen M, Steg PG, Storey RF, Jensen EC, et al. LongTerm use of ticagrelor in patients with prior myocardial infarction. $N$ Engl J Med. 2015;372(19):1791-800.

454. Furtado RHM, Nicolau JC, Magnani G, Im K, Bhatt DL, Storey RF, et al. Longterm ticagrelor for secondary prevention in patients with prior myocardial infarction and no history of coronary stenting: insights from PEGASUS-TIMI 54. Eur Heart J.2020;41(17):1625-32.

455. Mauri L, Kereiakes DJ, Yeh RW, Driscoll-Shempp P, Cutlip DE, Steg PG, et al. Twelve or 30 months of dual antiplatelet therapy after drug-eluting stents. $N$ Engl J Med 2014;371(23):2155-66.

456. Giustino G, Baber U, Sartori S, Mehran R, Mastoris I, Kini AS, et al. Duration of dual antiplatelet therapy after drug-eluting stent implantation: a systematic review and meta-analysis of randomized controlled trials. J Am Coll Cardiol. 2015 Apr 7;65(13):1298-310. 
457. Bonaca MP, Sabatine MS. Antiplatelet Therapy for Long-term Secondary Prevention After Myocardial Infarction. JAMA Cardiol. 2016 Sep 1;1(6):627-8.

458. Costa F, van Klaveren D, James S, Heg D, Räber L, Feres F, et al. Derivation and validation of the predicting bleeding complications in patients undergoing stent implantation and subsequent dual antiplatelet therapy (PRECISEDAPT) score: a pooled analysis of individual-patient datasets from clinical trials. Lancet.2017;389(10073):1025-34.

459. Yeh RW, Secemsky EA, Kereiakes DJ, Normand SLT, Gershlick AH, Cohen DJ, et al. Development and validation of a prediction rule for benefit and harm of Dual antiplatelet therapy beyond 1 year after percutaneous coronary intervention. JAMA - J Am Med Assoc 2016;315(16):1735-49.

460. Eikelboom JW, Connolly SJ, Bosch J, Dagenais GR, Hart RG, Shestakovska O, et al; COMPASS Investigators. Rivaroxaban with or without Aspirin in Stable Cardiovascular Disease. N Engl J Med. 2017 Oct 5;377(14):1319-30.

461. Connolly SJ, Eikelboom JW, Bosch J, Dagenais G, Dyal L, Lanas F, et al; COMPASS investigators. Rivaroxaban with or without aspirin in patients with stable coronary artery disease: an international, randomised, double-blind, placebo-controlled trial. Lancet. 2018 Jan 20;391(10117):205-18

462. Vranckx P, Valgimigli M, Jüni P, Hamm C, Steg PG, Heg D, et al. Ticagrelor plus aspirin for 1 month, followed by ticagrelor monotherapy for 23 months vs aspirin plus clopidogrel or ticagrelor for 12 months, followed by aspirin monotherapy for 12 months after implantation of a drug-eluting stent: a multicentre, open-la. Lancet. 2018;392(10151):940-9.

463. Takahashi K, Serruys PW, Chichareon P, Chang CC, Tomaniak M, Modolo R, et al. Efficacy and Safety of Ticagrelor Monotherapy in Patients Undergoing Multivessel PCI. J Am Coll Cardiol. 2019 Oct 22;74(16):2015-27.

464. Mehran R, Baber U, Sharma SK, Cohen DJ, Angiolillo DJ, Briguori C, et al. Ticagrelor with or without Aspirin in High-Risk Patients after PCI. N Engl J Med. 2019;381(21):2032-42.

465. O'Donoghue ML, Murphy SA, Sabatine MS. The Safety and Efficacy of Aspirin Discontinuation on a Background of a P2Y12 Inhibitor in Patients After Percutaneous Coronary Intervention: A Systematic Review and MetaAnalysis. Circulation. 2020 Aug 11;142(6):538-45

466. Fox KAA, Mehta SR, Peters R, Zhao F, Lakkis N, Gersh BJ, et al. Benefits and risks of the combination of clopidogrel and aspirin in patients undergoing surgical revascularization for non- ST-elevation acute coronary syndrome: The clopidogrel in unstable angina to prevent recurrent ischemic events (CURE) trial. Circulation 2004;110(10):1202-8.

467. Lopes RD,Pieper KS, Horton JR, Al-Khatib SM, Newby LK,Mehta RH, et al. Short- and long-term outcomes following atrial fibrillation in patients with acute coronary syndromes with or without ST-segment elevation. Heart. 2008,94(7):867-73

468. Dewilde WJM, Oirbans T, Verheugt FWA, Kelder JC, De Smet BJGL, Herrman $J \mathrm{P}$, et al. Use of clopidogrel with or without aspirin in patients taking oral anticoagulant therapy and undergoing percutaneous coronary intervention: An open-label, randomised, controlled trial. Lancet 2013;381(9872):110715.

469. Nicolau JC, Bhatt DL, Hohnloser SH, Kimura T, Lip GYH, Miede C, et al. RE-DUAL PCI Steering Committee and Investigators. Dabigatran Dual Therapy vs Warfarin Triple Therapy Post-Percutaneous Coronary Intervention in Patients with Atrial Fibrillation With/Without a Proton Pump Inhibitor: A Pre-Specified Analysis of the RE-DUAL PCI Trial. Drugs. 2020 Jul;80(10):995-1005.

470. Golwala HB, Cannon CP, Steg PG, Doros G, Qamar A, Ellis SG, Oldgren J, Ten Berg JM, Kimura T, Hohnloser SH, Lip GYH, Bhatt DL. Safety and efficacy of dual vs. triple antithrombotic therapy in patients with atrial fibrillation following percutaneous coronary intervention: a systematic review and meta-analysis of randomized clinical trials. Eur Heart J. 2018 ; 39(19):1726-1735.

471. Lopes RD, Hong H, Alexander JH. Antithrombotic therapy after acute coronary syndrome and/or percutaneous coronary intervention in atrial fibrillation: finding the sweet spot. Eur Heart J. 2019 Dec 7;40(46):3768-70.
472. Gargiulo G, Goette A, Tijssen J, Eckardt L, Lewalter T, Vranckx P, etal. Safety and efficacy outcomes of double vs. triple antithrombotic therapy in patients with atrial fibrillation following percutaneous coronary intervention: a systematic review and meta-analysis of non-vitamin Kantagonist oral anticoagulant-based randomized clinical trials. Eur HeartJ. 2019 Dec 7;40(46):3757-67.

473. Malachias MVB, Souza WKSB, Plavnik FL, Rodrigues CIS, Brandão AA, Neves MFT, et al,Sociedade Brasileira de Cardiologia. . 7ํㅗ Diretriz Brasileira de Hipertensão Arterial. Arq Bras Cardiol 2016; 107(3Supl.3):1-83.

474. Sleight P, Redon J, Verdecchia P, Mancia G, Gao P, Fagard R, et al. ONTARGET investigators. Prognostic value of blood pressure in patients with high vascular risk in the Ongoing Telmisartan Alone and in combination with Ramipril Clobal Endpoint Trial study. J Hypertens. 2009;27(7):1360-9.

475. Banach M, Michalska M, Kjeldsen SE, Małyszko J, Mikhailidis DP, Rysz J. What should be the optimal levels of blood pressure: Does the J-curve phenomenon really exist? Expert Opin Pharmacother. 2011;12(12):1835-44.

476. Bangalore S, Messerli FH, Wun C, Zuckerman AL, DeMicco D, Kostis JB, et al. J-curve revisited: an analysis of the Treating to New Targets (TNT) Trial. Eur Heart J. 2010; 31(23):2897-908.

477. SPRINT Research Group, Wright JT Jr, Williamson JD, Whelton PK, Snyder JK, Sink KM. A Randomized Trial of Intensive versus Standard Blood-Pressure Control. N Engl J Med. 2015 Nov 26;373(22):2103-16. Erratum in: N Engl J Med. 2017 Dec 21;377(25):2506

478. A randomized trial of propranolol in patients with acute myocardial infarction I. Mortality results. JAMA 1982;247(12):1707-14.

479. Hjalmarson Å, Herlitz J, Málek I, Rydén L, Vedin A, Waldenström A, etal. Effect On Mortality of Metoprolol In Acute Myocardial Infarction. A Double-blind Randomised Trial. Lancet. 1981;318(8251):823-7.

480. Goldberger IJ, Bonow RO, Cuffe M, Liu L, Rosenberg Y, Shah PK, et al. Effect of Beta-Blocker Dose on Survival after Acute Myocardial Infarction. J Am Coll Cardiol .2015;66(13):1431-41.

481. Bangalore S, Steg G, Deedwania P, Crowley K. B-Blocker Use and Clinical Outcomes in Stable Outpatients With and Without Coronary Artery Disease.J Am Med Assoc.JAMA. 2012;308(13):1340-9.

482. Piva e Mattos LA, Berwanger O, Santos ES, Reis HJ, Romano ER, Petriz JL,et al. Clinical outcomes at 30 days in the Brazilian Registry of Acute Coronary Syndromes (ACCEPT). Arq Bras Cardiol. 2013 Jan;100(1):6-13.

483. Lachin JM, Genuth S, Cleary P. Retinopathy and nephropathy in patients with type 1 diabetes four years after a trial of intensive insulin therapy. N Engl J Med. 2000;342(6):381-9.

484. Holman RR, Paul SK, Bethel MA. Follow-up of intensive glucose control in type 2 diabetes. N Engl J Med. 2008;359(15):1577-89.

485. Laiteerapong N, Ham SA, Gao Y, Moffet HH, Liu JY, Huang ES, et al. The legacy effect in type 2 diabetes:impactofearlyglycemic control on future complications (the Diabetes \& Aging study). Diabetes Care. 2019;42(3):416-26.

486. Gerstein C, Miller M, Byington R. Effects of Intensive Glucose Lowering in Type 2 Diabetes. N Engl J Med. 2008;358(24):2545-59.

487. American Diabetes Association. Standards of Medical Care in Diabetes — 2020 Diabetes Care. 2020 Jan;43((Suppl 1):S14-S31).

488. U.S. Food and Drug Administration. FDA revises warnings regarding use of the diabetes medicine metformin in certain patients with reduced kidney function. [Internet]. [Cited in 2019 Apr 12] Available from: Available from: http://www. fda.gov/downloads/Drugs/DrugSafety/UCM494140.pdf

489. Aroda VR, Edelstein SL, Goldberg RB, Knowler WC, Marcovina SM Orchard TJ, et al. Long-term metformin use and vitamin B12 deficiency in the diabetes prevention program outcomes study. J Clin Endocrinol Metab. 2016;101(4):1754-61.

490. Zelniker TA, Wiviott SD, Raz I, Im K, Goodrich EL, Furtado RHM, et al. Comparison of the effects of glucagon-like peptide receptor agonists and sodium-glucose cotransporter 2 inhibitors for prevention of major adverse cardiovascular and renal outcomes in type 2 diabetes mellitus: Systematic review and meta-analysis of cardio. Circulation .2019;139(17):2022-31. 
491. Furtado RHM, Bonaca MP, Raz I, Zelniker TA, Mosenzon O, Cahn A, et al. Dapagliflozin and cardiovascular outcomes in patients with type 2 diabetes mellitus and previous myocardial infarction. Circulation. 2019;139222516-27.,Circulation 2019; 139(22): 2516-27.

492. McMurray JJ V, Solomon SD, Inzucchi SE, Køber L, Kosiborod MN, Martinez FA, etal. Dapagliflozin in Patients with Heart Failure and Reduced Ejection Fraction. N Engl J Med .2019,381:1995-2008.

493. Perkovic V, Jardine MJ, Neal B, BompointS, Heerspink HJL, Charytan DM, etal. Canagliflozin and renal outcomes in type 2 diabetes and nephropathy. N Engl J Med 2019;380(24):2295-306.

494. Scirica BM, Bhatt DL, Braunwald E, Steg PG, Davidson J, Hirshberg B, et al. Saxagliptin and cardiovascular outcomes in patients with type 2 diabetes mellitus. N Engl J Med 2013;369(14):1317-26.

495. Sabatine MS, Giugliano RP, Keech AC, Honarpour N, WiviottSD, Murphy SA, et al. Evolocumab and Clinical Outcomes in Patients with Cardiovascular Disease. N Engl J Med 2017;376(18):1713-22.

496. Schwartz GG, Steg PG, SzarekM, BhattDL, Bittner VA, Diaz R, etal. Alirocumab and Cardiovascular Outcomes after Acute Coronary Syndrome. N Engl J Med . 2018;379(22):2097-107.

497. Bhatt DL, Steg PG, Miller M, Brinton EA, Jacobson TA, Ketchum SB, et al. Cardiovascular Risk Reduction with Icosapent Ethyl for Hypertriglyceridemia. N Engl J Med .2019;380(1):11-22.

498. Chang CH, Tseng PT, Chen NY, Lin PC, Lin PY, Chang JPC, et al. Safety and tolerability of prescription omega-3 fatty acids: A systematic review and metaanalysis of randomized controlled trials. Prostaglandins Leukot Essent Fat Acids. 2018 Feb;129:1-12.

499. Moukarbel GV, SignorovitchJE, Pfeffer MA, McMurray JJ V, White HD, Maggioni AP, et al. Gastrointestinal bleeding in high risk survivors of myocardial infarction: the VALIANT Trial. Eur HeartJ. 2009;30(18):2226-32.

500. Lin KJ, Hernandez-Diaz S, Garcia Rodriguez LA. Acid suppressants reduce risk of gastrointestinal bleeding in patients on antithrombotic or anti-inflammatory therapy. Gastroenterology. 2011;141(1):71-9.

501. Nichol KL, Nordin J, Mullooly J, Lask R, Fillbrandt K, Iwane M. Influenza vaccination and reduction in hospitalizations for cardiac disease and stroke among the elderly. N Engl J Med. 2003;348(14):1322-32.

502. Brasil.Ministerio da Saúde. Manual de Normas e Procedimentos para Vacinação [Internet]. [ Citado em 2020 Jan 12]. Disponível em: http://bvsms.saude.gov.br/ bvs/publicacoes/manual_procedimentos_vacinacao.pdf

503. Ridker PM, Everett B, Thuren T, Mac Fadyen JG, Chang WH, Ballantyne C, et al. Antiinflammatory therapy with canakinumab for atherosclerotic disease. $\mathrm{N}$ Engl J Med. 2017; 377(12): 1119-31.
504.Tardif JC, Kouz S, Waters DD, Bertrand D, Diaz R, Maggioni A, et al. Efficacy and Safety of Low-Dose Colchicine after Myocardial Infarction. N Eng J Med. 2019;381(26):2497-505.

505. Nicolau, JC, Timerman A, Marin-Neto JÁ, Piegas LS, Barbosa CJ, Franci A, et al, Diretrizes da Sociedade Brasileira de Cardiologia sobre Angina Instável e Infarto Agudo do Miocárdio sem Supradesnível do Segmento ST (II Edição, 2007) - Atualização 2013/2014. Arq Bras Cardiol. 2014;102(3 supl 1):1-61.

506.Daly CA, De Stavola B, Sendon JL, Tavazzi L, Boersma E, Clemens F, et al. Euro Heart Survey Investigators. Predicting prognosis in stable angina-results from the Euro heart survey of stable angina: prospective observational study. BMJ. 2006;332(7536):262-7.

507. Nagueh SF, Smiseth OA, Appleton CP, Byrd BF III, Dokainish H, Edvardsen T,et al. Recommendations for the evaluation of left ventricular diastolic function by echocardiography: an update from the American Society of Echocardiography and the European Association of Cardiovascular Imaging. J Am Soc Echocardiogr. 2016;29(4):277-314.

508.Steeds RP, Garbi M, Cardim N, Kasprzak JD, Sade E, Nihoyannopoulos P, et al. 2014_2016 EACVI Scientific Documents Committee. EACVI appropriateness criteria for the use of transthoracic echocardiography in adults: a report of literature and current practice review. Eur Heart J Cardiovasc Imaging. 2017;18(11):1191-204.

509. Knuuti J,Wijins W, Saraste A, Capodanno D, Barbato E, Funck-Brentano C, et al, 2019 ESC Guidelines for the diagnosis and management of chronic coronary syndromes. Eur Heart j.2020;41(3):407-77.

510.van Holten TC, Waanders LF, de Groot PG, Vissers J, Hoefer IE, Pasterkamp G,et al. Circulating biomarkers for redicting cardiovascular disease risk; a systematic review and comprehensive overview of metaanalyses. PLoS One. 2013;8(4):e62080.

511.Lindholm D, Lindback J, Armstrong PW, Budaj A, Cannon CP, Granger $\mathrm{CB}$, et al. Biomarker-based risk model to predict cardiovascular mortality in patients with stable coronary disease. J Am Coll Cardiol. $2017 ; 70(7): 813-26$.

512.Eapen DJ, Manocha P, Patel RS, Hammadah M, Veledar E, Wassel C, et al. Aggregate risk score based on markers of inflammation, cell stress, and coagulation is an independent predictor of adverse cardiovascular outcomes. J Am Coll Cardiol .2013;62(4):329-37.

513. Harb SC, Marwick TH. Prognostic value of stress imaging after revascularization: a systematic review of stress echocardiography and stress nuclear imaging Am Heart J. 2014;167(1):7-85. 